Portland State University

PDXScholar

Spring 6-2-2014

\title{
A Case Study of Collaborative Governance: Oregon Health Reform and Coordinated Care Organizations
}

Oliver John Droppers V

Portland State University

Follow this and additional works at: https://pdxscholar.library.pdx.edu/open_access_etds

Part of the Health and Medical Administration Commons Let us know how access to this document benefits you.

\section{Recommended Citation}

Droppers, Oliver John V, "A Case Study of Collaborative Governance: Oregon Health Reform and Coordinated Care Organizations" (2014). Dissertations and Theses. Paper 1824.

https://doi.org/10.15760/etd.1823

This Dissertation is brought to you for free and open access. It has been accepted for inclusion in Dissertations and Theses by an authorized administrator of PDXScholar. Please contact us if we can make this document more accessible: pdxscholar@pdx.edu. 
A Case Study of Collaborative Governance:

Oregon Health Reform and Coordinated Care Organizations

by

Oliver John Droppers V

A dissertation submitted in partial fulfillment of the requirements for the degree of

Doctor of Philosophy

in

Health Systems and Policy

Dissertation Committee:

Sherril Gelmon, Chair

Jill Rissi

Neal Wallace

Pamela Miller

Portland State University

2014 
C 2014 Oliver John Droppers V 


\begin{abstract}
The complexity of issues in health care in the United States - specifically insurance coverage, access, affordability, quality of care, and financing — requires effective new models for governing, in which governmental and non-governmental organizations seek to solve problems collaboratively rather than independently. This research explores collaborative governance as a model to form new partnerships among for-profit, nonprofit, and public organizations in an effort to create community-based, locally governed health care entities in Oregon through coordinated care organizations (CCOs). A key question is whether collaboration, through CCOs, brings together government and non-governmental organizations to solve "intractable problems" by establishing new public-private partnerships in Medicaid. The research focuses on the formation of CCOs, including the influence of local, political, institutional, and historical contexts, planning processes, and governance structures. The hypothesis is that conditions, norms, governance structures and processes, and the presence or absence of a combination of these factors, facilitate or impede participation and decision-making, and over time, successful system integration by these new complex organizations.

This study developed insights into similarities and differences among CCO governance structures by investigating three CCOs. Findings from the case study suggest that the following key factors influence the collaborative governance process among government and non-governmental organizations within CCOs: prior history of conflict or cooperation; open, transparent, and inclusive processes for stakeholders; face-to-face
\end{abstract}


dialogue, trust building, and shared understanding; and high-functioning governing boards. Results also indicate that maintaining stakeholder participation can be challenging due to time and cost, power imbalances and competing interests among stakeholders, and mistrust and lack of facilitative leadership. The results suggest that collaborative governance is a strategic approach for the allocation of limited resources across public, private, and nonprofit organizations to deliver services to Oregon's Medicaid population.

The significance of this study is that it identified starting conditions that facilitate and hinder the ability of CCOs to effectively solve problems through governance mechanisms. Oregon's CCOs offer an example of multiple layers of governing institutions — federal, state, and county—using formal authority to influence a specified set of outcomes, the Triple Aim, in a specific policy domain: provision of health care services for underserved Oregonians. Results of the study can help inform a larger, more fundamental question in public administration about contemporary governance: whether government through collaborative governance can create the "conditions for rule and collective action" through public-private partnerships to achieve policy goals (Stoker, 1998). Further research is needed to better understand whether local community-based organizations such as CCOs offer a sustainable model to address policy issues in other arenas by which there is "more government action and less government involvement" (Agranoff \& McGuire, 2003). This study contributes to the theory of collaborative governance and may inform future policy decisions about CCOs in Oregon and, more broadly, ongoing national health care reform efforts. 
Dedicated to my father, my wife and Bettye-Jean Marie 
OREGON HEALTH REFORM AND COORDINATED CARE ORGANIZATIONS iv

\section{Acknowledgements}

A doctoral program is a right of passage for a select few. The dissertation involves self-discovery, coupled with steadfastness, questioning the state of one's area of study and one's inner self: humility in its raw essence. $\mathrm{PhD}$ students would be remiss to not acknowledge that their academic, professional, and personal pursuits would not be possible without exceptional mentors. My own journey in pursuit of a doctorate likely parallels those who came before me, those I now call my mentors, whose footsteps I have sought to trace. To the scholars who endeavor to uphold the virtues of the academy, promote the importance and currency of knowledge, and challenge those of us willing to accept the odyssey — we, their students, are indebted with gratitude. To those who have come before us and who will follow, we owe much gratitude. To members of my dissertation committee, I thank you for your thoughtful guidance, wisdom, and compassion. I appreciate the level of commitment and encouragement shown by members of my committee throughout this process.

To Sherril Gelmon, my chair and mentor: Nine years ago, for reasons still not fully appreciated, you were willing to take on yet another unsophisticated, inexperienced graduate student. As a well-respected mentor to many junior colleagues fortunate enough to cross your path, please know your discipline and devotion as a mentor, teacher, adviser, and confidant is an everlasting gift to your students. Over the course of several grant-funded projects as well as coursework, presentations, and teaching opportunities, you both encouraged and challenged me — challenged me to develop a better understanding of myself; pushed me to excel in my writing and critical thinking; helped 
instill confidence when and where it was lacking; urged me to reconsider my professional goals and interests out of compassion, and all for the better. In reflecting on your technique or modus operandi in your role as a mentor, I have realized that the outcome, after years of caring and investing in me professionally and personally, is that you have afforded me with amazing opportunities, many unimaginable, all of which have significantly impacted and positively changed my life course. Thank you.

To my parents: Thank you both for the love and sacrifices in providing me the ability to take risks and seek opportunities, and for your encouragement of my many pursuits including the privilege of an education, now a doctorate. These sacrifices, borne from a parent's endless love for their child, without question, without judgment, have offered me the safety and protection that only a parent can provide in this world. It is through no virtue or accomplishment of my own that I've had and enjoyed these opportunities. I was merely fortunate enough to be born under the most comfortable conditions into a loving family. As my parents, you have shown me love without reservation, instilled in me a work ethic, and most importantly, were willing to make the necessary personal sacrifices to raise a child surrounded by a house of love.

In thinking about others' sacrifices and my own personal identity, it would be inexcusable for me not to acknowledge my forefathers and foremothers, for they took the real risks, bore unknown hardships, and endured immeasurable suffering. I owe a debt of gratitude and obligation to the farmer who sought a better life for his children by providing his offspring an education, sacrificing the family farm and moving into town to offer schooling for his children; to the minister who challenged his consciousness and 
decided to adhere to principles over convention for his sons, knowing that judgment would be harsh and hardships would be difficult to bare- he persevered, nevertheless, with his integrity intact; to a great grandmother who sought to alleviate the suffering of those served by her congregation, the poor-treating those less fortunate with dignity; to my beloved great-grandmother who traveled steerage class to the United States for an unknown, new world, and her staunch commitment to provide, through sheer toil and sacrifice, her great-grandson the educational opportunities never afforded to her; to a grandmother who traveled the railroad tracks picking up coal for heat, who worked tirelessly serving unknown faces, and yet somehow always remained buoyant and loving in the face of adversity, teaching me tolerance and tenacity; to a grandfather who invited his grandson to believe in himself, to respect and care for others, who is immensely responsible for instilling in me a sense of identity and self, and who in his final gift left me with a moral compass to guide myself through untold odysseys that still lie ahead.

To my lifelong partner, confidant, and faithful companion: my wife, Danielle. You have made the ultimate sacrifices and somehow managed to continue to believe in me. You encouraged me during the most difficult of times, when we both questioned the meaning and value of this particular journey. You kept me focused, helped carry me through grueling long hours of study; never doubting for a moment my ability to see this odyssey through. We have and continue to dream together and will continue to overcome life's unexpected challenges. I thank you for sacrificing time that I never can give back to you, time that wasn't spent together, borrowed time, spending countless evenings and weekends alone, for years, without me, and yet always holding steadfast in your love and 
faith in me- thank you. I am forever grateful for and indebted to you. I hope over the coming years, realizing I can never repay you, I will at the very least commit myself to being a loving and respectful husband and a loving and devoted father, committed to showing our unborn daughter, Bettye-Jean, unconditional love, just as her mother has shown me. And one day, we too will work to provide her with the same privileges and aspirations as those afforded to her parents. 


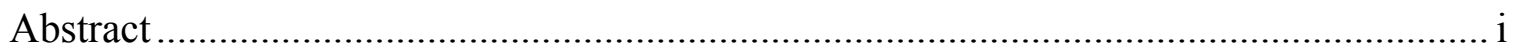

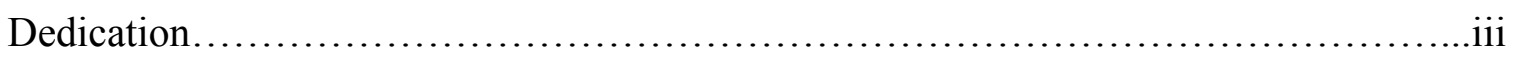

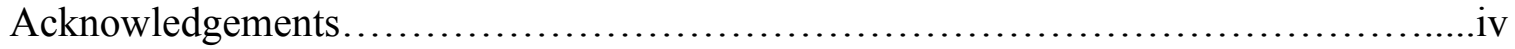

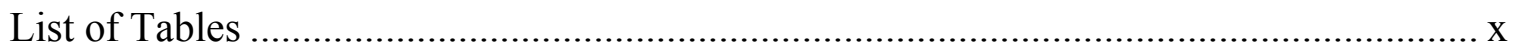

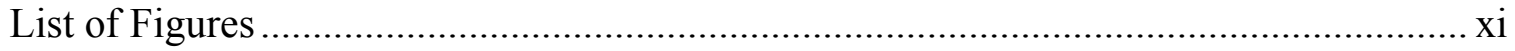

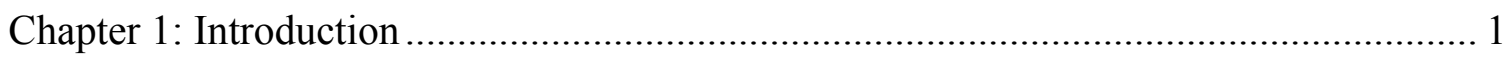

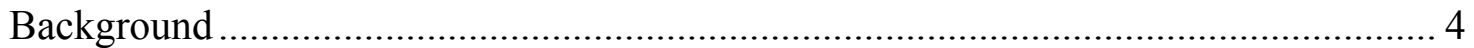

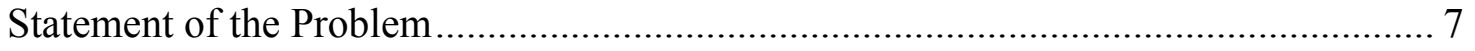

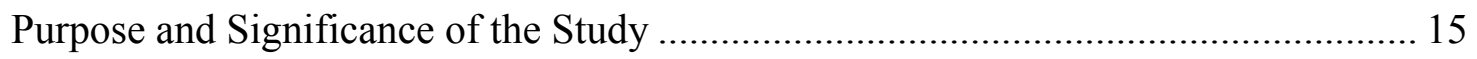

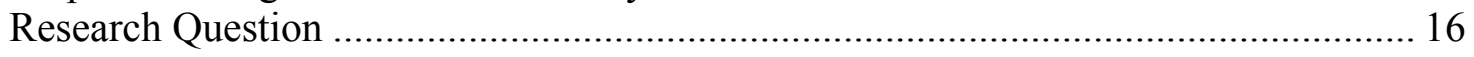

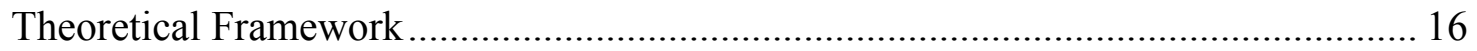

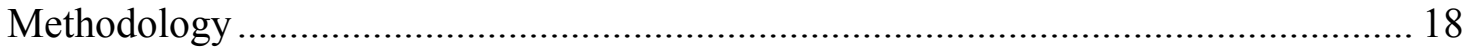

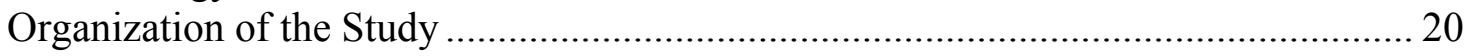

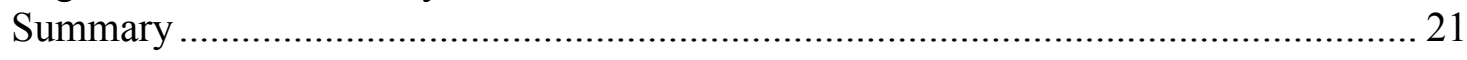

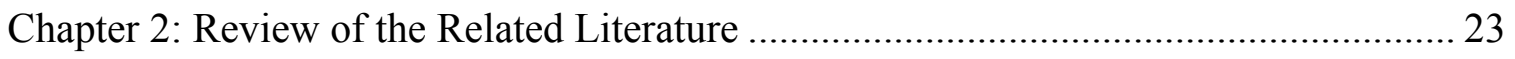

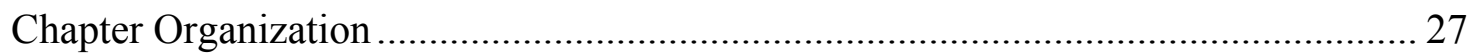

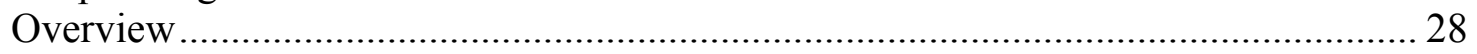

Framing the Historical Context and Oregon Perspective .......................................... 33

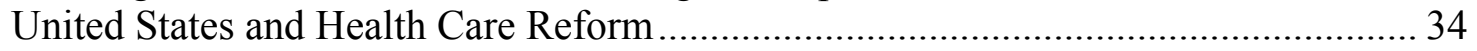

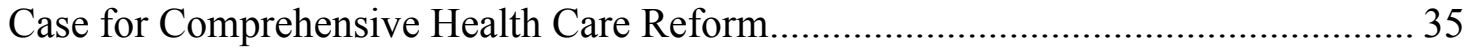

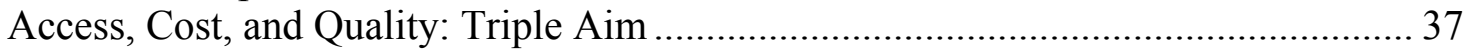

State Health Policy: Birth of Medicaid ......................................................... 41

Changing Paradigm: States as Health Policy Innovators..................................... 45

Blazing the Trail: History of the Oregon Health Plan ............................................... 46

Theoretical Perspective: New Governance, Complex Organizations in Health Care .. 58

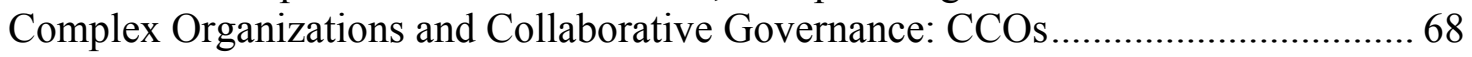

Issues with Collaborative Governance in Health Care ............................................ 75

Collaborative Governance and CCOs .............................................................. 76

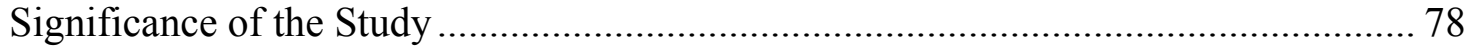

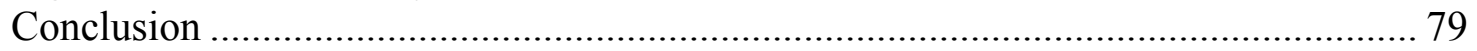

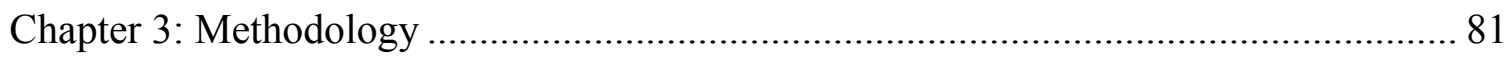

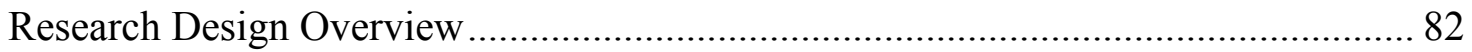

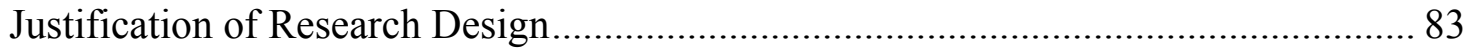

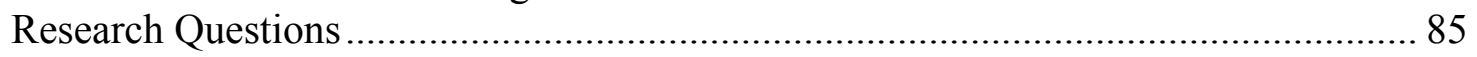

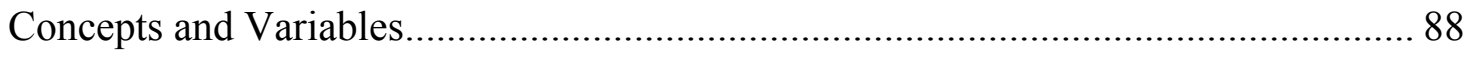

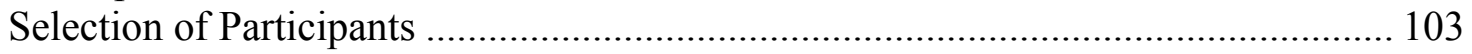

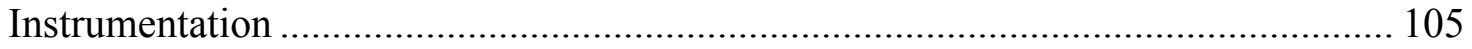

Research Approach and Assumptions ......................................................... 106 


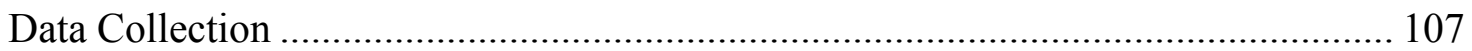

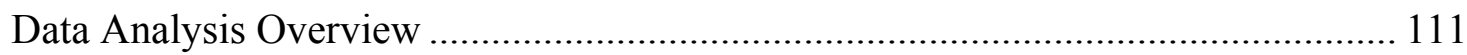

Revised Case Study Selection Process ................................................................... 119

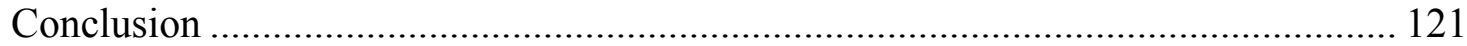

Chapter 4: Presentation and Analysis of Findings ................................................... 123

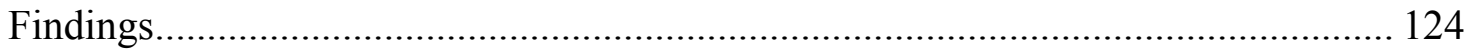

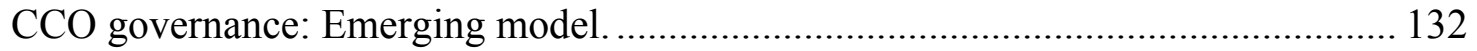

Findings from the Individual Cases ..................................................................... 136

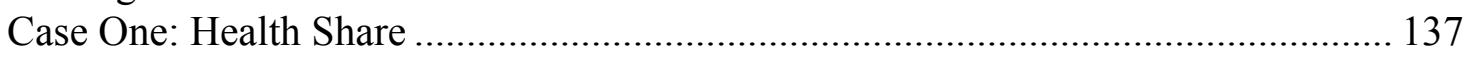

Case Two: Willamette Valley Community Health ................................................. 153

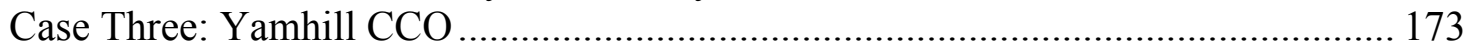

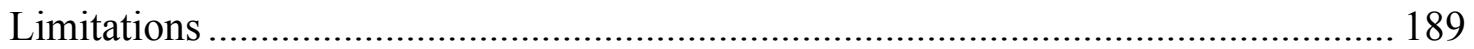

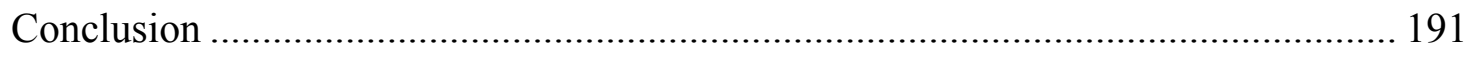

Chapter 5: Discussion, Conclusions, and Recommendations for Future Research ........ 192

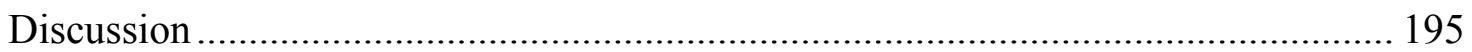

Collaborative Governance and CCOs ................................................................ 198

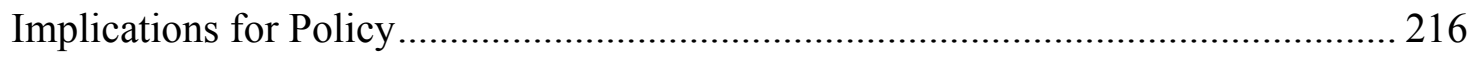

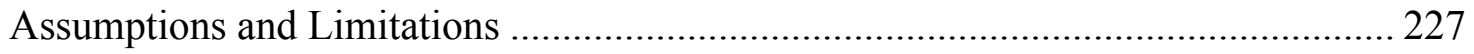

Recommendations for Future Research ..................................................... 228

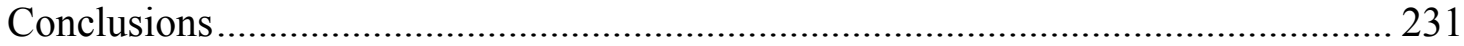

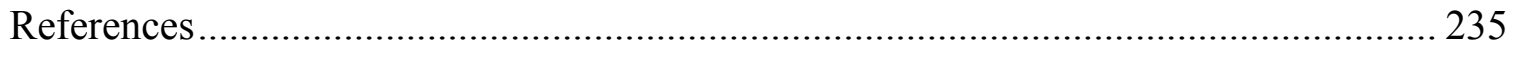

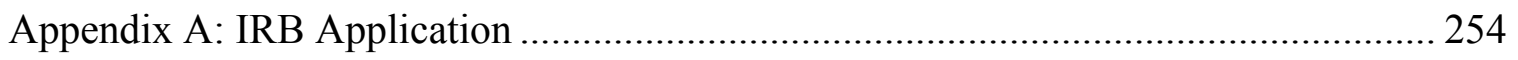

Appendix B: Coordinated Care Organization (CCO): Selection Criteria Matrix (*as of

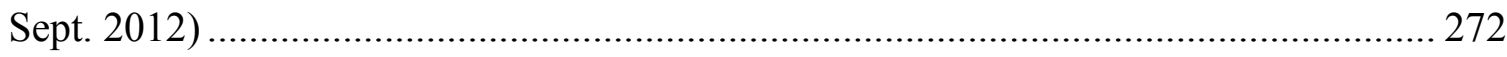




\section{List of Tables}

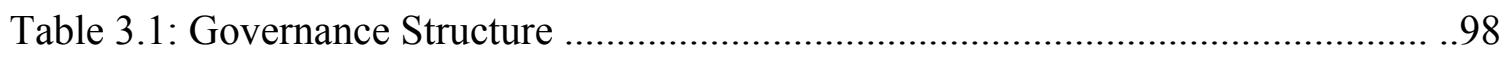

Table 3.2: Models of Collaborative Governance .................................................... 102

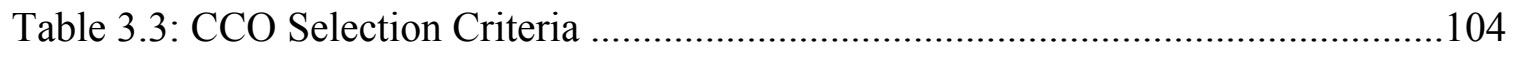

Table 3.4: Interview Protocol: Conceptual Collaborative Governance Framework ...... 110

Table 3.5 Primary Codes Applied to the Data ....................................................... 116

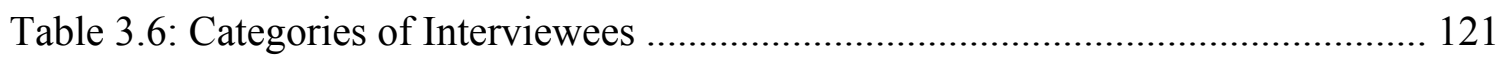

Table 4.1: CCO Collaborative Governance Matrix (as of Feb. 2014) ........................ 137

Table 5.1: Governance Structure Elements ......................................................... 200

Table 5.2: Collaborative Governance and CCOs .................................................. 217 


\section{List of Figures}

Figure 3.1: Conceptual Framework for CCO Collaborative Governance................... 105

Figure 5.1: Conceptual Framework for CCO Collaborative Governance …………...... 209 


\section{Chapter 1: Introduction}

Never before has there been such a political imperative to do something about health care. - Governor Kitzhaber, 1998

Through public policy and implementation, federal and state public institutions have served as active participants in promoting and supporting health care reform. This has primarily taken place through the private health care marketplace. Past and current reform efforts have been designed to create significant changes in the delivery, organization, and financing of health care services. Often these efforts seek to increase access to care, expand publicly funded health insurance coverage, promote quality improvement and patient safety, undertake cost containment, and foster community and population health advancements. At a national level, health care reform serves as an increasingly pressing social and economic issue, yet also a polarizing political issue, most recently observed with the passage of the Patient Protection and Affordable Care Act (ACA) in 2009.

Many of the policy goals and objectives proposed in the ACA- outlined in an extraordinarily, complex framework of Congressional legislation, federal statutes, and ongoing administration rule-making - aim to address one of the most fundamental, complicated, and politically divisive issues in recent U.S. history: the country's increasingly fragmented, failing, and unsustainable health care system (Schwartz \& Damico, 2010). A significant provision of the ACA is the Medicaid expansion, an attempt by Congress to build further on the success of Medicaid, a cooperative federal- 
state program. Medicaid has increased publicly funded health insurance coverage from four million to 47 million recipients over the past 40 years (Truffer, Klemm, Wolfe, \& Rennie, 2010).

The U.S. health care system has become intractably intertwined with federal, state, and local government through the policymaking process as part of a concerted attempt to confront persistent health care challenges. With passage of a host of federalstate health partnership initiatives such as Medicaid in the 1960s and the State Children's Health Insurance Program (SCHIP) in the 1990s, these efforts have resulted in a patchwork of attempts to solve a problem that requires a comprehensive national solution. In the absence of national health care reform, states have elected to take a more "aggressive role" in putting forth policy solutions to the problems of an imperfect health care system that is widely perceived to be in a perpetual state of crisis (Goldberger, 1990). A majority of states have enacted a number of local health reform efforts in the vacuum of comprehensive national health care reform. This effort has resulted in a complex structural misalignment between state government and health policy, i.e. the problem of governance (Morone, 2001). Most state health policy is interlaced with federal programs as well as agencies and funding mechanisms, providing the quintessential example of American federalism.

This American style of "marble cake" federalism has resulted in health care policy and funding responsibilities that are shared across different levels of government with substantial overlap in the health policymaking activities among federal and state officials and administrators. States, often characterized as "laboratories of democracy" 
(Justice Brandeis, 1932), ${ }^{1}$ are largely responsible for establishing new health care policies and programs, which offer an opportunity for early experimentation and evaluation before being adopted at the federal level. Over time, a number of health policy innovations, initially developed by states, have been adopted by the federal government and are evolving into national programs. For example, early health care reform efforts in New York and Massachusetts resulted in the CHIP and the individual mandate, a pivotal component of the ACA (Holahan et al., 2003; Morone, 2001).

Federal health care reform embodied in the ACA will require considerable effort by the states. Significant pieces of federal health care reform efforts will be implemented, including expansion of public health insurance through Medicaid by addition of eight million individuals among states that opt to expand Medicaid, ${ }^{2}$ and state and federal health insurance exchanges in 2014. These federal-state reform efforts are further complicated by the fact that most health services, including primary and community health, occur at the local level (Altman \& Morgan, 1983). Many states are now working to transform their health care delivery system faster and more comprehensively than as supported by the ACA. Oregon is one of the many states leading the way to establish an integrated and coordinated health care system that will improve quality of care, contain rising costs, and improve individual and community health (Oregon Health Policy Board [OHPB], 2010, p. 5).

\footnotetext{
${ }^{1}$ The term originates from a U.S. Supreme Court opinion issued by Supreme Court Louis Justice Brandeis (1932). New State Ice Co. v. Liebmann 285 U.S. 262. (1932). Retrieved from http://caselaw.lp.findlaw.com/scripts/getcase.pl?navby=CASE\& court=US\&vol=285\&page $=262$

${ }^{2}$ Individuals under age 65 with incomes up to $133 \%$ of the federal poverty level (FPL).
} 


\section{Background}

State governments are active participants in contributing to, and even leading, health care reform efforts. Oregon is no exception, having been at the forefront of health care reform efforts for more than two decades (OHPB, 2010). ${ }^{3}$ Through passage of House Bill 3650 in 2011, the Oregon Legislature and Governor John Kitzhaber laid the foundation for the creation of coordinated care organizations (CCOs). This legislation was the embodiment of transformation for Oregon's health care delivery system, designed around the Triple Aim of improving health, health care, and reducing costs (Berwick, Nolan, \& Whittington, 2008; OHPB, 2012, p. 9).

Oregon's CCOs are intended to create community-based organizations governed by health care providers, community members, and organizations responsible for financial risk to create a "more coordinated and affordable, patient-centered health care delivery system" (Oregon Health Authority, 2012, p. 1). Oregon's proposed model for health care reform parallels one of the key provisions of the ACA: establishing accountable care organizations (ACOs). ACOs are organizational arrangements in which provider groups voluntarily accept responsibility for the cost and quality of health care services for a specific population of Medicare fee-for-service beneficiaries (Shortell et al., 2010). Oregon's model for coordinated and integrated care delivery significantly expands upon the ACO framework. CCOs will be responsible for the integration and

\footnotetext{
3 Oregon legislation: Senate Bill 27 (1989), Senate Bill 27 (2007), Senate Bill 329 (2007), House Bill 3368 (2007), House Bill 2009 (2009), House Bill 3650 (2011), and House Bill 1580 (2012).
} 
coordination of physical, mental, behavioral, and dental care services for Oregon's Medicaid beneficiaries enrolled in the Oregon Health Plan (OHP).

In an effort to reform major components of the state's health care system at the community level, these newly established entities will offer a new care delivery model and serve as a single point of accountability in providing comprehensive and integrated health care services for a defined population (OHPB, 2012). Coordinated care organizations are required to meet a set of criteria in establishing a $\mathrm{CCO}$, operate within a new global budget model, achieve performance goals, and held accountable for the Triple Aim. The basic components of a CCO mirror a number of concepts put forward in key provisions of the ACA for ACOs, which include financial incentives and a bundled payment model, patient-centered care and integration of services, and measurement and accountability mechanisms (National Governors Association, 2011; Rittenhouse, Shortell, \& Fisher, 2009).

From a state policy perspective, unique to CCOs is the requirement to establish a board and comprehensive governing structure. The $\mathrm{CCO}$ governance structure was established through public contracting, state statutes, administrative rulemaking, and a federal waiver approved by the Centers for Medicare and Medicaid Services (CMS) in July 2012. A governance structure ensures adequate representation among legal entities that share the financial risk in caring for a defined Medicaid population, guarantees representation of stakeholders from the health delivery system (including those affected by the changes), and supports a sustainable model (OHPB, 2012). CCOs are encouraged to include organizations within their partnership such as hospital systems, managed care 
organizations, community health centers, insurers, local mental health authorities, county public health agencies, and dental providers (Oregon Health Policy Board, 2012).

According to the Health Policy Board's (OHPB) 2012 CCO implementation proposal, there is "no single governance solution" and "there is risk in being too prescriptive beyond the statutory definition of a CCO governing board" (p. 15).

Therefore, the governance structure will be critical in the impending success (or failure) of CCOs and, potentially, Oregon's broader effort to transform the state's health care system. The Health Policy Board put forward the following as the criteria for a CCO governance structure (OHPB, 2012, pp. 15-16; ORS 414.625):

- ensure entities bearing financial risk for the organization make up the governing board's majority interest;

- include members representing major components of the health care delivery system;

- include consumer representation on the governing board outside of those members sharing in financial risk;

- reflect the community's needs;

- assure the CCO's decision-making is consistent with the values of the members and the community;

- support the goals of state health care transformation (i.e. the Triple Aim); and

- provide a formal process for selecting members of the governing board, community advisory council (CAC), and any other councils or committees of the governing board. 
As CCOs develop, a fundamental challenge will be establishing and maintaining an effective governance model—one that is able to both meet the criteria put forth by the Oregon Health Authority (OHA) and still be responsive to the needs of its community. Multiple factors are likely to influence the effectiveness of CCO governance, including the following:

- governance structure, including rules, functions, and responsibilities;

- rules governing participation in a $\mathrm{CCO}$;

- public accountability, legitimacy, and transparency;

- implementation of and adherence to federal and state regulations and Medicaid policy governing CCOs, including how implementation barriers are addressed; and,

- coordination among stakeholders including state and local government partners, health care delivery organizations, individual medical providers, insurers, and consumer groups, among others.

\section{Statement of the Problem}

Federalism, health policy, and the Oregon Health Plan. The history of

Oregon's health care reform began with the creation of Medicare and Medicaid by Congress, signed into law by President Johnson in 1965 (Brown \& Sparer, 2003). This national effort addressed the lack of access to basic health care services among the nation's poor, elderly, and children. These two programs, along with the State Children's Health Insurance Program (SCHIP), have intertwined federal and state government in 
health policy, changes in health care delivery, and financing for the past 50 years - an inevitable outcome within a federalist system of government.

Medicare was established to provide universal, federally funded health insurance for all seniors over the age of 65 , without any responsibility among states for the financing or administration of the program. Medicaid, on the other hand, is a federal-state partnership comprised of federal and state financing that provides health insurance for certain categories of poor people, primarily children and pregnant women (Brown \& Sparer, 2003). Both programs have a complex and multifaceted history, especially Medicaid because it is a shared and joint responsibility among federal and state governments in the financing of health coverage for low-income Americans. Medicare and Medicaid now play a critical role in the U.S. health care system, but Medicaid is the program that has most often stirred the debate about the role of state and federal government in health care. For the past 25 years, Oregon has been at the forefront of this controversy in its commitment to reform the state's Medicaid program.

Medicaid remains a popular federal program among many states, largely because it provides flexibility in the design and ability to modify a state's Medicaid program, and it offers a beneficial financial arrangement for states (Holahan, Weil, \& Wiener, 2003). While it was originally intended to sponsor health insurance coverage for the very poor, innovative states such as Oregon have leveraged the program's flexibility to substantially expand insurance coverage, providing benefits and services to populations beyond the very poor. These populations include the elderly poor, disabled, working poor, individuals with developmental disabilities, and families and children above the federally 
mandated poverty level. The financial structure and dynamic in Medicaid is a federalstate arrangement in which the federal government finances the majority of state's Medicaid program's expenses. For states, every dollar potentially saved in general revenue from reducing Medicaid expenditures equates to two or three federal dollars lost due to the federal-state match requirement of Medicaid. Over the years, Oregon has sought to maximize this financial structure and is attempting to further leverage this favorable relationship in creating CCOs.

Medicaid, health care reform, and civic engagement: Oregon style. Through the federal demonstration waiver process, states have implemented a number of creative solutions to address a range of health care issues. Oregon is considered one of the more innovative states with its approach to Medicaid (see Bodenheimer, 1997; Brown, 1991; Jacobs, Marmor, \& Oberlander, 1999; Leichter, 1999; Oberlander, 2007; Sipes-Metzler, 1994; Wiener, 1992). Issues addressed through the federal waiver process include addressing the growing numbers of uninsured by expanding coverage and types of services to targeted population groups; improving the quality of services delivered and financed; attempting to control escalating health care costs, largely through managed care; reducing disparities of care including access and quality; or some combination thereof.

Oregon's Medicaid program, the Oregon Health Plan (OHP), has been a national leader, and continues to lead through innovative and committed policymakers and health care reformers, notably the "intellectual father" of the OHP, Governor John Kitzhaber (Wiener, 1992, p. 26). Prior to the creation of OHP, Oregon embarked upon a 
comprehensive public participation process, which led to the support of a deliberative decision-making process for the state's Medicaid program, which continues today. Community involvement in state health policy is a defining feature in Oregon, dating back to the early 1980s with Oregon Health Decisions, a nonprofit organization that was focused on utilizing citizen engagement to inform both health care related issues and the Oregon Medicaid Prioritization Project (Leichter, 1999; Sipes-Metzler, 1994).

Oregon as health policy entrepreneur. The Oregon Health Plan was designed to meet three main objectives, with the overarching goal to provide access to health care for all Oregonians. The first objective was to reform the state's existing Medicaid program by elimination of the categorical eligibility criteria set by the federal government. Oregon sought to expand the eligible population for Medicaid to all persons with incomes below the $100 \%$ federal poverty level (FPL), regardless of whether an individual was categorically eligible (Kitzhaber, 1993). Traditionally, those who were "categorically eligible" for Medicaid coverage have included individuals from families with children and pregnant women as well as low-income individuals, including the elderly, the aged, and the blind. A second objective was to reform the state's small group insurance market by offering guaranteed issue of insurance coverage, including automatic coverage renewal for individuals with preexisting conditions who were considered high-risk for insurance coverage in the private market. This objective would be achieved through a public-private partnership financed partially with employer contributions. The third objective was an attempt at cost containment through what became known as the prioritized list (DiPrete \& Coffman, 2007; Jacobs, Marmor, \& Oberlander, 1999). 
OREGON HEALTH REFORM AND COORDINATED CARE ORGANIZATIONS 11

The Oregon legislation that enacted OHP required the creation of an independent commission to oversee development of a prioritized list of medical services that would be funded for individuals enrolled in OHP (DiPrete \& Coffman, 2007). The Health Services Commission, established in 1987 was comprised of 11 members: five physicians, four consumer representatives, a public health nurse, and a social worker. The Committee was tasked to consider the comparative benefits of health services, ranking the services from most to least important, ensuring the final ranking of services reflected community values regarding treatments (Sipes-Metzler, 1999, p. 308). After a two-year period, the commission presented a list of 709 condition-treatment pairings or paired medical conditions and treatments, which are ranked hierarchically from the most to the least medically necessary, and which are based on the latest research on the effectiveness of treatments. In 1989, the Legislature agreed to fund a package of benefits that included the first 587 of the pairings. Oregon led the way for other states because it was the first state to finally succeed in establishing a formal process to determine the level of services to be covered based upon a priority ranking system and available state funding (DiPrete \& Coffman, 2007). Other services covered include diagnostic services to determine a patient's condition, ancillary services medically appropriate for the treatment of covered conditions, hospital services, and prescription drugs (DiPrete \& Coffman, 2007).

The state - the first to do so-succeeded in establishing a formal process by which to determine the level of services covered, based upon a priority ranking system, that is matched with available state funding. The list is modified and revised every two years, coinciding with Oregon's biennial legislative session (DiPrete, \& Coffman, 2007). 
The Oregon Legislature is statutorily prohibited from modifying the prioritized list; it may only determine how much will be funded based on state fiscal resources. Therefore, services for Medicaid beneficiaries above the cut-off line established by the State's budgetary resources are funded, and those below the line are not funded.

Another first during this two-year process was the level of public engagement in creating the prioritized list. The commission supported 11 public hearings, 47 community meetings in every county in the state, as well as a statewide telephone survey of 1,000 individuals (Kitzhaber, 1993; Wiener, 1992, p. 28). At the end of the public process, over 3,500 individuals provided information to the commission about citizen values regarding health coverage and health services (Sipes-Metzler, 1999, p. 309). From a state health policy and community engagement perspective, the level of involvement in the policy decision-making process that determined the state's benefit coverage for its Medicaid population was sweeping. It was also an intentionally open and transparent process. A key outcome embodied in the creation of the OHP prioritized list was that the state intentionally fostered a process for citizen participation in a health policy debate, and it was able to "blend medical fact and public value to form public policy" (Sipes-Metzler, 1999, p. 313). The final prioritized list reflected the community's values, to a degree, due to the extensive process of public involvement (Kitzhaber, 1993).

A decade after OHP. From 1994 through 2003, OHP rapidly expanded into a complex Medicaid delivery system in Oregon. In less than a decade, OHP provided 1.4 million individuals with access to health care; another 29,000 individuals, previously denied coverage due to preexisting conditions, obtained insurance coverage through a 
high-risk pool called the Oregon Medical Insurance Pool (Office for Health Policy and Research, 2003, p. 1). In 2003, in response to an economic downturn and the resulting state fiscal crisis, coupled with steadily increasing health care costs, Oregon redesigned OHP in an effort to maintain Medicaid coverage while containing costs (Office for Health Policy and Research, 2003). The intentional outcome was the creation of two different benefit packages for Oregon's Medicaid population: OHP Standard and OHP Plus. The unanticipated outcome of Oregon's Medicaid policy experiment was a significant decrease in the number of individuals enrolled in OHP Standard - up to a 50\% decrease among some of the most vulnerable Oregonians (Wallace, McConnell, Gallia, \& Edlund, 2010). A number of important policy lessons warrant consideration from these unanticipated outcomes; these will be addressed in Chapter 2. These important policy lessons, as well as the recognized value and importance of public participation in state health policy, have emboldened Oregon in its commitment to reform its Medicaid program.

Oregon's health system transformation. For the past 25 years Oregon has worked to improve the state's health delivery system, expand coverage through both its public and private health insurance markets, reduce unnecessary and non-effective health care treatments and services, and continually ensure public participation and engagement in the health policy decision-making process. These incremental steps in health reform continue today with the state's most recent health reform effort of establishing coordinated care organizations (CCOs). 
The CCO reform effort attempts, once again, to modify which services are covered for Medicaid beneficiaries in Oregon, the types of services financed, and how services are delivered at the community level. Oregon did not wait for national health care reform and for provisions of the ACA to take effect. Rather, the state took the initiative to reform its Medicaid delivery system, representing an "evolution of OHP" (OHA, 2012, p. 6). Oregon's most recent reform effort is designed to establish a coordinated and integrated health care model, enrolling the majority of the state's Medicaid population in CCOs, including the estimated 200,000 individuals who became eligible for Medicaid in 2014 (OHA, 2012). However, for CCOs to be successful and avoid any unanticipated and undesired outcomes such as those experienced in past reforms efforts around OHP, the issue of governance will need to be addressed.

According to Governor Kitzhaber, "Solving the health care problem is going to require some sort of new governance structure" (Goldsmith, 2003, p. 118). The CCO model of health care reform offers just that: a new model for community health governance in which the community accepts and shares the costs and risks of caring for its residents. Once again, Oregon's health care leaders and policymakers continue to leverage the state's participatory political culture to build support for advancing health care reform and further build upon the success initially achieved in establishing OHP and the prioritized list. A key strategy in advancing health reform is the open and transparent decision-making process, mobilization of broad stakeholder support, and buy-in through public forums. The CCO initiative is a logical extension of the state's commitment to 
advance health care reform through broad stakeholder support at the community level through CCO governance models.

\section{Purpose and Significance of the Study}

The purpose of this study was to explore CCOs and understand the process and conditions under which participation and decision-making among stakeholders is facilitated or impeded through collaborative governance. This study observed the governance process in order to assess and evaluate future policy considerations about CCOs and, more broadly, informs state-level health care reform. The theory of collaborative governance offers a promising analytic framework for investigating CCOs. Public, private, and nonprofit agencies must work collectively in new and distinctive ways, in accordance with Oregon statutes and federal rules that govern Medicaid, in order for CCOs to achieve the desired outcomes. It is unknown whether a preferred model of governance may emerge in terms of facilitating effective CCOs that generate benefits for providers; consumers; local, state, and federal agencies; and other stakeholders involved with health care reform efforts. The importance of researching the CCO collaborative governance infrastructure and process was to determine how the presence of a combination of key factors, or their absence, affect decision-making among these new complex organizations.

This study sought to enhance our understanding of a model of community governance intended to improve the health status of individuals and communities by involving local agencies and individuals in an effort to create a new health system that is responsive to, and accountable for, communities in Oregon. It is important to develop an 
OREGON HEALTH REFORM AND COORDINATED CARE ORGANIZATIONS 16

understanding regarding whether a collaborative governance model, including certain factors and arrangements, will be more or less effective in supporting state-level health care reform in Medicaid. This study explored and assessed principal differences in CCO development affected by local political, institutional, and historical contexts, planning processes, and governance structures. Important factors include the history of conflict or cooperation, incentives to participate among a broad and diverse group of stakeholders, power and resource differences, leadership, and presence of a formal structure (Ansell \& Gash, 2007). The significance of this study was that it (1) learned about conditions that facilitate or impede the ability of CCOs to effectively solve problems through governance mechanisms, (2) developed insights into similarities and differences among CCO governance structures, and (3) advanced present understanding of the potential for, and limitations of, a collaborative governance model in supporting health care reform.

\section{Research Question}

The central research question that guided this study was the following: What are the key factors of collaborative governance that facilitate or impede the ability of CCOs to implement health care reform?

\section{Theoretical Framework}

Health policy has drifted toward intervention while seeking to evade the dilemmas of governing the health system publicly. (Mead, 1977, p. 40) The theory of governance has been studied extensively within the fields of political science and public administration (Frederickson, 2007). Numerous scholars (see 
Hill \& Lynn, 2001) have sought to define, analyze, and redefine this concept as the role of government in contemporary America has evolved and shifted due to numerous external and internal forces. Furthermore, the role and responsibility of the public sector has been challenged and blurred while it tries to maintain accountability of public institutions, administrators, and elected officials (Hill \& Lynn, 2001). In the ensuing debate around the theory of modern governance, a precise and widely agreed upon concept has been somewhat elusive among scholars, with multiple governance models put forth, to the point of having "governance" described as "everywhere and [appearing] to mean anything and everything" (Frederickson, 2007, p. 287). Nevertheless, the concept remains of critical importance to scholars and public administrators. The problem of governance, ensuring either general welfare and maintaining effectiveness of public institutions, includes formation and implementation of public policy, in an attempt to deal with the increasing complexities of society. Such complexities include the ability to respond to persistent political and economic issues - in this case, principally promoting and protecting individual and community health by developing and implementing statewide health reform at the local level through a new model of health care delivery: CCOs.

It is postulated that governance clearly provides a useful analytic framework for scholars. One theory of governance in particular is collaborative governance, which was used to study the development of CCOs in Oregon. It has been stated that the theory of governance offers "a simplifying lens to a complex reality," one which can be used to study the intersections of public policy, health reform, and the emerging world of CCOs 
(Stoker, 1998, p. 26). The premise of collaborative governance involves broad participation in problem solving through an arrangement that provides a mechanism in which public, state, regional, and local government agencies, nonprofit organizations, businesses, and other non-governmental stakeholders can work together (Ansell \& Gash, 2007; Freeman, 1997). For the purpose of this study, in using Ansell and Gash's (2007) definition of collaborative governance, they defines governances as "a governing arrangement where one or more public agencies directly engage non-state stakeholders in a collective decision-making process that is formal, consensus-oriented, and deliberative and that aims to make or implement public policy or public programs or assets" (p. 544). A collaborative governance framework was used to identify and explore factors that influence whether this new model of governance can support achievement of the Triple Aim through CCOs.

\section{Methodology}

The design for this research was a multi-case study. The flexibility of using a case study is that this approach lends itself to the investigation of dynamic, rapidly changing social phenomena. In addition, conducting a case study is commonly used as a method in public administration and political science because it seeks to draw lessons from problems specific to government and governance (McNabb, 2002). By adopting a case study approach, different forms of collaborative governance can be studied together, helping to develop an understanding of this contemporary governance phenomenon (McNabb, 2002, p. 287). This study examined three CCOs; the selection criteria are described in Chapter 3. 
The preferred multi-case research approach was used to compare and contrast CCO governance models. Comparative analysis was used to help assess the relative role and function of the $\mathrm{CCO}$ governance structure by examining different organizations and their respective approaches to community-based governance. Findings from this study will help inform ongoing change and adaptation among CCOs seeking to modify existing governance arrangements, with the expressed goal of enabling and facilitating achievement of the Triple Aim. The unit of analysis for this study was coordinated care organizations responsible for taking care of individuals in Oregon who are eligible for Medicaid.

Governance research is challenging for a number of reasons. The foremost challenge is the difficulty in trying to understand any potential effect or causality among an identified policy intervention, utilizing data or measurable outcomes, couched within a theoretical framework, all of which are bound to be "embedded in a wider social, political, and economic" context (Lynn, Heinrich, \& Hill, 2002, p. 17). According to Lynn et al. (2002), a critical problem in governance research is "explor[ing] causal relationships beyond a narrow perimeter of theoretical possibilities that leaves too much out of the picture" (p. 18). The challenge or limitation in this study, and in all empirical research, is to not ignore the broader context in which $\mathrm{CCO}$ governance is emerging, and still engage in research that results in findings and contributions which have implications for scholars and practitioners (Lynn, 2001).

Data collection. Data collection consisted of two methods: in-depth interviews and document analysis. Interviews were comprised of semi-structured interviews with 
board members of CCOs, members of the Community Advisory Committees required for all CCOs, and policy experts and administrators from Oregon's executive branches. Document or content analysis of written materials included review of newly enacted policies, statutes and regulatory frameworks, and internal documents as available. A structured framework was developed and used to code collected data into themes with comparisons explored among potential relations among themes. Additional background and contextual materials were included in the analysis using the structured framework to assess profiles of CCO governance models.

Data analysis. The analysis of the data collected was conducted using a five-step approach: (1) organize data by key constructs (which is operationalized in Chapter 3), (2) generate categories and themes, (3) code data by categories and themes, (4) develop generalizations from the data and search for alternative interpretations, and (5) form final generalizable findings into a report (McNabb, 2002 p. 296). Upon completion of this procedure, a narrative description of key findings was prepared based on the analysis and interpretation of findings. Chapter 3 presents a detailed overview the study's data collection and analysis methodology.

\section{Organization of the Study}

This dissertation is divided into five chapters including the introduction. The introduction has framed the problem, identified the central research question, introduced the theoretical framework, and described the purpose and significance of the study. Chapter 2 provides a history of health care reform in the context of American federalism and history of the Oregon Health Plan. It also presents a theoretical framework and 
OREGON HEALTH REFORM AND COORDINATED CARE ORGANIZATIONS 21

comprehensive assessment of governance through an extensive literature review, drawing upon the fields of health services research, public administration, and political science.

Chapter 3 presents an overview of the methodology, including discussion of the qualitative approach, development of key research constructs or variables, unit of analysis, and the analytic framework deployed for analysis. In addition, the third chapter covers key assumptions and limitations of the study, including criteria used to exclude key relevant issues beyond the parameters of the study. Chapter 4 presents analysis of the research findings, including in-depth discussion of key findings within the context of the framework of the study. The fifth and final chapter synthesizes implications for policymakers, elected officials, state leaders, public administrators and researchers around state level health policy, and the administration and governance of community health systems. It concludes with a discussion of the limitations and assumptions of the study and identifies the need for additional research, framing research questions for future study.

\section{Summary}

Successful reform is going to require a sustainable process that will involve a number of incremental steps. These steps must be sequential and cumulative, leading over time towards a clear policy objective. - Governor Kitzhaber, 1999 America's health care system faces a Gordian Knot in that no single entity, public or private, has the "knowledge and resource capacity to tackle problems unilaterally" (Kooiman as cited in Stoker, 1998, p. 22). CCOs aim to tackle such fundamental problems by creating a unique interdependent relationship among diverse groups of 
OREGON HEALTH REFORM AND COORDINATED CARE ORGANIZATIONS 22

stakeholders by establishing a new interactive system of community health governance. Oregon, along with many other states, will continue to be challenged over the coming years to develop and implement new approaches to achieve significant health care reform, with or without national health reform. One step toward achieving this goal is to understand the potential of a collaborative governance model relative to CCOs as well as to assess influential factors in the model of governance among CCOs. Findings from this study can help inform the respective roles and responsibilities for public and private stakeholders within the context of coordinated care entities and inform potential reform efforts in other states.

Oregon's newest approach in addressing these issues, creating CCOs at the local level, offers a promising solution to these problems by fundamentally redesigning the state's "sick care" system into a health system. If promoting population health is the goal, containing costs and ensuring safe and effective health service delivery are viewed as vexing problems in today's health care system. CCOs provide a new approach to address these challenges and assess whether the collaborative governance model is most suited to manage this new complex governance relationship among public, private, and nonprofit entities. This research should serve as an informative and valuable exercise: It lays the foundation for researchers to further assess whether CCOs are viable models to leverage to advance broad health policy goals in Oregon. 


\section{Chapter 2: Review of the Related Literature}

Health care in the United States is a wicked social problem. Compared to other industrialized countries, access and quality of health care services in the U.S. are modest at best (Commonwealth Fund, 2011; Squires, 2012). The U.S. spends more on health care than any other country - almost twice more than all other industrialized countries-yet in 2000 , the U.S. health care system ranked $37^{\text {th }}$ in population-based health outcomes and ranked last in preventable deaths compared to 18 industrialized countries (World Health Organization, 2000; Nolte \& McKee, 2008). From an international perspective, the U.S. ranks near the bottom among most measures of health status, ranking $46^{\text {th }}$ in life expectancy and $42^{\text {nd }}$ in infant mortality, when compared with 192 other nations (Schroeder, 2007). The number of uninsured, estimated at 60 million in 2011, continues to increase, affordability continues to decline, and performance and quality are inconsistent (Cohen \& Martinez, 2011; Commonwealth Fund, 2011).

For decades, national and state health reform efforts have attempted to address the steady erosion of employer-sponsored health insurance as well as provide better access and affordable coverage, contain rising premiums and out-of-pocket expenses, and reduce the rates of uninsured (Gold, Mittler, Aizer, \& Lyons, 2001; Lilie-Blanton \& Hoffman, 2005; Kaiser Family Foundation, 2009; Paul-Shaheen, 1998). ${ }^{4}$ These issues are further compounded by an aging population burdened with an increasing prevalence of chronic diseases that include obesity, diabetes, and heart and cardiovascular disease to list a few.

\footnotetext{
${ }^{4}$ For a complete history of health care reform in the United States, see Starr, P. (1984). The Social Transformation of American Medicine, and Starr, P. (2011). Remedy and Reaction: The Peculiar American Struggle Over Health Care Reform.
} 
Such disease burdens often lead to expensive medical services and end-of-life care, where a large portion of total health care expenditures occur in the last year of life (Liu, Wiener, \& Niefeld, 2006).

Public agencies across all levels of government recognize the importance of a healthy population but are asked to "do more with less." In an era of decentralized and "smaller" government, the reality is that government can no longer single-handedly fix the health care crisis. Rather, the promise of government is satisfying the need to grapple with health care reform through facilitating new models of new governance in health care enterprise. At stake are the health of entire communities, which when put at risk adversely affect employment, educational opportunities, social cohesion, and the opportunity for individuals and families to live as productive members of society (see Marmot \& Wilkinson, 2006). Regrettably, this "risk" is becoming the reality for communities across the U.S. as overall health and well-being continue to decline in the face of unsustainable health care expenditures and increasing rates of uninsured. The U.S. continues to invest an increasing percentage of its Gross Domestic Product (GDP) in health related expenditures, estimated to reach $19.8 \%$ by 2020 (Centers for Medicare and Medicaid [CMS], 2012). We can no longer afford to invest $\$ 1$ out of $\$ 7$ into a dysfunctional, fragmented, and inequitable health delivery system (CMS, 2012). Government may no longer be the solution for addressing this wicked problem, but governance may offer an effective solution.

Confronted with these facts, most health policy researchers, elected officials, and policymakers have reached a tenable consensus: The fragmented health care delivery 
system is unsustainable (Justice, Hess, \& Weil, 2009; Stanek, Dierker, Henderson, \& Tollen, 2012). Faced with mounting federal debt and a historic recession that eroded coverage, affordability, and resources in almost every state, elected officials are taking action (Smith, Gifford, Ellis, Rudowitz, \& Snyder, 2011). Appointed public officials are responding by rethinking the role of public institutions in the context of financing, delivery, and organization of health services. States are working to maximize limited resources and address the complexities of health care in an era of economic and political uncertainty (Weil et al., 2009).

States have historically served as policy innovators, as "laboratories of democracy" in a federalist system of government (Justice Brandeis, 1932). ${ }^{5}$ Individual states are seeking reforms to control health care costs by bending the cost curve and sponsoring multi-payer efforts to improve primary care and increase care coordination. States continue to provide coverage to the growing ranks of uninsured through federalstate programs such as Medicaid and the Children's Health Insurance Program (CHIP), in addition to supporting insurance reform by setting up state-based health insurance exchanges (Stanek et al., 2012).

In a challenging economic and politically partisan environment, in which much of the national conversation revolves around federal health reform, states are moving ahead, laying the foundation for comprehensive reform and informing the federal government on broader national reform initiatives. Among these leading states is Oregon, which is

\footnotetext{
5 The term originates from a U.S. Supreme Court opinion issued by Justice Louis Brandeis (1932). New State Ice Co. v. Liebmann 285 U.S. 262. (1932). Retrieved from http://caselaw.lp.findlaw.com/scripts/getcase.pl?navby=CASE\& court=US\&vol=285\&page=262
} 
OREGON HEALTH REFORM AND COORDINATED CARE ORGANIZATIONS 26

pursuing comprehensive reform of its Medicaid health delivery system by creating community-governed and accountable integrated health systems: coordinated care organizations (CCOs). In May 2012, Oregon entered an historic five-year agreement with the Obama Administration and the Department of Health and Human Services (DHHS) to create a new federal-state partnership that supports a redesign of Oregon's Medicaid program. ${ }^{6}$

Oregon decided to move beyond implementation of major components of the federal health reform legislation provided for in the Accountable Care Act (ACA) passed by Congress in 2010. In 2012, the state moved to implement a new model of care delivery for its 600,000 Medicaid recipients. Oregon is working to advance comprehensive health care reform by establishing community-based integrated delivery systems or CCOs (Oregon Health Fund Board [OHFB], 2008; Oregon Health Policy Board [OHPB], January 2012). CCOs are required to accept a global payment for a defined Medicaid population, report on performance, and will be held accountable by the Oregon Health Authority (OHPB, January 2012). Oregon is working to build on its past successes with Medicaid, which include creating a prioritized list, expanding Medicaid coverage, and shifting resources from high-utilization inpatient settings to primary and preventive care services integrated at the community level (Oregon Health Authority [OHA], March 2012).

\footnotetext{
${ }^{6}$ Governor Jon Kitzhaber, Official Press Release, May 3, 2012. Retrieved from: http://governor.oregon.gov/Gov/media_room/press_releases/p2012/press_050312.shtml
} 
The overarching policy goal of Oregon's health reform, referred to as “health system transformation", is to achieve better health, better health care, and lower costs for Oregonians (OHPB, January 2012). However, the true promise of Oregon's CCO model is to demonstrate whether such goals are achievable at the state level. To substantially bend the cost curve, Oregon will need to reform their delivery system to empower local communities and pay for health outcomes instead of encounters. As the Affordable Care Act adds millions of new Medicaid enrollees across the country in 2014 (see Sommers, Swartz, \& Epstein, 2011), demonstrating on-the-ground solutions that sustainably improve client experience and contain costs will be particularly important. Oregon sees its health care reform amongst its Medicaid population as laying the foundation and framework to transform the entire state's health delivery system into a community-based comprehensive health system.

\section{Chapter Organization}

This chapter presents the rationale for conducting exploratory research on a new model of health care organization and delivery in Oregon. The research problem is described to support the importance and significance of exploring this model. This study seeks to contribute in both theory and practice by exploring whether collaborative governance serves as an effective model to support the transformation of communitybased health services. The literature review represents the body of knowledge and evidence pertinent to inform the research study, specifically state-level health care reform, the history of Oregon's Medicaid program, important historical factors unique to the state, and models of collaborative governance. 
OREGON HEALTH REFORM AND COORDINATED CARE ORGANIZATIONS 28

The chapter is organized into six sections. The first section provides a synthesis of issues that frame the research, specifically the U.S. health care system and Medicaid. The second section outlines the history of the Oregon Health Plan and the state's unique model of community engagement as well as its lasting influence on health policy. The third section presents salient theoretical perspectives related to contemporary governance, including integrated health delivery networks, along with the adopted framework for the CCO collaborative governance model. The next two sections highlight the central purpose and significance of the study, including the principal research question. The final section offers a conclusion and outline of Chapter 3.

\section{Overview}

With unprecedented collaboration between local communities, health care providers, and our federal partners, Oregon is on the right track to create a system that will both improve care and reduce costs. - Governor Kitzhaber, $2012^{7}$ Federal and state governments realize reform is inevitable because of health care's financial unsustainability, which has bankrupted industries and government agencies across the country. It remains a highly polarized and charged political and social issue. The states along with the federal government are struggling to finance health care coverage and services, particularly publicly funded health insurance, in an era of rapidly decreasing budgets and rising health care costs (Smith et al., 2011). Public officials and

\footnotetext{
${ }^{7}$ Press Release, May 3, 2012

http://www.oregon.gov/gov/media_room/pages/press_releasesp2012/press_050312.aspx
} 
agencies are seeking solutions to the problems of cost, access, and quality, while having to operate in an increasingly partisan and polarized political climate.

As a result of the "Great Recession," states have faced significant budget deficits that stem from shortfalls in revenue, budget cuts, restrictions on tax increases, and a prolonged stalled economic recovery. Still, several states are forging ahead by passing health reform legislation. Out of economic necessity, select states are navigating challenging political and economic issues. They are supporting health reform to manage the harsh fiscal realities of the prolonged Great Recession. Because of an unexpected and historic policy window, states are now pursuing health reform and are seeking to leverage this unique opportunity to pass and implement substantive legislation (Kingdon, 1995).

Whether supporting health reform or otherwise, almost all states are faced with less financial and human resources in an era of devolution and hollow government. Therefore, states that are working to implement reforms are engaged in unprecedented multi-sectorial approaches to a problem that spans the public, private, and nonprofit sectors. The public sector cannot achieve health care reform solely through legislation, administration rule-making, regulation, or other tools traditionally used by government (Salamon, 2003). New approaches and new partnerships are needed.

One new approach unites organizations across the public, private, and nonprofit sectors by collaborating to address problems of cost, access, and quality. Such an approach is largely unprecedented in terms of sharing responsibility with reforming health care in a dynamic and competitive marketplace. While entities and organizations are working together across sectors, a new strategy for improving the health care delivery 
system has taken hold, one which aims to improve quality, increase population health, and control cost and expenditures. Oregon has adopted this Triple Aim (Berwick, Nolan, \& Whittington, 2008) as its guiding strategy for health reform. In 2011 and 2012, a bipartisan legislature and a governor (who was formerly an emergency room physician) championed health reform and decided to lead efforts to adopt the Triple Aim and redesign the state's successful Medicaid program, the Oregon Health Plan (OHP).

The Oregon Health Plan, established in 1989, continues to offer quality health care services to the state's most vulnerable population groups (OHBP, 2012, p. 1). Simultaneously, OHP has managed to contain health care spending to some extent for Oregon's Medicaid Program, resulting in savings to the federal and state government of approximately \$15 billion since 1994 (OHA, March 2012). As with many other states from 2009-2011, Oregon's Medicaid expenditures increased at an unsustainable rate and far exceeded available state revenue (OHPB, 2012). Through CCOs, Oregon hopes to continue building upon the OHP's success and address the long-term issue around financial viability of the state's Medicaid program.

In 2009, the Oregon Legislature passed House Bill 2009, which was the culmination of a two-year planning process that began with the passage of the Healthy Oregon Act in 2007 (Senate Bill 329). The 2009 legislation was the result of an extensive public engagement process and input from over 2,000 individuals. This provided a "blueprint" to reform Oregon's health care system by addressing the issues of cost, quality, and access - referred to as the Triple Aim (Berwick et al., 2008; Oregon Health Fund Board [OHFB], 2008; OHPB, 2012). This legislation also established the Oregon 
Health Authority, appointed to serve as the "macro-integrator" of the Triple Aim (OHFB, 2008, p. 7). Then in 2011 the Oregon Legislature with support from Governor Kitzhaber passed House Bill 3650, creating the framework for statewide health care transformation, culminating in 2012 with House Bill 1580, which enabled legislation to implement a new model of health care delivery to OHP clients through CCOs.

Shifting from policy issues of access and coverage of health services, Oregon is now creating a new model for organizing, delivering, and financing the physical, behavioral, mental, and dental services for OHP beneficiaries (OHA, 2012; OHPB, 2012). CCOs are community-based organizations responsible for care integration and coordination for individuals eligible for Medicaid and eventually individuals dually eligible for Medicaid and Medicare. According to the Oregon Health Policy Board (2012) and Governor Kitzhaber, (2012), CCOs are merely the next stage of health reform, which started with the creation of the OHP (OHBP, 2012, p. 1).

Central to this new community-based health delivery model is the notion of collaborative governance, as required by Oregon statute 414.625 (2011 edition) and administrative rules issued 2012 (Oregon Administrative Rule 410-141-3015). It is unclear whether a collaborative governance model for CCOs will prove an effective model by which to facilitate the coordination and integration of health services for OHP beneficiaries. Nonetheless, this model of governance holds promise in transforming Oregon's health delivery system. The model requires entities across the public, private, and nonprofit sector-including organizations tied to financing, insurance, and delivery of services - to collaborate toward a set of shared goals: the Triple Aim. 
OREGON HEALTH REFORM AND COORDINATED CARE ORGANIZATIONS 32

The challenge is that many of these same entities have historically organized for survival in an external environment characterized by an imperfect yet competitive and regulated market place (Oregon Department of Consumer \& Business Services [ODCBS], 2012). The exact opposite is required through CCOs and collaborative governance. Health care organizations and provider communities now have been asked by the state to self-organize as a single coordinated organization. Without an effective and well-functioning model of collaborative governance for CCOs, Oregon risks being unable to implement health care transformation and not leveraging the $\$ 1.9$ billion available in federal funding over a five-year period.

The importance of CCOs as the driving vehicle for transforming Oregon's health care delivery system is clear. What is not as understood is whether collaborative governance will prove effective and resilient enough to achieve the desired outcomes proposed by the governor, the Oregon Legislature, and the Oregon Health Authority. The concept of collaborative governance is not new by any means; however, it is new as a model for organizing a comprehensive community-based system of coordinated and integrated care. In terms of governance, a key challenge for CCOs is shifting from illness to wellness, from inpatient and acute care to prevention and primary care. Some organizations that have historically benefited from the status quo could now be adversely affected financially; others will likely benefit. Shifting from the traditional medical model to an untested model of health promotion and disease prevention, one that is personcentered, presents significant challenges that will likely lead to conflict. This will start at 
the community level, as CCOs are held accountable by the state; and the state by the federal government.

\section{Framing the Historical Context and Oregon Perspective}

The history of the U.S. health care system and past efforts to reform health care, both nationally and among states, occurred in a system of federalism. Whether past reform efforts have attempted to manage costs, improve quality, or expand access, the delivery, financing, and organization of health care services has remained an almost unattainable end goal. This section will review the history of health care reform, focusing on Medicaid, and examine the environment for health reform, which consists of a mix of public-private entities operating in an imperfect health care market, regulated and financed by the public sector. Issues framing the research include an historical review of the Oregon Health Plan and assessment of how Oregon's community-participatory model has influenced health policy and OHP over the span of two-plus decades.

Drawing on appropriate theoretical domains and academic disciplines, instructive concepts relevant to the study include the dilemma of contemporary governance, specifically the challenge of collaborative governance in the context of CCOs and state health policy. These are examined and informed by the fields of public administration and policy, political science, and organizational theory. Taken as a whole, these issues frame the importance of collaborative governance as a potential model to help implement a redesigned system of health care delivery for a large population. They also begin to frame key constructs and factors that support an effective governance model for a community-based health delivery system. Finally, this set of issues highlights the 
significance and timing of this study in an era of broad scale health reform at the national and state levels.

\section{United States and Health Care Reform}

The financing, delivery, and costs of health care have been multi-faceted and multi-sector problems. Past efforts across the public, private, and nonprofit sectors have attempted to wrestle with issues including rising costs, increasing rates of uninsured, and problems related to access and quality. The most notable and broad scale historical effort was the creation of Medicare and Medicaid, from which most health care reform efforts stem. Other multi-sector efforts include the Leapfrog Group, comprised of large employers aimed to influence quality and affordability; the National Quality Forum and the National Committee for Quality Assurance, seeking to accredit and certify health care organizations and professionals; and managed care organizations (MCOs) and health maintenance organizations (HMO).

In the aggregate, such initiatives (and countless others) have demonstrated an inability for any single sector to contain the rising costs of health care, improve the quality of health services at a population level, or expand insurance coverage to the remaining tens of millions of uninsured and underinsured. These issues are intractable health care dilemmas that go beyond a single solution by any one sector, public or private. Although most of health care is delivered at the community level, these issues and challenges extend far beyond any one community or public institution. In Oregon, CCOs attempt to bridge federal and state policy and agencies, formally link health care organizations and providers, and thus affect access, cost, and quality. 


\section{Case for Comprehensive Health Care Reform}

The national conversation around health care and health reform is not necessarily about the legitimacy to support reform, but rather how to achieve reform and who should be responsible for it. Oregon has taken this conversation one step further by not only addressing what and when to reform, but also how to proceed. The case is no longer about whether to promote reform, either at the national or state level; it now appears focused on the means and mechanisms by which to achieve it. Whether undertaken at the federal or state level, all health reform occurs in a system of federalism, which is the federal-state structure by which reform must proceed, particularly for Medicaid. Prior to assessing federal and state health policy within the context of American system of federalism, it is helpful to review the three main components of contemporary health reform: improving care, population health, and cost containment (Berwick, Nolan, \& Whittington, 2008).

Without comprehensive national health care reform (achieved only recently with passage of the ACA in 2010), the lesson learned from past efforts is there is no single approach or strategy that will effectively achieve multiple goals around reducing costs, expanding coverage, and improving the quality and affordability of health care services to all Americans. To complicate matters further, most of health care is local. In other words, health care resources and service delivery are highly localized, which CCOs are working to integrate and coordinate across the state. In tandem, population or community-based health is also local. Approximately $10 \%$ of an individual's health status is attributed to health services (Shi \& Singh, 2008, p. 49), so reform efforts aimed to 
change the delivery and organization of health services are best suited at the regional and local level because health care is regionalized. ${ }^{8}$ Examples that illustrate this include federal designations such Health Professional Shortage Areas (HPSAs), which indicate localities that have shortages of primary medical care, dental, or mental health providers. ${ }^{9}$ Similarly, there are Medically Underserved Areas or Populations (MUA/MUP), which designate areas in the U.S. that have few primary care providers, high infant mortality, high poverty, or high numbers of elderly population. ${ }^{10}$ Because health care is best understood as being local, that is the logical starting place for transforming community delivery systems in Oregon.

In Oregon, community-based health services consist of numerous organizations. These range from individual and small primary care providers to independent practice associations (IPAs), hospitals, and integrated delivery systems as well as labs, pharmacies, community health centers, post-acute and long-term care organizations, mental health providers, dental providers, alcohol and drug treatment centers, and physical rehabilitation centers (for a comprehensive overview of the components of the U.S. health care system, see Shi \& Singh, 2008). These community organizations are forprofit, nonprofit, or operated by public agencies. Extent and availability of communitybased services varies by community, as does the number of health insurers in a specified marketplace. What is not unique, however, in most urban, suburban, and even rural communities is the delivery of health care services, which are fragmented, too often

\footnotetext{
${ }^{8}$ For example, see Dartmouth Atlas of Health Care.

${ }^{9}$ United States Department of Health and Human Services, Health Resources and Services Administration. Retrieved from http://bhpr.hrsa.gov/shortage/

${ }^{10}$ Ibid.
} 
uncoordinated, and offer duplicative, unnecessary, and non-evidence based services. Some of these inefficient outcomes are the result of a largely unregulated sphere, often referred as the competitive health care marketplace. The bottom line is that many health delivery systems across communities in Oregon and elsewhere are not supporting the Triple Aim.

\section{Access, Cost, and Quality: Triple Aim}

The best evidence suggests that most individuals receive only half the preventive care recommended, people with acute or chronic conditions receive about two-thirds of the care they need, and about one-fifth to one-third of both acute and chronic care is unnecessary (Schuster, Elizabeth, McGlynn, \& Brook, 1998). This estimate does not factor in the tens of millions of uninsured and underinsured who often have minimal-tono access to primary care services, delay seeking services, or seek treatment in inappropriate and costly settings such as emergency departments (Wolman \& Miller, 2004). Further complications include the limited differences of health care services, utilization, and cost when comparing private and public health coverage. Individuals, largely those covered from their employers or the small and individual insurance market, often do not appear to have better health outcomes than individuals insured through publicly funded program including Medicaid and the Children's Health Insurance Program (CHIP). This does not apply to the uninsured or those with limited access to primary, preventive, or tertiary services.

Access and coverage. Having access to health services - predominately insurance coverage - matters. Health insurance is one of the most significant factors in 
determining an individual's access to health care services in the United States including Medicaid coverage (Hadley, 2003; Smedley, 2008; Baicker, Taubman, Allen, Bernstein, Gruber, Newhouse, et al., 2003; Sommers, Long, \& Baicker, 2014). Compared to their insured counterparts, uninsured individuals are less likely to receive preventive and primary care services or have a regular source of care. They are more likely to go without needed medical care and more likely to have poorer health outcomes (Hadley, 2003; Weinick, Zuvekas, \& Cohen, 2000). This is especially true for low-income racial and ethnic minorities (see Smedley, Stith, \& Nelson, 2002). The fragmented U.S. health care system has historically disadvantaged the poor. This is especially the case for low-income minorities because the most significant factor in their access to health care services is the presence or absence of health insurance (Andrulis, 1998; Weinick et al., 2000; Zuvekas \& Taliaferro, 2003). Numerous studies have shown that public health insurance coverage, including Medicaid, improves access to health care services, the likelihood of receiving appropriate services when needed, and health outcomes among both adults and children (Berk \& Schur, 1998; Hadley, 2003).

Published in 1982, the landmark RAND health insurance experiment was the result of a decade-long study of over 7,000 participants, which sought to understand the effects of health insurance and cost sharing (Rand, 2006). The study found an important relationship between insurance status and the consequences for health: The poorest and sickest individuals in the study had improved health outcomes, which were attributed to having access to health services (Rand, 2006). Another key finding was the effect of costsharing and use of medical services, based on five types of health insurance plans 
provided to study participants. In essence, participants who experienced cost sharing available through four of the five plans, the fifth being free, decreased service utilization of both needed and unneeded health services.

As a result of historical, political, and economic factors as well as persistent inequalities in American social structure, disparities in access to health care remain widespread (Hargraves \& Hadley, 2003; see Shi \& Stevens, 2005). From a health system perspective, there is compelling evidence that access to primary care is associated with preventing illness and premature death, improving health, and increasing equity in health services across population subgroups (Starfield, Shi, \& Macinko, 2005).

The absence of health insurance contributes to racial and ethnic disparities because the uninsured lack a steady source of health care, frequently experience delays in seeking needed care, receive less care when they do, and have poorer levels of health generally (Zuvekas \& Taliaferro, 2003). Individuals from diverse racial and ethnic backgrounds are adversely affected by widespread disparities in health status and the quality of health care services (Zuvekas \& Taliaferro, 2003). Historical rates of racial and ethnic disparities found in accessing health care services and utilization are alarming (Smedley et al., 2002). Therefore, public policies are particularly important for achieving national priorities that seek to expand insurance coverage and access to health care services. Medicaid provides coverage to a disproportionate number of racial and ethnic minorities, including the poor and children (the population coverage among Medicaid enrollees will be covered in the section on the history of Medicaid). 
Quality and costs. The United States is one of the only advanced economic countries devoid of a single payer health delivery system or universal insurance. Access to affordable, quality, and continuous health services is increasingly difficult for tens of millions of individuals, particularly those not eligible for publicly funded or employersponsored health insurance. Spiraling health care costs, estimated to reach $\$ 2.7$ trillion by 2020 (or 20\% of GDP) (CMS, 2012), along with poor health status and outcomes among the elderly, poor, disabled, individuals with chronic morbidities, working poor, people of color, uninsured and underinsured, and undocumented aliens are nearing a tipping point. As the cost of health care continues to increase, the number of uninsured continues to increase.

Although the U.S. invests greatly in health care, the quality of health care services is at best marginal and at worst poor (see Institute of Medicine [IOM], 2001). The country's fragmented, disjointed, and massive health care industry continues to require increasing financial and human resources. Americans can no longer afford to invest increasing rates of the country's GDP into a system that is responsible for affecting approximately $10 \%$ of an individual's health status (Shi \& Singh, 2008). The tradeoff in this scenario is that other public goods such as education and community infrastructurefactors that contribute far more to one's health and health status - are being cut because of lacking resources, namely public funding. To start understanding the array of factors contributing to this unsustainable paradigm, it is helpful to consider the broader environmental context in which health care operates, primarily the nexus of federalism and state health policy. 


\section{State Health Policy: Birth of Medicaid}

The American style of "marble cake" federalism has resulted in health policy and

funding being shared across different governments with a substantial overlap in the health policymaking activities among federal and state officials and administrators. States are often responsible for establishing new health care policies and programs, sometimes independently, other times in partnership with the federal government. Federalism offers an opportunity for early experimentation and evaluation of health policy and implementation at the state level before being adopted at the federal level. This is evident in that many health policy innovations developed by states over time are adopted by the federal government and evolve into national programs. For example, early health care reform efforts in New York and Massachusetts resulted in the CHIP and the Individual Mandate (a pivotal component of the ACA) (Holahan et al., 2003; Morone, 2001). Federal health care reform embodied in the ACA requires considerable effort among the states. Significant components of federal health care reform will be implemented, including the expansion of public health insurance through Medicaid s and the establishment of state and federal health insurance exchanges by 2014 .

History of Medicaid in a federalist system. Medicare and Medicaid were created by Congress and signed into law by President Johnson in 1965 to address the lack of access to basic health care services among the nation's poor, elderly, and youth. These two programs, along with the State Children's Health Insurance Program (CHIP), established in 1997, have intertwined federal and state government in health policy, health care delivery, and financing for the past 50 years; some would argue this was 
inevitable within a federalist system of government. Medicare was established to provide universal federally funded health insurance for all seniors over the age of 65 , without any state responsibility to finance or administer the program.

Medicaid is a federal-state partnership comprised of joint financing that provides health insurance for certain categories of poor people, primarily pregnant women and children (Brown \& Sparer, 2003). Medicaid has a complex and multifaceted history as a shared financial responsibility among federal and state government to provide health coverage for low-income Americans. Medicare and Medicaid now play a critical role in the U.S. health care system. However, Medicaid often stirs the policy debate about the role of state and federal government in health care. Oregon has often been at the forefront of this controversy in its effort to reform the state's Medicaid program (see Bodenheimer, 1997; Brown, 1991; Jacobs, Marmor, \& Oberlander, 1999; Leichter, 1999; Oberlander, 2007; Sipes-Metzler, 1994; Wiener, 1992).

Medicaid has successfully improved access to health services for tens of millions of low-income individuals (see Engel, 2006; Weil, 2003). The program is often called the “backbone" for financing and providing health coverage to the country's most vulnerable (Holahan, Weil, \& Wiener, 2003). Through the federal demonstration waiver process, states continue to implement creative solutions that address a range of health care issues, which are authorized through the federal review and approval process, commonly referred to as the waiver process (Thompson \& Burke, 2007). Historical waiver issues have included attempts by states to address the growing number of uninsured by expanding coverage and types of services to targeted population groups; improving the 
quality of services delivered and financed; controlling escalating health care costs, often through managed care; reducing disparities of care including access and quality; or some combination of these. Medicaid remains a popular federal program among many states, largely because it provides flexibility in the design and ability to modify a state's Medicaid program, and it offers a beneficial financial arrangement for states (Holahan, Weil, \& Wiener, 2003).

Medicaid from a state perspective. As individuals lose insurance coverage either through unemployment or transitioning to employers that do not provide health coverage, those eligible for Medicaid and CHIP increase. Consequently, there is an interesting trend between employment and Medicaid coverage. As individuals lose employment in periods of economic downturn, such as the recent "Great Recession" as well as previous economic downturns, they simultaneously lose health coverage, which often extends to the entire family (e.g. children or dependents). Simultaneously, federal and state governments experience a decrease in funding as the result of a retracting economy. These combined factors compound the problem of coverage: While individuals lose their employer-sponsored coverage and government agencies lose funding for publicly available health insurance, the demand for Medicaid and CHIP increases (Kaiser Commission on Medicaid and the Uninsured, 2011).

Many states have balanced budget amendments and cannot borrow to backfill state budgets. They often bear the brunt of the harsh economy and are faced with difficult decisions including modifying eligibility for programs such as Medicaid and CHIP to meet available revenue targets (Boyd, 2003; Smith et al., 2011). This creates a perfect 
storm, exacerbated by the reality of spiraling health care costs, increasing numbers of uninsured, growing ranks of the working poor, and a sicker population because of rising rates of obesity, diabetes, cardiovascular disease, and an aging generation of baby boomers. Faced with these challenges, states continue to reform their health care systems in an effort to control costs, improve quality, expand access, and capitalize on resources in an era of the shrinking public sector and decline in the role of government, especially at the federal level.

Many States are actively seeking to reform their health care systems (see National Governors Association [NGA] 2011 report). In response to the economic downturn, some states such as Arizona even had to consider cutting services such as coverage for organ transplants, which are costly, while other states have sought to reduce provider reimbursement rates in order to contain costs. ${ }^{11}$ On the other hand, several states have taken a different approach with delivery systems and financing reforms. Examples include Massachusetts, Rhode Island, Vermont, Pennsylvania, Minnesota, and Oregon (NGA, 2011). These states are working to address multiple issues including insurance expansion, cost containment or payment reform, quality and patient safety, access to comprehensive services, health information technology, and moving from a fragmented to a coordinated system of care delivery through the tools available via public policy (Justice, Hess, \& Weil, 2009; NGA, 2011). Essentially, these states are working to restructure health delivery systems to improve quality and efficiency of services while moving toward a sustainable health care system.

\footnotetext{
${ }^{11}$ http://www.nytimes.com/2010/12/05/us/05transplant.html
} 


\section{Changing Paradigm: States as Health Policy Innovators}

States have been driving reform efforts, past and present, creating innovative approaches to health reform (Bovbjerg, Wiener, \& Housman, 2003). They continue to explore new models for payment, integration, care coordination, cost-effective treatments and coverage, financing methodologies, incentive structures, and efforts to either maintain existing coverage rates or expand coverage and access to primary care services. These changes are occurring in an era symbolized by the devolution of public programs and funding from the federal government. States are working cooperatively through a variety of partnerships among private and nonprofit entities to establish a continuum of integrated and comprehensive models of health services.

States are learning how to leverage public policy as a means to foster the networks and new "paradigms of care" while maintaining costs and ensuring performance and accountability. They are fostering new models of care such as patientcentered medical homes, payment bundling and pay-for-performance methodologies, and promotion of health homes and accountable care organizations (ACOs) (NGA, 2011). Building new networks and partnerships, however, presents challenges in a sector that historically has been fragmented and beholden, often through the political process, to powerful stakeholders. Nevertheless, states continue to move forward with health reform, often out of economic necessity and driven by external forces beyond the control of their legislatures.

The emerging intra- and inter-organizational relationships necessary to establish integrated or coordinated delivery systems is unprecedented. Past attempts of establishing 
health maintenance organizations or managed care organizations were largely contained to hospital systems. Physical, behavioral, and dental providers as well as hospitals, longterm care providers, and payers need to collaborate to establish community-based comprehensive integrated care systems. This requires new approaches and ultimately new models for governance.

That said, there are two important considerations in terms of state health policy: (1) establish statewide integrated delivery systems that support better patient care, better community health, and reduce costs; and (2) foster new networks and partnerships for creating integrated statewide delivery systems for the Medicaid population. To transition to a new delivery system, states can no longer approach reform in a piecemeal fashion. States need to enact and support comprehensive legislation that fosters re-engineering of the delivery system by encouraging collaboration among groups of providers, hospitals and hospital systems, specialty practices, payers, and non-medical community partners as well as state, county, and city agencies. Oregon is leveraging competition by targeted changes through Medicaid, the commercially insured market, and public employee insurance. As significant payors, regulators, and administrators of health care programs and services, states have an opportunity to serve in a new capacity or modified role as the facilitators and conveners in the health care marketplace.

\section{Blazing the Trail: History of the Oregon Health Plan}

Oregon has a national reputation as a leader in reforming health care and is considered one of the more innovative states in its approach to Medicaid. This reputation took hold in 1994 when the Centers for Medicare \& Medicaid Services (CMS) granted 
Oregon its initial section 1115(a) Demonstration under the Social Security Act (OHA, 2012). The federal waiver allowed the state to implement the Oregon Health Plan, which continues to lead by innovative and committed policymakers and health care reformers, including the "intellectual father" of the OHP, Governor John Kitzhaber (Wiener, 1992, p. 26).

In March 2012, the Oregon Health Authority (OHA) requested an amendment to its existing federal waiver for Medicaid. Through this modified federal waiver, the state received approval by CMS to support Oregon in its goal to integrate physical, behavioral, and dental services for OHP beneficiaries through CCOs. The Oregon Health Authority (OHA) is the agency responsible for the state's health programs including public health, Medicaid and CHIP programs, and its sister agency, the Department of Human Services among other programs, and it is working to integrate several of these intra-agencies for better health reform. The OHA is leveraging the state's purchasing power in the health care marketplace, initially through Medicaid, but eventually by integrating an additional 800,000 individuals covered through the Public Educators Benefit Board (PEBB), the Oregon Educators Benefit Board (OEBB), and the state's employee health program (see Oregon House Bill 3650, Section 13[2][e], 2011). The next sections examine the historical development of Oregon's Medicaid program within social, political, and institutional contexts.

\section{Oregon as a policy entrepreneur: Historical perspective. Community} involvement in state health policy has become a defining feature in Oregon, dating from the early 1980s with Oregon Health Decisions, a nonprofit organization that was focused 
on health care related issues and citizen engagement (Sipes-Metzler, 1994). Aside from serving as a leader in state health reform, Oregon has a distinct reputation for extensive community and stakeholder input into health policy development and implementation. Early efforts in the state to develop comprehensive health reform policy started with the Health Policy Commission created in 2003, and continued with the Health Fund Board between 2007-2009. The current Health Policy Board (2009-present) involves hundreds of individuals on work groups, committees, and boards and encourages input and public comment from thousands of Oregonians.

Oregon continues to rely on public committees and councils to formulate significant health policy. For example, the executive branch supports over 220 standing public committees and councils that cover education, transportation, natural resources, labor, and health care among countless others. ${ }^{12}$ These committees provide public forums for input and stakeholder feedback. This same process resulted in the implementation proposal for CCOs, which involved more than 60 public meetings and input from over 2,000 Oregonians (OHPB, 2011).

In 1987, Oregon Health Decisions, under the leadership of John Kitzhaber (then state senate president), held a forum regarding a recent decision by the Oregon Legislature to stop funding optional Medicaid services for the majority of organ transplants (Sipes-Metzler, 1994). The forum resulted in a proclamation titled "Quality of Life in Allocation Health Care Resources," which outlined a framework and set of principles for decisions about the allocation of health care resources (Sipes-Metzler,

\footnotetext{
12 http://www.oregon.gov/Gov/boards.shtml
} 
1994, p. 27). The Oregon Health Decisions initiative resulted in the active engagement and participation of Oregonians at the community and state levels on an unprecedented scale on important health policy issues. Around the same time, the Oregon Legislature initiated the Oregon Medicaid Prioritization Project (Sipes-Metzler, 1994, p. 27). The result of this project was a consensus that health services in the state could be prioritized (Leichter, 1999).

The Oregon Health Plan is guided by a lasting vision to provide access to health care for all Oregonians. From a policy perspective, Oregon historically has tried to expand Medicaid coverage to previously non-categorically eligible Oregonians, and finance the expansion by limiting medical services for all individuals covered in OHP, thus controlling costs by using the prioritized list. This approach was viewed as highly contentious and considered by proponents an attempt to ration medical care for the poor (Jacobs, Marmor, \& Oberlander, 1999). The net result did not ration or significantly contain Medicaid expenditures as anticipated (Jacobs et al., 1999). Instead, it created a formal process that defines health benefits for Oregon's Medicaid program. Creation of the prioritized list also addressed the contentious and difficult question regarding which services would be covered under OHP.

The Oregon legislation that enacted OHP required an independent commission to oversee the process, which then lead to the prioritized list of medical services. Oregon's Health Services Commission, established in 1987, was a governor-appointed, senateconfirmed group of experts and public members that regularly reviewed the available evidence on clinical effectiveness and cost-effectiveness of health services (DiPrete \& 
Coffman, 2007). When formed, the commission included 11 members: five physicians, four consumer representatives, a public health nurse, and a social worker. The commission was tasked to consider the comparative benefits of health services, rank the services from most to least important, and ensure that the final ranking of services reflected community values regarding treatments (Sipes-Metzler, 1999, p. 308). The final list would determine which services could be funded for individuals enrolled in OHP.

The public input and development process of the prioritized list involved review and debate of over 10,000 medical diagnoses and treatments, eventually whittled down to a final list of 709 condition-treatment pairings presented by the commission (Leichter, 1999, p. 149). In 1989, the legislature agreed to fund a package of benefits that included the first 587 of the pairings (Leichter, 1999). The prioritized list now consists of paired medical conditions and treatments, ranked hierarchically from the most to the least medically necessary based on the latest research on the effectiveness of treatments (DiPrete \& Coffman, 2007). Other services covered include diagnostic services to determine a patient's condition, ancillary services medically appropriate for the treatment of covered conditions, hospital services, and prescription drugs (DiPrete \& Coffman, 2007).

The state - the first to do so — succeeded in establishing a formal process by which to determine the level of services covered, based on a priority ranking system that was matched with available state funding. The list is modified and revised every two years by the commission, coinciding with Oregon's biennial legislative session (DiPrete \& Coffman, 2007). The Oregon Legislature is statutorily prohibited from modifying the 
prioritized list; it may only determine funding based on state fiscal resources. This structure explicitly creates accountability by determining which services are funded. Services above the cut-off line, established by the state's budgetary resources, are funded; those below the line are not.

Evidence-based benefit design in Oregon continues to be a centerpiece of the Oregon Health Plan and serves as the mechanism to determine which benefits are covered by the state's Medicaid managed care and fee-for-service programs. The Health Services Commission was a forum for public input and participation in the decisionmaking process that resulted in coverage of Medicaid services for OHP beneficiaries. Then in January 2012, after nearly a quarter of a century, the Health Services Commission's work was transitioned to the Health Evidence Review Commission (HERC), along with comparative effectiveness reviews of medical technology that was previously managed by another public committee. The governor has requested that the HERC expand upon the Health Services Commission work to date by developing and gaining consensus on evidence-based clinical guidelines and other coverage guidance that will support CCOs in providing high quality care and reducing unnecessary utilization of services.

A notable outcome of the two-year process that resulted in the prioritized list was the level of public engagement. The commission supported 11 public hearings, 47 community meetings in every county of the state (36 total), and a statewide telephone survey of 1,000 individuals (Kitzhaber, 1993; Wiener, 1992, p. 28). At the end of the public process, over 3,500 individuals provided information to the commission regarding 
citizen values around health coverage and health services (Sipes-Metzler, 1999, p. 309). From a health policy and community engagement perspective, the level of involvement in determining the state's benefit coverage for its Medicaid population was unprecedented. It was an intentionally open and transparent process. According to Sipes-Metzler (1999), a key outcome of creating the OHP prioritized list was that the state intentionally fostered a process for citizen participation in a health policy debate, blending medical fact and public value to form public policy (p. 313). The final prioritized list reflected the community's values, an outcome attributed to the extensive process of public involvement (Kitzhaber, 1993). This process has become institutionalized in formulation, and implementing health policy in Oregon's Medicaid waiver for the prioritized list was initially denied by the federal Department of Human and Health Services (DHHS). In 1994, the waiver was finally approved. Oregon had successfully shifted the health care policy debate from coverage of individuals to coverage of services (Speight as cited in Leichter, 1999, p. 157). Oregon's approach to modifying its Medicaid program allows the state to use the prioritized list, especially during periods of economic recession, to reduce covered benefits instead of changing eligibility (reducing OHP enrollment) as a means to control costs. Oregon has also been able to better manage Medicaid costs through mandated managed care enrollment for the majority of OHP beneficiaries.

\section{A decade after OHP: Setbacks through incremental health reform. From}

1994 through 2003, OHP rapidly expanded into a complex Medicaid delivery system in Oregon. In less than a decade, OHP managed to provide 1.4 million individuals access to health care, largely through Medicaid managed care organizations (MCOs). Another 
29,000 individuals previously denied coverage due to preexisting conditions were also able to obtain insurance coverage through a high-risk pool called the Oregon Medical Insurance Pool (OHPR, 2003, p. 1). An important change to the OHP delivery system during this time was a shift from large managed health plans and organizations to locally developed managed care organizations for the OHP population (OHPR, 2000).

After a period of stability, Oregon's Medicaid delivery system faced some difficult challenges. The first of these challenges was caused by a competitive marketplace and disruptive market forces. The result was a series of mergers, acquisitions, and conversions among managed care organizations (MCOs), physicians, and hospitals. Some hospitals and clinics closed, physician group practices dissolved, and large MCOs exited the Medicaid insurance market (OHPR, 2000, p. 5). During this time, insurance premiums and provider payment levels changed, often due to steady increases in insurance premiums and decreases in provider payments among those that provided care to OHP beneficiaries. The mergers and consolidation of Oregon's health care organizations significantly changed Oregon's OHP delivery system (OHPR, 2000, p. 5).

In 2000, the Office for Health Policy and Research (OHPR) reported governance as a key determinant of delivery system stability (p. 2). The issue of stability of the Medicaid governance and delivery system continues to be a pivotal challenge, one with which CCOs have been tasked. The second challenge was the economic downturn and resulting state fiscal crisis, coupled with steadily increasing health care costs. In 2002, Oregon decided to redesign OHP in an effort to maintain Medicaid coverage through cost containment beyond the prioritized list (OHPR, 2003). The immediate result was two 
different benefit packages for Oregon's Medicaid population: OHP Standard and OHP Plus.

OHP Plus was designed to provide the existing Medicaid benefit package to the categorically eligible (Wallace, McConnell, Gallia, \& Edlund, 2010). For OHP Standard, the idea was to expanded coverage to adults or the working poor, those not categorically eligible but still eligible under the state's initial Medicaid waiver (Wallace et al., 2010; Wright, Carlson, Allen, Homgren, \& Rustvold, 2010). There are important distinctions between OHP Plus and OHP Standard. At that time, individuals enrolled in the OHP Standard benefit package would receive a smaller benefit package than individuals in OHP Plus. They were also assessed higher copayments and required to pay monthly premiums (which were not income based) for coverage. One other notable difference was individuals covered by OHP Standard who did not pay their monthly premium for coverage were automatically disenrolled for a six-month period (Wallace et al., 2010).

Results of OHP Plus and OHP Standard were mixed. Some of the intended goals were achieved, but more importantly there were some unintended results. Oregon's second experiment in Medicaid created a significant decrease in the number of individuals enrolled in OHP Standard, as much as a 50\% decrease among some of the most vulnerable Oregonians (Wallace et al., 2010). This adverse outcome was due to increased premium payments combined with elimination of benefits, which significantly disadvantaged those expressly intended to be helped by Medicaid, i.e. the poor. Also, parents with children who lost OHP coverage during this period were more likely to have uninsured children even though they were eligible for Medicaid coverage (Devoe, Krois, 
Edlund, Smith, \& Carlson, 2008). The unifying theme around most of this work is Oregon's continued engagement and public process, which continue to shape the state's health policy and resultant implementation effort. Building on the success of past Medicaid initiatives, including the prioritized list, the level of civic engagement and stakeholder participation, and lessons learned through OHP Standard and OHP Plus, Oregon continues to further reform the state's Medicaid system.

Oregon's health system transformation: Governing the ungovernable. Over the past two decades, Oregon has attempted to redesign the state's Medicaid program to expand coverage through both the state's public and private health insurance markets. Oregon has also used health policy to improve the state's Medicaid delivery system, reduce unnecessary and non-effective health care treatments and services, and continually ensure public participation and engagement in the decision-making process around health policy. These incremental reforms in health care delivery continue today with the state's most recent health reform effort-establishing coordinated care organizations, or CCOs. As with prior health reform initiatives, numerous communities and stakeholders continue to be involved in the various stages of development and implementation of CCOs.

Oregon is implementing its most ambitious OHP redesign plan to date, focusing on person-centered, integrated, coordinated care and alignment of financial incentives. The state expects to demonstrate that such innovations can improve health outcomes and the quality of care as well as protect individuals' rights and hold costs to a sustainable, fixed rate of per capita cost growth. Oregon's Health System Transformation, the next stage of innovation for Oregon's mature managed care system, has the promise to 
OREGON HEALTH REFORM AND COORDINATED CARE ORGANIZATIONS 56

improve health outcomes and simultaneously bend the health cost curve. Oregon has been successfully using managed system for the past 30 years, which has resulted in following achievements (OHA, March 2012, p. 3):

- cost savings of $\$ 15$ billion per the federal evaluations of Oregon's 1115 waiver since 1989;

- limited reliance on institutional care for those needing long-term supports and services;

- comparatively low hospitalization rates; and

- among the highest rates of Medicaid managed care, with approximately $78 \%$ of OHP enrollees.

What is a care organization? Oregon envisions CCOs as community-based organizations governed by a partnership among care providers, community members, and those taking financial risk, namely existing MCOs and hospital systems. Oregon envisions that CCOs will be flexible in addressing community needs and will be held accountable not just to the OHA, but primarily to those served by the $\mathrm{CCO}$, the community. CCOs will partner with local public health departments, hospital systems, and local mental health agencies. These organizations are tasked to focus on health disparities in their communities and to take into account the needs of individuals served by OHP as well as ensure that provider networks are organized to be responsive to community needs. Coordinated care organizations effectively started operating in August 2012 (OHPB, 2012). 
Each CCO is responsible for the integration and coordination of physical, behavioral, and oral health care for individuals eligible for Medicaid, and beginning in 2014, an additional 200,000 individuals are now covered through OHP. CCOs are the single point of accountability for the health quality and outcomes for the enrolled Medicaid populations they serve. Considered as the sum of numerous parts, each CCO includes traditional and non-traditional health care providers, MCOs, behavioral health specialists, hospitals, community health centers, dentists, and naturopaths. These organizations serve as a new model for integration of care delivery at the community level.

CCOs operate with a single global budget for their populations, which grows at a fixed rate per capita with some financial flexibility to ensure available resources are used to achieve the best possible outcomes. The goal is to create financial incentives that support the Triple Aim with CCO global budgets designed to cover the broadest range of funded services for the most individuals to combat unsustainable health care costs. The global budget approach allows CCOs maximum flexibility to dedicate resources to the most efficient forms of care. After establishing the baseline global budget, OHA is seeking to contain $\mathrm{CCO}$ global budgets to a sustainable, fixed annualized rate of growth after developing an appropriate methodology by working with CMS. CCOs also have the flexibility to adopt alternative payment methodologies for their providers, thus changing the incentive structure and moving towards pay-for-performance models or health outcomes, rather than fee-for-service based on utilization. CCOs are responsible for services historically provided outside the managed care system. This approach enables 
CCOs to fully integrate and coordinate services and achieve economies of scale and scope.

In summary, CCOs are accountable for outcomes associated with better health, better quality of care, and more sustainable costs for their defined OHP populations. CCO performance is accessed via publicly reported metrics and contractual quality measures that function both as an assurance that these entities are providing quality and preventative care for their population and as an incentive to encourage them to transform care delivery. OHA is phasing in accountability metrics and performance expectations over time (OHBP, 2012). Quality incentives have been incorporated into the global budget methodology to reward CCOs for improving health outcomes and to increase payments for quality of care instead of quantity of care.

\section{Theoretical Perspective: New Governance for Complex Organizations in Health}

\section{Care}

There is nothing more difficult to take in hand, more perilous to conduct, or more uncertain in its success, than to take the lead in the introduction of a new order of things. (Machiavelli, p. 21)

Environmental and contextual factors. The evolving U.S. health care system creates economic and societal incentives for public, private, and nonprofit organizations to collaborate in pursuit of a collective benefit. For decades, in response to changing environmental conditions, health care organizations adapted by developing new strategies and structures. This was especially the case in the 1980s and 1990s, when countless health care organizations found themselves reorganized to improve efficiency, control 
costs, improve patient outcomes, enhance accountability, and help ensure long-term survival (Bazzoli, Dynan, Burns, \& Yap, 2004, p. 248). According to Bazzoli et al. (2004), there were three main types of organizational change during these two decades: (1) horizontal integration and consolidation of hospitals, (2) horizontal integration and consolidation of physicians, and (3) vertical integration and consolidation among hospitals and physicians (p. 250). Examples of the complex organizations include independent practice associations (IPAs), preferred provider organizations (PPOs), health maintenance organizations (HMOs), managed care organizations (MCOs), and integrated delivery networks (IDNs), among others (Mick \& Wyttenbach, 2003; Shi \& Singh, 2008). Essentially, multiple organizations joined in order to carry out the delivery of health services through organizational integration of financing, insurance, delivery, and payment functions (Shi \& Singh, 2008, p. 343). The organizational changes were in response to turbulent environmental conditions and external contextual factors (Bazzoli et al., 2004).

Since the passage of Medicare and Medicaid in 1965, the federal government has become increasingly intertwined in the financing, delivery, and regulation of health services delivery. Shortly after the passage of Medicare and Medicaid, new public organizations and actors emerged in health care that included politicians, federal policymakers, and administrative agencies (Mick \& Wyttenbach, 2003, p. 37). Newly established federal and state agencies took on new regulatory and administrative functions, which introduced a new layer of complexity in terms of governance structure for the new complex health care organizations. The most complex of these organizations 
are integrated systems, defined by Shortell et al. (1993) as "a network of organizations that provides or arranges to provide a coordinated continuum of services to a defined population and is willing to be held clinically and fiscally accountable for the outcomes and the health status of the population served" (p. 447). In an effort to reform care delivery and control costs, integrated delivery systems or networks (IDNs) emerged through significant horizontal and vertical integration of health care organizations, including IPAs, PPOs, and MCOs. In 2008, there were over 580 IDNs in operation (Shi \& Singh, 2008, p. 368). Integrated delivery networks or systems have in turn led to increasingly more complex, multi-sector health care organizations, which in turn have created a need to develop new, less hierarchical models of effective governance to sustain these complex partnerships. Coordinated care organizations offer yet another model for integrated health care delivery.

Another phenomenon occurred during this period: the emergence of the "corporatization of American medicine" (Starr, 1984). At issue was the transformation and rise of for-profit organizations in health care, marked by increasing market competition and consolidation of health care entities across the country (Alexander \& D’Aunno, 2003). Organizational theory can start to explain the vertical and horizontal integration of health care entities during the era of the corporatization of medicine. This section will examine key theorists and concepts from organizational theory to inform the concept of coordinated integrated care organizations. Important concepts include organizational field, complex organizations, open systems, institutional logic, actors, and governance structures. 
Organizational theorists Mick and Wyttenbach (2003) use the concept of "organizational field" to conceptualize and measure institutional and organizational change in health care services (p. 25). Drawing upon DiMaggio and Powell's 1983 study (as cited in Mick et al., 2003), the concept of organizational field refers to organizations that, in the aggregate, constitute a recognized area of institutional life: key suppliers, resource and product consumers, regulatory agencies, and other organizations that produce similar services or products (p. 25). In health care, the organizational field consists of a geographic area in which certain actors are involved in the financing and delivery of health care services. According to Scott (as cited in Mick \& Wyttenbach, 2003, p. 127), there are three important concepts in organizational field: institutional logic, actors, and governance structures. Institutional logic refers to the goals within an organizational field and the means by which they are achieved; actors are defined by and operate according to the principles of the institutional logic; governance structures refers to the mechanisms that legitimately enforce and modify the institutional logic (Wholey \& Burns, 2003, p. 126).

For CCOs, the health care organizational field consists of local health care markets, institutional logic, actors, and governance structure (Wholey \& Burns, 2003, p. 127). Institutional theory states that organizations, in health care or otherwise, should be understood as "open systems" in which organizations are influenced by their external environments (Scott, 2003, p. 119). They are also considered as having the ability to shape their external environments. This contrasts with the early theory of "closed systems" in which organizations are considered as not being influenced by their 
environments. The organizational field offers an important level of analysis for CCOs because it provides a construct by which to describe a collection of organizations that compete and cooperate; operate with common rules, norms, and values; and share horizontal and vertical ties among similar and dissimilar organizations (Scott, 2003, pp. 130-131). The notion of organizational field is also useful to help describe CCOs' localized environments, an important contextual factor.

Another important factor is determining which actors decide to participate as members of a CCO. It is conceivable that incentives established through the governance structure will likely affect which organizations decide to initially participate, continue to participate over time, or initially participate but then discontinue based on the incentive structure (Scott, 2003, p. 175). According to Scott (2003), there are three types of incentives for organization to employ: (1) material, which often include tangible monetary rewards or value; (2) solidary, which are intangible rewards derived from being associated with an organization; and (3) purposive, also intangible in nature but attributed to rewards created by supporting the organization and its goals (Scott, 2003, p. 176).

The creation of CCOs is vastly affecting regional and local health care markets and organizations therein for the explicit purpose of integrating a fragmented marketplace through formal authority and government policies established in HB 3650. With bipartisan support of the legislative branch, the governor and OHA (otherwise known as the executive branch of government) are deploying institutional pressures to reshape the health care delivery system for 600,000 Oregonians (as of 2012). This regulation establishes norms through the pursuit of the Triple Aim, and it prescribes a complex 
model for integrating and coordinating the physical, mental, and behavioral services within a community (eventually extending to dental services). A critical question that emerges from these broad scale changes is how these new complex organizations are governed. To understand contemporary governance in terms of complex health care organizations or CCOs, including roles and structure, it is important to first describe the underlying concept of contemporary governance.

Blurred boundaries: Contemporary governance. The theory of governance has been studied extensively within the fields of political science and public administration (Frederickson, 2007). Scholars have sought to define, analyze, and redefine this concept as the role of government in contemporary America has evolved and shifted due to numerous external and internal forces (see Hill \& Lynn, 2001). Furthermore, the role and responsibility of the public sector has been challenged and blurred while it has tried to maintain accountability of public institutions, administrators, and elected officials (Hill \& Lynn, 2001). In the ensuing debate around the theory of modern governance, a precise and widely agreed upon concept has been somewhat elusive among scholars. Multiple governance models have been put forth, to the point of having "governance" described as "everywhere and [appearing] to mean anything and everything" (Frederickson, 2007, p. 287). Nevertheless, the concept remains of critical importance to scholars and policymakers, particularly for administrators.

Traditional democratic governance and contemporary public institutions have been challenged over the past century. A new environment of governance exists due to the rapid growth and increasing complexity of the modern state and administration of 
public affairs, gradual deregulation and decentralization, privatization, devolution from the federal government to states, and new public management reforms efforts (Hill \& Lynn, 2001). These efforts have sought to address the premise that the "state is the problem, not the solution" to the challenges of modernity. In response to these trends, all levels of government are seeking creative solutions to continue to solve complex problems, but through a decentralized model of governance. New models of governance are needed to effectively address practical problems through cooperation rather than competition (Fung \& Wright, 2001). The history of the OHP is an example in which the state experimented with addressing practical problems related to health care by governing Oregon's Medicaid program (Fung \& Wright, 2001, p. 17).

The traditional model of governance, or the vertical model, was grounded in hierarchical authority. This model has now been superseded by "contemporary" model(s) of governance as power is increasingly decentralized and horizontally dispersed with negotiated authority, often through contracting (Cooper, 2005, p. 5). This presents a challenging dilemma for public institutions in terms of governance-either govern by authority or govern by contract. The Oregon Health Authority has elected to implement transformative health policy through state statutes and administrative rules, which is governing by authority. However, OHA is also governing by contract — contracting with CCOs to provide comprehensive and integrated health services to individuals enrolled in Medicaid.

According to Stoker (1998), governance refers to "the development of governing styles in which boundaries between and within public and private sectors have become 
blurred" (p. 17). The world in which public policy, including health policy, is formulated and then implemented is vastly more complex and interdependent than a century ago. Oregon's CCOs are an example of such complexity and interdependencies. This new environment is characterized as an "ecosystem" of modern governance that is increasingly reliant upon public and nonprofit actors operating across sectors as the means by which to achieve an end: maintaining the functions of government while promoting and protecting the general welfare. Creating CCOs is example in which boundaries between and within state and local health departments, as well as between private and nonprofit sectors, are "blurred" in an effort to reorganize Oregon's health care delivery system through CCOs.

It is important to define and conceptualize contemporary governance. According to Stoker (1998), there are five key propositions that describe governance. The first proposition states that governance consists of a set of government institutions, but these institutions can include actors outside traditional government (Stoker, 1998, p. 18). Second, responsibilities traditionally managed by public institutions are transferred beyond the traditional governance boundaries, thus the "blurring" of boundaries and responsibilities across sectors (Stoker, 1998). The third and fourth propositions describe governance as requiring collective action between institutions and often involve "selfgoverning" networks of actors that are autonomous. The fifth proposition views government (or institutions) as having the authority to "steer and guide" resources and entities in the private and nonprofit sectors towards problem solving (Stoker, 1998, p. $18)$. 
The underlying premise is that although there is less direct government involvement, there is more government action. Because of the complexity of modern social and economic issues, there is no single actor, public or private, that has the knowledge, resources, or capacity to tackle problems unilaterally (Kooiman as cited in Stoker, 1998, p. 22). Modernity necessitates new forms of interaction and partnership across sectors. The notion of CCOs is just that: requiring local and regional private, public, and nonprofit entities to enter a partnership that involves collective action and shared accountability in working towards a shared vision of the Triple Aim. The Oregon Legislature and the Oregon Health Authority are "steering and guiding" health care reform through implementation of CCOs, while recognizing the limitations of state or local government in being able to adequately address the issues of health care costs, quality, or population health. Oregon's public institutions, which are legislatively responsible for the health and well-being of Oregonians, are working to create new environmental conditions by blurring the traditional boundaries found across the multisector health care enterprise. This is done to foster engagement among public, private, and nonprofit actors in an effort to collectively solve problems, such as in health care (Stoker, 1998).

\section{Contemporary governance paradox: Less government and more governance.}

Another problem of contemporary governance is the creation of 'hollow government.' This concept describes government functioning as a network comprised of various government agencies and private organizations collaborating to deliver public goods and services. This contrasts the vertical model of governance, where government is 
the sole provider of public goods and services. In contemporary governance, government no longer has the capacity to deliver significant portions of many of its mandated services, and thus it is "hollowed out." In other words, government must utilize and depend upon nongovernmental organizations to deliver public goods and services, accomplished via contracting out these services through networks (Cooper, 2003, p. 113). Traditionally many of these goods and services were directly provided by public agencies. The foremost problem associated with hollow government is the degree, which a governing institution becomes so hollow it can no longer serve its primary functions.

The Oregon Health Authority, an agency within the executive branch, is using its authority to promulgate administrative rules that govern $\mathrm{CCO}$ activity. They are also contracting with nongovernmental organizations to ensure provision of services to 900,000 individuals enrolled in OHP (as of May 2014). Therefore, OHA is partnering with non-governmental organizations as a means of solving a capacity dilemma (Cooper, 2003, p. 58). The OHA is collaborating and contracting with nongovernmental organizations as a means to provide resources and services at the community level because such services either cannot or should not continue to be provided solely by government (Agranoff \& McGuire, 2003, p. 4). A key question is whether this arrangement will effectively address the contemporary governance paradox as described by George Frederickson (2007): "What people want is less government and more governance" (p. 2). It is too early to answer such a fundamental question; nonetheless, it is one of great importance. 
Governing by contract presents another dilemma: inadequate capacity by public agencies to manage contracts for goods and services (Cooper, 2003, p. 44). Contract management capacity of state and local agencies is often inadequate. As part of the contracting process and stipulated by the Oregon Legislature, the OHA is requiring that CCOs be held accountable for performance and quality criteria. Similarly, the Oregon Legislature is requiring the OHA to report quarterly on the implementation progress of CCOs to ensure accountability among one of the largest state agencies in Oregon, which is responsible for the health and well-being of hundreds of thousands of individuals. Although outside the scope of this study, the capacity, expertise, or resources required to effectively manage contracts with CCOs may present an interesting set of challenges to the Oregon Health Authority in an era of "hollowed out" government.

\section{Complex Organizations and Collaborative Governance: CCOs}

The scarce commodity in health policy is not so much resources, as governance and the political fortitude it requires.... (L. Mead, 1977, p. 44)

It is postulated that governance, especially contemporary governance, still offers a useful analytic framework for scholars. The main theory of governance, collaborative governance, used in this study to explore the early development of CCOs in Oregon, may serve as an innovative organizational form capable of meeting the challenges of integration and coordination in health care reform. The theory of collaborative governance offers "a simplifying lens to a complex reality," one used to study the intersections of public policy, health reform, and the emerging world of CCOs (Stoker, 1998, p. 26). The premise of collaborative governance involves broad participation in 
problem solving through a mechanism in which public, state, regional and local government agencies, nonprofit organizations, businesses, and other non-governmental stakeholders can work together (Ansell \& Gash, 2007; Freeman, 1997).

A key factor in creating effective and lasting partnerships in integrated health systems or other managed care arrangements is governance. Governance is the "ultimate integrator" and defining feature of integrated delivery systems (Pointer, Alexander, \& Zuckerman, 1995, p. 3). Coordinated care organizations are a new hybrid model of an integrated delivery system with a distinct set of governance issues. The first issue is the levels of governance (Pointer et al., 1995). CCOs can develop a centralized or decentralized model with multiple layers of governance depending on the number of boards created to govern its various components. A second issue is created by the size and complexity of a $\mathrm{CCO}$, including the number of sub-organizations. Organizations that form a CCO will likely retain a substantial amount of organizational independence and autonomy, which may present a set of governance issues. A third challenge stems from a shift in responsibility toward improving the health of a defined population and away from illness prevention (Pointer et al., 1995, p. 9). This new responsibility calls for new performance measures, accountability mechanisms, and performance assessment across the CCOs, including the effectiveness of the individual sub-organizations. A fourth challenge is answering the question of "who participates" in the $\mathrm{CCO}$ as well as on the governing board. A CCO governing board requires a mix of "skills, knowledge, experience, and perspectives" that spans the health care continuum, including community members. An important challenge for any $\mathrm{CCO}$ is to determine how its governance 
OREGON HEALTH REFORM AND COORDINATED CARE ORGANIZATIONS 70

structure "aligns with, and facilitates development" of the CCO (Pointer et al., 2005, p. 14).

A collaborative governance framework can be used to identify and explore factors that influence whether this new model of governance supports achievement of the Triple Aim through CCOs. The study did not evaluate "outcomes" of CCOs but rather the conditions in which stakeholders decided to engage with one another-essentially the governance structure and process.

Collaborative governance can take any number of forms. Examples are somewhat extensive, ranging from deliberative democracy and network democracy to dispute resolution in the policy process (Bingham, 2010). The principal premise of collaborative governance describes the relationship between governing entities and the governed, an approach that can foster increased participation and collaboration. One of the unique and principal aspects of collaborative governance is its inclusiveness: It often includes collaboration among a range of public agencies including state, regional, and local government agencies, nonprofit organizations, businesses, and other nongovernmental stakeholders (Bingham, 2010). This emerging governance model offers an alternative for solving problems in an era when the traditional hierarchical and bureaucratic structure of governance, traditional command, and control can no longer effectively support this function. A critical aspect is the model's ability to broadly engage the public and affected stakeholders in a deliberative and consensus-oriented process, i.e. public participation, in a governance model that is explicitly constructed to resolve one or more issues within a community - in Oregon's case, the health care delivery reform. 
The collaborative governance model provides an innovative approach for consensus around making decisions, setting priorities, selecting among the priorities, and implementing solutions to the issues identified. Collaborative governance is multisectorial and includes involvement through civic engagement, dialogue, deliberative democracy, multi-stakeholder collaboration, and dispute resolution (Bingham, 2010, p. 299). Several important factors distinguish collaborative governance from traditional models of governance. First, collaborative governance is not the traditional commandand-control model of governing. Second, collaborative governance presents a bottom-up approach. Third, collaborative governance offers a new model that attempts to address the rapidly transitioning world of increasing privatization of activities and functions, the devolution of traditional pubic responsibilities to lower levels of government, and outsourcing contracting services and functions to the private and nonprofit sectors. It is important to recognize the substantial body of literature that addressed the concept of hollowing out of government (see Salamon, 2002; Cooper, 2003; Agranoff \& McGuire, 2003).

Collaborative governance is a useful theory because CCOs consist of public and private stakeholders joined to support a unified purpose or mission. The majority of research on collaborative governance is from case studies (Ansell \& Gash, 2007). An early scholar of collaborative governance defined the model as requiring problem solving, broad participation, provisional solutions, the sharing of regulatory responsibility across the public-private divide, and a flexible engaged agency (Freeman, 1997, p. 3). Freeman's (1997) model of collaborative governance is characterized by five defining 
features: (1) problem-solving orientation, (2) participation by affected parties in the decision-making process, (3) interim or temporary solutions, (4) accountability that is no longer merely between public and private parties but also toward each other, and (5) the facilitation and convening of an agency (p. 23). The first feature, 'problem-solving orientation,' requires that actors participating in the governance process share information and try to identify practical solutions. 'Participation,' Freeman's second concept, requires that participants or stakeholders affected by the problem(s) engage in all stages of the decision-making process. The third concept entails the governance entity settling on temporary or interim solutions due to external factors and uncertainty. The fourth concept of 'accountability' moves away from traditional accountability mechanisms that exist in hierarchical governance models. Accountability in this context refers to participants keeping one another accountable, often requiring new oversight mechanisms. The last concept of an "engaged agency" refers to when the state serves in the role of "facilitator" and often provides technical assistance, funding, and organizational support, often as the "final decision-maker" (Freeman, 1997, p. 23).

Definition of collaborative governance. This study used Ansell and Gash's (2007) definition of collaborative governance as "a governing arrangement where one or more public agencies directly engage non-state stakeholders in a collective decisionmaking process that is formal, consensus-oriented, and deliberative and that aims to make or implement public policy or public programs or assets" (p. 544). There are six key constructs or criteria embedded in their definition. First is the notion that collaborative governance occurs through initiation by public agencies or institutions. Second is that 
participants in the model are non-state actors. The OHA is the public agency responsible for "approving and certifying" CCOs in Oregon. At any time, a CCO can lose its certification status if the OHA determines it is not meeting the required benchmarks or outcomes. Third, non-state actors directly engage in the decision-making process, rather than indirectly through those that initiate the model, i.e. public entities. The fourth notion is that the "forum" or governance model is formalized and facilitates meetings. This entails a structure, organization, and shared resources among the stakeholders. The fifth and sixth criteria are that the decision-making process occurs through consensus and the collaborative is focused on public policy or management (Ansell \& Gash, 2007, pp. 544$545)$.

An important consideration is that this model conceptualizes "governance" as a decision-making model, guided by consensus, formalized and facilitated by non-state actors. The premise of governance in their model is "collective decision-making," in which all stakeholders are directly included in the decision-making process (Ansell \& Gash, 2007, p. 545). A distinctive feature of collaborative governance is that it focuses on public policies and issues. There are alternative models where public agencies and nonstate actors engage in decision-making processes. One such model is the concept of a policy network. However, there is a distinct difference between policy networks and collaborative governance. The difference is that collaborative governance consists of formal decision-making processes and structure, contrasted with a policy network, which may be intentionally informal in structure. A third model for decision-making among state and non-state actors is through public-private partnerships. Again, the difference 
between these two models is that public-private partnerships are established to "coordinate" activities between public and private actors, whereas collaborative governance is intentionally designed to foster a consensus-oriented approach to decisionmaking, which is different than mere coordination across sectors.

The Oregon Legislature passed legislation requiring CCOs to adopt a collaborative governance model. According to Ansell and Gash (2007), collaborative governance is "favorable when policies are determined to result in a difficult implementation process" (p. 563), which one could argue is the case with CCOs. Two additional aspects of Ansell and Gash's (2007) model are that non-state actors or participants, including the public stakeholder that initiated the governance model, engage with one another as well as recognize that the collaborative is responsible for policy implementation and the resultant outcomes.

It is important to also define the concept of collaboration. According to Gray (1989), collaboration is a "process through which parties who see different aspects of a problem can constructively explore the differences and search for solutions that go beyond their own limited visions of what is possible" (p. 5). More recently, Lawrence, Phillips, and Hardy (1999) described collaboration as a "cooperative, interorganizational relationship that relies on neither market nor hierarchical mechanisms of control" (p. 481). The researchers, after conducting a systematic review of the literature, defined collaboration as the following:

A process in which autonomous or semi-autonomous actors interact through formal and informal negotiation, jointly creating rules and structures governing 
OREGON HEALTH REFORM AND COORDINATED CARE ORGANIZATIONS 75

their relationships and ways to act or decide on the issues that brought them together; it is a process involving shared norms and mutually beneficial interactions. (Thompson, Perry, \& Miller, 2007, p. 25)

According to Thomson et al. (2007), the least researched and understood aspect of collaboration is the "interactive process," or the structure and decision-making process used to solve problems of collection action, i.e. governance.

\section{Issues with Collaborative Governance in Health Care}

It falls to governance to determine how to allocate scarce resources in the community interest and whether health care organizations are, in fact, community service organizations or competitive business entities. (Alexander \& Zuckerman, 1989, p. 762)

The literature indicates there are a number of issues and challenges in collaborative governance, particularly in the context of health care organizations. Problems among collaborating organizations include little to no history of working together, suspicions and mistrust, cultural differences among organizations, lack of commitment to a shared mission, inadequate infrastructure, and a breakdown in sharing resources, risks, responsibilities, and accountability among the partnering organizations (Pointer, Alexander, \& Zuckerman, 1995). One of the most challenging aspects for collaborative governance models in health care is the unequal position of power and information asymmetries that can exist among organizations. Some organizations within a collaborative or community health partnership may have more resources or broader and more influential power within a community, and thus may dominate the decision-making 
process. The challenge is larger, well-resourced organizations dominating weaker organizations to unreasonably advance their interests.

An effective governance model will manage the inherent tension between individual organizational interests and the collective interests of the CCO. Such tensions can occur when the collaboration's goals conflict with those of individual organizations. An individual organization's mission, if challenged through the collaborative, may lead to that organization exiting the $\mathrm{CCO}$. The key for organizations participating in a $\mathrm{CCO}$ is to ensure that individual and shared interests are complementary. In any collaborative organization, an individual organization's interests and goals vary and are in frequent conflict. Additionally, smaller organizations may fear losing control. Governance is at the forefront of these tensions.

\section{Collaborative Governance and CCOs}

According to Governor Kitzhaber, "Solving the health care problem is going to require some sort of new governance structure" (Goldsmith, 2003, p. 118). The CCO model of health care reform offers just that: a new model for community health governance in which the community accepts and shares in the costs and risk of caring for its residents. Again, Oregon's health care leaders and policy makers continue to leverage the state's participatory political culture to build support for advancing health care reform, further building upon the success initially achieved in establishing OHP and the prioritized list. Key strategies in advancing health reform are the open and transparent decision-making process, mobilization of broad stakeholder support, and buy-in through public forums. In other words, Oregon's health care reformers continue to involve 
individuals in the health care decision-making and priority-setting process, thereby legitimizing the policy process and any ensuing outcomes.

Coordinated care organizations were created through the expansion of existing networks of health care providers and organizations, consolidation of hospitals and managed care organizations in certain markets, increased demand in the health care workforce including different types of care providers, new infrastructure, new partnerships, and possibly significant horizontal and vertical integration of health care organizations. To achieve these desired ends, the state prescribed that CCOs adopt a model of collaborative governance. Oregon established criteria for CCOs and their governing boards to support the creation of sustainable, successful organizations. Each CCO's governance structure is required to include a majority interest of entities that share in the financial risk of the organization. In the context of $\mathrm{CCO}$ governance, an entity has financial risk when it assumes risk for health care expenses or service delivery either through contractual agreements or as the result of administering a global budget. In addition, each $\mathrm{CCO}$ is required to convene a community advisory council (CAC) that includes representatives of both the community and county government, but with consumers representing the majority of membership (OHPR, 2012). This council is required to meet regularly to ensure that the health care needs of the consumers and the community are being addressed by the $\mathrm{CCO}$.

In 2000, the Oregon Health Council's Subcommittee on Access identified the importance of governance (OHPR, 2000, p. 7). At that time, the subcommittee stated governance can either "make or break the health care delivery system in a community or 
region" (OHPR, 2000, p. 7). This assumes a governance entity exists within a community, which is not the case for most Oregon communities. The study identified key factors that will likely affect governance of delivery systems at the community level in Oregon, which are all present in the $\mathrm{CCO}$ concept. These factors are the following:

- community-based mission,

- local/regional control versus "remote control" by outside entities,

- financial management approach that supports the mission and includes cost sharing,

- timely availability of data that is useful and actionable,

- collaborative relationships among providers and hospitals, and

- equitable sharing of savings and losses in relation to the "burden" of patient care. (OHPR, 2000, p. 6)

\section{Significance of the Study}

This study sought to enhance our understanding of three community-based organization's approach to collaborative governance in an effort to improve the health status by being responsive to and accountable for community health in Oregon. It is important to understand to what degree collaborative governance is effective in supporting state-level health care reform. This study explored and assessed principal differences in CCO development affected by local political, institutional, and historical contexts, planning processes, and governance structure. Important factors include the history of conflict or cooperation, incentives for participation among a broad and diverse group of stakeholders, power and resource differences, leadership, and presence of a 
formal structure (Ansell \& Gash, 2007). The significance of this study is that it (1) learned about conditions that facilitate or impede the ability of CCOs to effectively solve problems through governance mechanisms, (2) developed insight into similarities and differences among $\mathrm{CCO}$ governance structures, and (3) advanced the present understanding of the potential and limitations of a collaborative governance model in supporting health care reform.

It is unknown whether CCOs will be successful as intended and whether some CCOs may fail over time, thus affecting the 900,000 Oregonians covered in OHP as of May 2014. Also unknown is whether CCOs will be able to generate sufficient

commitment, shared values and common vision, and interdependency to serve as a lasting model for reforming health care. CCOs may only realize incremental improvements in a largely unchanged and still fragmented Medicaid system. A worst-case scenario is not realizing the state's long-term goal of extending the CCO model to all OHA covered lives, approximately 1.4 million individuals. The result is one less model to support health reform. To place a finer point of what is at risk: the collapse of any $\mathrm{CCO}$ as a result of failed governance, potentially crippling the Oregon Health Plan, and a loss of an estimated cost-savings of $\$ 3.1$ billion to the state and $\$ 1.9$ billion in federal revenue over a five-year period.

\section{Conclusion}

With the combination of its early work towards establishing a health insurance exchange, a legislatively approved blueprint for Oregon's health system transformation, and the OHP, Oregon has a proven track record of being at the forefront of health reform. 
The CCO model, implemented statewide in Oregon with its focus on local community needs assessment and accountability for outcomes, will be widely replicable in other areas around the country. This model squarely targets the Triple Aim and will allow communities to move beyond addressing the low-hanging fruit, with one-time cost savings that fundamentally realigns the health system to achieve desired health outcomes while reining in cost growth. This type of system transformation and cost-curve bending is a promising direction for the rest of the country, and the model being developed in Oregon will demonstrate how it can be replicated in other states.

Valid and reliable instruments are needed to assess the factors of collaborative governance among CCOs. These will measure and describe early stages of CCO formation and implementation in Oregon and are important to help understand what factors may determine the effectiveness and sustainability of a CCO. They can also help gain a better understanding of the factors likely to affect $\mathrm{CCO}$ governance and ultimately influence the ability of CCOs to support Oregon's pursuit of the Triple Aim. Understanding these constructs can promote the successful implementation of future CCOs within Oregon as well as other states in an unwavering effort to achieve comprehensive health care reform.

In Chapter 3, the study methods are covered and include the research design, approach to data analysis, and data collection instruments. In addition, key variables, definitions, and constructs of CCO governance are operationalized, including an analytic framework for the study. 


\section{Chapter 3: Methodology}

Chapter 3 presents a detailed overview of the qualitative multi-case research design. The main sections described in this chapter include an overview and justification for the research design; review of the guiding research questions; study population and selection criteria; working definitions, key concepts, and conceptual variables; methods for data collection and analysis; limitations and assumptions; and conclusion. The flexibility of using this collective or multi-case study approach lends itself to the investigation of dynamic, rapidly changing social phenomena (Stake, 1994). In addition, case studies are commonly used in public administration and political science because they seek to understand and draw lessons from problems specific to government and governance (McNabb, 2002). By adopting this approach, different forms of collaborative governance models among Oregon's coordinated care organizations (CCOs) can be studied simultaneously, which will help develop an understanding of this contemporary governance phenomenon (McNabb, 2002, p. 287). This study examined three CCOs based on selection criteria (described later in the chapter).

The multi-case research approach compared and contrasted CCO governance models in Oregon. Comparative analysis helps to assess the relative role and function of the CCO governance structure by examining different organizations and their respective approaches to community-based collaborative governance. Findings from this study can inform change and adaptation among CCOs seeking to establish effective existing governance arrangements, with the expressed goal of enabling and facilitating the Triple 
Aim. The unit of analysis for this study is coordinated care organizations responsible for Oregon's Medicaid population.

\section{Research Design Overview}

Governance research is challenging for several reasons (see Hill \& Lynn, 2001). The foremost difficulty is understanding the potential effects or causalities among an identified policy intervention, utilizing data or measurable outcomes, couched within a theoretical framework, all of which are bound to be "embedded in a wider social, political, and economic" context (Lynn, Heinrich, \& Hill, 2002, p. 17). According to Lynn et al. (2002), a critical problem in governance research is "explor[ing] causal relationships beyond a narrow perimeter of theoretical possibilities that leaves too much out of the picture" (p. 18). The challenge or limitation in this study, and in all empirical research, is to acknowledge the broader context in which CCO governance is emerging, and still engage in research that results in findings and contributions that have implications for scholars and practitioners (Lynn et al., 2002).

This study was structured to allow for flexibility in response to the dynamic and rapidly evolving CCO landscape. Explicitly, this approach allowed the study to better understand how change is transpiring within and across CCOs as well as identify key internal and external contextual factors that influence the effectiveness of CCOs' collaborative governance structure. The results of this study, aimed at exploring the process of CCO development and early implementation, provide important insights and hypotheses for future quantitative studies that aim to assess outcomes over time. Assessing outcomes in terms of enhanced integration or coordination of health services, 
changes in utilization, or cost implications from health system transformation is likely to take a minimum of 1-2 years. This study focused on the process rather than outcomes of CCOs.

This study developed an understanding of the CCO governance structure and any variations therein and learned about the collaborative governance process adopted and deployed within CCOs. The hypothesis was that a preferred governance structure or model would influence and affect the collaborative process. An effective collaborative governance model and its key functions and structure are interdependent to the extent of significantly affecting desired outcomes of CCOs. For any organization, including complex organizations such as CCOs, the governance structure influences the decisionmaking processes, which either facilitate or impede the effectiveness of the organization in the short- and long-term.

\section{Justification of Research Design}

According to Yin (1984), the case study approach to research attempts to examine "a contemporary phenomenon in its real-life context, especially when the boundaries between phenomenon and context are not clearly evident; and in which multiple sources of evidence are used" (as cited in McNabb, 2002, p. 286). The study examined three CCOs. Studying multiple individual cases will develop an enhanced understanding of the phenomenon, i.e. collaborative governance models (McNabb, 2002, p. 287). The selected cases chosen for study were CCOs that present "new" solutions to problems rooted in the delivery of health care: the financing and quality of care for Oregon's Medicaid population. The phenomenon of interest is the governance structure and 
processes of CCOs and the relationships therein. By using multiple data collection strategies (in-depth key informant interviews and extensive documentation review), the study incorporated triangulation to examine the collaborative governance process.

There are several additional characteristics that make a case study the most appropriate design. The first characteristic is when randomization is either not possible or suitable, such as in this study. The second characteristic is the infeasibility of studying an entire population, in this case all $14 \mathrm{CCOs}$; there are insufficient resources available to include all 14 proposed CCOs for this study. The last characteristic that supports use of this design is when there is value in collecting information cost-effectively (Depoy \& Gitlin, 1998, pp. 142-143), which is the case for this dissertation research study.

There are five components or structure to any case study: (1) research question, (2) set of propositions, (3) unit(s) of analysis, (4) rationale linking the information to the propositions, and (5) selected criteria used to interpret the case(s) (Yin as cited in McNabb, 2002, p. 291). The inquiry in the phenomenon of collaborative governance models is again best suited using a case study approach because the phenomenon is newly emerging and rather dynamic. By selecting a subset of the potential 14 CCOs in Oregon (as of May 2012), the study had an opportunity to explore different concepts that constitute the model of collaborative governance as defined in the study. The selected CCOs serve as representative cases for study and provided information about models of collaborative governance across different CCO types and geographic regions in Oregon. Lang and Heiss (1990) assert that case studies are optimal for researching "processes and interactions, which cannot be studied effectively except as they interact and function 
within the entity itself' (p. 86). To examine structure and governance within a CCO, which include processes and interactions, a case study is the preferred approach.

\section{Research Questions}

The central research question that guided this study was the following: "What are the key factors of collaborative governance that facilitate or impede the ability of CCOs to implement health care reform?" Stated differently, the purpose of this study was to answer "to what extent, and in what way, does governance enhance system integration and effectiveness" so that the desired outcome occurs: improvement in the health status of Oregon's Medicaid population over time (Pointer et al., 1995, p. 10). The challenge is determining which governance structure and processes are more or less effective in integrating components of a system that has historically been fragmented and unorganized.

The study developed insights into the types and processes of CCO governance structures and functions as well as identified potential internal and external barriers that impede integration of services at the CCO level. Of particular interest was identifying the experiences that facilitate collaboration, success, and failure in CCOs. Important dimensions needed to be examined to develop an understanding of the potential relationships between newly formed organizations. The dimensions below are adapted from Fung and Wright (2001, p. 30) and Thompson, Perry, and Miller (2007). These were used to design the interview protocol, described later in this chapter. Exploring key dimensions of complex governance arrangements requires addressing the following questions: 
OREGON HEALTH REFORM AND COORDINATED CARE ORGANIZATIONS 86

- How genuinely collaborative is the actual decision-making process in the CCO?

- How effectively are decisions that are made through the CCO governance structure translated into real action?

- Is there clarity of roles and responsibilities, communication processes to enhance coordination, and mechanisms to monitor activities of all CCO participants?

- To what extent does the governance structure manage any tension between the collective interests of the $\mathrm{CCO}$ and those of the individual collaborative partners?

- To what extent are the entities within a $\mathrm{CCO}$ able to effectively monitor the implementation of their decisions?

- To what extent are decisions coordinated among the organizational units that collectively form the $\mathrm{CCO}$ ?

- To what extent does the collaborative governance model constitute an effective problem-solving process for the $\mathrm{CCO}$ ?

- Which attributes of the governance structure are more desirable in terms of effectiveness with the CCO?

As part of the OHA certification process, $\mathrm{CCO}$ applicants were required to submit answers to a series of questions related to their proposed governance structure (OHA RFA, 2012, p. 58), which were then used to inform the data collection. The questions are as follows:

- How do entities bearing financial risk for the organization make up the governing board's majority interest? 
- How does the governing board include members representing major components of the health care delivery system?

- How will consumers be represented in the portion of the governing board that is not composed of those with financial risk in the organization?

- How does the governing board makeup reflect the community needs and support the goals of health care transformation?

-What are the criteria and processes for selecting members on the governing board, $\mathrm{CAC}$, and any other councils or committees of the governing board?

- How will the CAC and any other councils or committees of the governing board support and augment their decision-making?

- What are the initial and lasting structures that will support meaningful engagement and participation of CAC members, and how will they address barriers to participation?

- What are the governance structure criteria?

- What criteria were used to select governing members?

- How will the CCO assure transparency in governance?

Combined, these questions begin to offer an analytic framework for structuring and organizing data into concrete components by which to assess and compare collaborative governance structure and processes within and across CCOs. These potential elements indicate existence of a governance structure, type of structure, composition and representation of the governance structure, and the selection process adopted for inclusion on a CCO's governing board. Throughout this chapter, the term 
"governing board" is used interchangeably with the term "board." Also, the term "system" is used interchangeably to refer to a coordinated care organization. The next section will describe the operationalization of the key concepts and variables relevant to the study.

\section{Concepts and Variables}

There are a number of important concepts of interest in the study. Key concepts include governance, collaborative governance, governance structure, and coordinated care organizations. Conceptualizing complex concepts involves breaking down individual concepts into components or dimensions. The process occurs when concepts are operationalized into variables (Singleton \& Straits, 2005). Drawing on the literature describing governance structures and functions within integrated hospital systems, including the theory of collaborative governance, a conceptual model of CCO collaborative governance is constructed. Prior to having developed the analytic framework or conceptual model for this study, a brief review of the key concepts were performed, which included their operationalization and related variables as necessary.

One key concept is the CCO governance structure. According to the Oregon Health Authority, a CCO is required to "support a sustainable and successful organization that can deliver the greatest possible health care within available resources, where success is defined through the Triple Aim (Oregon Health Authority [OHA], 2012, p. 71). As defined under Oregon Revised Statute (ORS) 414.625, a CCO is "a corporation, governmental agency, public corporation or other legal entity that is certified as meeting the criteria adopted by the Oregon Health Authority to be accountable for care 
management and to provide integrated and coordinated health care for each of the organization's members." This definition was adopted for this study.

Oregon Revised Statute 414.625(1) states that CCOs "may be local, communitybased organizations or statewide organizations with community-based participation in governance or any combination of the two." Furthermore, a CCO may contract with counties or any public or private entities to provide services to its members. Also, a CCO can be a single corporate structure or a network of providers organized through contractual relationships. The underlying principle of any $\mathrm{CCO}$ governance structure is that it should emphasize collaborative governance for community benefit (OHA, 2012, p. 71).

The governance structure of a CCO is complex because multiple organizations have joined with one another. The complexity of the arrangements and governance structure is determined in large part by the number of organizations; the size of partnering organizations; types of organizations involved; mix of for-profit, nonprofit, and public organizations; and past history, among other factors. Two additional factors are the region and population(s) covered. For this study, the term region refers to the geographical boundaries of the area served by a CCO as well as the governing body of each county that has jurisdiction over all or part of the CCO's service area (ORS 414.018[5][b]). A CCO's population includes all Medicaid beneficiaries who decide not to voluntary opt-out of their assigned CCO. The level and degree of integration and coordination achieved across all of a CCO's organizations will directly facilitate or impede its ability to effectively function and support the Triple Aim. 
The CCO governance structure is specified in Oregon legislation and statute. According to the OHA's implementation proposal, CCOs are required to create a "governing board with a majority interest consisting of representation by entities that share financial risk as well as representation from the major components of the health care delivery system" (Oregon Health Policy Board [OHPB], 2012, p. 15). The OHA also stipulated that participation of local agencies and other nonprofit agencies in the CCO governance structure served as an important consideration in the certification process required by all CCOs. The governance structure as required in Oregon Senate Bill 1580 (2012) includes the following requirements for all CCO boards:

- a majority interest consisting of individuals who share in the financial risk of the organization and who must constitute a majority of the governance structure;

- major components of the health care delivery system that include

$\circ$ at least two health care providers in active practice, including a licensed physician or a nurse practitioner whose area of practice is primary care, and

- a mental health or chemical dependency treatment provider;

- at least two members from the community at large, to ensure that the CCO's decision-making is consistent with the values of the members and the community;

- representation on the governing board that should reflect the needs of its defined populations; and

- at least one member of the community advisory council. 
OREGON HEALTH REFORM AND COORDINATED CARE ORGANIZATIONS 91

In addition to the requirements described above, a $\mathrm{CCO}$ governance structure board is also required to do the following:

- implement and formalize coordination and ensure relationships exist between CCOs and the local Medicaid-funded long-term care (LTC) providers;

- enter into agreements with local mental health authorities and community mental health programs to develop a Memorandum of Understanding (MOU) or contract, detailing coordination agreements for members that receive mental health services; and

- develop relationships with social and support services in a CCO's service area. The Oregon Health Authority also created a broad and comprehensive list towards developing a comprehensive and integrated Medicaid delivery system. According to the Request for Applications (RFA), the following treatments and providers were considered as constituting an integrated and coordinated delivery system (OHPB, 2012, pp. 66-67):

- Acute inpatient hospital psychiatric care

- Addiction treatment

- Ambulance and emergency medical transportation

- Assertive Community Treatment

- Chemical dependency treatment providers

- Community health workers
- Community prevention services

- Dialysis services

- Federally qualified health centers

- Health care interpreters (qualified/certified)

- Health education, health promotion, health literacy

- Home health

- Hospice 
- Hospital

- Imaging center

- Intensive case management

- Mental health providers

- Navigators

- Oral health providers

- Palliative care

- $\quad$ Patient-centered primary care homes

- Peer specialists
- Pharmacies and durable medical providers

- Rural health centers

- School-based health centers

- Specialty physicians

- $\quad$ Supported employment

- Tertiary hospital services

- Tribal and Urban Indian Health Services

- Urgent care

The complexity and composition of any CCO governance structure is significant.

For the 30 treatments and provider types listed above, there could be 30 or more organizations that partnered through a CCO to ensure individuals covered under the Oregon Health Plan (OHP) are able to access comprehensive and integrated care services across the care continuum. Newly established CCOs had to adopt and modify, as needed, governance structures and functions that support it and its potentially large number of sub-organizations. After participants in a $\mathrm{CCO}$ were selected and the entity was formed, relationships among the partnering organizations need to be effectively managed through the adopted governance structure.

Governance and organizational relationships. Multiple factors contribute to the complexity of a CCO's governance and organizational relationships as specified in House Bill 3650 (2011). As expressly stated in House Bill 3650, a CCO's governing board and 
organizational structure is required to sufficiently meet "the needs of the communities they will serve." According to the Oregon Health Policy Board and the OHA, the underlying premise is that "there is no single governance solution, and there is risk in being too prescriptive beyond the statutory definition of a CCO governing board" (OHPB, 2012, p. 15). The measure of success in terms of an effective "governing board" is set by the OHA as an organization that supports the Triple Aim.

A governing board is responsible for specifying the organization's vision, mission, and goals and ensuring the effectiveness and efficiency of governance (Alexander, Zuckerman, \& Pointer, 1995). Of interest was whether an adopted governance structure serves as a facilitator or a barrier to achieving integration of organizations and service delivery within a CCO (Pointer, Alexander, \& Zuckerman, 1995). Prior to this study, what was not understood is how a model of collaborative governance within CCOs will "facilitate or impede the formation, development, and performance of integrated systems" (Pointer et al., 1995, p. 4).

Organizational relationships within a CCO likely influence the effectiveness of the governance structure and process. Among the 14 CCO applications submitted in April 2012, the number of partnering organizations within each CCO ranged from 2 to a high of 30 (OHA, 2012 unpublished). Understanding the relationship between CCO governance boards and existing boards of the partnering organizations was important because "governance structures and processes suited to one type of organization will not work equally well in others" (Alexander et al., 1995, p. 79). Effective governance of a large multistate hospital system will not necessarily translate to effective governance of a 
nonprofit regional mental health organization, nor should it. The underlying premise is that there is no definitive governance model. Rather, ongoing experimentation is needed to develop an effective governance structure that clarifies roles and responsibilities. This may vary region to region or by the composition of the partnership.

Dimensions of governance. In the health administration literature, four dimensions of governance are often cited for integrated delivery systems or networks: control, structure, composition, and functioning (Pointer, Alexander, \& Zuckerman, 1995; Savage, Taylor, Rotarius, \& Buesseler, 1997). These were adopted with some modification as the key constructs for examining the governance structure of a CCO. When combined, the four dimensions construct a governance model. Operationalizing these key dimensions or concepts can help identify important factors of a collaborative governance model, which can then be assessed in terms of effectiveness as well as limitations. Developing an understanding of these four governance dimensions can lead to understanding important issues ranging from the level of governance, system complexity, functions of governance, and board composition (Savage et al., 1997, p. 12). These dimensions affect an organization's ability to effectively manage issues and challenges faced by a CCO.

Control refers to layers of governance and the number of boards needed to effectively govern the system (Pointer, 1995). More broadly, control focuses on the governance of the system, or $\mathrm{CCO}$, and its parts, the organizations that form the system (Pointer et al., 1995, p. 17). There are two main approaches in control, centralized or decentralized. In a centralized model, the governance board is a single entity in which the 
OREGON HEALTH REFORM AND COORDINATED CARE ORGANIZATIONS 95

decision-making function and authority are centralized. The governance system of a CCO may consist of a single board with advisory entities (Pointer et al., 1995, p. 16). However, the advisory entities are not decision-making bodies, but rather serve at the discretion of the governance board.

In contrast, the decentralized approach has multiple layers of subordinate boards that share decision-making functions and authority. This approach is more often found in community-based organizations, whereas centralized approaches are found in corporations. For the purposes of this study, it is important to assess which approach is more consistent with the characteristics of the system or CCO. Within a single CCO, both centralized and decentralized governing boards can exist, although that is not likely. The issue is to determine which arrangement facilitates overall governance. This study assessed which model or combination of models (1) facilitate effective governance and (2) ensure that the principles of structure and representation outlined in HB 1580 are best supported.

Structure refers to how the board, subordinate boards, and/or advisory entities are arranged. A key concern of the study was to assess which parts of a CCO are governed by which boards and the degree of integration among the diverse CCO partnering organizations and possible subordinate boards within or across the system (Pointer et al., 1995, p. 13). An underlying question is gauging how much autonomy the partnering organizations retain in relationship to the CCO.

Any CCO governance structure may be relatively complex. For example, if each partnering organization has a governing board and 1-2 subordinate boards, multiplied by 
8-10 partnering organizations and their respective boards, there could plausibly be 20 different boards in total. This could be further complicated if a CCO decides to create a governance structure that includes boards by region and/or service type. The greater the number of boards and subordinate boards within a $\mathrm{CCO}$, the greater the complexity in terms of decision-making and diffused authority across the entity.

The challenge for CCOs is to determine which boards at which levels "should perform particular functions" to minimize duplication of efforts and internal conflicts (Pointer et al., 1995, p. 8). There is also the question of the amount of authority necessary for individual subordinate boards to function effectively, yet not transcend the authority of the main governing board. This configuration is critical to the structure, decisionmaking, and authority structure of the governance model.

Composition pertains to whether members of a CCO board and any subordinate boards consist of representatives, non-representative members, or a combination of both (Pointer et al., 1995). There are two important components of composition, board size and member characteristics (Pointer et al., 1995). The distinguishing feature between representatives and non-representatives is whether a board member has a direct relationship with any of the partnering organizations in a CCO. There are several important issues within this construct. First, who should participate in the governance structure? Second, what partnering organizations should be represented in the governance model? Third, what competencies should individual board members have? In essence, according to Pointer et al. (1995), the issues are identifying the correct mix of characteristics, skills, knowledge, experience and perspective needed for the board (p. 
10). Given the range of distinctive partners within any given $\mathrm{CCO}$, the demands of a CCO governance board are different than those in governing boards of hospitals, clinics, or any businesses within the health delivery system. The composition of board members will be an important governance dimension, especially since the enabling legislation requires a $\mathrm{CCO}$ governance structure to include non-representative members on the board.

Functioning refers to roles and responsibilities within the governance structure. In other words, how governance functions within the system, including what issues a board should address and how it should govern. Function pertains to how roles and responsibilities are fulfilled by the governing board (Pointer et al., 1996, p. 13). A governing board should perform three core roles: policy formulation, decision-making, and oversight (Pointer et al., 1995, p. 26). This includes organizational policy formulation and direction, direct oversight including financial controls, decision-making through formal authority or delegating decision-making to subordinate boards or internal management structure(s), and active monitoring and oversight of the decision-making processes. In addition to roles among the board, a board also has responsibilities. According to Pointer et al. (1995), there are five key responsibilities: (1) formulating the mission, vision, and goals of the organization; (2) ensuring organizational performance including executive management; (3) ensuring financial health of the entity; (4) assuring the quality of health services; and (5) assuming responsibility for accountability to itself and the board as well as accountability among the partnering organizations to the main 
governing board (Pointer et al., 1995, p. 25). All four dimensions of a governing structure were operationalized including key indicators in Table 3.1.

Table 3.1: Governance Structure

\begin{tabular}{lll}
\hline Concepts & Operational Definition & Indicators \\
\hline Control & $\begin{array}{l}\text { Presence of centralized or } \\
\text { decentralized governance } \\
\text { system }\end{array}$ & $\begin{array}{l}\text { Single board; } \\
\text { Multiple subordinate boards; } \\
\text { Advisory bodies }\end{array}$ \\
$\begin{array}{l}\text { Configuration and } \\
\text { relationships among the } \\
\text { system board, subordinate } \\
\text { boards, and/or advisory } \\
\text { boards }\end{array}$ & $\begin{array}{l}\text { Number and arrangement of boards; } \\
\text { Bylaws and decision-making processes divested } \\
\text { among the board, subordinate boards, and } \\
\text { advisory entities in relation to one another }\end{array}$ \\
$\begin{array}{l}\text { Membership of the system } \\
\text { board, subordinate boards, } \\
\text { or a combination thereof } \\
\text { and relationship to the }\end{array}$ & $\begin{array}{l}\text { Board size; } \\
\text { Representation (representative or non- } \\
\text { seprentative); } \\
\text { Them }\end{array}$ & $\begin{array}{l}\text { Member characteristics } \\
\text { Functioning }\end{array}$ \\
& $\begin{array}{l}\text { and the way it is } \\
\text { performed }\end{array}$ & $\begin{array}{l}\text { Clearly defined roles; } \\
\text { Explicit set of responsibilities; } \\
\text { Execution of decision-making; }\end{array}$ \\
\hline
\end{tabular}

One challenge for $\mathrm{CCO}$ governing boards is determining how effectively they can fulfill "an expanded and different mix of governance responsibilities" (Pointer, 1995, p. 9). Each $\mathrm{CCO}$ is accountable for the health and well-being of a defined population group, including coordination and integration among a continuum of services within its community. There are a considerable number of components that comprise a CCO. The board must ensure that all components work collaboratively, and that individual components and sub-organizations are accountable to one another based upon their individual performances as well as the overall performance of the CCO.

There are numerous combinations among these four dimensions, which result in a number of different governance forms. Two important considerations in the context of 
the CCO governance model are that not all forms are "equally effective" and that the effectiveness of one form over another is likely situational in nature (Pointer et al., 1995). Operationalizing the structural dimensions of governance may help facilitate collaborative processes. Having operationalized the conceptual definition of the governance structure, the chapter now turns to describing the concepts of collaborative governance.

Model of collaborative governance. This study adopted Ansell \& Gash's (2007) definition of collaborative governance as "a governing arrangement where one or more public agencies directly engage non-state stakeholders in a collective decision-making process that is formal, consensus-oriented, and deliberative and that aims to make or implement public policy or manage public programs or assets" (p. 544). Ansell and Gash (2007) developed this definition and analytic framework based on a meta-analysis of 137 studies of collaborative governance that spanned a wide range of policy areas. This study sought to build on and incorporate variables from Ansell and Gash's analytic framework in order to learn which variables or concepts facilitate successful collaboration through CCO governance arrangements.

Adopting this working definition, the next step was to develop a model of collaborative governance that included four key concepts: starting conditions, institutional design, leadership, and collaborative process (Ansell \& Gash, 2007, p. 549). These concepts are a contribution "to or context for" a collaborative process for any system (Ansell \& Gash, 2007, p. 550). 
OREGON HEALTH REFORM AND COORDINATED CARE ORGANIZATIONS 100

Understanding the history and context of the starting conditions of any collaborative may serve to facilitate or deter cooperation among the partners. The three concepts which form the starting conditions are (1) presence of any imbalances between resources or power among the various partners, (2) presence of incentives to collaborate, and (3) history of conflict or cooperation, which will hinder or facilitate collaboration (Ansell \& Gash, 2007, pp. 550-551).

The institutional design, another import element in the collaborative governance model, refers to the guidelines and ground rules that exist for collaboration, which are designed to create an open, transparent, and inclusive environment for stakeholders (Ansell \& Gash, 2007, p. 555). This can be achieved through the formalization of a governance structure. CCOs will need to determine to what degree the collaborative is inclusive or exclusive with stakeholder participation.

Leadership is a key for any governance system. For collaborative governance, leadership will play a vital factor in a CCO's ability to bring stakeholders together and engage in the collaborative (Ansell \& Gash, 2007). Ansell \& Gash (2007) state that leadership is "crucial for setting and maintaining clear ground rules, building trust, facilitating dialogue, and exploring mutual gains" (p. 554). Leadership can also help balance power when power and resources among the stakeholders are asymmetrical.

The collaborative process is an iterative cycle that builds on communication, mutual trust, increased commitment to the process, enhanced and shared understanding, and mutually beneficial outcomes (or not); then the cycle starts over (Ansell \& Gash, 2007). The first step in this process is communication or dialogue between stakeholders, 
OREGON HEALTH REFORM AND COORDINATED CARE ORGANIZATIONS 101

which is face-to-face (Ansell \& Gash, 2007). The notion of having stakeholders interact in person is important but not "necessary" for effective collaboration to transpire (Ansell \& Gash, 2007, p. 558). Face-to-face dialogue can break down existing stereotypes and provide stakeholders a direct forum for identifying opportunities for mutual gain achieved through the collaboration.

The collaborative process seeks to build trust, often among a group of stakeholders where mistrust is present. Trust building is a time intensive process, one best supported by a prolonged period in which stakeholders are able to interact with one another. An effective collaborative process requires stakeholders to engage in a level of commitment; one study found member commitment as the "most important factor facilitating collaboration" (Margerum, 2002, p. 247). For CCOs, commitment requires stakeholders to develop trust and a shared understanding that the CCO is the best way to achieve the policy outcomes established by Oregon's health system transformation initiative. Over time, this process can result in "mutual recognition" or "joint appreciation" that the policy objectives for CCOs are only achievable through the collaboration. Any collaborative process must include ongoing deliberation and negotiation efforts and be transparent and consensus-oriented, with stakeholders sharing a sense of shared responsibility for the process (Ansell \& Gash, 2007). This is true with "mandated" forms of collaboration such as CCOs.

Another important factor in the collaborative process is "shared understanding." This refers to the collaborative having a clear mission, a common and shared definition of the problem, and an identification of common values across the stakeholders in the 
collaborative. The final concept in a collaborative governance model is outcome, which is not within the scope of this study. Four of the five concepts that construct a model of collaborative governance were operationalized below in Table 3.2.

Table 3.2: Model of Collaborative Governance

\begin{tabular}{|c|c|c|}
\hline Concepts & Operational Definition & Indicators/Variables \\
\hline $\begin{array}{l}\text { Starting } \\
\text { Conditions }\end{array}$ & $\begin{array}{l}\text { Basic level of trust, conflict, and } \\
\text { social capital that become } \\
\text { resources or liabilities during } \\
\text { collaboration }\end{array}$ & $\begin{array}{l}\text { Power-resource imbalance; } \\
\text { Incentives for and constraints on } \\
\text { participation; } \\
\text { History of conflict or cooperation }\end{array}$ \\
\hline $\begin{array}{l}\text { Institutional } \\
\text { Design }\end{array}$ & $\begin{array}{l}\text { Basic ground rules under which } \\
\text { collaboration takes place }\end{array}$ & $\begin{array}{l}\text { Participatory } \\
\text { inclusiveness/exclusiveness; } \\
\text { Guidelines and rules for participation; } \\
\text { Open, transparent, and inclusive } \\
\text { process }\end{array}$ \\
\hline $\begin{array}{l}\text { Facilitative } \\
\text { Leadership }\end{array}$ & $\begin{array}{l}\text { Facilitation, engagement and } \\
\text { empowerment of stakeholders }\end{array}$ & $\begin{array}{l}\text { Facilitation; } \\
\text { Engagement; } \\
\text { Empowerment; }\end{array}$ \\
\hline $\begin{array}{l}\text { Collaborative } \\
\text { Process }\end{array}$ & $\begin{array}{l}\text { An iterative cycle that builds on } \\
\text { communication, mutual trust, } \\
\text { commitment to the process, shared } \\
\text { understanding, and mutually } \\
\text { beneficial outcomes }\end{array}$ & $\begin{array}{l}\text { Face-to-face dialogue; } \\
\text { Trust building; } \\
\text { Commitment to process; } \\
\text { Shared understanding; } \\
\text { Intermediate outcomes; }\end{array}$ \\
\hline
\end{tabular}

The conceptual framework for studying CCO collaborative governance was constructed from the four dimensions of governance from Pointer et al. (1995) and Ansell and Gash's (2007) four concepts of collaborative governance. 
Figure 3.1: Conceptual Framework for CCO Collaborative Governance

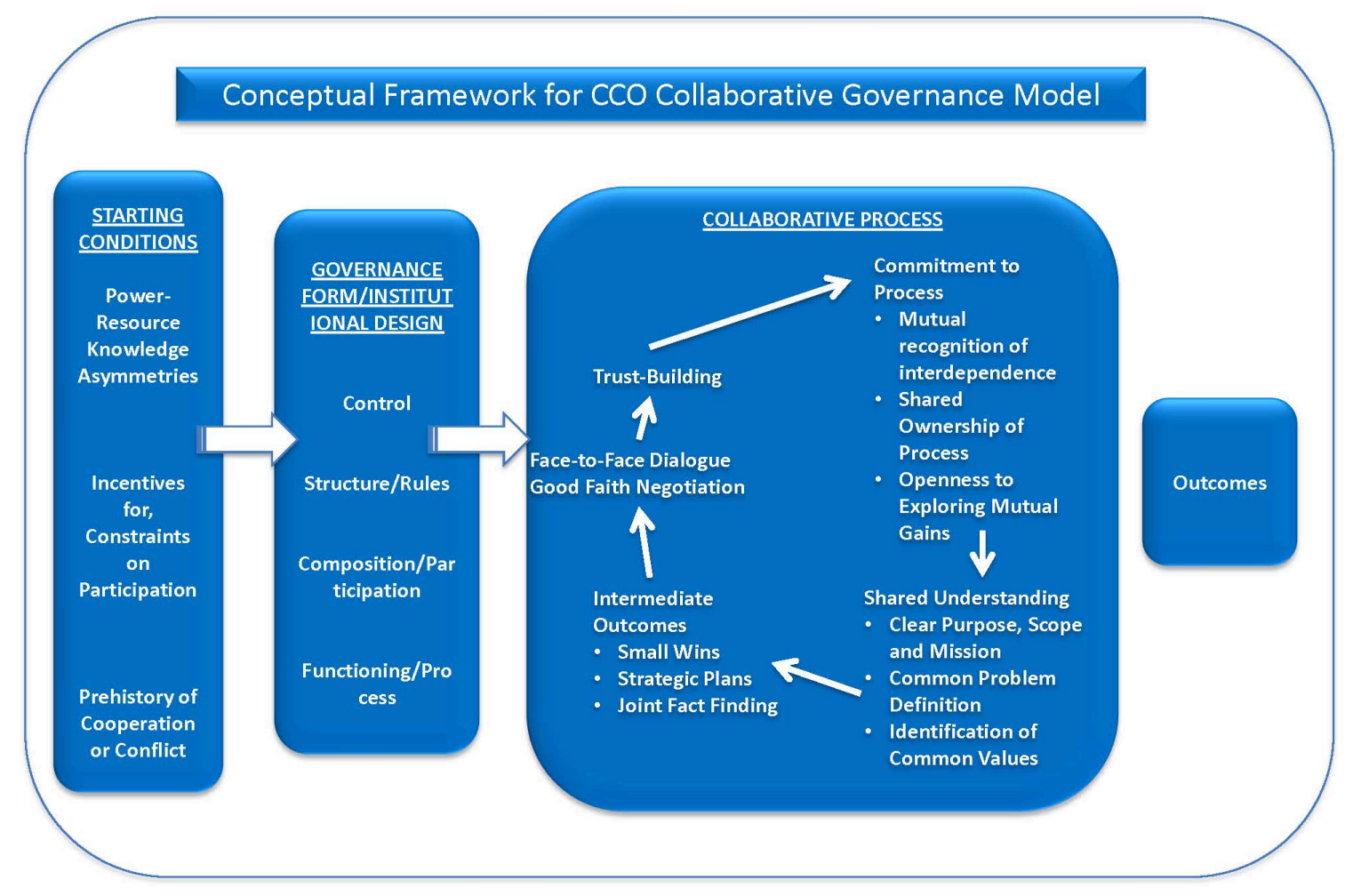

\section{Selection of Participants}

The unit of analysis for this study was the CCO, specifically its governance structure and organizational relationships. As of April 30, 2012, fourteen entities had submitted applications as part of OHA's initial wave to become certified as local CCOs. According to the Oregon Health Authority, as of August 2012, 14 of the 16 applicants had been provisionally certified during the initial wave. For CCOs, the organizational size, structure, and composition are critically important.

Inclusion and exclusion criteria. The inclusion criteria consisted of whether an organization was certified as a CCO by the Oregon Health Authority. The exclusion 
criteria were any organizations not certified as CCOs, specifically any managed care organizations that continue to operate outside of a certified CCO. The study initially selected four CCOs. However, because of limitations in resources necessary to support a study of this size and scope, three organizations were included using the selection criteria developed below in Table 3.3, adapted from the CCO application requirements (OHA RFA, 2012, p.15).

\section{Table 3.3: CCO Selection Criteria}

\begin{tabular}{|c|c|}
\hline Criteria & Definition of Criteria \\
\hline Coverage Area & $\begin{array}{l}\text { Geographic service area of a CCO defined by county and zip } \\
\text { code, including urban, suburban, or rural regions }\end{array}$ \\
\hline Size & Size of the defined Medicaid population \\
\hline Organizational Structure & $\begin{array}{l}\text { Single corporate structure or a network of providers organized } \\
\text { through contractual relationships such as fully capitated health } \\
\text { plan (FCHP), physician care organization (PCO), mental health } \\
\text { organization (MCO), and dental care organization (DCO) }\end{array}$ \\
\hline Prior History & $\begin{array}{l}\text { Whether CCO is currently an MCO (e.g. hospital system, new } \\
\text { legal entity, etc.) and prior history as an MCO }\end{array}$ \\
\hline $\begin{array}{l}\text { Existing OHA } \\
\text { Relationship(s) }\end{array}$ & $\begin{array}{l}\text { Whether CCO covers identical service area already under contract } \\
\text { with OHA, and/or past experience in covering Medicaid } \\
\text { population }\end{array}$ \\
\hline $\begin{array}{l}\text { Prior } \\
\text { Coordination/Integration } \\
\text { of Services }\end{array}$ & $\begin{array}{l}\text { Experience in coordinating physical health care, mental health, } \\
\text { and chemical dependency services, or oral health care }\end{array}$ \\
\hline Composition & $\begin{array}{l}\text { Core components and presence of organizations required to } \\
\text { establish an integrated and coordinated delivery system }\end{array}$ \\
\hline Linkages & $\begin{array}{l}\text { Involvement with local governments in governance and delivery } \\
\text { of services }\end{array}$ \\
\hline
\end{tabular}

The final set of CCOs was selected in an effort to generalize to other CCOs, and potentially to other community-based or governance organizations, such as Accountable Care Organizations (ACO), working towards care integration and coordination for a defined population. Further research would be required to achieve any generalization of findings beyond CCOs. 


\section{Instrumentation}

A list of thematic questions informed by the literature was used to construct a semi-structured interview protocol. This allowed the researcher to pursue lines of questioning with the respondents, clarify answers, and capture additional information that emerged during the interview process. The interview protocol was designed to elicit discussion and information about participants' experience in governance of CCOs. Topical areas were selected and questions were developed to guide the researcher and the participants in building answers to the research questions. The final list of topical questions was designed to focus discussion on governance and decision-making, and to serve as a checklist for the researcher to ensure coverage of the topics of interest. A potential list of topical areas and related questions covered during the interviews are provided in (see IRB Application, Appendix A).

In October 2012, the research study received approval (\#122343) by the Portland State University Human Subjects Research Review Committee (HSRRC), also referred to as the Institutional Review Board (IRB) (see Appendix A). This study fell in the exempt review category as the study did not present risk to study participants, anonymity was safeguarded through the data collection and analysis phases of the study, and confidentiality of all study participants and any responses provided during the interview process has been kept private and not revealed to anyone except the researcher. All study participants were adults and therefore not considered vulnerable subjects and were able to provide informed consent. 
OREGON HEALTH REFORM AND COORDINATED CARE ORGANIZATIONS 106

\section{Research Approach and Assumptions}

Qualitative research is many things to many people. (Denzin \& Lincoln, 2000, p. 8)

The multi-case research study was adopted to explore CCOs to understand the process and conditions in which participation and decision-making among stakeholders is facilitated or impeded through a collaborative governance model. The goal is to replicate findings across cases. Because comparisons are made, the cases were chosen carefully so the researcher can predict similar or contrasting results based on a theory (Yin, 2003). Three individual cases were selected to establish a clear and definitive pathway to recommend future research on CCOs in Oregon. The selection of multiple sites is more likely to provide conclusions for future in-depth analyses to build a body of empirical knowledge about collaborative governance in the context of transforming regional health delivery systems. A small sampling of multiple sites enabled the researcher to compare common themes across variables such as organization size, type of services delivered, and the organization's financial status. At the same time, the researcher was able to compare themes within organizations that are not completely heterogeneous but are similar in regard to governance structure and approaches to collaborative governance. This approach may increase the scholarly value of the study (Creswell, 2009).

A multiple or collective case study allows the researcher to analyze within each setting and across CCO settings. Yin (2003) describes that using multiple case studies either "(a) predicts similar results (a literal replication) or (b) predicts contrasting results but for predictable reasons (a theoretical replication)" (p. 47). In addition to identifying 
the "case" and the specific "type" of case study to be conducted, researchers must consider whether it is more prudent to conduct a single case study or if a better understanding of the phenomenon will be gained through a multiple case study.

\section{Data Collection}

Data for this study were collected using two techniques: semi-structured in-depth interviews and qualitative document analysis (McNabb, 2002). Semi-structured interviews were conducted with board members of CCOs, members of the CCO Community Advisory Committees, and policy experts and administrators from Oregon's executive branches. Interviews were conducted to understand CCO board members' perceptions about the role and influence of the early formation process, including the perceived roles for stakeholders and their power to collaborate in the community and within their delivery system. Qualitative document analysis (QDA) was employed to corroborate findings. QDA was completed on key documents, including operational documents and state-mandated transformation plans from each CCO. These documents were chosen to better understand the structure, function, and intermediate outcomes for stakeholders within each CCO and to what extent, if any, organizational composition influenced a CCO's ability to engage in decision-making. The following section describes the methods employed in semi-structured in-depth interviewing and qualitative document analysis.

Semi-structured in-depth interviews. Semi-structured in-depth interviews show how the subject frames their understanding of an experience (Kvale \& Brinkman, 2009, p. 124). Marshall and Rossman (2006) further define the semi-structured interview as 
OREGON HEALTH REFORM AND COORDINATED CARE ORGANIZATIONS 108

"much more like conversations than formal, structured interviews. The researcher explores several general topics to help uncover the participant's perspective, but otherwise respects how the participant frames and structures the responses" (p. 82). Semistructured in-depth interviews are guided by a predetermined theme and questions. One of the advantages in deploying this data collection tool is the flexible order or form of questions, which can help encourage respondents to reveal deeper insight into their experiences (Kvale \& Brinkmann, 2009).

All interviews were conducted with an interview protocol that contained questions constructed according to the theoretical framework. Interview questions primarily focused on gathering respondents' perspectives about the early development and implementation of their CCOs in order to learn about the governance structure, identify existing factors including board members' perceived influence on setting priorities for the $\mathrm{CCO}$, and articulate factors that facilitated or impeded achievement of the organization's goals. In general, the protocol was used to understand respondents' perceived utility of collaborative governance as the "adopted governance" mechanism for solving problems for those served by Medicaid in their community (see Appendix A for the IRB application, including the two interview guides).

Questions were designed to explore themes emerging from in-depth interviews with $\mathrm{CCO}$ board members and staff, learn about the history of the $\mathrm{CCO}$, assess the early starting conditions, determine governance structure, and understand overall perceptions of collaborative governance and its potential to support CCOs. The intent with this line of questioning was to determine if board members could conceptualize a need for 
OREGON HEALTH REFORM AND COORDINATED CARE ORGANIZATIONS 109

collaborative governance, if they had identified barriers to collaborative governance, and if they had identified strategies to overcome those barriers. The interviews for this study were conducted in two phases: The first phase consisted of six exploratory interviews with state officials, and the second phase consisted of 22 in-depth interviews with CCO board members and executive staff.

Interviews are recognized as the most suitable approach when seeking rich data illuminating individuals' experiences and attitudes, and they can provide insight unavailable to researchers working with large survey samples (Singleton \& Straights, 2005). On the other hand, interviews are very time-consuming to conduct and analyze. The questions for both interviews were based on constructs from the literature, previously presented in Tables 3.1 and 3.2 (see Table 3.4 for more detail). The questions were asked in a non-directive manner (to the extent possible) to meet the study's principal aim of learning about the interviewees' perceptions. 
Table 3.4: Interview Protocol: Conceptual Collaborative Governance Framework

\section{Concepts}

\section{Protocol Question}

Control;

Structure;

Composition;

Institutional

Design
1. I would like you to think back to the events that led up to the creation of the [insert CCO name]. Please describe the key events that occurred, identifying what occurred, who were the key players, and when these events occurred. Also, were there any organizations excluded from participating or any that opted out? If so, why? Please try to do this in chronological order, but we can skip around if necessary.

\section{Functioning; Collaborative Process \\ 3. How does your organization set priorities and problem-solve through its existing governance structure? For example, does your CCO use standard operational procedures such as formal rules, policies, and committees, or do you have an open, transparent, and inclusive process?}

2. Please describe the existing partnership, organizational structure, and prior relationship among the key players within [insert $\mathrm{CCO}$ name]. For example, does your $\mathrm{CCO}$ have a formal agreement between partner organizations or any guidelines or rules that govern activities, including how decisions are made by the CCO board?

Functioning; Collaborative Process
4. What arrangements do you think work well in your CCO's decisionmaking process? For example, is there mutual recognition of interdependence within your community, a shared purpose, common problem definition, or shared mission and set of values? Alternatively, what arrangements do you think have not been helpful for your organization to date?

5. Have there been any events or incidents that have created barriers or challenges to decision-making or establishing an effective governance structure? What arrangements would you suggest as helpful to improve the governance structure or decision-making processes of your $\mathrm{CCO}$ ?

Interview process. The researcher asked participants structured open-ended questions. This open-ended interview technique provided the flexibility required for study participants to provide rich and extensive information in response to interview questions (Yin, 2003). The main research questions were addressed in these questions. 
Each participant was informed of the nature of the study, the voluntary status of participation in the study, and that results of the study will be shared with the study participants prior to publishing results. The study participants were informed of the confidential nature of the study, including that no names would be used. The study participants' names were coded using a special organization identifier: a two-digit identifier for each participant. The final selection of case study participants was contingent upon their agreement to participate via an email, which also served as informed consent. Prior to conducting each interview, the participants were again notified about their rights and confidentiality.

The majority of study participants were interviewed at their parent or host organizations for their convenience. Three CCO participants were interviewed via the phone. Digital audio recordings were utilized to support the accuracy of transcription. Data collection began in August 2013 and concluded in February 2014, lasting approximately 180 days. Interviews were transcribed usually within 2-3 days of completing the interview. Text from the transcribed interviews was entered into Microsoft Office software, and word count applications were used for initial tabulation and theme construction. All recordings and data were accessible only by the researcher, and were stored on a password, protected computer.

\section{Data Analysis Overview}

The central task of the data analysis of the interviews was to elaborate and flesh out the interworking of collaborative governance as a model for effective integration of regional health systems in Oregon as identified in the research propositions. The majority 
of this analysis occurred through the coding process as empirical instances of collaboration are put into the conceptual "boxes" of the primary codes, with concepts defined to support these codes. Beyond categorizing, the researcher used empirical examples to illuminate essential aspects of the primary codes. For instance, an in-depth analysis of key facets of the model for collaborative governance could reveal that starting conditions, including prior history among organizations within a $\mathrm{CCO}$, may influence the functions and ability of the new organization. This empirical work is combined with conceptual development through review, recoding, and consultation with the literature.

The process adopted for analysis and interpretation follows the case study approach. According to Creswell (2009), there are six steps: (1) create and organize the data; (2) read through text, make notes, and form initial codes; (3) describe the case and context; (4) use categorical aggregation to establish themes or patterns; (5) use direct interpretation and develop naturalistic generalizations; and (6) offer an in-depth depiction of the case(s) (pp. 156-157). Drawing upon the existing literature and theoretical concepts identified in Chapter 2, the researcher initially developed a list of codes based on the key constructs previously developed for both "governance structure" and "collaborative governance" (see Table 3.5).

For each category or concept in the model, the researcher developed a list of "prefigured" codes using an a priori method, again by drawing upon the theoretical literature (Creswell, 2009, p. 151). For the governance structure, four categories or concepts were operationalized, with each category assigned a set of codes. Similarly, for the model of collaborative governance, five concepts or constructs were operationalized, 
again with each category assigned a set of codes. The fifth concept, outcomes, was not coded as it was beyond the parameters of the present study.

The second data analysis task was to describe the external environment and context(s) in which CCOs were formed. Examining which secondary codes concur with the primary codes provided information regarding when, where, and how collaboration was most likely to occur for each CCO. These relationships were explored using qualitative analysis software. This type of analysis, for instance, showed whether "history of conflict" happened most often through voluntary, independent coordination or via a coordinating organization. From these data, the researcher could make predictions (which would require further testing) regarding which kind of forum was most conducive to achieving "effective" collaborative governance.

Data analysis procedures. An Excel spreadsheet was used to track the documentation from the researcher's face-to-face interviews and journaling as well as other case study documents (Yin, 2003). The researcher's journaling provided another method of consistency for examining process and logic throughout the study (Creswell, 2009). This was particularly important due to the lack of availability of board meeting minutes and other CCO-specific documents for review.

The interviews were transcribed using Microsoft Word, then, the document was assigned a case ID. The individual transcripts were organized by $\mathrm{CCO}$ with the exception of the transcripts from the six interviews with state officials, which were organized into a single file. After each transcription was completed, the contents were reviewed. Upon completion of the interview process, all transcripts were reformatted with a two-inch 
margin on the right hand side of the document. The printed transcripts of each individual case were then carefully reviewed several times. The first review helped the researcher to identify major organizing ideas (Creswell, 2009, p. 151). During subsequent reviews, the researcher noted key words, concepts, codes, and quotes in the margins of the transcripts. The manual process served as a valuable process for developing a richer and more indepth understanding of the individual cases.

Coding process. There are multiple approaches to begin coding (Yin, 2003). According to Yin (2003), it is possible to start coding with themes identified from $a$ priori ideas such as pre-existing theories. Alternatively, researchers can develop codes that emerge from the data set as it is reviewed, which is referred to as grounded theory (Yin, 2003). For this study, the researcher adopted a priori codes that were identified from the following sources, in order of priority: (1) existing research and theory, (2) research questions the study addressed, (3) topics that emerged from the interviews, and (4) topics of interest or ideas that emerged during the data collection process.

A total of 287 pages of interview transcripts were read and coded manually, with notes and reflections written in the margins of the transcripts. In addition, the researcher also created and referred to a reflection journal from the face-to-face interviews to determine if additional themes or key words should be added to the transcripts. The documents were reviewed for content, key words, and short phrases (for example "transparency" or "structure") for each interview transcript, which were then circled and recorded using NVivo (see next section). For each transcript, approximately 50-70 key words and phrases were recorded. As the transcriptions were classified and interpreted, 
the codes were sorted into existing and newly created categories based on emerging themes for unexpected information, including "conceptually interesting," which often helped provide additional context for the experiences of the interviewees (Creswell, 2009, p. 153).

According to Saldana (2012), "A code in qualitative inquiry is most often a word or short phrase that symbolically assigns a summative, salient, essence-capturing, or evocative attribute to a portion of language-based or visual data" (p. 3). For this study, the data consisted of interview transcripts. In the first phase of coding, the researcher coded the interview transcripts looking for single words, full sentences, and passages of text. In the second phase, the identified words and sentences of passages were then coded.

The central task with the coding process was to apply "primary codes" to the data, representing the five concepts of governance that were previously conceptualized. For a primary code to be applied, the benefit represented by that code (e.g. presence of conflict, face-to-face dialogue, or inclusiveness) had to be clear from the passage text. The next step was to classify the data into secondary codes related to the two models: governance structure and collaborative governance. Each model was constructed with themes or constructs/concepts from the literature. Each set of interview transcripts by CCO was reviewed for themes based on previous coding. The next step was to interpret the data or “make sense of the data" (Lincoln \& Guba, 1985, as cited in Creswell, 2009). The researcher opted to transcribe the data to initiate a process of immersion into the data to identify themes (Creswell, 2009). 
Table 3.5: Primary Codes Applied to the Data

\begin{tabular}{lll}
\hline Primary Codes/Themes & Secondary Codes \\
\hline Starting Conditions & - & Power-resource imbalance \\
& - Incentives for and constraints on participation \\
Institution Design & - History of conflict or cooperation \\
& - Participatory inclusiveness/exclusiveness \\
Facilitative Leadership & - Fach, transparent, and inclusive process \\
& - Engagement \\
Collaborative Process & - Empowerment \\
& - Trust building \\
& - Commitment to process \\
& - Shared understanding \\
& - Intermediate outcomes \\
\hline
\end{tabular}

Prior to coding the two sets of interview transcripts with the help of NVivo (see next section), a more traditional approach to the analysis of interviews was deployed. First, the researcher worked through each of the transcripts and used line-by-line coding to note themes and phenomena in the margins. Keywords and phrases were noted using differently colored highlighters. This system of confirming an a priori set of primary and secondary codes, combined with reflection, was maintained for coding all interviews.

During the coding process, the researcher looked for word repetitions and key terms in context, which entailed identifying phrases and sentences in context.

The Microsoft Word computer software program was used to organize data. As data analysis progressed, the researcher matched the information being reviewed with existing codes. At the same time, other codes were added to the template as required. The codes were then captured in broad themes of structure, function, composition, control, starting conditions, institutional design, facilitative leadership, and collaborative process. 
The researcher examined these themes for their response to the central research question, secondary research questions, propositions and assumptions posed by the researcher, and the outcome of data analysis as related to the theoretical model presented by the researcher for the study.

Use of software for data management and analysis. Computer assisted qualitative data analysis software has become a common tool for the qualitative researcher. Weitzman (2000) suggests the following benefits of using software in research projects: writing up, editing, coding, storage, search and retrieval, data linking, content analysis, data display, and graphic mapping. Weitzman (2000) also recognizes that qualitative software programs are not able to conduct the analysis process for the researcher. The utility of the software is to support the research process; ideas and intellectual efforts need to come from the researcher conducting the analysis.

Still, there are several advantages in using qualitative software programs. Primarily, coding helps minimize challenging and time-consuming tasks such as printing, highlighting, and writing marginal notes; cutting and pasting can be automated using such programs. Another advantage of using computer software is the ability to code multiple categories, support complex code structures, and construct searchable memos and annotations. There are also limitations with using qualitative software programs. For instance, Bringer, Johnston, and Brackenridge (2004) suggest that the ability to conduct frequency counts disregards the opportunity for contextual analysis presented by the data, which can unintentionally lead to an inappropriate quantification of the research study. 
OREGON HEALTH REFORM AND COORDINATED CARE ORGANIZATIONS 118

Similarly, the ability to easily code and retrieve can result in a fragmentation of the data, which loses the narrative flow (Bryman \& Bell, 2007).

For this study, the processing software Microsoft Word and the qualitative analysis software NVivo were used to support the analysis and help manage the interview data. NVivo was utilized to efficiently and significantly facilitate the process of organizing, rearranging, and managing the considerable amount of data. The interview transcripts were formatted in Microsoft Word to facilitate importing them into NVivo, which resulted in the questions being displayed in the content panel in the NVivo explorer. Hence when selecting a question, it was possible to jump to this section in the interview transcript. After coding the interviews in NVivo, all passages were assigned a specific code that could be viewed on the screen and printed. In the same manner, searches for specific text strings could be conducted across all interviews, and relevant paragraphs containing the search string could be compared on-screen or printed.

As noted above, a preliminary set of primary codes was established prior to analysis, based on the theoretical framework, the research aim and research questions, and the key concepts drawn from the literature. These informed the initial structure of the NVivo 10 "project," as they did for the interview themes. The qualitative software tool aided the researcher in storing the data in categories (nodes, as they are named in NVivo 10) and in developing themes. It also allowed the researcher to "lay out" the data to visualize potential patterns as they emerged.

Throughout the study, written materials retrieved online were accessed and stored as PDFs. Each of the CCO's transformation plans, including additional background 
documentation from public committees, hearings, and internal documents, were reviewed to provide clarification or augment key findings from the interviews. The primary documents reviewed for the study were individual CCO transformation plans submitted and approved by the Oregon Health Authority in $2012 .^{13}$

\section{Revised Case Study Selection Process}

Based on the pre-constructed selection criteria and information shared by the initial set of interview participants, four CCOs were initially selected for the study. These four organizations provided diversity across organizational size and structure, geographic coverage area, prior organizational history and starting conditions, and number of partnering organizations within a CCO. The four CCOs initially selected prior to conducting any data collection were Health Share of Oregon, PacificSource Community Solutions (central Oregon), Umpqua Health Alliance, and Willamette Valley Community Health. See Appendix B for the selection criteria matrix that was developed in September 2012 and used to select the initial set of cases for inclusion in the study.

After completing the first round of interviews with state officials, one of the originally selected CCOs, Umpqua Health Alliance, was removed from the list and replaced by Yamhill CCO. Furthermore, after completing more than 12 interviews among individuals from three of the CCOs, the researcher decided to drop PacificSource Community Solutions due to two factors: (1) limited time and resources available after more than six months of conducting interviews as well as the unanticipated time and

\footnotetext{
13 http://www.oregon.gov/oha/OHPB/Pages/health-reform/certification/Oregon-CCO-TransformationPlans.aspx
} 
OREGON HEALTH REFORM AND COORDINATED CARE ORGANIZATIONS 120

effort to schedule interviews with executives from health plans, hospitals, and managed care organizations, among other senior level staff from CCOs; and (2) determination that there was sufficient information from the three CCOs to address the central research question after reviewing the transcripts as the interviews were transcribed. At that point the researcher verified that conducting another 6-8 interviews with representatives of the three remaining CCOs would suffice to ensure a final set of 22 interviews were conducted. The final three cases were Health Share, Willamette Valley Community Health, and Yamhill County CCOs. The identity of the individual board members and staff from the three CCOs has been blinded throughout the presentation of findings and discussion in order to ensure confidentiality of the study participants.

The individual CCOs and interview participants were assigned alphanumeric codes to maintain the confidentiality of the sites and individuals interviewed. The various quotes highlighted in the chapter four have been labeled by a citation, including an alphanumeric code to assure equal representation from different sites and interview participants, indicating if the quote came from a state official or board member. Table 3.6 provides the distribution of board members and staff interviewed for each case. The initial set of interviews with state officials was labeled as Case ID 1. In total 28 individuals were interviewed with 22 participants from the three selected CCOs. 
Table 3.6: Categories of Interviewees

\begin{tabular}{ccccc}
\hline Case ID & $\begin{array}{c}\text { State } \\
\text { Officials }\end{array}$ & $\begin{array}{c}\text { Board } \\
\text { Members }\end{array}$ & $\begin{array}{c}\text { Senior } \\
\text { Staff }\end{array}$ & $\begin{array}{c}\text { Total Number } \\
\text { of Interviews }\end{array}$ \\
\hline $1-6$ & 6 & - & - & 6 \\
$7-15$ & - & 5 & 4 & 9 \\
$16-21$ & - & 4 & 2 & 6 \\
$22-28$ & - & 5 & 2 & 7 \\
Total & $\mathbf{6}$ & $\mathbf{1 4}$ & $\mathbf{8}$ & $\mathbf{2 8}$ \\
\hline
\end{tabular}

\section{Conclusion}

The research study design and proposed methodology provided an opportunity to explore governance structure and the collective governance process among CCOs in Oregon. Methods were selected to sufficiently collect relevant information that would address the principal research question: "What are the key factors of collaborative governance that facilitate or impede the ability of CCOs to implement health care reform?" The study sought to also address "to what extent, and in what way, does governance enhance system integration and effectiveness" due to different arrangements of governance across CCOs as well as learn from experiences of CCO board members with respect to governing a $\mathrm{CCO}$. The objectives of the study were to (1) describe the governance structure or arrangements in CCOs, (2) describe the collaborative decisionmaking governance process with respect to CCOs, and (3) draw upon the theory of collaborative governance to inform models of governance among CCOs and other models of community-based health reform such as Accountable Care Organizations (ACOs). 
OREGON HEALTH REFORM AND COORDINATED CARE ORGANIZATIONS 122

This chapter provided an overview and justification for the research design; a review of the guiding research questions; and description of study population and selection criteria, working definitions, key concepts, and conceptual variables, methods for data collection and analysis, and conclusion. By adopting a case study approach, different forms of collaborative governance models among Oregon's coordinated care organizations (CCOs) were simultaneously studied, which helped to develop a better understanding of this contemporary governance phenomenon (McNabb, 2002, p. 287). 


\section{Chapter 4: Presentation and Analysis of Findings}

The governance is more than just the Board. (ID 4)

The purpose of this study was to explore CCOs and understand the processes and conditions in which a collaborative governance model facilitates or impedes decisionmaking among stakeholders. A secondary purpose of this study was to examine CCO board members' perceptions of the relevance of collaborative governance to the overall interests of their communities and to the long-term viability of these nascent organizations in Oregon. Obtaining perceptions from CCO board members helped identify mutual goals and objectives, which can be realized through collaborative governance as a realistic model to form new partnerships among for-profit, nonprofit, and public organizations to integrate new models of community-based health services.

Collaborative governance is emerging in the United States in response to changes in public policy, the need for efficient use of both public and private resources, and the need for consensus-based decision-making among stakeholders in nongovernmental and governmental organizations (Ansell \& Gash, 2007). Identifying barriers to engagement in collaborative governance and external environmental factors that are conducive to collaborative governance may contribute to the better use of collaborative governance structures - in this study, the reform of Oregon's Medicaid system through collaborative governance at a regional level by coordinated care organization (CCOs). However, there is a knowledge gap about newly formed CCO governing models and board members' perceptions of the advantages and disadvantages of collaborative governance as a tool for building organizational capacity and increasing public value. 
The research question. The central research question guiding this study was the following: "What are the key factors of collaborative governance that facilitate or impede the ability of CCOs to implement health care reform?" The challenge is determining which governance structure(s) and processes are more effective in integrating components of a health system that has historically been fragmented and disorganized.

The discussion of findings in this chapter is organized into three sections. The first section highlights findings from initial interviews with state officials about key external factors that affected early CCO formation and implementation across the 16 CCOs in Oregon, focusing on initial conditions and prior history within the CCOs selected for study. The second section provides an in-depth description of the governance structure from each individual case studied here. The third and final section presents findings related to the conceptual model of collaborative governance as demonstrated in this chapter by individual cases. The chapter concludes with the identification of the principal differences among the CCOs regarding what constitutes collaborative governance.

\section{Findings}

The whole basis of a CCO has been about local governance. The whole notion of CCOs is based on the notion that all health care is local. (ID 3)

The findings inform the research question addressing whether collaborative governance serves as a promising model for supporting health care reform in Oregon. The findings also indicate which facets of collaborative governance are important to successfully govern these new locally controlled organizations. As observed by Merriam 
(1988), “There is no standard format for reporting case study research" (p. 193). This section provides an in-depth description of each individual case based on information collected during the interviews as well as review of secondary data. Next, the cross-case comparison, including similarities and differences, is presented to illustrate key findings related to the question of whether collaborative governance is an effective model to support health reform for Oregon's Medicaid program.

The tables on the following pages provide summaries of the cases and concepts to visualize and assess the results of the individual cases. The details of each CCO case study are presented, including sub-sections for each individual collaborative governance concept. Three cases were used to view events through the lens of the conceptual model and primary variables: starting conditions, institutional design, facilitative leadership, and collaborative process. Each section (where appropriate) is organized to address the four key constructs in that order. Before providing an in-depth description of each case and relevant findings, the findings from the interviews with state officials are summarized below and offer important historical context and policy perspective to understand the formation of CCOs, including key legislation.

\section{State officials.}

Across Oregon, unprecedented collaboration. - Tina Edlund, Deputy Director, $\mathrm{OHA}^{14}$

Historical context. The first set of interviewees were key informants employed by the Oregon Health Authority (OHA) and the Governor's Office, as well as senior OHA

\footnotetext{
${ }^{14}$ http://www.ohsu.edu/xd/outreach/oregon-rural-health/about/rural-health-conference/upload/Thu-TinaEdlund.pdf
} 
OREGON HEALTH REFORM AND COORDINATED CARE ORGANIZATIONS 126

leadership and policy advisors. The purpose of this initial set of interviews was to gather insights and background information from key public officials who led Oregon's effort to establish CCOs through passage of legislation in 2011 and 2012. The intent was to seek guidance and/or verification from those most familiar with the relatively new CCOs in order to assist in the selection of relevant and robust cases for this dissertation research.

The first wave of interviews informed the CCO selection process, given the indepth knowledge of these individuals. The state officials interviewed were uniquely positioned, and they offered historical local context and unpublished information about key environmental factors that affected early $\mathrm{CCO}$ formation and implementation efforts across the 16 CCOs in Oregon, particularly regarding initial starting conditions and prior organizational history. Through the interviews, the researcher invited state officials to reflect on historical and environmental factors unique to individual CCOs and verify the presence of facilitative leadership among the CCOs selected for the study. Interestingly, five of the six participants recommended at least one alternative CCO to the list of four CCOs initially selected by the researcher (using the selection criteria created based on the available literature), offering a compelling rationale for inclusion.

One unique aspect and important observation shared by several of the state officials is that CCOs are "local." They are governed locally and controlled by community organizations. All 16 new organizations were formed under guidelines for coordinated care organizations established by the Oregon Legislature in 2011, when it enacted House Bill 3650, which established the initial framework for the creation of coordinated care organizations (CCOs) with the State of Oregon through the Oregon 
Health Authority. Section 26 of HB 3650 specified that CCOs are responsible and will be held accountable for "providing fully integrated physical health services, chemical dependency and mental health services, and dental health services" (with services phased in over a two year period). In 2012, the Oregon Legislature passed Senate Bills 1509 and 1580, which provided legislative approval of OHA's proposals for CCOs and made modifications to the provisions in HB 3560.

The legislation essentially specified the basic governance framework for creating CCOs before being certified by the Oregon Health Authority. Furthermore, each CCO is statutorily required to establish a community advisory council. The majority of members must be consumers (i.e. OHP members), including representatives from each county government in the service area(s) with the explicit responsibility of conducting the community health assessment (CHA) and corresponding community health improvement plan (CHIP). Each CCO was required to meet the specifications listed above. The extent to which the final composition of partners that were organized to form a CCO was inclusive or exclusive varies from region to region. Some of the variation in types of governing boards and participating organizations can be attributed to the starting conditions in each community where CCOs were formed.

\section{Starting conditions.}

We understood that governance was going to be really key. (ID 3)

The initial set of questions posed to the state officials inquired about the historical and environmental factors unique to the creation of CCOs in Oregon. A number of valuable insights emerged. Several of the most salient insights related to the early 
formation of Oregon's CCOs as well as perspectives on different emerging governance models. By and large, the majority of respondents stated that the three selected CCOs offered "very different perspectives" on how various communities in Oregon are approaching the question of governance. There are multiple perspectives on "shared governance" models among Oregon's 16 certified CCOs. The differences were attributed to distinct historical conditions, dissimilar cultures, and varying approaches in establishing a CCO, with all CCOs having unique and different starting conditions. An important historical aspect to the creation of CCOs in Oregon dates back several decades and was emphasized by some of the state officials. Approximately 20 years ago, a number of large regional health plans served individuals in the Oregon Health Plan (OHP). However, these larger managed care entities abruptly exited Oregon and stopped serving the state's Medicaid market. As a result of a number of commercial health plans exiting the market, smaller local community-based organizations "spontaneously" opted to enter the Medicaid market. A number of these organizations, including hospitals and local providers (frequently IPAs), became the prevailing "home grown" health plans that evolved over time to serve the vast majority of OHP members in Oregon. The notion of local control and autonomy among communities that formed CCOs has roots that stem back to these historic events in Oregon's Medicaid history.

A coordinated care model requires relationships with the local mental health authority, the local public health authority, area hospitals, and providers. It also requires social support and services from a traditional human services realm, which are often not connected in a traditional medical model. There was "intentionality" in designing 
legislation that specified the governance framework but was flexible enough to recognize that local area needs will vary. Oregon's policymakers were concerned with specifying the composition of partners and creating a flexible structure in which work could be adapted to meet the needs of individual communities.

In order to be a successful coordinated care model you have to move away from a purely medical model and move into a social model... There was a very explicit conversation about putting in those requirements to force some of the partnerships. (ID 4)

Another important historical event was the state's 2011 fiscal crisis during that legislative session. Oregon's Medicaid program had already experienced considerable cuts in terms of provider reimbursements, and it was likely to experience another $10-15 \%$ cut across the board. A majority of organizations that served or participated in Oregon's Medicaid community at that time recognized that financing Medicaid services was increasing at an unsustainable rate in the state. Consequently, a "sense of urgency" emerged and served as a catalyst to encourage organizations within and across Oregon's rural and urban communities to consider addressing the unsustainable growth of health care costs with a novel approach: the creation of CCOs. As stated by one official, "Everyone recognized that we can't keep going down the same old path" (ID 4). The perception among health care leaders and organizations in Oregon that served Medicaid was the following: "At a community level it was change, or be changed" (ID 3).

The concept of "incentives to participate" was often identified as an important starting condition, specifically the legislative role in creating governance conditions that 
OREGON HEALTH REFORM AND COORDINATED CARE ORGANIZATIONS 130

required community organizations to learn how to "partner" to meet the requirements for CCO certification. The legislation was viewed as creating the "incentives" or "necessary conditions" for organizations to partner and work together under the auspices of becoming a CCO. In other words, the state created the conditions or "incentives to participate" in communities across Oregon. The legislation also created financial incentives. Through a CCO, partnering organizations could receive additional funds. As stated by one official, "What the composition looked like was a balance between the people with the money and the people who care about the community... The statute (HB) was trying to balance that" (ID 5).

The theme of local control emerged throughout the interviews. A fundamental premise of $\mathrm{CCO}$ governance is fostering local community health governance by key stakeholders. As described in the interview process, Oregon's CCO legislation was designed to "push authority" down from the state and into the local communities. One state official described it this way: "We don't need to be making all the decisions in Salem," (ID 1) regarding the creation of new models of coordinated care or legislating "overly prescribed" models of governance. Another state official stated, "The other beauty of how the legislation was constructed was everything was about pushing authority down and into the local communities" (ID 4). It was crucial to create a governing framework that would allow for "local control" among community partners. Part of the notion of "local control" was for newly formed organizations to have community input, which resulted in the legislative mandate for community advisory 
OREGON HEALTH REFORM AND COORDINATED CARE ORGANIZATIONS 131

councils as part of the governance structure and to serve as an accountability mechanism by influencing resource allocation decisions.

From a state perspective, what was in the legislation was very broad and as least prescriptive as possible... so that communities really have the flexibility to figure out. (ID 1)

Each community's history was likely to influence the pace at which each individual CCO would have a working or "functioning" board. The history of “cooperation" or "conflict" among multiple organizations that historically have been competitors, but recently agreed to "share responsibility," likely influenced the level of trust for any one CCO governing board. For one of the CCOs, key partners that formed the organization had a "long history of working together," bringing together partners on specific projects. In contrast, another $\mathrm{CCO}$ was described as having a history of conflict, which influenced its overall structure. The result was that a dominant local IPA took the lead in establishing the CCO board. Oregon's history of managed care at the local level was important as an initial starting condition of CCOs.

The most important element is where there has been historical tension, frankly. The beauty of requiring certain kinds of partnerships in the legislation is it has forced this; it forces partnership. (ID 4)

The legislative intent of creating community advisory councils (CACs) was to provide the community with leverage by assigning responsibility for conducting the community health assessment and creating the health improvement plans. The CCOs are required to address the community health improvement plans. State officials described 
the CACs as an important and distinct feature of a "shared" model of community governance. State officials perceive the CACs as a critical component of the proposed governance model and should be understood as a key "nexus" for input into any governance framework. In the first one to two years of $\mathrm{CCO}$ formation, state officials considered whether consumers were involved in the governance decision-making process in a meaningful way as intended by the enabling legislation, which is still largely unknown. The interviewees described CACs as an "essential" aspect of the governance framework and that they should be considered a key component of any CCO governance model.

CACs are valuable to the overall governance.... Their value is giving, allowing a consumer voice, a person with low income to express their news, their worldview to a health care delivery system that has not traditionally heard that voice. (ID 5)

\section{CCO governance: Emerging model.}

Collaborative governance, it does vary by every community. You are going to have different players and stakeholders that want to have a part in that governing process. (ID 1)

Based on the state officials' perspectives, several important factors of collaborative governance within a CCO were identified. First, a CCO governing board should engage their community advisory council (CAC) in an "open and transparent" manner. A number of $\mathrm{CCO}$ board members have spent their professional careers in the private sector, which has a different culture than public sector organizations. Therefore, the notions of "transparency" and public accountability are relatively new concepts. This 
may present an issue for senior executives from partnering organizations in the private sector. Also, having "broad representation" of communities served by a CCO is an important aspect to collaborative governance.

What is interesting... is how they [CCOs] drove conversations within the communities themselves and how they kind of adjusted and adapted to pull in particular community members and built on that to create this governance structure.... It speaks to some of the reasons why we are seeing some of the early successes. (ID 5)

Another theme is the notion of CCOs accepting responsibility at a population level for community health. The concept is "responsibility" for the Triple Aim, the framework to which these newly formed organizations will be held accountable. CCOs will need to show evidence of effective governance through clarity of vision, identification of their community's needs and understanding of their population, expectations for the board, the ability to develop new capabilities and capacities, and management of their resources (i.e. within a global budget).

The big issue...is governance. When asked how are CCOs different than managed care there are two key pieces: one is governance and the other is managing outcomes - accountability. (ID 3)

Another important finding pertains to the importance of leadership and its role in CCOs. Effective leadership is the means to build trust among CCO governing boards. State officials also perceive leadership as engaging the community and a broad set of stakeholders. Leadership among the governing board will require such individuals to 
build relationships with communities and create feedback loops. As one official stated, "Building of trust...really engenders how to move the organization forward" (ID 2). The concept of goal setting was a recurring theme. Officials described the need for senior or executive leaders serving on the governing boards to ensure CCOs are able to effectively prioritize and set goals for the board. This includes being able to effectively set and achieve benchmarks, milestones, and targets put forth in the transformation plans submitted by the individual CCOs. A third theme emerged related to the governing process. Effective governing in a collaborative model requires decision-making with an agreed-upon framework and with equal decision-making authority. One official stated, "Within the community, the CCO definitely needs a powerful leadership, a charismatic leader with a vision that can help facilitate and bring together the distinct groups" (ID 5).

The last theme that emerged was the leadership of Governor Kitzhaber. Officials repeatedly referred to the governor's "visionary" leadership and "hands on" approach throughout the legislative process and early formation of the new organizations. Through facilitative leadership, the governor was able to convince organizations of the need to partner and create new models for the state's Medicaid system.

Summary of findings. From a state perspective, key precipitating factors that helped to foster support for the CCO legislation were the looming budget crisis of the "Great Recession," recognition and acknowledgement of unsustainable growth in health care, a general "sense of urgency," particularly the impact of Medicaid expenditures on Oregon's biannual budget, and an opportunity to achieve broad health reform in Oregon. These factors contributed to bipartisan support, along with Governor Kitzhaber's 
leadership, creating an unprecedented effort to transform Oregon's health care system, starting with the Oregon Health Plan.

Based on information shared by the state officials, it was evident that the initial starting conditions, primarily the history of conflict or cooperation, serve as significant factors in influencing the initial "success" in terms of establishing new partnerships in the early formation of CCOs. From a state policy standpoint, the intent of the CCO legislation was to develop a model by which to reform the state's Medicaid program through localized control and by fostering accountability among communities across Oregon. The notion of collaborative governance as the preferred model was adopted, as it allows for "local control" among community partners, which resonates with Oregon's culture of public participation and preference for local flexibility. Furthermore, state officials perceived the level of consumer involvement in the CCO governance decisionmaking process, specifically through the CACs, as an unanswered but pivotal issue as it relates to local accountability. The question is whether consumer input through the CCO governance structure occurs as intended by the enabling legislation. Two other emerging themes were responsibility by the CCOs for their community's health and the importance of leadership across all 16 CCOs.

In sum, it is clear that initial starting conditions and prior organizational history affected early CCO formation with leadership as a considerable factor in the successful implementation in the majority of the still nascent newly formed CCOs. Based on the information shared by five of the six state officials and recommendations to include at least one alternative case from the initial list of CCOs selected by the researcher, one 
OREGON HEALTH REFORM AND COORDINATED CARE ORGANIZATIONS 136

$\mathrm{CCO}$ was removed from the inclusion list, Umpqua Health Alliance, and a new CCO was added, Yamhill County CCO. State officials considered Umpqua as similar to Willamette Valley Health Authority in that prior to the creation of CCOs the organizations were Independent Practice Associations. In contrast, Yamhill County CCO was the only CCO that did not originate from an IPA, managed care organization, hospital system, or other previously existing Medicaid health financing or delivery organization.

\section{Findings from the Individual Cases}

The next section provides a description of each case presented with findings on the governance structure and model of collaborative governance. The governance structure for each case study is based on the definitions adopted in Chapter 3: control, structure, composition, and functioning (Pointer et al., 1995; see Table 3.1 in previous chapter). Next, findings related to the conceptual framework for collaborative governance are described in-depth by individual case study (Ansell \& Gash, 2007). The four concepts of collaborative governance are starting conditions, institution design, facilitative leadership, and collaborative process. The fifth concept, outcomes, was not included because the researcher viewed any outcome-related variables as beyond the scope of the study. Table 4.1 provides an overview of the individual cases. 
Table 4.1: CCO Collaborative Governance Matrix (as of Feb. 2014) ${ }^{\mathbf{1 5}}$

\begin{tabular}{|c|c|c|c|c|c|c|}
\hline \multirow[t]{2}{*}{$\mathrm{CCO}$} & \multicolumn{2}{|c|}{$\begin{array}{c}\text { Organizational } \\
\text { Size }\end{array}$} & \multirow{2}{*}{$\begin{array}{c}\begin{array}{c}\text { Starting } \\
\text { Conditions }\end{array} \\
\text { Prior Org. } \\
\text { History: } \\
\text { Yes, Some, } \\
\text { No }\end{array}$} & \multirow{2}{*}{$\begin{array}{c}\text { Org. } \\
\text { Structure } \\
\text { New/ } \\
\text { Existing } \\
\text { Org. }\end{array}$} & \multirow{2}{*}{$\begin{array}{c}\text { Composition } \\
\text { Number of } \\
\text { Partnering } \\
\text { Orgs. }\end{array}$} & \multirow{2}{*}{$\begin{array}{c}\begin{array}{c}\text { Facilita- } \\
\text { tive } \\
\text { Leader- } \\
\text { ship }\end{array} \\
\begin{array}{c}\text { (High, } \\
\text { Medium, } \\
\text { or Low) }\end{array}\end{array}$} \\
\hline & $\begin{array}{l}\text { Service } \\
\text { Area (by } \\
\text { County) }\end{array}$ & $\begin{array}{l}\text { Number } \\
\text { of OHP } \\
\text { Members }\end{array}$ & & & & \\
\hline $\begin{array}{l}\text { Health } \\
\text { Share }\end{array}$ & $\begin{array}{l}\text { Clackamas, } \\
\text { Multnomah, } \\
\& \\
\text { Washington } \\
\text { counties (3) }\end{array}$ & 188,000 & Yes & $\begin{array}{l}\text { New: } \\
\text { Public } \\
\text { benefit } \\
\text { corp. }\end{array}$ & $\begin{array}{l}11 \text { private } \\
\text { and public } \\
\text { affiliates }\end{array}$ & High \\
\hline Willamette & $\begin{array}{c}\text { Marion } \\
\text { County, } \\
\text { parts of Polk } \\
\text { and Yamhill } \\
\text { counties (3) }\end{array}$ & 81,000 & $\begin{array}{c}\text { Some } \\
\text { history: } \\
1 \mathrm{MCO}, \\
\mathrm{MHO}^{\text {and }} \\
\mathrm{DCO}^{16}\end{array}$ & New: LLC & $\begin{array}{l}13 \text { private/ } \\
\text { public } \\
\text { affiliates }\end{array}$ & Low \\
\hline Yamhill & $\begin{array}{c}\text { Yamhill, } \\
\text { parts of } \\
\text { Clackamas, } \\
\text { Washington, } \\
\text { Polk, } \\
\text { Marion, \& } \\
\text { Tillamook } \\
\text { counties (6) }\end{array}$ & 18,000 & No & $\begin{array}{c}\text { New: } \\
501(\mathrm{c}) 3\end{array}$ & $\begin{array}{l}14 \text { private/ } \\
\text { public } \\
\text { affiliates }\end{array}$ & High \\
\hline
\end{tabular}

\section{Case One: Health Share}

Noah's ark of health care. (ID 9)

Health Share is the largest CCO in Oregon in terms of organizational size, complexity, and number of covered lives in the Oregon Health Plan (OHP). The organization is comprised of public and not-for-profit organizations across the three

\footnotetext{
15 OHA CCO enrollment report, February 2014.

${ }^{16}$ MCO refers to managed care organization; MHO refers to mental health organization; and DCO refers to dental care organization. In Oregon all three organizations are examples of managed care by physical, mental, and oral health.
} 
counties that comprise the Portland Metropolitan Area: Multnomah, Clackamas, and Washington. According to the organization's transformation plan, their goal is to "create a regional system of self-regulating and aligned service providers (physical, behavioral, addictions, oral and social service) who are committed to achieving the same Triple Aim measureable targets, but provide flexibility to achieve those targets based on creativity and knowledge of the needs of the members in their community" (Health Share, March 2013, p. 1).

Composition. Health Share consists of 11 "member organizations" listed in alphabetical order: Adventist Health, CareOregon, Central City Concern, Clackamas County, Kaiser Permanente, Legacy Health, Multnomah County, Oregon Health \& Science University, Providence Health \& Services, Tuality Healthcare, and Washington County. The size of the board is 20 individuals who are both representative and nonrepresentative (described in the section below titled "Functioning"). The members are executives from nonprofit hospital systems, local public health agencies, health plans, and social services organizations. Eleven member organizations are considered "founding members" that have permanent seats. The remaining nine members are elected positions that represent partners of Health Share.

The CEOs of the large health plans and area hospital systems serve on the Health Share Board. These organizations have historically competed for the commercial health plan market in Oregon. The chair of the CAC also serves as a full member of the board of directors. The competency of the individual board members is notable in that there are primarily senior level executives with decades of experience; they are highly trained, 
educated, and skilled in the health care arena. The other members of the board are health care professionals, primarily clinicians. As one board member explained, "The Board is very different than what it would have been before CCOs. And that changes the conversation very much; it changes the dynamics of the business very much" (ID 9). The dynamic is that having providers, dentists, specialists, and mental health and addictions providers all serving on a board significantly changes the conversation compared to the board of a traditional health plan or hospital system.

Structure. The board has chartered advisory councils, including the community advisory council (CAC), clinical advisory panel (CAP), and a finance committee. The primary role of the advisory councils is to provide "strategic direction" to the board of directors. The CAC is comprised of nine Medicaid consumer members and eight community members, including an appointed representative from each county (Health Share Transformation Plan, 2013, p. 14). In addition to the standing advisory entities, the organization also has chartered five workgroups: Chief Medical Officer Workgroup, Information Technology Workgroup, Care Management Workgroup, Quality Assessment and Performance Improvement Workgroup, and Cultural Competence Workgroup (Health Share Transformation Plan, 2013, p. 49). ${ }^{17}$

When the CCOs were created, we were charged with making sure that the people on our board were the people who were taking risk with serving the population, and that really changed the dynamics. (ID 10)

${ }^{17}$ http://healthshareoregon.org/members/member-newsletter/ 
Control. The organization is governed by the board of directors. The two chartered advisory councils share decision-making functions and authority with the board of directors. For Health Share, the issue of control is directly related to the risk-accepting entities. As shared by a participant, "Governance ultimately comes down to how do you divide up the money and who gets to decide how you divide up the money" (ID 12). The board of directors is responsible for making decisions. The board oversees advisory entities. The board has clear decision-making authority, oversight, and responsibility to the partnering organizations. Board members are responsible for formulating the mission and vision of the organization as well as the financial health of the CCO. For the first 12 months after establishing the $\mathrm{CCO}$, the board was very "hands on" and served as executive staff and sought to manage the day-to-day operations of the new organization.

The multiple organizations that comprise the board control the decision-making related to the finances of the organization. The board does provide some direct decisionmaking to the advisory councils previously identified.

You can't take independent organizations and meld them into one; that's not going to happen and it's not in our best interest, and it's not in the best interest of the community. However, we will cooperate, and I think we've done that. We've got good governance, and I think people are aligned and there's a strong sense of trust. (ID 7)

Functioning. Health Share's functioning is unique as described by the board members. According to the interviewees, the "founding members" make all the executive decisions, which create a governance structure and function unique to Health Share's 
governance arrangement. The founding members are the initial partner organizations, which are also the "risk-accepting entities" (RAEs). Health Share RAEs are required to monitor availability and access to health care as well as quality of care measures through routine reports (Health Share, Transformation Plan, p. 49). The founding members are able to veto any decision made by the full board of directors that consists of nonrepresentative members, including community-at-large members, the chair of the CAC, or health care professionals. Non-representative members are selected by a nomination and selection process, which is overseen by the founding members. When consensus is not achieved among the founding members, a simple majority is required for decisionmaking.

The size of the Health Share board requires additional resources from a staffing perspective. A challenge is to make sure that all 20 board members are engaged, informed, and understand the multiple moving pieces of Health Share in the rapidly changing environment of health reform. Another issue that stems from the size of the board is the sheer number of organizations represented. By having the major players of the metro Portland Medicaid delivery system involved, there is an inherent conflict within the governing board. Any number of decisions brought to the board likely result in one or more of a board member's parent organizations experiencing a negative financial impact. Board members are required by the bylaws to make decisions solely in the interest of Health Share and not consider the potential impact on their parent organizations. 
This complexity presents a challenging governing situation. Members of the board have responsibilities to Health Share and also fiduciary responsibilities to the board(s) of their parent organization(s). The CEOs of local hospitals, serving as members of Health Share, also have governing boards to whom they are accountable. When serving on Health Share, however, these CEOs are required to represent the needs and interests of the $\mathrm{CCO}$ and set aside any financial or other conflicts between Health Share and their parent organizations. As one interviewee described, "That with almost every single conversation they [the board] have, there's always someone at the table who has a conflict, which from a governing or board perspective is a really big deal" (ID 11). The issue of inherent conflict among members of the board and their partner organizations was repeatedly mentioned among the interviewees.

The CEOs — who are they really responsible to? They're responsible to their boards. They're responsible to their boards for the success of their organizations.... If something Health Share wants to do is significantly detrimental to the success of the organization, they're going to have to think long and hard about taking that step. (ID 13)

Aspects of the inherent conflict have been lessened as a result of a socialization process that has occurred among the board. The socialization was described as the recognition and commitment that "working together is more important than my principled point on this particular issue" (ID 12).

The board has defined objectives, strategies, and tactics that it has agreed upon. The role of the CAC in the governing structure in terms of responsibilities to the board 
has evolved over time. A challenge, however, is that the notion of a community advisory council is new to many of the founding members of Health Share. The board receives monthly updates from the CAC. As with all three of the CCOs, the role of the CAC was specified in the CCO enabling legislation. However, Health Share's CAC continues to define its exact role in relation to the board. The staff of Health Share has invested considerable time, resources, and expertise in working to engage and educate members that serve on the CAC. Members of the board are still somewhat reluctant to receive input from the CAC while acknowledging that the chair of their $\mathrm{CAC}$ is an engaged and wellrespected consumer advocate.

It's a learning process.... We've had to do a lot of skill building to get them $[\mathrm{CAC}] \ldots$... And then you have the board who gets a little suspect about saying, "What do you mean, these consumers are going to tell us? Wait a minute." (ID 12)

Members of the board are skeptical about the role of the CAC and more broadly with consumers advising a board comprised of highly trained professional executives.

The community advisory council. It's a unique position for a consumer to be sitting at the table of a board that has the presidents of all these partner organizations and CEOs...like a CEO of Providence at this table and then you have a consumer member that's on the board. (ID 14)

\section{Collaborative governance.}

CCOs were very much initially about forced adaptive change. (ID 12) 
Starting conditions. A critical important starting condition for Health Share was the presence of collaboration among the local community health leaders in the Portland Metro region. The health care executives from the region had been actively engaging and cooperating with one another. For example, Legacy and OHSU played an important role in establishing CareOregon 20 years prior to the creation of Health Share.

Historically, the large health plans and hospitals were "fierce competitors." These competitors, however, agreed to collaborate through Health Share. Larger hospital systems, health plans, and provider networks, which often are competing for the same finite resource pool of funding, agreed to set aside their prior history of conflict and power imbalance(s). Health plans and hospitals are often in conflict over rate settings, as are health plans and provider networks over reimbursement fees.

The hospital systems absolutely are competitors and to get them all, us and them, together, and there's traditionally been tension between delivery systems and health plans, too, so it's not just the apples competing with the apples, and the oranges with the oranges, you know, there was some tension between the payer and the provider about rates, historically. (ID 9)

Prior to Health Share and dating back to before the creation of the Health Leadership Council (described below), the Portland Metro region was a contentious environment among the local area health care organizations with "deep mistrust" of each other. In 2008, the HLC was formed as "collaborative organization" aimed to identify potential solutions to address the issues of cost and quality of health care in Oregon. ${ }^{18}$

${ }^{18}$ See: http://www.orhealthleadershipcouncil.org/about-us 
The HLC is comprised of large health plans, medical groups, hospitals and health systems, and state representatives. In 2011, building on the work of the HLC, a subset of hospitals and health plans in the Portland Metro region created the Tri-County Medicaid Collaborative. The CEOs of six large health plans and hospitals agreed to convene and consider how to "create an integrated community delivery system that will achieve better community health for the Medicaid and high-risk population in the Tri-County community."19 The collaborative met weekly for months. The purpose of these meetings was to explore what a CCO could look like in the region. The result of these meetings was a commitment in response to Governor Kitzhaber's challenge to design a "new paradigm of how we might do business" for Medicaid, which eventually lead to the creation of a new organization. Six regional hospital systems and five health plans all participated in the collaborative. Through ongoing and frequent face-to-face meetings, the principals of these organizations engaged with one another and started to establish trust.

The next event was a federal grant opportunity through the Centers for Medicare and Medicaid Innovation (CMMI). In the winter of 2011, CareOregon, Providence, and Kaiser decided to pursue the CMMI challenge grant. During the process of preparing the grant, the three organizations engaged the three county health departments, OHSU, and a number of community organizations in an effort to "make the grant a more viable opportunity" (ID 9). In July 2012, the newly formed organization received the largest CMMI grant awarded in the first round of funding: $\$ 17$ million. The partnerships that

${ }^{19}$ Page 2 (2012): http://www.oregon.gov/oha/OHPB/meetings/2012/2012-0110-tri-county.pdf 
were developed as part of the grant application process served as a springboard for the creation of Health Share.

In February 2012, the Oregon Health Policy Board issued the state's CCO implementation plan. At the time of receipt of the CCMI grant, the state was facing a budget crisis in which cuts to Medicaid were under consideration. According to one board member, "Each organization has slightly different motivations; the motivation of the budget shortfall cannot be underestimated" (ID 9).

The next key date in the creation of Health Share was March 2012 when Dr. Bruce Goldberg, Director of the OHA, convened the physical health managed care plans that operated in the Portland Metro Medicaid market, which included primarily members of the Tri-County Medicaid Collaborative. The executives of the large area health plans engaged in a series of meetings to explore whether the area benefited by having multiple health plans in the tri-county region. A consensus was achieved among the executives of the large health plans that there was an opportunity to integrate the existing fragmented networks in the region. The Tri-County Medicaid Collaborative hired a consultant to assess the possible options. Approximately seven to eight months after the initial meeting with OHA, the consultant submitted a report, which was not well received by the majority of the stakeholders.

In April of 2012, four of the five Medicaid health plans (MCOs) that were participating in the Tri-County Medicaid Collaborative agreed to incorporate as Health Share and submit a letter of intent to the OHA to apply to become a CCO. The fifth health plan, Family Care, opted not to join and created a separate CCO that also serves 
the Portland Metro area. Health Share is the only example of the $16 \mathrm{CCOs}$ where multiple health plans engaged and cooperated with one another; this was an unprecedented turn of events both for the largest city in Oregon as well as for other parts of the state.

With federal health reform and the pending changes in the commercial market, the participants in Health Share recognized that a significant change was on the immediate horizon: They would no longer be able to shift costs from Medicaid to the commercial insurers. The recognition was that the historic cost-shifting model in health care was no longer sustainable in Oregon. Furthering this was the awareness that an estimated 200,000 Oregonians would be enrolled in Oregon's Medicaid program starting in January 2014. The number of soon-to-be eligible OHP members could not be absorbed by Oregon's commercial marketplace through any means of cost-shifting. The member organizations opted to address the collective resource management issue that was being faced by the entire Portland Medicaid delivery network. The hospitals and health plans had made the conclusion that there was "not a future" in Medicaid managed care in Oregon. There was an incentive to collaborate and form Health Share. The only exception that was raised during the interviews was the slight tension between Providence Oregon and Providence corporate headquarters, which is located in Seattle, Washington. The leaders of Providence Oregon were very collaborative and supportive of Health Share. The challenge with Providence is that it is one of only two organizations not solely located in Oregon (Kaiser is the second one). Members of Health Share perceived tension between the Providence leadership in Oregon and the corporate headquarters. One board commented that "CCOs were to be regional and the major 
players had a vested stake in seeing that there was a regional solution...that helped to bring them together" (ID 8).

A third event was the passage of the CCO legislation in $2012 .{ }^{20}$ The large health plans in Portland, principally CareOregon, Providence, and Kaiser, recognized that their organizations would be affected from a business standpoint by this legislation. It incentivized these organizations to explore financial options that would create savings and administrative simplifications.

There is evidence of a power imbalance among the founding partners, based on the interviews conducted. Although all of the founding partners are nonprofit organizations, not all the organizations operate an insurance plan. In other words, a hospital system such as Legacy does not own or operate a health plan, as compared to Providence or Kaiser. The latter two organizations have the ability to better manage risk than the former. This dynamic creates a power imbalance among the founding members.

Organizations that can manage member premiums, especially from commercial lines of business that have relatively higher profit margins than premiums for OHP members, have the ability to spread risk across multiple lines of business. Medicaid reimbursement from the state historically has been, on average, 30\% less than the rates in the commercial marketplace. For example, OHA provides Health Share with a global budget for all Medicaid funding. Health Share then allocates these resources to the riskaccepting entities, which then pay for services rendered. If the risk-accepting entity is also the service provider, such as Providence or Kaiser, there is one less organizational

${ }^{20}$ Reference to Senate Bill 1580 referred to as the CCO implementation legislation. 
layer involved and thus lower direct costs incurred and potentially more profit. As one board member pointedly commented, "It is very definitely from a purely financial perspective a losing proposition for those that don't have health plans.... This has been the elephant in the room for the governance of Health Share" (ID 10).

A related issue is the percentage of Medicaid lives served by a hospital or health plan. The issue within Health Share is which organizations disproportionately care for higher volumes of Medicaid members in the Metro region. Several of the hospitals and health systems in Health Share are located in the Metro region and see a higher percentage of those enrolled in OHP. The challenge in Health Share is "how do you make this a level playing field for everybody from that perspective" (ID 9). The issue of inherent greater exposure to risk from seeing a higher portion of Health Share's covered lives has yet to be resolved.

Institutional design. The level of participation and the extent to which competing organizations partnered to form Health Share is a key aspect of the CCO's institutional design. Key to Health Share's design is that all of the participant organizations are nonprofits. The notion of transparency and openness, however, required cultural change for several board members, including individuals serving on the CAC. Staff with the new $\mathrm{CCO}$ was intentional in making sure that the $\mathrm{CAC}$ meetings were facilitated in an open and transparent environment. The monthly CAC meetings are open to the public for the first portion of each meeting. Afterward the council enters into executive session, in which members of the public are not allowed. 
OREGON HEALTH REFORM AND COORDINATED CARE ORGANIZATIONS 150

Facilitative leadership. Facilitative leadership was an important concept in both creating Health Share and establishing the board, committees, decision-making processes, bylaws, and governance structure. The engagement of the future leaders of Health Share dates back to the founding of the Health Leadership Council. Through the HLC, competitors were able to develop relationships, understand the different aspects of the industry, learn about the insurance companies' challenges, and develop a broader understanding about the challenges in the health care system. The socialization of the future members of Health Share started with the HLC. A key facet of the socialization process was developing an understanding that the hospitals and health plans were "interdependent."

The CEOs of the member hospitals and health plans are well known leaders within the health care community. The number of regional leaders is notable. The leaders were able to engage with one another and through consensus building, adopt a governance structure that was acceptable to the board.

There are some barriers and some obstacles, but I think well-intentioned people sitting around the table and trying to do the right thing, and that's what you have in Health Share. These are really good, very smart people who are trying to make this work. (ID 10)

Collaborative process. Starting with the Health Leadership Council in 2008 and continuing with the Tri-County Medicaid Collaborative in 2011, the historical mistrust among the area hospital systems, health plans, and provider groups gradually diminished. One of the causal factors for the erosion of mistrust was the result of transparency among 
the participating organizations, mainly the health plans and hospitals. The creation of Health Share provided a concerted and intentional opportunity for these organizations to be transparent about financing and cost of services as well as working towards developing a budget and making decisions about how to allocate funding across the partnering organizations. In order to engage in decision-making, the financial figures needed to be transparent and shared among the entire board. Historically, the financing and reimbursement models and formulas between hospitals and health plans were proprietary and closely guarded secrets.

The transformation funds ${ }^{21}$ created an opportunity for the board to engage in priority setting and to facilitate collective decision-making. The Oregon Legislature allocated $\$ 30$ million as "Transformation Funds" to support CCOs with investing in an array of projects through a grant program. The priority-setting also helped the board develop collective values. One executive staff member commented that, "The transformation funds have been a really good thing.... an opportunity for the boards to figure out who they are and what they want to be" (ID 7).

The commitment among the executives of the large hospitals and health systems was key in the collaborative process. These individuals invested many hours. The shared understanding created through the face-to-face dialogue and enhanced trust among the board members has been beneficial to the board in its ability to engage in collective decision-making on behalf of the $\mathrm{CCO}$, in an open and transparent process.

${ }^{21}$ https://olis.leg.state.or.us/liz/2014R1/Downloads/CommitteeMeetingDocument/34299 
OREGON HEALTH REFORM AND COORDINATED CARE ORGANIZATIONS 152

Dialogue improved their understanding of each other's operations in many ways beyond just this relations and whether and where they're coming from. They're still competitors but there's a better appreciation and trust-I mean, you talk to people face-to-face regularly, you develop trust. (ID 11)

One of the coolest things I've seen from a governance perspective is when you see health plans talking like members and members talking like providers, and providers talking like health plans, all around the table. (ID 13)

As Oregon's largest CCO by number of OHP enrollees, Health Share offers a number of insights about key factors that contribute and impede the ability of these newly formed organizations to effectively engage in collaborative governance. The founding members may influence the decision-making process, particularly the allocation of resources in the coming years. The founding members also serve as the risk-accepting entities (RAEs), which have direct control over Health Share through executive decisionmaking. This governance arrangement is unique to Health Share. One of the challenges or impeding factors identified among participants is ensuring that all 20 board members are well informed and engaged. This challenge is partially the result of the technical sophistication and expertise required to operate and oversee an organization with this level of complexity in a rapidly changing and growing organization.

Another potentially impeding factor is the inherent conflict among board members and their partner organizations. Members of the board are responsible to both Health Share and the boards of their "home" organizations, which could present a challenge in terms of dual accountability when the interests of Health Share are in 
OREGON HEALTH REFORM AND COORDINATED CARE ORGANIZATIONS 153

conflict with one or more of the partner organizations, especially those of the "founding members." In terms of functioning, the board has evolved over the past 12-18 months. It is no longer as directly involved in the immediate oversight of the operations of Health Share and has defined the board's relationship with the various advisory entities.

The starting conditions of Health Share significantly influenced the early formation of the CCO. The prior history with the Health Leadership Council and the TriCounty Medicaid Collaborative served to help the partners of Health Share develop relationships, understand different aspects of the health industry, and most notably, do away with historical mistrust by establishing relationships among the regional leaders in the Portland Metro area.

\section{Case Two: Willamette Valley Community Health}

The Willamette Valley Community Health (WVCH) CCO is located in the Salem area with the majority of OHP members in Marion and then Polk counties, respectively. The CCO was formed as a limited liability company (LLC) as it "provides the greatest degree of flexibility" (unpublished operating agreement, p. 2). Specifically, an LLC allowed for local governmental entities, nonprofit hospitals, and for-profit organizations to participate without violating state or federal regulations.

Composition. The organization is comprised of 13 public and private organizations or "member organizations" and are listed in alphabetical order: ATRIO Health Plans, Capitol Dental Care, Marion County, Mid-Valley Behavioral Care Network, WVP Health Authority, Northwest Human Services, Polk County, Salem 
Clinic, P.C., Salem Health/Salem Hospital, Santiam Memorial Hospital, Silverton Health, West Valley Hospital, and Yakima Valley Farm Workers Clinic.

Another important aspect to composition is the size of the governing board or "board of directors." WVCH consists of 19 individuals who are executives from nonprofit and for-profit hospital systems, local public health agencies, health plans, and social service based organizations. As with Health Share and in accordance with legislation, the chair of the $\mathrm{CAC}$ also serves as a full member of the $\mathrm{WVCH}$ governing board. The individual board members' competency consists of primary senior level executives who are highly trained, educated, and skilled in the financing and delivery of health care services. Similar to Health Share, WVCH's clinicians make up the remaining composition of the board. Members of the board are CEOs and executive directors of partnering organizations with years of experience providing physical and mental health services, operating health plans, and managing risk.

Structure. The structure of WVCH consists of a governing board referred to as the "board of directors." The board has established two advisory councils and one committee: the community advisory committee (CAC), clinical advisory panel (CAP), and the Health IT Committee. The primary role of the CAC is to "ensure that the health care needs of the consumers and the community are being addressed, provide strategic direction to the governing body, and to develop recommendations to WVCH." The CAC is comprised of 18 members. ${ }^{22}$ In addition to the standing advisory entities, the organization has also established three sub-boards: finance, audit, and provider contract

${ }^{22}$ CAC Roster: http://wvchealth.org/images/pdf/CAC_Roster.pdf 
committees. The structure is somewhat complex, but more importantly, the advisory panels and sub-boards have undefined responsibilities in relation to the board. Initially, the CAP was comprised of approximately 20-30 members, a large advisory group that gradually scaled down to a more manageable number (less than 20 members).

Control. The WVCH is largely controlled by the WVP Health Authority, formerly the Mid Valley Independent Physician Association (MVIPA), which still represents over 500 providers, mainly primary and specialty providers but now also four community hospitals across Marion and Polk counties. ${ }^{23}$ The WVP Health Authority is governed by a 15 member board comprised entirely of physicians. ${ }^{24}$ The WVP Health Authority is an Independent Physicians Association (IPA) that has contracts with behavioral health providers, community hospitals, and specialty providers in Marion and Polk counties. The WVCH board is staffed by the WVP Health Authority with a centralized model: The board has all decision-making authority. The advisory subgroups serve as advisory entities to the board but do not have decision-making authority. Members indicated that the board does not have a change strategy and were unable to act upon recommendations from either the CAC or CAP.

There are 13 organizations who know how to do this but you need one organization and I don't mean pick one of the 13; the 13 have to become one. Legally they're one. (ID17)

I know across the state that typically an IPA or a hospital system has been the dominant character. And in Salem, it's been a firefight. It's calming down and

\footnotetext{
23 http://www.wvphealthauthority.org/

${ }^{24} \mathrm{http}$ ://www.wvphealthauthority.org/board-members
} 
starting to become more functional, but in the beginning it was like, who's going to own this thing? (ID 16).

The CCO has agreements with the local mental health and public health authorities (LMHA and LPHA) in Marion County. ${ }^{25}$ One issue that emerged during the interviews relates to responsibility and accountability by the LMHAs and LPHAs within the WVCH CCO. Specifically, public officials have stated that the LMHAs and LPHAs are responsible and accountable, as specified in legislation and statutorily required, to ensure the overall health and safety of Oregon's communities. ${ }^{26}$ A number of respondents repeatedly referenced the issue of "shared responsibility." To resolve the issue of "shared responsibility," Marion County required WVCH CCO to enter into an agreement that specified the responsibilities between the local health authority and the WVCH board. Specifically, the LMHA has the authority to advise WVCH on adult behavioral health, children's systems of care, public health, and cross-system coordination for all publicly funded and mandated community-based services in Marion County.

The agreement also specified that $\mathrm{WVCH}$ is responsible for the following functions: maintaining sufficient funding for mental health services; maintaining existing levels of support for addiction treatment services for OHP members; ensuring long-term follow-up care; supporting the use of non-traditional health workers; coordinating with emergency medical services (EMS) agencies; providing health data to public health

\footnotetext{
${ }^{25}$ http://www.co.marion.or.us/NR/rdonlyres/88712ECB-F183-4607-AE38F9543C73733F/45557/2012CCOAgreement1.pdf

26 The Local Mental Health Authority has statutory authority under ORS 430.620 to operate a community health programs. ORS 431.412 statutory requires that the LPHA provide public health services. ORS 414.153 directs that there be a written agreement between all 16 CCOs and the local health authority in areas served by the CCO.
} 
agencies; supporting transparent governance, including information sharing and performance metrics for $\mathrm{WVCH}$; and evaluating cost-sharing for OHP members.

Based on internal documents, including unpublished meeting minutes shared with the researcher, after a year into the creation of $\mathrm{WVCH}$, the board was still working to address the following issues: (1) unclear structure to support the various committees, including a lack of alignment between the existing committees and the strategic focus of the board; (2) absence of a permanent executive director after the founding executive director resigned; (3) lack of clarity among the board roles, responsibilities, and strategic direction, which were not clearly defined or set; (4) lack of clarity about the accountability of the board; and (5) minimal interest in community involvement and public engagement.

In September 2013, the governing board participated in an all-day retreat. The intent of this "strategic planning" retreat was to provide members with an opportunity to consider the organization's mission and purpose, identify and share accomplishments, assess the quality of the board's process, including suggestions for improvement, and share the most significant issues and concerns facing the organization and members. The board and advisory committees do not coordinate or interact in a structured and wellfacilitated way, to the point of being referred to as "dysfunctional." Towards the end of the retreat one of the board members stood up and said (according to one interviewee), "This is the most dysfunctional group of people I have ever worked with" (ID 18).

That's part of the challenge right now for $\mathrm{WVCH}$... really discovering its identity as an organization. (ID 20) 
The main activities of the board have been reviewing metrics, passing budgets and allocating finances across the partnering organizations, including disbursement of transformation funds, and voting on contracts. These three activities, all technical in nature, have been the focus of the majority of board meetings during the initial year of operation. One of the reasons for this was the 2013 lawsuit involving Salem Health and WVCH.

We rarely talk about clients and what's going on, or strategies or things like that. Initially, we were dominated by the lawsuit, which threw everything back, but now at last it's resolved, we're still...stuck in looking at numbers and that type of thing. (ID 18)

We have been spending the lion's share of our time talking about contracts and budgets. (ID 17)

Functioning. In terms of function, the board of directors has the authority to manage and conduct WVCH's operations and budgetary oversight as well as set the policy and direction of the organization. The WVCH board has two unique characteristics related to voting rights, executive decision-making, and authority. First, the two counties represented on the governing board have "veto power," which is referred to as a "special vote." Any decision put forward by the board for a vote can be vetoed if the two counties do not both support the proposed decision. The second unique characteristic is that the hospitals have "increased representation." The four hospitals represented on the board are allocated two votes each. Any approval of the operating and capital budgets and contracts requires a "supermajority" or approval by at least $70 \%$ of the "owning interests" and at 
least one of the public partners, i.e. the counties. Consequently, the board may take action on an item with $70 \%$ of members in favor but if both of the county represented members vote no, the issue is considered vetoed by the board.

In fact, there is veto authority on the part of the counties over anything the LLC does. No county has that kind of influence. (ID 15)

The hospital positions on the board also have weighted authority to influence the decision-making process, but the remaining "represented" members of the board have single votes. Represented members are the organizations that provided capital during the formation of the CCO. The agreement was that each member would have a vote and contribute an equal share towards the initial capital costs or reserve account required by law for each CCO. Interestingly (and described in the next section), the board was created with two county positions, neither of which contributed to the capital reserves.

\section{Collaborative governance.}

Starting conditions are just given.... There's nothing the legislature can do about that history. (ID 15)

Starting conditions. CCOs are likely influenced by any number of external environmental factors, beginning with the initial starting conditions that ranged from political, legal, and economic issues. For the purposes of the study, three main concepts emerged relative to the primary concept of starting conditions: (1) history of conflict or cooperation, (2) power-resource imbalance, and (3) incentives and constraints on participation. 
OREGON HEALTH REFORM AND COORDINATED CARE ORGANIZATIONS 160

The starting conditions for WVHC were challenging primarily due to the history of conflict in the Willamette Valley region. Salem is the second largest metropolitan area in Oregon and home to the state's capital. Prior to the passage of the CCO-enabling legislation, there had been a history of conflict between the local IPA (MVIPA) and the area hospitals, especially with Salem Hospital. During 2012-2013, state officials were involved in discussions in Salem about forming a CCO to the point of offering mediation services between the majority of the founding partners and Salem Health, the local forprofit hospital that operates Salem Hospital and West Valley Hospital in Dallas, Oregon. Conflict between physicians and hospitals, however, is not unique to Salem or Oregon. Physicians and hospitals are often in conflict due to competing economic interests coupled with the historic consolidation of hospitals and physician groups. The historical strife became a focal point with the creation of $\mathrm{WVCH}$. According to one participant, there was "a tremendous history of animosity between the leadership of the physician's association and the leadership of Salem Hospital” (ID 15).

In Salem, historically, the physician association operated as a fully capitated health plan through which the area hospitals were reimbursed. Salem Health sued the newly formed WVCH over the proposed new reimbursement methodology. The lawsuit lasted approximately seven to eight months during 2012-2013. During this litigation, state officials introduced House Bill 3309, referred to as the "bad actor" bill, in the Oregon Legislature. Salem Health did not want to transition to a global budget payment model for serving covered lives in Medicaid. The change in reimbursement model—from a fee-for-service method to a global or capitated model — was not acceptable to Salem 
OREGON HEALTH REFORM AND COORDINATED CARE ORGANIZATIONS 161

Health. Members of WVCH perceived that without a capitated payment model that included Salem Health, which owns two of the four regional hospitals, the newly formed $\mathrm{CCO}$ could not structure an accountability mechanism needed to manage the global budget. Interestingly, Salem Health did not perceive sufficient incentives to participate on the governing board, which WVCH interpreted as an unwillingness to help reduce and control costs in two of the four regional hospitals.

State officials became involved by proposing legislation that would allow a twothirds majority from a CCO governing board to remove a member with approval by the director of the Oregon Health Authority (OHA). If passed, WVCH could continue to contract with Salem Health for services, but Salem Health would not serve on the governing board and thus would be unable to participate in the CCO's decision-making process. The underlying issue was a power imbalance between WVCH and Salem Health because two of the four regional hospitals in Marion County were owned and operated by Salem Health, which had the leverage to request a preferred reimbursement model from WVCH. Historically, a sizable portion of OHP members received inpatient services from Salem Health. The economic power imbalance between the CCO and the local hospital system created a dynamic that resulted in litigation. Salem Health did not perceive an incentive, financial or otherwise, to participate in the newly formed organization. However, WVCH was incentivized for Salem Health to join the CCO because two of the four hospitals in the region are owned and controlled by Salem Health. During the 2013 legislative session, Governor Kitzhaber agreed to sign the bill, if passed. At that time, 
OREGON HEALTH REFORM AND COORDINATED CARE ORGANIZATIONS 162

Salem Health agreed to mediation with WVCH. The result was that Salem Health was given two votes on the WVCH governing board, one for each hospital.

A second area of conflict that emerged in the creation of WVCH was between the private and public entities that serve on the governing board. The conflict stemmed from the issues of control, public trust, and accountability. The local county public health and mental health authorities were concerned about ceding authority and control to a limited liability corporation. The issue also stemmed from another power imbalance, this time between the local county authorities and private organizations working to form the CCO.

There's a lot of regional work going on around the state. There's a perspective among the counties that the regionalizing of this is really designed to kind of cut counties out. (ID 18)

From the local authority's perspective, the issue was changing the longstanding and historic relationships between the state and county governments and their constituents, and forming a new and unfamiliar relationship between a CCO and county government. At question was whether the counties would continue to receive public funding for public health, mental health, and social services and continue to be held responsible for the provision of such services, or contract with a CCO to provide them. Local county officials expressed concern that over the long run, the existing infrastructure supported by state and local taxes, which had been developed over decades, would be gradually dismantled. As one participant commented, "If this whole system fails and people aren't served, generally they end up in the public safety system - a much more expensive system that really isn't designed to care for them" (ID 17). 
"Responsibility" in county government was an underlying theme for WVCH. County government was considered accountable to both the local citizens by elected officials and to the state through existing laws, which mandate that county governments ensure provision of basic services that span public health, mental health, and social services, including protecting individuals and families with disabilities. The role and function of county government was perceived as being under scrutiny.

After a series of meetings in which each partnering organization brought legal representation, the issue was resolved through a memorandum of understanding between the two area counties, Marion and Polk, and the WVCH. This arrangement influenced the collaborative process because the two county officials who served on the governing board were skeptical of the goals and objectives of the newly formed CCO. They were concerned about the financial risk and, specifically, funding that was historically allocated to support public health and mental health services would now be redistributed to the $\mathrm{CCO}$. If $\mathrm{WVCH}$ were to fail, then the existing public infrastructure maintained by the counties would be placed at risk, taking over the public health and mental health services if failure occurred by the $\mathrm{CCO}$. The resolution was to finalize an operating agreement between the two counties and $\mathrm{WVCH}$, in which the two counties were ceded authority and did not have to serve as a capital partner, a requirement for the other partnering organizations to participate.

The idea that you can take, for example, the mental health funds and transfer them to a private provider blending in with general care, then the county still has 
statutory responsibility or health, and the money is over here, how does that work? (ID 15)

Although this conflict was settled, the outcome was mistrust between the two counties and members of the board.

County commissioners... were negotiating with a bunch of people that run hospitals and doctors, and we're seeing that maybe we'll get lost in a power struggle. (ID 18)

It also provided the two counties with authority and influence in the decisionmaking process, which influenced their control over the board's governing process. If you have a regional body [CCO] that is quasi-private, partially public, with multiple counties, there's no legal governance entity that has authority that is equivalent to what the state authority is. (ID 18)

Institutional design. Public involvement at the local level included broad participation among more than a dozen organizations prior to forming $\mathrm{WVCH}$. Community partners were invited to a number of meetings to participate in the initial discussions around forming a CCO in the Salem area. These meetings were inclusive and included the area "power players." The early planning conversations were initiated to discuss and develop consensus on the organizational form. The participants in these planning conversations decided on a limited liability corporation (LLC), which would allow county commissioners to participate. The form also offered a perceived legitimacy from the standpoint of creating a new organization in which private and public partners were "equal partners" on the board. 
OREGON HEALTH REFORM AND COORDINATED CARE ORGANIZATIONS 165

Since the CCO was formed and the lawsuit transpired, the board meetings are no longer open or transparent. As described by a board member, “Transparency: It's a code word for Salem Hospital wanting to know some things..." (ID 15).

An interesting theme emerged about board composition and dynamics. The issue is an inherent tension among board members of the $\mathrm{CCO}$ who are the same board members responsible to their parent organizations' boards. This dynamic complicates goal setting and decision-making by the board. The inherent conflict is that decisions and resource allocations made by the CCO governance board and its members can negatively impact one or more of the partnering organizations financially, which creates a conflict of interest for those board members. This dynamic is occurring in an environment without a significant amount of trust among board members who represent hospitals, counties, and physician associations.

They still operate independently. The board members, they're representing the bottom line of their agency at the same time representing the bottom line to the CCO. It's a balance between the collective good versus the...you know, I'm the CEO of my entity and am responsible to my own board. Board members of the CCO are responsible for the bottom line of their organization. (ID 20) It is clear there is an inherent tension and conflict present in the governing board's control structure.

Facilitative leadership. The founding chair of WVHC worked with community partners to find a resolution with Salem Health. Through engagement with both community partners and senior executives of Salem Health, the founding chair worked to 
OREGON HEALTH REFORM AND COORDINATED CARE ORGANIZATIONS 166

mediate the dispute regarding the model for reimbursement. After several face-to-face meetings with Salem Health staff, the chair and members of the board were not well received by senior executives of the hospital system. Based on the interviews, the president of Salem Health declined to participate in a series of discussions that transpired during the initial formation of the $\mathrm{CCO}$, opting to not engage with the WVCH board or commit to a resolution process.

After approximately one year, the founding chair of $\mathrm{WVCH}$ resigned. The WVCH board has yet to recruit and hire a new full-time permanent chair, and the lack of leadership has created a few challenges. One theme was empowerment or lack thereof. Members of the board are not often provided information in a timely manner. The knowledge base and expertise among the board was described as lacking, in particular for those members not well versed in health care operations. In order to have a functioning board, members require actionable information offered through a facilitated process. Without a permanent director, and with WVP Health Authority actively leading the board in terms of agenda setting and managing the advisory board(s), the ability to engage and empower the board has been absent. For example, the board often does not receive meeting materials or minutes from the two advisory groups. The acting chair appears to not value inclusiveness or be open to an extensive process and dialogue during board meetings. This has limited the board's ability to explore issues or encourage trust between non-physician provider organizations and WVP Health Authority. 
OREGON HEALTH REFORM AND COORDINATED CARE ORGANIZATIONS 167

The IPA, the hospitals, and health plans, they're already cutting deals all over the place for the PEBB agreement... I know there's a lot of backroom deals going on. (ID 16)

The founding chair was viewed as having influential leadership, although no direct authority. The loss of the first chair of the board, which was tied up with the lawsuit initiated by Salem Health, created considerable distrust and an environment that was neither transparent nor open in terms of process and participation by community members beyond those serving on the governing board. Adding to this conflict was the relationship of board members and their parent organizations, which are privately held and operated, working with public agencies that have a culture of "open and transparent" decision-making processes.

There were a lot of issues by commissions about open meeting laws about what you share and not, what's transparent or not—counties run a little differently. (ID 16)

When we get a new executive director, there's going to be a bit more balance in terms of the conversation and maybe a bit more conversation and maybe more around the work of the $\mathrm{CCO}$ in terms of its responsibility to reform health care. (ID 19)

Among the board members are a number of local competitors who have historically competed against one another in the Salem area. The board has the responsibility for reviewing contracts, which requires a level of transparency and openness among board members. Several member organizations expressed concern that 
the level of transparency required to review the contracts would offer a competitive advantage to those around the table. Furthermore, WVP Health Authority has contracts with local service providers, similar to the contracts needed by the CCO to operate and often with the same contracting organizations, which sets up a power imbalance and a perception of information asymmetry between members of the board and WVP Health Authority executives. This arrangement has also created distrust among several of the partner organizations represented on the board, and it raised questions regarding the boundaries between WVP Health Authority and WVHC.

\section{Collaborative process.}

There are still some really deep fundamental things that we just aren't in agreement on and don't get. (ID 17)

With the exception of Salem Health, the founding members of WVCH were committed to the CCO development process. Over a period of months, numerous planning meetings served as a forum for county commissions and local area health leaders to engage in a dialogue. WVP Health Authority, previously the local IPA, convened the community partners. These planning meetings, in which face-to-face dialogue transpired, helped to create trust among individuals who did not know one another previously, particularly county officials and senior executives of the private health organizations who ultimately transitioned to serving on the governing board. This process allowed relationships to develop among civic and health care leaders in the community and built trust for the partnering organizations that spanned across the public, nonprofit, and private entities. Initially, the meetings of community partners did not 
include the local federally qualified health centers (FQHCs). Another area of contention was the inclusion of Atrio, which offered Medicaid and commercial plans but not a Medicaid insurance product, and which is partially owned by WVP Health Authority. Providing Atrio a seat on the board was perceived as providing WVP Health Authority with two votes.

The theme of control was present throughout the interviews. The issue is control of the CCO by the IPA, the WVP Health Authority.

The biggest challenges have been, how do you take a successful IPA, which ran M-CHIP, the former Medicaid program, and turn that into a collaborative effort when it's been very comfortably run as a private entity? (ID 16$)^{27}$

Based on WVCH's control structure, which has a single board with decisionmaking authority, the advisory boards waited for the board to define their role and provide direction. During the first year of operation, the board did not provide direction. The outcome was twofold. First, the advisory boards were directionless, operating without any guidance or clear set of expectations or authority. Second, the clinical advisory panel lost some credibility with the board because the clinical advisory panel was not operating in connection with the board. As a result, the CAP put forward proposals that were "disconnected" from the financial realities the board was facing. The result was a loss of credibility. The CAP has gradually started to earn trust and regain credibility among the board because members of the CAP are serving on the CAC, which has resulted in crossover and enhanced communication as well as shared understanding

\footnotetext{
27 "M-CHIP" refers to Title XIX and XXI of the Social Security Act referred to as Medicaid and Children's
} Health Insurance Program or CHIP. 
between the two advisory groups. The clinical advisory panel now has a steering committee, comprised of a smaller group of individuals from the full advisory panel.

An important event transpired approximately one year after the creation of the WVCH. The organization was awarded transformation funds from the Oregon Health Authority along with the other 15 CCOs. The board was then required to focus on allocating the funds, which temporarily created a shared goal for the entire board. The decision-making process used to award proposals was unclear without decision-making principles, however, and it ultimately became contentious. The need to award the transformation funds did help the clinical advisory panel define its role in relationship to the board by focusing its efforts on putting together the transformation initiatives, which included working toward the accountability metrics set by the state. The clinical advisory panel created four subcommittees. Recently the CAP has focused on developing clinical systems and processes to achieve the $\mathrm{CCO}$ metrics.

WVP Health Authority's control of the advisory councils was a recurring issue. The CAP and CACs were both staffing these two entities. According to one respondent, "WVP Health Authority has tried to work around the committee by creating its own subcommittees" (ID 16). Similar to the CAP, the community advisory committee has not had a clear and well-defined role in relation to the board.

The CAC.... We don't totally know what we're are doing except we meet regularly and want to get in front of the board. (ID 19)

Decision-making by the board has continued to be an issue. Several members perceive that there are certain partner organizations, primarily physician groups that 
would prefer to make decisions behind the scenes rather than through a collaborative process. A secondary theme that emerged was the issue of culture among physicians, in which they are not naturally inclined, trained, or incentivized to be engaged in protracted collaborative processes, an important feature of collaborative governance. Collaboration is achieved through dialogue and process rather than a hierarchical command and control structure.

The notions of shared understanding and mission are an important factor in any collaborative process. For $\mathrm{WVCH}$, the board operated initially without a shared understanding or agreed-upon mission statement, leaving the board to govern without any strategic direction besides what is required in the OHA transformation plan. After one year of operations, the board had neither a finished mission statement nor had it adopted principles or set of values.

We're more driven by the fear of what will happen if we don't do anything than the...it's my perception, than the driving vision that this is the most wonderful thing to do. I think for everyone around the table, that we're just kind of hoping that it works as opposed to believe in our heart of hearts that this is the right way to go.... We're all here to make money. They want to make sure that they're financially solvent. (ID 18)

The prior history of conflict between Salem Health hospital and the local IPA resulted in litigation, influencing the early functioning of the $\mathrm{CCO}$ in terms of impeding the organization's ability to engage in decision-making and agenda setting for the advisory entities. The lack of trust among the partnering organizations led to an inability 
among the board to develop and adopt a mission statement and vision, to identify common problems, or even achieve a commitment to the process after a year of having created Willamette Valley Community Health CCO. The board has been challenged to define the role of the advisory boards, which had initially created a lack of credibility of the CAP among the board.

The composition and function of the board is unique in that the two counties represented on the board have "veto power." Another important aspect to the composition and functioning is that there are four hospitals represented on the board with Salem Health having two votes. The hospitals and two counties are disproportionately represented on the board in terms of influence in the decision-making process and authority over the CCO. The local IPA, WVP Health Authority, continues to staff the newly created $\mathrm{CCO}$, which has influenced the institutional design, in terms of staff controlling the information and agenda setting for the board.

The creation of the Willamette Valley Community Health CCO was led by an existing regional IPA, which influenced the structure, function, and control of the new CCO. The executive director of the IPA has been serving as the interim director for the CCO. For more than 18 months, the $\mathrm{CCO}$ has not hired a permanent executive director. The absence of facilitative leadership has limited ability of the board and CCO to function effectively and efficiently. Furthermore, the board continues to operate without transparency, with its meetings not open to the public.

The conflict among the private entities and the two counties that formed the CCO was perceived as impeding the organization's progress towards clearly defining roles and 
responsibilities for the new $\mathrm{CCO}$. Issues of control, public trust, and accountability between the two county governments and the CCO initially affected the collaborative process as the various organizations sought to develop a shared and agreed-upon understanding regarding responsibilities of county government in Oregon according to state law.

Combined, these factors have limited the board's ability to develop a shared understanding or agreed-upon set of goals and priorities, long-term, for the new CCO. The ability of the new $\mathrm{CCO}$ and its board to engage in a collaborative governance process as a means to achieve the desired outcomes of Oregon's health system transformation has not been fully realized.

\section{Case Three: Yamhill CCO}

The Yamhill County Care Organization (YCCO) was created as a new 501(c)3 nonprofit organization in a geographical area comprised of the largest percentage of open-card OHP enrollees in the state. Open-card refers to OHP members who are not enrolled in a managed care organization (MCO). In essence, there was limited Medicaid managed care in Yamhill County prior to the creation of YCCO. Compared to the other 15 CCOs, Yamhill is unique because it was not created by an existing health plan, provider association, hospital system, or other existing managed care organization. This approach was influenced by the community leadership's interest in local control and accountability.

Yamhill is the only area where there was no predecessor organization. (ID 4) 
The organization serves OHP members in Yamhill County as well as Clackamas, Washington, Polk, Marion, and Tillamook counties. ${ }^{28}$ Prior to Oregon's Medicaid expansion in January 2014, the organization served approximately 18,000 OHP members who reside primarily in the two cites of McMinnville and Newberg (Yamhill CCO Transformation Plan, 2013, p 1). ${ }^{29}$ The organization has adopted vision and mission statements as well as a set of 10 guiding principles.

Composition. The organization's partners include health plans, physical and behavioral health providers, two hospital systems, and a large FQHC. The composition of the organization consists of 14 member organizations listed in alphabetical order is: CareOregon, Head Start of Yamhill County, Lutheran Community Services, Mid-Valley Behavioral Care Network, McMinnville Imaging Associates/McMinnville Physicians Organization, Physicians Medical Center, Providence Medical Group and Providence Newberg Medical Center, Virginia Garcia Memorial Health Center, Willamette Valley Medical Center, and Yamhill County Health Department and elected officials.

The board of directors consists of 15 individuals: executives from one nonprofit and one for-profit hospital system, members of Yamhill County agencies, two regional health plans, and three social service based organizations. As with Health Share and Willamette Valley Community Health, in accordance with legislation, the chair of YCCO's CAC also serves as a member of the board of directors. The individual board members are competent senior level health care executives and public officials with decades of experience-highly trained, educated, and skilled in the health care entities.

${ }^{28} \mathrm{http}: / / w w w . y a m h i l l c c o . o r g / s u b-g r o u p / a b o u t-u s$
29
${ }^{2}$ http://www.oregon.gov/oha/OHPB/CCOTransformationPlans/YCCO\%20Abstract.pdf 
OREGON HEALTH REFORM AND COORDINATED CARE ORGANIZATIONS 175

The other members who make up the remainder of the board are health care professionals, primarily clinicians.

Structure. The organization's governance structure is comprised of three main groups that were established to conform to the state legislation. These groups include the governing board, the clinical advisory panel (CAP), and the community advisory council (CAC). The role of the CAC is to "assure communications, outreach, member engagement, and services are tailored to cultural, health literacy and linguistic needs" (Transformation Plan, 2013, p. 14). Of the 13 members of the CAC, the majority are either OHP members or family of an OHP member. The CAP is comprised of 19 members, including physicians (allopathic and osteopathic), dentists, emergency medical practitioners, and a pharmacist.

Control. The board has established a number of subcommittees within three workgroups: the board, the CAP, and the CAC (YCCO 2013 Transformation Plan, p. 3). For the governing board, there are the "alternative pay" and "finance" subcommittees. There are five subcommittees under the CAP, which include emergency department (ED) utilization, specialty care, transitions of care, behavioral health, and patient-centered medical home. These subcommittees serve as advisory entities to the board, CAP, and CAC (also referred to as workgroups). During the first year of its existence, the board of directors held periodic joint sessions with its CAC and CAP. Several of the board members also serve on the CAP, CAC, or both. Another unique aspect of YCCO is that it 
was the first CCO to apply and be designated by the state as an Early Learning Hub. ${ }^{30}$ That success was partially the result of creating the community partnership through the $\mathrm{CCO}$, which then leveraged the partnership to work towards integration of health and education services in the county.

The board was designed to be self-perpetuating, as listed in the board's bylaws, mandating that the existing board members recruit new members when a position becomes vacant or a term expires.

Yamhill created something new and decided how they were going to staff it, run it, and finance it. (ID 23)

The CAP is an active advisory committee to the board, operating without considerable guidance or direction from the board. The CAP consists of highly engaged clinicians who serve as experts within the community. The CAC has also been active since its creation, and after a year continues to meet twice a month. The CAC is comprised of community volunteers with diverse backgrounds who are actively engaged in serving on the CAC and initiatives being led by Yamhill CCO. Both the CAP and CAC operate in an open and transparent manner; their meetings are open to members of the public.

Functioning. The governing structure of the $\mathrm{CCO}$, including the board and advisory entities, operates well. There are clearly defined roles for the advisory panels and workgroups under the board. The CAP is focused on addressing the CCO incentive metrics, the CAP is leading the community health assessment, and the finance

\footnotetext{
${ }^{30}$ News release: http://www.yamhillcco.org/sub-group/news/2013/11/20/ycco-celebrates-one-yearanniversary
} 
subcommittees are reviewing the financials and assessing the revenue for the new organization. The role of the CAC has been to provide insight about gaps in the community and identify issues the CAP should address from a community-needs perspective. The CAC also developed the CCO's mission and vision statement; the CAP then reviewed the documents and provided input with a focus on the guiding principles. The board reviewed the materials and approved the mission and vision statement with the set of guiding principles.

The organization realized that it was very important that the community of the people we serve had a strong input in developing the mission and vision and guiding principles. (ID 26)

The board has facilitated meetings larger than their monthly meetings, in which the CAP, CAC, and subcommittees convene. These larger meetings have helped members engage with one another as well as assisted the various panels and subordinate committees in setting explicit responsibilities with one another and in relation to the board, i.e. clear boundary setting.

The whole board is engaged.... We've had longer, almost mini-board retreats, where we brought all the different committees together to really engage the various parts of the $\mathrm{CCO}$ in, overall look at where the $\mathrm{CCO}$ is, what are the issues, where it's going, which have also been helpful in getting different committees talking to each other. (ID 27) 
OREGON HEALTH REFORM AND COORDINATED CARE ORGANIZATIONS 178

The clinical advisory panel, the clinical vision, then the governing board approved the funding for different [community] projects that met the clinical visions developed by the CAP. (ID 22)

The explicit set of responsibilities that Yamhill needed to address was risksharing among the founding members of the $\mathrm{CCO}$. The new organization would be required to manage risk locally and not have a third party organization serve as the riskbearing entity. The organization functions under a set of "simple rules":

1. Community spirit should guide transformation.

2. Plans and projects should be data-driven and monitored.

3. Process and outcome goals should work toward the Triple Aim.

4. Payments should be based on measurable production of value.

5. Transformational plans and projects should follow the general stepwise format of

- smart standardization adoption,

- meaningful metric adoption,

- respectful reporting of metrics, and

- reimbursement development based on reported data.

6. Care transformation should focus on care coordination, cost control, and patient choice. (YCCO Transformation Plan, Feb. 2013, pp. 2-3)

According to YCCO's transformation plan, these rules were adopted by the board to guide the organization towards the Triple Aim of health system transformation. 


\section{Collaborative governance.}

There are lessons there that are really unique among the other CCOs. (ID 28)

Starting conditions. The starting conditions in Yamhill were unique compared to the other two CCOs. Prior to the creation of the CCO legislation, there had been minimal managed care in Yamhill County. The lack of an existing Medicaid managed care organization or large IPA serving OHP members created a set of starting conditions that did not spring from a history of conflict. Leadership of the local county health and human services organizations initiated a series of community meetings, inviting public, private, and nonprofit executives across Yamhill county to discuss the possible formation of a $\mathrm{CCO}$. Not having a large or dominating $\mathrm{MCO}$ or IPA in the county meant there was not a power imbalance or struggle among existing health plans, IPA(s), or the local area hospitals.

Yamhill County probably had the least penetration in managed care of all the different other counties in the state. That means there was not the experience from either the providers or from the patients of being in a managed care environment, nor was there a lot of data to share. (ID 27)

This was a "hallmark" starting condition for the CCO. The majority of providers that served OHP members prior to the creation of CCOs were reimbursed on a fee-forservice basis; however, a considerable number of local providers opted not to see OHP members.

We should go back to the mid-90s and the creation of the Oregon Health Plan, and the fact that the Yamhill physician community, which at the time was largely 
OREGON HEALTH REFORM AND COORDINATED CARE ORGANIZATIONS 180

an independently-run, individual business model in the McMinnville area, anyways (and somewhat Newberg), was resistant to the Health Plan, was resistant to serving Medicaid patients, reimbursement, client population/demographics... (ID 21)

The idea of forming a CCO and moving to a global budget did not provide a financial incentive for area providers to participate.

I think initially having these organizations step up to the plate for the betterment of the community and willing to take on this additional work and deal with that, they're not easily earned dollars dealing with the Medicaid population, I think has been a real driver. (ID 26)

As a direct result of the vacuum of any MCO or large IPA in Yamhill County, the community had an opportunity to collaborate and envision what a CCO might look like in the county. Through a series of public meetings, which were inclusive, open, and well attended by community leaders and interested stakeholders, the participants explored different organizational forms and ultimately agreed to create a 501(c)3. The rationale for a nonprofit rather than a limited liability corporation was that community partners believed it was important to operate a nonprofit rather than a for-profit enterprise. Another reason was that it would be easier for counties to participate in the CCO if formed as a nonprofit rather than an LLC.

After the participants opted to establish a 501(c)3, the head of the county mental health department, who had been facilitating the series of public forums, asked the entire group of executives and local leaders whether they would participate in the CCO. The 
participants unanimously agreed and committed to form a CCO. Many of these same participants had not previously been champions of Medicaid in their community. The level of participation was notable among the interviewees. The steering committee grew from the community meetings and gradually transitioned into the governing board once Yamhill CCO was established. The steering committee also served as a forum; a number of conversations were facilitated early on regarding infrastructure decisions, composition, and ownership models.

What I saw as key was everybody's dedication. Especially in that steering committee and then the governing board, especially in the beginning. We had, I think, I think there were bimonthly meetings, for months, like two to three hours. So it was a big time commitment. And then, time and time again, everybody was showing up, everybody was there and was talking and it wasn't hostile at all. I mean, I think, in the beginning, people were kind of very willing to acknowledge their ignorance. (ID 22)

I'm going to go around the table and say, "Are you in this or not? Are we going to do a CCO?" And everybody said, I'm in and here's why. (ID 24)

The incentive for agreeing to participate in the $\mathrm{CCO}$ was described as wanting to help the local community. There are two hospitals in Yamhill County, a for-profit and a nonprofit. The CEO of the for-profit did not foresee any financial incentives to their hospital for participation but still agreed to participate, which surprised several of the local health care leaders. 
The Yamhill CCO provided a forum for us to start problem-solving around this and we were able to come up with a plan. Now those things wouldn't have happened, at least not without a structured environment, so I think that's been helpful. (ID 27)

Institutional design. The member organizations that partnered to create Yamhill are not at financial risk, which to some extent is unique compared to the other CCOs. From an incentive-to-participate perspective, not exposing one's organization to financial risk from participating in the $\mathrm{CCO}$ is significant. As one board member commented, “They all recognize that on a community level, they're all at risk. They need to make decisions that are beyond what's good for their own organization" (ID 23). In Yamhill, the providers individually are not at financial risk. The risk, if they were here, what they would say is the risk they have is that their payment is far below their cost, in Medicaid. And they would be right. They don't have... No individual provider or hospital or clinic is at risk if Yamhill CCO loses moneythere's not a direct correlation to the provider losing money. So technically, none of those providers are risk-accepting entities. The organization is at risk. (ID 23) The lack of an existing health plan or MCO in the area resulted in needing to either build the necessary administrative infrastructure required to operate a health plan or contract with a third party to provide administrative services. The early partners in Yamhill CCO held a series of meetings with two managed care organizations in Oregon that had historically served OHP clients. The meetings were designed to assess whether one of the two organizations would contract with Yamhill CCO to provide administrative 
services, referred to as "infrastructure partners." The governing board decided early on it was in the interest of the organization to maintain local control rather than be a subsidiary of another organization such as a health plan or IPA.

The key to Yamhill is that the community came together and decided very early on that they were only going to have one $\mathrm{CCO}$ and that they were going to steer it — in fact they called it a steering committee. So they were very intentional from the beginning about some of the things that were important to them - that it be locally-driven, that it be Yamhill County, and that the leadership of Yamhill be the one to drive some of the decisions. (ID 23)

Yamhill CCO said, "We're expected to run our own business, we are going to be our own organization.” (ID 24)

The community strongly valued the notion of local control. The preference to maintain local control served as a mechanism to develop consensus and build an initial set of principles and values that the majority of participants could endorse. As one member described it, "No matter what we ought to have, local control and design, that was our strongest asset, community cohesion" (ID 21).

The guidelines for participation with Yamhill were that any contracting organizations would provide services, either administrative or clinical, but would not have significant influence or control over the $\mathrm{CCO}$, compared to other CCOs that were largely managed by a health plan, hospital system, or IPA. The board decided that local control and autonomy from parties outside of the region were of paramount importance. One example was that Yamhill CCO opted to directly hire an executive director who had 
previously been working for the organization that was contracted to provide administrative services. The $\mathrm{CCO}$ delegates administrative functions to a third party organization through contracting, which includes customer services claims, billing, and related insurance administrative functions. The $\mathrm{CCO}$ was concerned about to whom the executive director would be responsible: either the $\mathrm{CCO}$ or the administrative services provider (ASP).

After several conversations and discussions about executing an agreement with an ASP, and in order to solve the issue, the CCO decided to hire the individual who had previously been serving as the regional director in Yamhill on behalf of the ASP, CoverOregon. A member of the ASP also serves as a member of the governing board. I think that's actually quite unique within the state in terms of provider groups and the community coming together and saying, "Ok, we're going to do this and we've got a plan, but this is going to be a locally controlled process." (ID 22) Creating the $\mathrm{CCO}$ offered a new forum for community providers to engage in dialogue. The CAP in particular has brought together provider groups that now interact and discuss population health across the different systems, which had occurred prior to the CCO. As stated by one board member, "This is our opportunity to address substance abuse in our community, providers in our community...this is our opportunity." (ID 21) An unprecedented level of enthusiasm now exists, at least in a coordinated and actionable manner that resulted from engaging a diverse group of providers, i.e. individuals who volunteer their time to serve on the CAP. 
The CCO has generated this collaboration and coming together and talking about everything from access to behavioral health and integration, to screening, or substance abuse within primary... and is getting the community mobilized and thinking about the Triple Aim. (ID 27)

Facilitative leadership. Prior to the creation of the Yamhill CCO, a small group of leaders in the community were closely tracking the CCO legislation, starting with House Bill 3650 passed in 2011. Several months after the 2012 legislative session, a county commission convened a meeting in September to kick off the community conversation about creating a $\mathrm{CCO}$ in the county. Early on, local officials in the community took an active leadership role in engaging and convening community partners around forming a CCO. The county served as the intended neutral convener for the early planning conversation with health care leaders in the community.

Facilitative leadership was instrumental in the creation of Yamhill CCO. Leaders within the $\mathrm{CCO}$ have engaged public and private organizations and actively sought to engage a broad and diverse set of stakeholders across the county, with a targeted focus on hearing the voice of consumers. For example, $\mathrm{CCO}$ leaders facilitated a series of public forums and community meetings attended by individuals from across the community. Since forming the $\mathrm{CCO}$, the organization continues to hold community forums that bring together the local partners, members of the governing board, the CAP, and the CAC, along with interested stakeholders including local officials. 
The things that have impressed me about Yamhill, beside the leadership, is the openness and transparency with which they’ve interacted with the community partners, providers, and the hospitals. (ID 28)

The leader behind the genesis of Yamhill was the Director of Yamhill Health and Human Services. In contrast to other CCOs, the leader was not a physician or part of a health plan, but had an extensive background from a government perspective in public health and social services.

The leadership within the CCO was frequently referred to as "visionary." The evident strong leadership at the CAP and CAC level has helped with engagement, an important and defining feature within Yamhill CCO. The organization continues to be engaged with its partner organizations and the broader community. Interestingly, physician and provider organizations that historically had not been actively involved in Medicaid did become "involved and really engaged" through the community meetings and visioning process that resulted in the $\mathrm{CCO}$. This engagement likely led to a considerable level of physician participation in the CAP. One of the participants shared a reaction from a meeting attended just prior to the interview, which was a meeting of a subcommittee of the CAP:

I couldn't believe it. I showed up.... I thought I'd be one of four people. I walk in and there's people from public health, there's people from this community hub, people from Virginia Garcia, their head administrator, people from the hospital calling in, people from physicians' medical centers, this private primary care clinic there, so...pretty exciting. (ID 26) 
Yamhill was a little slow to come to the game, but they did via very strong leadership and a very collaborative, community-focused, organic, initial investment and gathering of individuals. (ID 28)

As previously described, the board, CAP, and CAC conduct open meetings. According to one board member, "Within the $\mathrm{CCO}$, at the board level or finance committee levels - the financial transactions and the nuts and bolts are very transparent" (ID 23). Although the CCO is not subject to Oregon public meeting laws, the leaders of the board, in particular those who serve in an official public capacity, value openness and transparency as part of encouraging participation and ensuring that an inclusive process is supported by the board and various advisory committees. The one exception is when the board needs to hold an executive session, which can be held if sensitive personal or private information will be disclosed among board members.

Collaborative process. The collaborative process that resulted in the formation of the CCO was extensive, inclusive, and deliberate. Through the series of public forums and community meetings, the leadership of the CCO was able to become established by convening organizations and local leaders that had not historically collaborated beyond one-time initiatives. In addition to helping build trust, the face-to-face meetings also fostered a shared understanding about the opportunity for the community by creating the CCO. Community partners perceived a unique and unprecedented set of circumstances that could be "leveraged" to improve the health and well-being of Yamhill County residents. Over the past 18 months, the local medical community developed a different, 
broader understanding about health versus health care and is starting to think beyond the traditional model of medical care in the community.

The collaborative process has been used to facilitate dialogue, develop relationships, and foster trust within the community. It also helped create a shared understanding in Yamhill about the role and function of county government, local public health needs, the interconnection between physical and mental health providers in the community, and the value of working together as a community to address the unmet health needs of OHP members.

In the beginning, we really didn't know what public health did. We didn't know what the Department of Health and Human Services did.... I had no clue they had three different divisions and what all they did. So, we really had to educate ourselves on that. On the same token, a lot of people in behavioral health, they don't know what physicians do. And we're still learning a lot from each other. (ID 26)

The efforts in Yamhill really came about in a very grassroots sort of way. It was really though a series of community meetings that were convened by the county. (ID 25)

This is a local community stepping up and taking on something here, and I think quite extraordinary in terms of a new approach to managing the care and benefits for this population. (ID 27)

Yamhill is distinct from the other two cases in that the newly created 501(c)3 nonprofit organization was not formed by an existing organization. Furthermore, the 
creation of Yamhill was largely the result of local leadership among officials with Yamhill County government. Also notable as a starting condition, compared with the other two cases, was that there was minimal managed care present in the region prior to the creation of the CCO. The majority of Medicaid enrollees were not enrolled in managed care for physical health services. Without a dominant MCO or IPA, there was not a perceived power imbalance among the local area providers or health care organizations, including the hospitals. Lastly, Yamhill was one of the last CCOs certified by the OHA. The community purposefully sought to take sufficient time to develop trust, build relationships, and foster identification of shared values among community leaders prior to legally establishing the CCO.

Through a comprehensive and intentional strategy of engaging the community and seeking participation through a collaborative process, the partnering organizations developed a shared understanding and commitment to assume responsibility for the health and well-being of those covered by Oregon's Medicaid program. The local leadership in Yamhill was instrumental in the creation of Yamhill CCO. The presence of collaborative processes facilitated by local leadership served as a key factor that influenced the effectiveness of the collaborative governance model adopted by the CCO.

\section{Limitations}

The research design for this study has a number of limitations. First, the scope of the study is limited to specific geographical regions, i.e. only three of the $16 \mathrm{CCOs}$, each with their own unique historical context, political culture, and community norms that ay not be applicable to other regions in Oregon or the country. Subsequently, themes 
identified from the three cases may contain some geographical, cultural, political, or normative bias that may limit the generalizability of any conclusions. Also, the limited number of interviewees from each $\mathrm{CCO}$ provides only a partial picture about the emerging CCO governance models. Furthermore, due to the limited number of cases selected and minimal number of respondents, the transferability of some of the conclusions in regard to collaborative governance serving as an effective model is limited at best. The more subjective nature of this research may be viewed as less rigorous than a quantitative research design and may open the research study's conclusions to considerable scrutiny. Finally, the research design does not lend itself to analysis of the data over a lengthy period of time, which may decrease the dependability and confirmability of the conclusions offered in the study.

Role of the researcher. One potential sensitive issue was the researcher's role as an employee with the Oregon Health Authority, which oversees the state's Medicaid program. This role likely helped in the level of access and responsiveness among state officials, all of whom agreed to participate, including the three Innovator Agents with the OHA's Transformation Center. Innovator Agents are employees of the Oregon Health Authority and provide technical assistance to CCOs, help foster the spread of best practices among CCOs, and serve to help facilitate issue resolution among CCOs. ${ }^{31}$ Only one $\mathrm{CCO}$ board member was knowledgeable about the researcher's professional role with the OHA because of a prior working relationship; however, the individual was candid, honest, and open during the interview, perhaps due to pre-established respect and trust.

${ }^{31} \mathrm{http}: / /$ transformationcenter.org/innovator-agents/ 
No other interviewees were aware of the researcher's role with the OHA or the Oregon Medicaid Advisory Committee. Therefore, the researcher did not notify the interviewees that he was an employee of the OHA until after the interviews had been conducted.

\section{Conclusion}

The findings regarding collaborative governance resembled Ansell and Gash's (2007) variables: institutional design coincided with CCO institutional design, relationship dynamics with CCO collaborative process and facilitative leadership, starting conditions and history of conflict or cooperation, and collaborative governance and trust building. Ansell and Gash (2007) identified that future research may be most fruitful in examining natural experiments or actual cases of collaborations, and especially comparative examination of multiple independent cases. This study provides recommendations (described in Chapter 5) for future policy that seek to develop an overarching framework for the purposes of collaborating on complex social challenges. Collaborative governance is an interesting and promising approach for addressing the need for more efficient use of both public and private resources as well as the need for consensus-based decision-making among stakeholders across nongovernmental and governmental organizations. Although the scope of this study is narrow, the implications for future research as a result of this study are broad. This analysis may be applied by future researchers to other policy contexts plagued by resource constraints and limited prior cooperation or partnership. It may also enhance management of the collective good from a community perspective through new governance models such as CCOs that span the private, nonprofit, and public sectors. 


\section{Chapter 5: Discussion, Conclusions, and Recommendations for Future Research}

The purpose of the study was to explore and understand the structure, processes and conditions in which collaborative governance facilitates or impedes the ability of Oregon's coordinated care organizations (CCOs) to integrate and deliver comprehensive health care services. Obtaining insights from CCO board members helped identify mutual goals and objectives as well as assess collaborative governance as a viable model to form new partnerships among for-profit, nonprofit, and public organizations in an effort to create new models of community-based health services. A key question was whether collaboration, through CCOs, brings together governmental and non-governmental organizations to solve "intractable problems" by establishing new public-private partnerships (Trist, 1983). Issues of governance of CCOs may serve as barriers to, rather than facilitators of, successful system integration. Specifically, governance may hinder formation, performance, and sustainability of CCOs in Oregon (Pointer, Alexander, \& Zuckerman, 1995).

The central research question guiding this study was the following: "What are the key factors of collaborative governance that facilitate or impede the ability of CCOs to implement health care reform?" Stated differently, the goal of this study was to assess to what extent, and in what way, governance enhances system integration and effectiveness and to identify areas for future research. The study also sought to describe the degree to which collaborative governance can be utilized as a new "organizing framework" or model to form productive, noncompetitive collaborations among nonprofit, for-profit, and 
public organizations to better utilize available limited resources to improve the health and well-being of those served by Medicaid.

The state played an important, if not critical, role in establishing CCOs by creating a new regulatory framework and the "necessary conditions" through public policy. CCOs are working to solve fundamental problems within the financing, delivery, and organization of health and health care services for a specified population. Results of this study suggest that collaborative governance offers a new and innovative approach for local communities to collaborate through new partnerships to set priorities, make decisions, and implement solutions to problems identified by the community. Through a new model of governance in community-based and locally governed organizations, CCOs have developed a flexible governing structure to address the needs of individual communities. In response to environmental changes, these new complex organizations serve as a promising new model with new rules, norms, and values implemented through horizontal and vertical integration and new governance arrangements.

The results of the study support existing theory and literature (Pointer, Alexander, \& Zuckerman, 1995; Savage, Taylor, Rotarius, \& Buesseler, 1997), which suggest that four broad dimensions influence the model of collaborative governance within a CCO: (1) prior history of conflict or cooperation; (2) open, transparent, and inclusive processes for stakeholders in the governing process; (3) face-to-face dialogue, trust building, and shared understanding; and (4) the functioning of an organization. However, results also indicate that maintaining stakeholder participation can be challenging due to time and cost, power imbalances and competing interests among stakeholders, and mistrust and 
lack of facilitative leadership. Furthermore, the results suggest that stakeholders' involvement in CCO collaborative governance is a dynamic process, evolving over the life of the collaboration and conflict-resolution processes during the early formation of these new organizations.

Based on two dozen interviews with board members and executive staff from three of Oregon's 16 CCOs, this study identified distinguishing characteristics of the governance of CCOs. It also explored and assessed key differences in CCO development affected by local political, institutional, and historical contexts, planning processes, and governance structure. The study also examined $\mathrm{CCO}$ board members' perceptions of collaborative governance, including the relevance of collaborative governance to the goals and objectives of the CCOs and the communities they serve. Key factors included the history of conflict or cooperation, incentives for participation among a broad and diverse group of stakeholders, power and resource imbalances, leadership, and presence of a formal structure (Ansell \& Gash, 2007). The significance of this study is that it achieved the following: (1) identified conditions that facilitate and impede the ability of CCOs to effectively solve problems through governance mechanisms, (2) developed insights into similarities and differences among three $\mathrm{CCO}$ governance structures, and (3) advanced the present understanding of the potential and limitations of a collaborative governance model in supporting Medicaid reform.

Results of the study can help to inform a larger, more fundamental question in public administration about contemporary governance: whether government through collaborative governance can create the "conditions for rule and collective action" 
through public-private partnerships to achieve policy goals (Stoker, p. 1, 1998). CCOs in Oregon offer an example of multiple layers of governing institutions (federal, state, and county) using formal authority to influence a specified set of outcomes, the Triple Aim, in a specific policy domain, health care for the poor (Forbes, Hill, \& Lynn, p. 454, 2007). This chapter discusses the implications presented by the research findings as they relate to the study's literature review. The primary research questions are reviewed and key findings are summarized. Finally, the limitations of this study, conclusions, and recommendations for future research are presented.

\section{Discussion}

In Chapter 2, the relevant literature was summarized by drawing on different theoretical foundations, including organizational theory and the notion of complex organizations within the context of health care, institutional theory and open systems, governance structure and composition, and the concept of collaborative governance. CCOs are new organizations that are responding to a rapidly changing environmentenvironments that influence organizations, structures, and outcomes (Scott, 2003). To understand CCOs, it is necessary to assess the environment, including the interactions and interdependencies or "open systems" perspective as offered by Scott (2003), which places importance on the environment. According to Meyer and Rowan (1977), formal organizations such as CCOs are influenced by institutional and cultural factors as posited by institutional theory.

Institutional theory suggests that an organization will enter into partnerships in an effort to meet legal or regulatory requirements (Meyer \& Scott, 1992). In Oregon, a new 
OREGON HEALTH REFORM AND COORDINATED CARE ORGANIZATIONS 196

"rules system" of legislation, statutes, administrative rules, and contracts was created, which mandated a new set of norms for organizing the state's Medicaid program. The outcome was the creation of new complex organizations, CCOs, which are geographically bounded organizations that collaborate through contractual mechanisms. CCOs are a "set of interdependent parts which together make up a whole," in which each organization "contributes something and receives something from the whole, which in turn is interdependent with some larger environment" (Thompson, 2003, p. 4). The Oregon Legislature, a public institution, reshaped the environment of Oregon's Medicaid system by requiring new governing functions for organizations that serve the state's Medicaid population (Scott, 2003). According to Guo and Acar (2005), the potential for collaboration is more likely among nonprofit organizations that receive public funding, which is the case with the majority of partnering organizations among the three CCOs, in particular Health Share and Yamhill.

Institutional theory also suggests that an organization's ability to survive is "improved by...conformity to the norms and social expectations of the institutional environments," which can include political and legal frameworks (Shafritz et al., 2005, p. 478). Scott (2003) states that institutional theory focuses on the notion that "organizations are open systems, strongly influenced by their environments" (p. 119). According to Scott (2003), there are "regulative" features that emphasize institutions as "systems of rules or as governance systems" (p. 135). To accomplish a given end, two of Oregon's public institutions, the legislative and executive branches, modified the environment by specifying the governance structure and collaborative model, including setting norms and 
the desired organizational form: complex organizations (Scott, 2003, p. 137). Partnering organizations recognized the new "regulative" features of Oregon's CCO legislation. Consequently, these same organizations decided to collaborate rather than continue to operate as individual entities in the new environment.

The CCOs in the study contend they serve as both "problem-facing and problemsolving" complex organizations responding to the changing environments of financing, policy, and health care delivery in Oregon. New formal complex organizations were formed in response to changes in the environment. New laws were enacted in response to the larger environment of health systems, public financing, and changes in the federal and state heath policy institutional environment (Meyer \& Rowan, 1977). Specifically, there were significant changes in resources and the dependence of organizations across Oregon on Medicaid funding. Through the Oregon legislative process and the Oregon Health Authority, a new legal and rules-based framework was established, reshaping the external environment for Medicaid services and more broadly the organization and financing for health care services for one-fifth of Oregon residents. Over time, it will be important to monitor whether the modified external environment (Meyer \& Rowan, 1977), controlled by the new regulatory framework, "stabilizes" Oregon's Medicaid system, which for decades has been buffeted by cyclical fiscal crises.

According to Scott (2003), CCOs serve as an example of organizations that combine "technical requirements with a strong public good component" (p. 140). Such organizations often have complex structures that include advisory boards and administrative structures (Scott, 2003, p. 140). One could posit that Oregon's legislative 
and executive branches (or regulative institutions) served as a "coercive mechanism" among organizations that historically constituted the Medicaid system (DiMaggio \& Powell, 1983). Either way, CCOs offer a new economic organization for the state's Medicaid system and potentially serve as a model for the larger health care system with new complex structures, functions, and responsibilities.

\section{Collaborative Governance and CCOs}

Conclusions of the findings from Chapter 4 are presented here in two sections.

The first section describes implications for the understanding of the governance structure of CCOs. The second section describes findings related to collaborative governance. In

general, the results offer an understanding of how and why CCOs were formed as well as key internal and external factors or characteristics that influence the structure and effectiveness of CCOs' collaborative governance processes, all of which are operating in a dynamic and rapidly evolving environment. The results offer both insights into the process of CCO development and early implementation as well as important new understandings that aim to inform future studies that are focused on $\mathrm{CCO}$ outcomes. The key for future studies will be to assess outcomes in terms of enhanced integration or coordination of health services. Furthermore, changes in utilization or cost implications from health system transformation will take years to understand, and thus are not a part of the present study. Rather, this study is focused on the processes rather than the outcomes of CCOs.

The hypothesis for the study was that a preferred governance structure or model would influence and affect the collaborative process. Results indicate that collaborative 
governance and its key functions and structure are interdependent, to the extent of having significant potential to influence the desired outcomes of CCOs. For any organization, including complex organizations such as CCOs, the governance structure influences the decision-making processes, and it facilitates or impedes (or both) the effectiveness of the organization, at least in the intermediate future.

Governance structure. In the health administration literature, four dimensions of governance are often cited for integrated delivery systems or networks: control, structure, composition, and functioning (Pointer, Alexander, \& Zuckerman, 1995; Savage, Taylor, Rotarius, \& Buesseler, 1997). The results of this study provide an understanding of whether the four governance dimensions affect an organization's ability to effectively manage issues and challenges faced by a CCO (Savage et al., 1997, p. 12). Developing an understanding of these four governance dimensions leads to understanding important issues, including the level of governance, system complexity, functions of governance, and board composition among Oregon's newly formed CCOs (Savage et al., 1997, p. 12).

Results indicate that these dimensions do affect a CCO's ability to effectively manage issues and challenges faced by these new organizations. A CCO's governing board is responsible for specifying the organizational vision, mission, and goals and ensuring the effectiveness and efficiency of governance (Alexander, Zuckerman, \& Pointer, 1995). Of interest in this study is the finding that the governance structure adopted among the selected CCOs served more as a facilitator to the formation and development of the new organizations than a barrier to achieving integration among organizations that provide services within a CCO (Pointer, Alexander, \& Zuckerman, 
1995). What is not understood is how a model of collaborative governance within CCOs will "facilitate or impede the...performance of integrated systems" (Pointer et al., 1995, p. 4). Table 5.1 displays the presence of the four concepts that comprise the CCO governance structure.

Table 5.1: Governance Structure Elements

\begin{tabular}{|c|c|c|c|c|}
\hline Concepts & Indicators & Health Share & Willamette & Yamhill \\
\hline \multirow{3}{*}{ Control } & Single board & Yes & Yes & Yes \\
\hline & $\begin{array}{l}\text { Multiple subordinate boards } \\
\text { or workgroups for each } \\
\text { CCO }\end{array}$ & 5 & 3 & 5 \\
\hline & Advisory bodies & 5 & 3 & 3 \\
\hline \multirow[b]{2}{*}{ Structure } & $\begin{array}{l}\text { Number and arrangement } \\
\text { of boards }\end{array}$ & Central & Central & Central \\
\hline & $\begin{array}{l}\text { Bylaws and decision- } \\
\text { making processes divested } \\
\text { among the board, } \\
\text { subordinate boards, and } \\
\text { advisory entities }\end{array}$ & $\begin{array}{l}\text { Central; } \\
\text { bylaws; } \\
\text { shared- } \\
\text { decision } \\
\text { making }\end{array}$ & $\begin{array}{l}\text { Central } \\
\text { decision- } \\
\text { making by } \\
\text { board }\end{array}$ & $\begin{array}{l}\text { Semi-central; } \\
\text { bylaws; } \\
\text { shared- } \\
\text { decision } \\
\text { making } \\
\end{array}$ \\
\hline \multirow[b]{3}{*}{ Composition } & Board size & 20 & 13 & 13 \\
\hline & $\begin{array}{l}\text { Representation } \\
\text { (representative or non- } \\
\text { representative) }\end{array}$ & Both & Both & Both \\
\hline & Member characteristics & $\begin{array}{l}\text { Health care } \\
\text { executives, } \\
\text { public, } \\
\text { private, not- } \\
\text { for-profit } \\
\end{array}$ & $\begin{array}{l}\text { Health care } \\
\text { professionals, } \\
\text { public, } \\
\text { private, not- } \\
\text { for-profit } \\
\end{array}$ & $\begin{array}{l}\text { Health care } \\
\text { professionals, } \\
\text { public, } \\
\text { private, not- } \\
\text { for-profit } \\
\end{array}$ \\
\hline \multirow{4}{*}{ Functioning } & Clearly defined roles & Yes & No & Yes \\
\hline & $\begin{array}{l}\text { Explicit set of } \\
\text { responsibilities }\end{array}$ & Yes & No & Yes \\
\hline & $\begin{array}{l}\text { Execution of decision- } \\
\text { making }\end{array}$ & Yes & No & Yes \\
\hline & Intermediate outcomes & Yes & Yes & Yes \\
\hline
\end{tabular}


OREGON HEALTH REFORM AND COORDINATED CARE ORGANIZATIONS 201

Control. Control refers to layers of governance and the number of boards needed to effectively govern the system (Pointer, 1995). More broadly, control focuses on the governance of the system, or $\mathrm{CCO}$, and its parts - the organizations that form the system (Pointer et al., 1995, p. 17). There are two main approaches in control, centralized or decentralized. In a centralized model, the governance board is a single entity in which the decision-making function and authority are centralized. In contrast, the decentralized approach has multiple layers of subordinate boards that share decision-making functions and authority. This approach is more often found in community-based organizations, whereas centralized approaches are found in corporations.

The governance system of the three CCOs studied consisted of a single board with advisory entities. However, the advisory entities are not decision-making bodies, but rather serve at the discretion of the governance board. The decentralized approach to control, with multiple layers of subordinate boards that share decision-making functions and authority, was not present in any of the three cases. This is interesting in that CCOs are perceived as community-based organizations in which the decentralized approach is more often found, whereas centralized approaches are more common in corporations (Pointer et al., 1995).

The findings indicate that the centralized arrangement was the main governance model among the three CCOs. For all three CCOs, the main board had clear decisionmaking authority and oversight of the subordinate boards. Without a comparative CCO that operates with a decentralized governing board, it is not possible to compare which of the two approaches may better fulfill the principles of HB 3650. One conclusion is that a 
OREGON HEALTH REFORM AND COORDINATED CARE ORGANIZATIONS 202

centralized approach — which Health Share, Willamette Valley Community Health, and Yamhill all adopted based on the professional expertise of the board members - was more favorable to meeting the needs of the CCOs, at least during the early forming stages of development and implementation.

Although Willamette Valley Community Health's board has direct decisionmaking authority, there are several important differences when compared to Health Share and Yamhill. Willamette Valley Health Authority, the local IPA, continues to staff the new CCO with direct influence of the board through executive board staff. A second dissimilarity is the influence of hospitals and the two county governments that serve on Willamette's board. The two positions represented on the board by Marion and Polk counties have veto authority. The county public health and mental health authorities did not want to cede authority or relinquish "control" to a limited liability corporation. The arrangement influenced the functioning of Willamette's board (see section on functioning).

Structure. Structure refers to how the board, subordinate boards, or advisory entities are arranged, i.e. the governance structure. Each CCO governance structure was relatively complex. For example, each $\mathrm{CCO}$ was comprised of ten or more partnering organizations. Each CCO had a governing board and at least three or more subordinate boards, multiplied by partnering organizations and their respective boards. Although each CCO could be perceived as having a sizeable number of boards and subordinate boards, the level of complexity presented in terms of decision-making and diffused authority across the entity was not a significant factor. One of the questions proposed before the 
OREGON HEALTH REFORM AND COORDINATED CARE ORGANIZATIONS 203

start of the study was to gauge how much autonomy the partnering organizations retained in relationship to the $\mathrm{CCO}$. Based on the findings, each partnering organization retained a large degree of autonomy.

Each CCO had one or more advisory entities and all three CCOs had a clinical advisory panel (CAP) and community advisory council (CAC). Two of the CCOs also had additional subordinate boards or workgroups that focused on financing and quality within the CCO. For example, Health Share had five chartered workgroups and two chartered advisory councils that had decision-making functions and authority delegated by the board. Similarly, Yamhill's board also delegated "some" minimal amount of decision-making authority to its subordinate boards.

One of the CCOs was challenged by determining which boards at which levels "should perform particular functions" to minimize duplication of efforts as well as internal conflicts (Pointer et al., 1995, p. 8). Two of the CCOs were similarly challenged by determining the amount of authority necessary for individual subordinate boards to function effectively, yet not transcend the authority of the main governing board. This configuration is critical to the structure, decision-making, and authority of the governance model (Alexander, Zuckerman, \& Pointer, 1995). In general, findings from the three CCOs indicated similar configuration and relationships among subordinate boards/advisory bodies and the governing board.

Composition. Composition pertains to whether members of a $\mathrm{CCO}$ board and any subordinate board consist of representatives, non-representative members, or a combination of both (Pointer et al., 1995). The distinguishing feature between 
OREGON HEALTH REFORM AND COORDINATED CARE ORGANIZATIONS 204

representatives and non-representatives is whether a board member has a direct

relationship with any of the partnering organizations in a CCO. For all three $\mathrm{CCO}$ boards in this study, members of the governing board were representatives of one or more of the partnering organizations in the CCO.

In terms of composition, there were two key aspects for the CCOs: (1) whether the representatives and their partner organizations were risk-accepting entities (RAEs), and (2) whether a partnering organization was granted a special vote, such as was observed for the local county departments in Willamette. Based on the findings, all three CCOs had adequate board representation from the array of organizations that serve OHP members within each of their respective communities, including the chairs of the CACs serving on the governing board. By having an inclusive and participatory process during the early formation of all three CCOs, the partner organizations were representative of the various community-based organizations that care for OHP enrollees in Oregon.

Each CCO board was noted as having the professional mix of skills, knowledge, experience, and perspectives needed for the board (Pointer et al., 1995, p. 10). The challenge, however, was ensuring that board members were kept informed by staff about activities across the CCO. The challenge was complicated by the size of the governing boards, which is an important factor. Larger governing boards can be "inefficient" and impede governance effectiveness (Prybil et al., 2008). According to a 2008 report on governance among nonprofit health systems (Prybil et al., 2008), a "hallmark of good governance" is limiting the number of members who vote and serve on a governing board (p. 4). The issue is ensuring the governing board does not become too large and unable to 
OREGON HEALTH REFORM AND COORDINATED CARE ORGANIZATIONS 205

make decisions. For example, Health Share has 20 board members whereas Yamhill and Willamette both have a 13-member board. The composition of CCO board members is an important governance dimension as the enabling legislation requires a $\mathrm{CCO}$ governance structure to include non-representative members, including community members, on the board.

Functioning. Functioning refers to roles and responsibilities within the governance structure, in other words, how CCO governance functions, including what issues a board should address and how it should govern. Function pertains to how roles and responsibilities are fulfilled by the $\mathrm{CCO}$ governing board (Alexander \& Zuckerman, 1989; Pointer et al., 1996, p. 13). A governing board, including those of CCOs, should perform three core roles: policy formulation, decision-making, and oversight (Pointer et al., 1995, p. 26).

By and large, the three cases demonstrated the presence of organizational policy formulation and direction, direct oversight including financial controls, and decisionmaking through formal authority. For Health Share and Yamhill, findings did not indicate that the boards delegated decision-making to subordinate boards. The various advisory boards provide input and recommendations to the governing board. In contrast, the board of Willamette Valley Community Health had delegated, perhaps unintentionally, decision-making to the internal management structure of the IPA.

In addition to roles, a board also has responsibilities. According to Pointer et al. (1995), there are five key responsibilities: (1) formulating the mission, vision and goals of the organization; (2) ensuring the organizational performance, including executive 
OREGON HEALTH REFORM AND COORDINATED CARE ORGANIZATIONS 206

management; (3) ensuring the financial health of the entity; (4) assuring the quality of health services; and (5) assuming responsibility for accountability to itself, the board, as well as accountability among the partnering organizations to the main governing board (Pointer et al., 1995, p. 25). The CCOs varied considerably in their demonstrated ability to fulfill the five responsibilities of an executive board.

Yamhill CCO is best characterized as fulfilling all five of these key functions or responsibilities with the possible exception of the fifth, which has more to do with the limited duration of the study and the newness of the organization. Health Share was clear in its organizational mission and goals; the board was actively overseeing the organizational performance, even to the extent of trying to manage the day-to-day operations of the CCO. Further, Health Share's board actively reviewed financial reports of the CCO. Study participants did not provide much insight into whether and how Health Share and its board were working to ensure the quality of services. Health Share's Transformation Plan, however, did provide explicit goals for improving the quality of services, including identification of performance targets. This is an example of an "intermediate outcome" in which participants recognize the potential value or advantage from collaborating, which can encourage trust and further commitment to the collaborative process (Vangen \& Huxham, 2003). Findings indicate that Willamette Valley Community Health did not have a clear mission or goals and as a board was not overseeing the executive management of the $\mathrm{CCO}$, which was led and directed by the IPA (Toomey \& Toomey, 1993). 
For all three CCOs, an inherent conflict was identified that influenced the boards' ability to fulfill their responsibilities and execute decision-making. The issue is as follows: Decisions acted upon by the board may result in one or more of the board member's parent organizations experiencing a negative financial impact. However, board members are required to act upon decisions solely in the interest of the organization, the CCO. This complexity in terms of governing was noted especially with Health Share and Willamette Valley Community Health. Board members of Health Share are responsible to the $\mathrm{CCO}$ while concurrently needing to ensure their fiduciary responsibilities to the board of their parent organization. This dynamic is an example of organizations responding to changing environmental conditions: recognizing scarce resources and resource interdependencies and the advantages created by collaboration over competition in forming interorganizational partnerships (Pfeffer \& Salancik, 1978; Thomas, Ketchen, Trevino, \& McDaniel, 1992; Lowndes \& Skelcher, 1998). For Yamhill, the partnering organizations in the $\mathrm{CCO}$ were not significant risk-accepting entities and thus did not have the inherent conflict evidenced with Health Share. It is unknown whether this aspect of Health Share and Willamette Valley Community Health may influence the boards' ability over time to fulfill all five responsibilities of a functioning governing board of an integrated health system.

Collaborative governance. This study adopted Ansell \& Gash's (2007) model of collaborative governance that includes four key concepts: starting conditions, institutional design, leadership, and collaborative process (Freeman, 1997; Ansell \& Gash, 2007, p. 549). These concepts are a contribution "to or context for" a collaborative process for any 
system (Ansell \& Gash, 2007, p. 550). By building on and incorporating variables from Ansell and Gash's (2007) analytic framework, the study was able to identify and assess which of the four concepts influence collaboration through CCO governance arrangements.

A conceptual framework for studying CCO collaborative governance was constructed from the four dimensions of governance from Pointer et al. (1995) and Ansell and Gash's (2007) four concepts of collaborative governance. Findings support the framework shown in Figure 5.1. The starting conditions influenced the governance structure, which in turn influenced the collaborative process. These concepts are interdependent of one another and when taken together as a whole describe the governance model of CCOs. 
Figure 5.1. Conceptual Framework for CCO Collaborative Governance

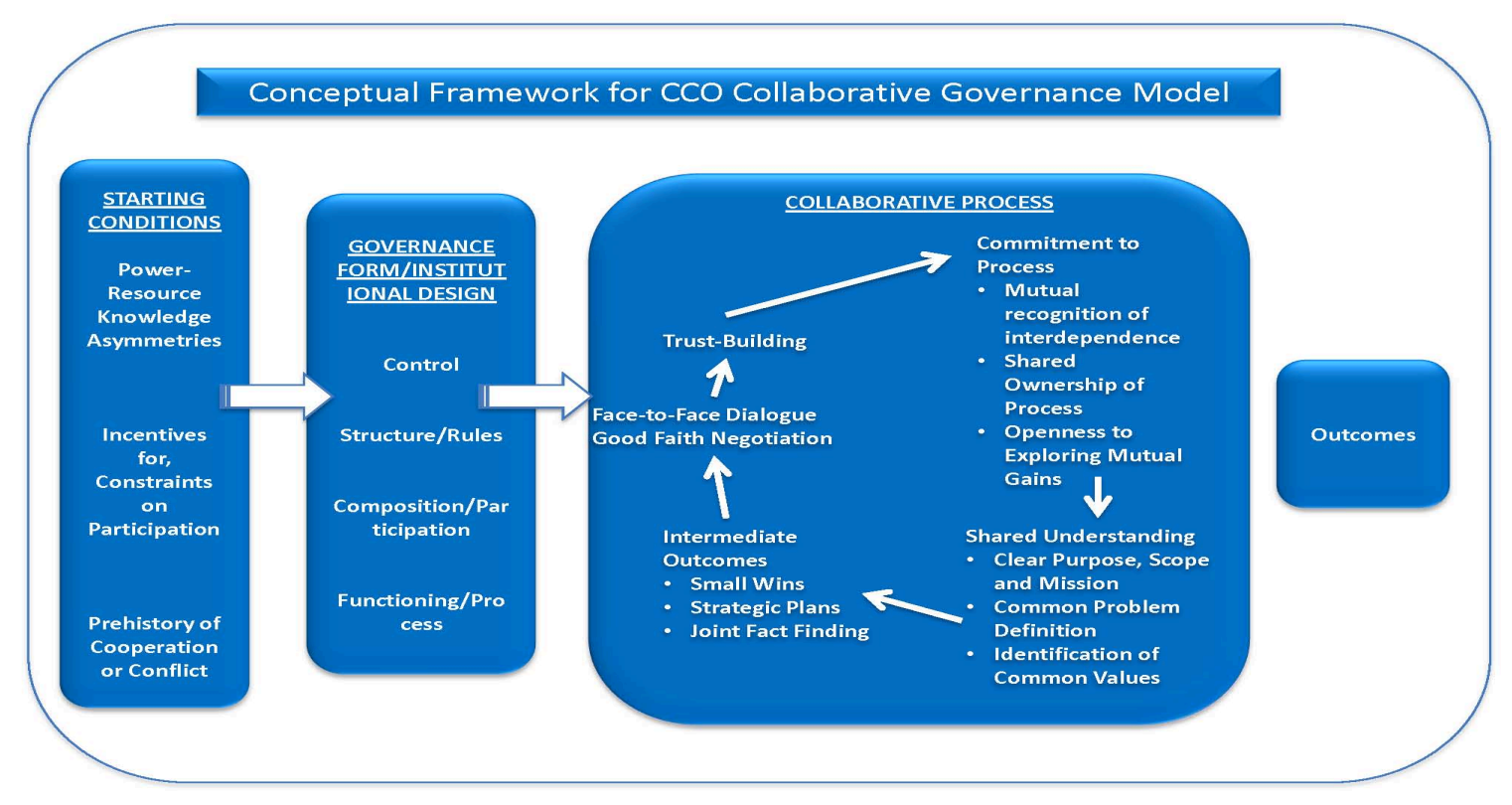

Starting conditions. The history and context of the starting conditions of any collaborative have been found to be important variables that facilitate or deter (or both) cooperation among the partners (Gary, 1989). For this study, three concepts were adopted to form the starting conditions: (1) presence of any imbalances between resources or power among the various partners, (2) presence of incentives to collaborate, and (3) history of conflict or cooperation, which will hinder or facilitate collaboration (Ansell \& Gash, 2007, p. 550-551).

From a state perspective, key precipitating factors that helped to foster support for the CCO legislation were the looming budget crisis of the "Great Recession"; recognition and acknowledgement of unsustainable growth in health care; a general sense of urgency, particularly the impact of Medicaid expenditures on Oregon's biannual budget; and an 
opportunity to achieve health reform in Oregon. These factors contributed to bipartisan support, and along with Governor Kitzhaber's leadership, created an unprecedented effort to transform Oregon's health care system, starting with the Oregon Health Plan.

The environment or starting conditions influenced the early formation of the CCOs. For Health Share, the prior history with the Health Leadership Council and TriCounty Medicaid Collaborative helped the partners of the CCO leverage existing relationships, further recognize different aspects of the health industry, and remove historical mistrust. In the case of Willamette Valley Community Health, the history of conflict between the IPA and the largest for-profit, privately owned hospital affected the institutional design, collaborative process, trust building, and ability of the CCO to work towards intermediate outcomes, including developing a mission statement and vision. Salem Health and its two affiliated hospitals, which serve the majority of OHP members in the Salem region, experienced a power differential. Salem Health did not perceive sufficient incentives to participate in the Willamette Valley CCO's new financial model of a global budget. Salem Health preferred to continue providing hospital-based services through the existing financial model, which was more lucrative for the organization. In contrast, the starting conditions in Yamhill were unique compared to the other two CCOs. Prior to the creation of the CCO legislation, there had been minimal managed care in Yamhill County. The lack of an existing Medicaid managed care organization or large IPA serving OHP members created a set of starting conditions that did not spring from a history of conflict. 
OREGON HEALTH REFORM AND COORDINATED CARE ORGANIZATIONS 211

The role of incentives served as a key factor among the three CCOs and partnering organizations (Gunton \& Day, 2003; Imperial, 2005). For example, in Yamhill the incentives identified by participants were more focused on wanting to help the "community" and less financial in nature; partnering organizations were not riskaccepting entities. In comparison, the role of financial incentives was a significant factor in organizations partnering in Health Share. In Willamette Valley Community Health, financial incentives influenced one of the larger hospital systems to not participate initially in the new CCO arrangement.

Institutional design. The institutional design refers to the guidelines and ground rules that exist for collaboration (Weech-Maldonado \& Merrill, 2000; Fung \& Wright, 2001; Ansell \& Gash, 2007). In a model of collaborative governance, the institutional design should foster an open, transparent, and inclusive environment for stakeholders (Ansell \& Gash, 2007, p. 555). For this study, institutional design was an outcome of the formalization of a governance structure among the CCOs. CCOs had to determine how inclusive or exclusive they were in terms of stakeholder participation, which included not only partnering organizations but organizations beyond those that formed the CCO. All three CCOs supported an open and inclusive process during the early forming stage of these new organizations. Public involvement at the local level included broad participation among dozens of organizations prior to forming each $\mathrm{CCO}$. In the early planning stages, community partners were invited to participate in the initial discussions around forming a $\mathrm{CCO}$. After formation, however, the notion of transparency and openness with Health Share required cultural change for several board members. For 
OREGON HEALTH REFORM AND COORDINATED CARE ORGANIZATIONS 212

example, staff with the new $\mathrm{CCO}$ was intentional in making sure that the CAC meetings were facilitated in an open and transparent environment. Conversely, after Willamette Valley Community Health was formed and the lawsuit transpired, the board meetings were no longer open or transparent. The board continues to operate without transparency, with its meetings still closed to the public. In comparison to Willamette Valley Community Health, Health Share and Yamhill value openness and transparency as part of encouraging participation and ensuring that their boards and advisory bodies support an inclusive process.

An important design aspect among the CCOs was the type of organization: the LLC or 501(c)3. All three CCOs needed to incorporate because they were "new" organizations. Health Share and Willamette Valley Community Health both expressed an early concern about the type of organization because the mixture of local governmental entities, nonprofits, and for-profit partnering organizations required caution to avoid compromising state or federal regulations. The type of organization was an important design feature in terms of legitimacy among stakeholders.

Leadership. Leadership is key for any governance system and played an important influencing factor in a CCO's ability to bring stakeholders together and engage in the collaborative (Ryan, 2001; Lasker \& Weiss, 2003). Collaboration does not happen in a leadership vacuum. Ansell and Gash (2007) state that leadership is "crucial for setting and maintaining clear ground rules, building trust, facilitating dialogue, and exploring mutual gains" (p. 554). Leadership can also help to achieve balance when power and resources among stakeholders are asymmetrical. The presence of leadership 
OREGON HEALTH REFORM AND COORDINATED CARE ORGANIZATIONS 213

within individual CCO board members, coupled with leadership by state officials and the governor, has been an instrumental force in Oregon. Leadership is a necessary condition for collaborative governance, and it was a necessary starting condition for CCOs. This was most evident with Yamhill and the local leadership from the county government, which was instrumental in the creation of Yamhill CCO. With Health Share, the CEOs of the member hospitals and health plans were well known leaders within the health care community. The leaders and future board members were able to engage with one another and through consensus design a governance structure that was acceptable to the board. In contrast, the change in and lack of leadership within Willamette Valley Community Health hindered the board's ability to engage in decision-making or develop an agreedupon mission and vision for the new organization.

\section{Collaborative process.}

Success is pulling together the community in forming a coordinated care organization...trying to establish new relationships. (Case ID 3)

Collaboration can be cooperative or required by formal processes, in this case through public policy-making by the Oregon Legislature. The purpose of collaboration is to solve one or more problems that cannot be solved by a single organization (Agranoff \& McGuire, p. 21, 2003). Through collaborative governance, CCOs leverage “interdependencies with the nongovernmental sector" while simultaneously directly involve public sectors across the horizontal and vertical levels, in this case state and county intergovernmental agencies (Agranoff \& McGuire, 2003). Governmental collaboration is occurring vertically through CCOs, the Oregon Health Authority, and the 
OREGON HEALTH REFORM AND COORDINATED CARE ORGANIZATIONS 214

federal Centers for Medicare and Medicaid Services (CMS). Horizontal governing is also occurring through county agencies, nonprofits, and private organizations within a CCO's geographically defined community.

Ansell and Gash (2007) state that the collaborative process itself is an iterative cycle that builds on communication, mutual trust, commitment to the process, shared understanding, and mutually beneficial outcomes. For CCOs, the first step in this process was direct and frequent communication between partnering organizations. For all three CCOs, the direct and frequent dialogue lasted over a period of months and was face-toface (Ansell \& Gash, 2007). For Health Share, the collaborative process was initiated with the creation of the Health Leadership Council, continued with the Tri-County Medicaid Collaborative, and ultimately led to the creation of the CCO.

The notion of having stakeholders interact in person is important but not “necessary” for effective collaboration to transpire (Ansell \& Gash, 2007, p. 558). Consistent with the literature, however, the interaction among CCO board members was “necessary" for collaboration, particularly face-to-face dialogue (Lasker \& Weiss, 2003; Huxam, 2003). The "endless hours" of long in-person meetings led to a shared understanding for two of the CCOs. Another finding consistent with the literature was that the personal meetings among board members served as a forum to help develop relationships and trust, mutual understanding, and a new appreciation for one anotherall of which were achieved through the collaboration (Weech-Maldonado \& Miller, 2000; Daniels \& Walker, 2001; Vargen \& Huxham, 2003). 
OREGON HEALTH REFORM AND COORDINATED CARE ORGANIZATIONS 215

Any collaborative process must include ongoing deliberation and negotiation and be transparent and consensus-oriented, with stakeholders sharing responsibility for the process (Ansell \& Gash, 2007). This was evident in each of the three CCOs. For CCOs, the collaborative process built trust, often among organizations where mistrust was present, and more importantly where mistrust was a product of historical conflict. Through a time-intensive process of meetings that spanned months, CCO board members were able to build trust by interacting frequently and regularly with one another in person. This was especially the case with Health Share, where the historical mistrust among area hospital systems, health plans, and provider groups diminished through the process. In contrast, Willamette Valley Community Health was not able to build trust or a shared understanding through a collaborative process. The findings indicate that, for CCOs, commitment required that board members develop trust and a shared understanding as a means of working towards outcomes. This process, over time, resulted in "mutual recognition" that the objectives for CCOs are only achievable through collaboration.

Consistent with the literature is that through the collaborative process, "shared understanding" can emerge. This refers to the collaborative having a clear mission, a common and shared definition of the problem, and an identification of common values across the stakeholders. For Health Share and Yamhill, the board members developed a mission and shared understanding for the $\mathrm{CCO}$ as well as a shared understanding that extended beyond the CCO. Board members developed new understanding and insights into different professions, different organizations, and their roles as part of a community 
OREGON HEALTH REFORM AND COORDINATED CARE ORGANIZATIONS 216

health system, which offered individual board members a clear understanding of the roles and responsibilities across the health care spectrum. This included the role of local health authorities, behavioral health providers, the dental community, community health workers, health plans, and hospitals. The findings suggest that collaboration is best achieved through dialogue and process, not hierarchical command and control structures.

\section{Implications for Policy}

CCOs offer a new complex governing model at the local level that is characterized by new structural relationships among public, private, and nonprofit organizations. The literature reviewed for this study, reinforced by the study findings, indicated that collaborative governance is a strategic approach for the optimal utilization of resources provided to public, private, and nonprofit organizations to deliver services to Oregon's Medicaid population within regional communities with local control and accountability. Additionally, this study focused on expanding the knowledge base related to the development of partnerships between public, private, and governmental agencies (Austin, 2003). Table 5.2 provides a summary of which indicators were present or absent (i.e. yes/no) across the CCOs that were used to construct the individual concepts that form the collaborative governance model. 
Table 5.2: Collaborative Governance and CCOs*

\begin{tabular}{|c|c|c|c|c|}
\hline Concepts & Indicators & $\begin{array}{l}\text { Health } \\
\text { Share }\end{array}$ & Willamette & Yamhill \\
\hline \multirow{3}{*}{ Starting Conditions } & Power-resource imbalance & + & + & - \\
\hline & $\begin{array}{l}\text { Incentives for and constraints on } \\
\text { participation (legal, economic, } \\
\text { political) }\end{array}$ & + & + & + \\
\hline & History of conflict or cooperation & + & + & + \\
\hline \multirow{5}{*}{ Institutional Design } & $\begin{array}{l}\text { Participatory } \\
\text { inclusiveness/exclusiveness: } \\
\text { public involvement, local } \\
\text { involvement }\end{array}$ & + & + & + \\
\hline & $\begin{array}{l}\text { Broad participation: composition } \\
\text { of membership by expertise or } \\
\text { geographic location }\end{array}$ & + & + & + \\
\hline & $\begin{array}{l}\text { Procedural legitimacy: guidelines } \\
\text { and rules for participation }\end{array}$ & + & - & + \\
\hline & $\begin{array}{l}\text { Open, transparent, and inclusive } \\
\text { process }\end{array}$ & + & - & + \\
\hline & Skills and knowledge & + & - & + \\
\hline \multirow{3}{*}{$\begin{array}{l}\text { Facilitative } \\
\text { Leadership }\end{array}$} & Facilitation & + & - & + \\
\hline & Engagement & + & - & + \\
\hline & Empowerment & + & - & + \\
\hline \multirow{6}{*}{$\begin{array}{l}\text { Collaborative } \\
\text { Process } \\
\text { (Relationship } \\
\text { Dynamics) }\end{array}$} & Collective choice decision-making & + & - & + \\
\hline & Face-to-face dialogue & + & + & + \\
\hline & Trust building & + & - & + \\
\hline & Commitment to process & + & - & + \\
\hline & Shared understanding & + & - & + \\
\hline & Intermediate outcomes & + & + & + \\
\hline
\end{tabular}

* Key: Present/Yes $=+;$ Not present $/$ No $=-$

The results in this study align with Goldsmith and Eggers's (2004) belief that the devolution of governmental services to the private and nonprofit sectors has resulted in a reduction of more hierarchical types of governance and the emergence of more horizontal models that focus on public value. $\mathrm{CCO}$ board members who participated in the study 
OREGON HEALTH REFORM AND COORDINATED CARE ORGANIZATIONS 218

expressed a strong concern for engaging in key functions of collaborative governance due to their perception of the benefit to the community and the need to identify solutions to problems within their locale. This indicated a certain willingness of CCO board members and partnering organizations within a $\mathrm{CCO}$ to relinquish a degree of autonomy and authority for the benefit of those served by a publicly financed program, in this case Medicaid (Chi, 2008).

Bingham, Nabatchi and O'Leary (2005) indicate that new governance models should include quasi-legislative processes such as citizen input and targeted dialogue among stakeholders and that future research should identify the environments in which new governance processes would thrive. The emerging themes in this study are important factors for collaborative governance among CCOs: community inclusion and engaged deliberative participation, the perception of mutual gain and shared benefit through collaboration across sectors, recognition of shared understanding, and trust building.

Inclusive processes encompass for-profit and not-for-profit health care organizations, including governmental entities within a geographically defined community being incentivized and engaged in a problem-solving enterprise. Furthermore, the themes emerging from this research imply readiness by the study participants to test more complex systems, such as collaborative governance in CCOs, that will provide opportunities for the optimal utilization of organizational and financial resources, which will likely result in a more efficient and systematic allocation of resources in Oregon (Agranoff \& McGuire, 2003). 
OREGON HEALTH REFORM AND COORDINATED CARE ORGANIZATIONS 219

Ceding authority from the county public health and mental health agencies to a non-governmental agency raises issues of control, public trust, and accountability. Historically, public agencies were considered accountable to the local citizens by elected officials and to the state through existing regulatory structures. Oregon law mandates that county agencies ensure provision of basic services, which include public, mental, and social services. The role and function of county government is evolving under the collaborative governance model of CCOs, blurring the boundaries between county government and private agencies and resulting in issues around control, public trust, and accountability that affect the collaborative process.

Results suggest a number of key factors as contributing to both the success of collaborative governance as well as strategies for the resolution of identified conflicts. Most of the study participants indicated that, at some level, the communities and other stakeholders who are involved in a collaborative governance process must perceive a "shared understanding" and that the process is mutually beneficial. A summary of recurring statements related to the starting conditions that facilitate effective governance includes: (a) commitment, consistency, and perception of credibility and trust within the $\mathrm{CCO}$; (b) existence of facilitative leadership within the board; (c) prior history of cooperation that encouraged the success in the early formative period of the CCO; (d) recognition of incentives to participate; and (e) clarity and commitment regarding roles, responsibilities, goals, and objectives of the new $\mathrm{CCO}$, including functioning among the board and advisory entities. 
OREGON HEALTH REFORM AND COORDINATED CARE ORGANIZATIONS 220

The results suggest several challenges regarding participation in collaborative governance models: (a) clearly defining the extent of the decision-making authority of board members, including clearly defining the roles of advisory entities in relation to the governing board; (b) clearly defining the mission of the $\mathrm{CCO}$, including the mission statement and vision; (c) clarifying the accountability of the individual board members to the $\mathrm{CCO}$ and their parent organizations; and (d) ensuring the development of a model that is appropriate for all of the communities represented within the collaborative governance structure, i.e. those served by the OHP.

A number of factors were identified as potentially impeding the ability of a CCO to adhere to a collaborative governance approach. The main factor identified was the potential for conflicting or competing agendas among board members. Emerging themes were for-profit verses nonprofit orientation, transparency of purpose, and recognition that board members may at times be required to make decisions that conflict with the financial interests of their home organizations. Such statements imply that the study participants were aware of the possibility of conflict related to competing agendas as well as the potential adverse influences on the development of strong collaborative relationships within a CCO. Although the issue of inherent conflict was identified, the themes of inclusion and perceptions of empowerment and shared understanding implied that the participants perceived that collaborative relationships can exist within a formal collaborative governance structure if the proper foundation exists to promote and maintain such relationships. Study participants recognized the importance of overcoming a history of conflict and mistrust through ongoing engagement and face-to-face dialogue. 


\section{OREGON HEALTH REFORM AND COORDINATED CARE ORGANIZATIONS 221}

Therefore, the model of collaborative governance can offer a novel approach for a diverse group of stakeholders with complex and often intertwined historical relationships: the opportunity to collaborate and seek strategies to meet the needs of both urban and rural communities in Oregon.

CCOs' support of a collaborative governance structure was evidenced by transparency, commitment, and shared understanding. Emerging themes such as fear and mistrust may compete with the desire for consensus building and were expressed in the desire of study participants to diminish power struggles and other forms of power imbalances. Ongoing dialogue and communication were identified as strategies to mitigate mistrust and conflict within a $\mathrm{CCO}$. One assumption is that public and private organizations will participate in collaborative governance structures when perceptions of mistrust and inequality are less than perceptions of mutual benefit and gain. Conversely, when public and private organizations do not perceive a shared interest or commitment along with a presence of distrust, such organizations are less likely to participate in a collaborative governance arrangement. All three cases demonstrated that stakeholders should be encouraged to continue their engagement in boundary-spanning activities. These activities, along with the utilization of personal and professional influence, are necessary to gain access to additional resources that will strengthen the sustainability of the participating organizations and legitimize their value to the community (Kumar \& van Diessel, 1996; Miller-Millesen, 2003).

The study participants' perceptions of inclusion and empowerment may also compete with perceptions of power imbalance and may reduce conflicts related to 
OREGON HEALTH REFORM AND COORDINATED CARE ORGANIZATIONS 222

mistrust if stakeholders are brought to the table with clearly defined roles, missions, goals, and objectives, and with the majority of participants committed to the formation of a collaborative governance structure. Results indicated that the following factors impeded the collaborative governance process according to the study participants: sources of conflict, such as not viewing the collaborative governance process as beneficial; lack of legitimacy, ineffective communication; mistrust; insufficient information and knowledge; perceptions of the lack of empowerment; resource allocation; and ineffective leadership.

The results of the study are consistent with Ansell and Gash's (2007) notions regarding key factors for collaboration: (a) if some stakeholders perceive a lack of empowerment, or if there is not equal access to resources, the level of commitment required for effective collaboration will be diminished; (b) a strong sense of interdependence provides the incentive for stakeholders to pursue mutual/shared goals and objectives; (c) stakeholders must perceive that the outcomes of their collaboration are respected by other forums; (d) existing conflicts among stakeholders must be resolved or minimized; and (e) strong relationships and social capital must exist among stakeholders. In sum, results indicate that trust, inclusion, transparency, mutual gain, empowerment, and community benefit must be present for collaborative governance processes to work.

The analysis identified several distinct (but related) roles played by CCOs that resulted from a collaborative governance approach, summarized below:

- CCOs address competitive pressures among participating organizations.

Competing organizations would otherwise be reluctant to expend their own 
resources on collective goals that help competitors, even when benefits are shared.

- CCOs assist in solving significant and fundamental problems in the health care industry that are too complex for voluntary, independent coordination, especially among participants distracted by their own organizational-level goals in conflict with other organizations.

- CCOs serve as a new structure for coordination by creating a new institutional design that is transparent and requires that competitors share information. This only applies when a CCO has earned the trust of the organizations with which they work.

- CCOs have developed or contracted for the expertise and infrastructure required to complete the administrative tasks of running a large health care organization, allowing the board to engage in collective and community problem-solving that is too time-consuming for individual organizations to manage on their own.

- CCOs provide accountability when partner organizations cannot enforce commitments upon each other either because they either lack the capacity or compete with them. Enforcement (or at least pressure) from a neutral CCO is perceived as more acceptable. This extends to accountability of the partner organizations to the $\mathrm{CCO}$, which is then held accountable by the state. The role of the state or public institutions in stimulating collaborative partnerships, in particular the role of a government, is as a topic of continued importance. The Oregon legislative and executive branches of government intentionally and 
deliberately adopted and required new governing arrangements. Through legislation, administrative rulemaking, and contracting, Oregon's executive branch required the key concepts of a collaborative governance model for all CCOs. In Oregon, legislation and regulation served as facilitating forces and shapers of both a collaborative governance model and its processes. The initiation and/or success of collaboration could, in fact, be potentially dependent on credible threats of imminent or future regulation, the "shadow of the state," as was the case with Willamette Valley Community Health (Ansell \& Gash, 2007).

Findings support the notion that CCOs are "intergovernmental" as evidenced by regulatory and contractual relationships in which the boundaries of government and its functions, including public and mental health services, are no longer the exclusive domain of state and county governments in Oregon (Agranoff \& McGuire, 2003). Furthermore, CCOs are new organizations, purposive in nature, and operate through contractual and multi-organizational arrangements to solve problems in the financing and delivery of comprehensive health care services for hundreds of thousands of low-income Oregon residents (Agranoff \& McGuire, 2003, p. 4).

According to Agranoff \& McGuire (2003), the level of "interdependencies...both vertical and horizontal" between governmental and non-governmental organizations illustrate the "greater the need for coordination and collaboration" (p. 35). CCOs are a case in point with the federal and state (vertical) government dollars responsible for funding services through both governmental and nongovernmental (horizontal) 
organizations. Furthermore, county government is at the "hub of both horizontal and vertical connections" through 16 CCOs that span all 36 counties in Oregon.

The need for facilitating forums indicates that collaboration across sectors, at least in health care, is unlikely to occur merely due to the recognition and support for the larger community or public good. In the case of CCOs, if participants do not foresee immediate gains or "benefit" for their parent organization, and if there is no pressure from regulations, laws, or coordinating organizations, incentives to collaborate could be minimal. In fact, they could be insufficient to achieve the desired outcomes, in this case the fundamental restructuring of Oregon's Medicaid financing and delivery system, including bringing about local control and accountability in communities throughout Oregon. Furthermore, when there are a number of difficult conditions present, such as interorganizational competition, finite resources (primarily funding), accountability concerns, goal divergence, and time-consuming collaborative processes, the likelihood of promoting the public good as the motivating factor of a collaborative governance model is suspect. Based on the findings from the three case studies, additional motivating factors or incentives are needed, depending on the local environmental factors and composition of the potential partnering organizations (e.g. for-profit versus nonprofit). Results indicate that regulations or laws that encourage financial incentives to CCOs and Oregon's CCO collaborative endeavors help further "spur" collaboration.

Results from the thematic analyses also have other practical implications. For instance, interpersonal relationships among area health care leaders and government officials were critical to both building future working relationships and resolving 
OREGON HEALTH REFORM AND COORDINATED CARE ORGANIZATIONS 226

conflicts. It is important for public officials, therefore, to cultivate personal relationships with potential partners. Interviewees stressed the importance of frequent face-to-face dialogue and engagement, willingness to understand different perspectives, and willingness to engage in the process. Results suggest that organizations often find common ground through sustained engagement, even when the principal players disagree on goals and values. The Tri-County Medicaid Collaborative that evolved into Health Share is an example of such engagement.

As described in this chapter, it is critical to know whether collaboration creates and distributes public benefits at a reasonable cost to society. Collaboration is often mandated or strongly encouraged as a policy tool because of expected benefits, even without hard evidence of those benefits. Furthermore, collaborative processes are thought to be costly, especially in terms of time, so it is important to know whether they are worth it. In 2011 and 2012, an unprecedented "policy window" (Kingdon, 1995) was created in Oregon with the convergence of (a) the growing problems in health care, both in Oregon and nationally; (b) policies under development for reforming Oregon's Medicaid system; (c) the politics of the elections, locally of Governor Kitzhaber and nationally of President Obama; and (d) passage of the ACA. The result was that Oregon's policymakers passed legislation that sought to reform Oregon's health system starting with coordinated care organizations. For policymakers and public administrators looking for new governing models, collaborative governance holds considerable promise for a range of policy issues beyond health care. 


\section{Assumptions and Limitations}

There are several methodological limitations of this research. First, there are no comparison cases of non-collaboration. While problematic for a traditional case study, the lack of non-collaboration cases is less concerning because the three cases offered an opportunity for comparative analysis.

Researchers might be concerned with the narrow focus on collaborative governance within three limited geographic regions in Oregon when approaching such a broad topic. However, what appears to be a narrow policy focus is, in reality, quite broad. For example, issues of conflict, cooperation, limited resources, fragmentation, and crosssector actors expand beyond the delivery and financing of health care services. Examples include land conversion, public resource management, and education (see Ansell \& Gash, 2007). The interviewees worked in diverse areas in health care and public health. Insights obtained from analysis of the transcriptions are therefore assumed to be at least broadly generalizable to similar policy areas in other localities in the United States.

Another limitation of the study was the number of participants interviewed from each CCO. Due to the limited number of individuals who were willing or able to participate in the interview process, the findings are not necessarily representative of the full spectrum of partnering organizations within each case study. The ability to draw formal conclusions based on a limited sample of board members and staff necessarily limits the ability to draw conclusions with any degree of certainty. A number of organizations represented on the three CCO boards were not able to participate in the study and thus were not represented in the findings. For example, if the majority of 
OREGON HEALTH REFORM AND COORDINATED CARE ORGANIZATIONS 228

participants from one $\mathrm{CCO}$ were from partner organizations that are nonprofit, it would be difficult to ascertain implications in the context of for-profit organizations, including incentives for and constraints on participation, cultural differences, and commitment to a shared or "collective" interest among the newly formed CCO.

A final limitation relates to the reality of time and resources available to complete this study. Because this research was conducted as dissertation research, it was necessary to articulate certain parameters and constraints in order to ensure the timely completion of the dissertation. Despite these stated limitations and assumptions, the findings provide one of the first descriptive assessments of CCO governance in Oregon.

\section{Recommendations for Future Research}

Given the limited focus of this study, the findings raise a number of recommendations for future research. For future research that includes qualitative, quantitative, and mixed methods, larger number of cases may be beneficial in further testing theoretical models for collaborative governance, including the influence of the main concepts explored in this study: starting conditions, institutional design, facilitative leadership, and collaborative process. Of equal importance will be for future studies to assess the influence of these factors on the desired outcomes of CCOs, and more broadly the ability for collaborative governance to serve as a means to achieve the desired end(s). It will be valuable to understand the expected versus realized outcomes when organizations collaborate, including outcomes from interorganizational collaboration among nonprofit and for-profit organizations. 
At this point, it unknown to what extent CCOs will take on the historical roles of county agencies in relation to public and mental health services. Also unknown is whether the state and county governmental agencies' responsibility for and accountability to the public, in this case low-income Oregonians, is "compromised and limited" by the use of collaborative governance in CCOs (Agranoff \& McGuire, 2003, p. 189). The state is required to hold CCOs accountable for achieving the goals of the Triple Aim, and the CACs are designed to hold the CCOs accountable to the communities served by these organizations. The extent to which either of these accountability mechanisms will function is also an unknown.

Also of considerable interest for future research is whether local communitybased organizations such as CCOs offer a model by which there is "more government action and less government involvement" (Agranoff \& McGuire, 2003, p. 24). State and federal governments have central authority in the context of contemporary societal issues. However, the complexity of today's issues - specifically around insurance, access, quality of care, and financing - requires effective new models for governing, in which governmental and non-governmental organizations seek to solve problems collaboratively rather than independently; thus recognizing the organizational interdependencies in health care, specifically Medicaid.

Over the coming years, it will be important to conduct quantitative studies to determine whether collaborative governance influences the outcomes of CCOs as evaluated by their ability to contain health care expenditures per capita, increase quality of care delivered, or be held accountable to the communities served. Furthermore, the 
OREGON HEALTH REFORM AND COORDINATED CARE ORGANIZATIONS 230

extent of the relevance of themes identified through qualitative research and the development of collaborative governance models will need to be supported by multiple sources and types of empirical data. Mixed methods studies on the topic of collaborative governance, by design, might be able to move beyond identification of themes and concepts. Such studies can also provide quantitative data to more accurately and confidently determine the key facets of collaborative governance, including arrangements that ultimately impede and facilitate governing in a multi- or cross-sector environment. Longitudinal studies will certainly benefit a scholarly, theoretical approach to the development of collaborative governance models in health care.

Another area for consideration is whether previously well-organized interests with significant financial resources, such as large hospital systems, retain the power differential that existed prior to the creation of CCOs, either lasting or changing over time through collaboration and institutional designs (Fung, 2002). An intriguing question is whether larger hospitals and health plans will co-opt smaller, less resourced organizations in the governing or decision-making process within a CCO.

Future research will be able to confirm whether CCOs achieve the desired outcomes including the Triple Aim, and if they effectively coordinate and integrate comprehensive community-based services for hundreds of thousands of Oregonians in the years to come. Researchers will be able to determine whether and how key concepts of collaborative governance are transferable to other policy domains and regional settings beyond Oregon. 


\section{Conclusions}

What do all the CCOs have in common? And we all sat around to think about what we have in common... and what we have in common-we all reflect our community. That's what we have in common. (Case ID 5)

Results from this study enhance the early understanding of coordinated care organizations, which are a new and innovative model of community governance intended to improve the health status of individuals and communities by involving local agencies and individuals to create a new health system that is responsive to, and accountable for, communities in Oregon. The results indicate that organizations that have formed CCOs are characterized by a problem-solving orientation, are participatory and seek broad representation, are actively engaged in collaborative processes, are interdependent and accountable to each other, and transcend the public-private divide (Freeman, 1997). A number of differences were identified as influencing early CCO development: local political, institutional, and historical contexts; different starting conditions; leadership; and governance structures. Important factors identified in the collaborative governance process were history of conflict or cooperation, incentives and willingness to participate among a broad and diverse group of stakeholders, power and resource differences, presence and commitment of leadership (or lack thereof), and presence of a collaborative process. The model of collaborative governance examined in this study offers a new and effective regional approach to address community-based problems that span public and private sectors. 
OREGON HEALTH REFORM AND COORDINATED CARE ORGANIZATIONS 232

The significance of this study is that it identified important starting conditions that facilitate or impede the ability of CCOs to effectively solve problems through governance. Since CCOs are a new organizational form, there was no previous research studying these governance mechanisms. Collaborative governance models for CCOs serve as a mechanism to address the collective resource management issue faced by health care that spans public and private boundaries in Oregon. Oregon's CCOs are an example of Kettl's (1993) assertion that "government refers to the structure and functions of public institutions. Governance is the way government gets its job done” (p. 11). Collaborative governance offers a new model for public institutions to create effective public-private partnerships where integration of public and private entities at the local or regional level can solve complex problems within a particular policy arena.

The analytic framework of collaborative governance used to explore CCOs in this study offers a descriptive model to assess these new organizations. CCOs are designed to deal with one of the most vexing problems presented by the U.S. health care systempublicly financed health care services in Medicaid. The study suggests that CCOs serve as an emerging governing model to implement community-level reforms, in which collaborative governance extends the functions of the state by leveraging public-private partnerships, intergovernmental organizations, and use of contracting to support functions and responsibilities through a "hollowed out" administrative bureaucracy in a postmodern era (Rhodes, 1997; Frederick, 2007). The Oregon Legislature used its legal and financial resources to create conditions believed to achieve cost reductions in Medicaid 
and promote efficiency and quality improvements in the health care delivery system (Skelcher, 2007).

According to Forbes et al. (2007), the services delivered and utilized serve as outputs of the U.S. health care industry, with the health status of individuals and populations serving as outcomes. In Medicaid, the outputs and outcomes are the result of complex interactions among interdependent organizations, public and private, with public policies that specify "rules" and "allocate" resources to organizations (Forbes et al., 2007, p. 474). Without an adequate understanding of the governance structure or arrangements, and processes, it will be difficult to (1) determine what factors or attributes of CCOs facilitate success or failure, and (2) assess outcomes at two levels. The first level is the $\mathrm{CCO}$ in terms of community health status; the second level is collaborative governance as a model to address complex social issues including delivery of publicly funded health and human services at the community level. The study sought to address the question posed by Alexander and Zuckerman (1989) 25 years ago about whether health care organizations such as CCOs "are community service organizations or competitive business entities" (p. 762). A critical question is whether for-profit versus nonprofit matters. Based on the study results, the notion of for-profit versus nonprofit may influence the outputs and outcomes of Oregon's Medicaid delivery systems in the future.

This study developed insights into similarities and differences among CCO governance structures by investigating three CCOs. The study advances our present understanding of the potential and limitations of collaborative governance as a promising new model to effect health care reform. As stated by Rhodes (1997), "Messy problems 
OREGON HEALTH REFORM AND COORDINATED CARE ORGANIZATIONS 234

demand messy solutions" (p. 15). Oregon's financing and delivery of Medicaid services illustrates a messy problem: CCOs are potentially messy, yet also have the ability to create an innovative solution that offers a new strategy designed around creating new complex organizations that build trust through collaboration in a resource-scarce and competitive environment.

As governmental organizations continue to recognize the limitations of the traditional command-and-control, hierarchical model of governing, collaborative governance serves as a new model for public agencies to use formal authority to address particular governance challenges by creating new processes of collaboration over time among a complex set of organizations that span the multiple sectors of public, private, and nonprofit. The potential for federal, state, and local governmental agencies to create and influence the conditions for collaborate governance in sectors beyond health care holds promise. Through public policy, including establishing new laws and rule-making, public institutions can enhance their ability to govern and achieve public policy goals by forming new public-private partnerships through collaborative governance. In the specific example of Oregon, which provided the basis for this study, the new coordinated care organizations can promote effective collaborative governance across communities and help Oregon along its path to achieve the Triple Aim and improve the health of Oregonians through cost-effective delivery of Medicaid services. 
OREGON HEALTH REFORM AND COORDINATED CARE ORGANIZATIONS 235

\section{References}

Andrulis, D. (1998). Access to care is the centerpiece in the elimination of socioeconomic disparities in health. Annals of Internal Medicine, 129(5), 412-416.

Agranoff, R., \& McGuire, M. (2003). Collaborative public management: New strategies for local governments. Washington, DC: Georgetown University Press.

Alexander, J., \& D’Aunno, T. (2003). Alternative perspectives on institutional and market relationships in the U.S. health care sector. In S. Mick, \& M. Wyttenbach, M. (Eds.) Advances in health care theory ( $1^{\text {st }}$ ed.) (pp. 45-47). San Francisco, CA: Wiley \& Sons.

Alexander, J., \& Zuckerman, H. (1989). Health care governance, are we keeping pace? The Journal of Health Administration Education, 7(4), 760-77.

Alexander, J., Zuckerman, H., \& Pointer, D. (1995). The challenges of governing integrated health care systems. Health Care Management Review, 20(4), 69-81.

Altman, D., \& Morgan, D. (1983). The role of state and local government in health. Health Affairs, 2(4), 1-12.

Ansell, C., \& Gash, A. (2007). Collaborative governance in theory and practice. Journal of Public Administration Research and Theory, 18(4), 543-571.

Baicker, K., Taubman, S., Allen, H., Bernstein, M., Gruber, J., Newhouse, J., et al. (2013). The Oregon Experiment: Effect of Medicaid on clinical outcomes. New England Journal of Medicine, 368(18) 1713-1722. 
OREGON HEALTH REFORM AND COORDINATED CARE ORGANIZATIONS 236

Bazzoli, G., Dynan, L., Burns, L., \& Yap, C. (2004). Two decades of organizational changes in health care: What have we learned? Medical Care Research Review, 61(3), 247-331.

Berk, M., \& Schur, C. (1998). Access to health care: How much difference does Medicaid make? Health Affairs, 17(3), 169-180.

Berwick, D., Nolan, T., \& Whittington, J. (2008). The triple aim: care, health and cost. Health Affairs, 27(3), 759-69.

Bingham, L., Nabatchi, T., \& O'Leary, R. (2005). The new governance: Practices and processes for stakeholder and citizen participation in the work of government. Public Administration Review, 65(5), 547-558.

Bingham, L. (2010). The next generation of administrative law: Building the legal infrastructure for collaborative governance. Journal of Dispute Resolution, 269, 298-359.

Bodenheimer, T. (1997). The Oregon Health Plan: Lessons for the nation, second of two parts. The New England Journal of Medicine, 337(10), 720-723.

Bovbjerg, R., Wiener, J., \& Housman, M. (2003). State and federal roles in health care: Rationales for allocating responsibilities. In J. Holahan, A., Weil, \& J. Wiener (Eds.), Federalism and health policy (pp. 25-57). Washington DC: The Urban Institute Press.

Boyd, D. (2003). The bursting state fiscal bubble and state Medicaid budgets. Health Affairs, 22(1), 46-61. 
OREGON HEALTH REFORM AND COORDINATED CARE ORGANIZATIONS 237

Bringer, J., Johnston, H.\& Brackenridge, C. (2004). Maximizing transparency in a doctoral thesis: The complexities of writing about the use of QSR*NVIVO within a grounded theory study. Qualitative Research 4 (2): 247-65.

Brown, L. (1991). The national politics of Oregon's rationing plan. Health Affairs, 10(2), 28-51.

Brown, L., \& Sparer, M. (2001). Window shopping: State health reform politics in the 1990s. Health Affairs, 20(1), 50-67.

Brown, L., \& Sparer, M. (2003). Poor program's progress: The unanticipated politics of Medicaid policy. Health Affairs, 22(1), 31-44.

Centers for Medicare and Medicaid (2012, January). National health expenditure projections 2010-2020: Forecast summary. Retrieved from https://www.cms.gov/Research-Statistics-Data-and-Systems/Statistics-Trendsand-Reports/NationalHealthExpendData/Downloads/proj2010.pdf

Cohen, R., \& Martinez, M. (2011, September). Health insurance coverage: Early release of estimates from the national interview survey, January-March, 2011. Retrieved from National Center for Health Statistics: http://www.cdc.gov/nchs/data/nhis/earlyrelease/insur201109.pdf

Commonwealth Fund (2011, October). Why not the best? Results from the national scorecard on U.S. health system performance, 2011. Retrieved from http://www.commonwealthfund.org/Publications/Fund-Reports/2011/Oct/WhyNot-the-Best-2011.aspx?page=all

Cooper, P. (2003). Governing by contract: Challenges and opportunities for 
OREGON HEALTH REFORM AND COORDINATED CARE ORGANIZATIONS 238

public managers. Washington DC: CQ Press.

Creswell, J. W. (2009). Research design: Qualitative, quantitative, and mixed methods approaches $\left(3^{\text {rd }}\right.$ ed.). Thousand Oaks, CA: Sage.

Daniels, S., \& Walker, G. (2001). Working through environmental conflict: The collaborative learning approach. Westport, CT: Praeger.

Denzin, N., \& Lincoln, Y. (2000). The Handbook of qualitative research $\left(2^{\text {nd }}\right.$ Ed.). Thousand Oaks, CA: Sage.

Depoy, E., \& Gitlin, L. (1998). Introduction to research: Understanding and applying multiple strategies. St. Louis, MO: Mosby.

Devoe, J., Krois, L., Edlund, T., Smith, J., \& Carlson, N. (2008). Uninsurance among children whose parents are losing Medicaid coverage: Results from a statewide survey of Oregon Families. Health Services Research, 43(1), 401-418.

DiMaggio, P., \& Powell, W. (1983). The iron cage revisited: Institutional isomorphism and collective rationality in organizational fields. American Sociological Review, 48(2), 147-60.

DiPrete, B., \& Coffman, D. (2007). A brief history of health services prioritization in Oregon. Retrieved from http://www.oregon.gov/OHA/OHPR/HSC/PrioritizationHistory.shtml.

Engel, J. (2006). Poor people's medicine: Medicaid and American charity care since 1965. Durham, NC: Duke University Press.

Forbes, M., Hill, C., \& Lynn, L. (2007). The logic of governance in health care. Public Management Review, 9(4), 453-477. 
OREGON HEALTH REFORM AND COORDINATED CARE ORGANIZATIONS 239

Frederickson, G. (2007). Whatever Happened to Public Administration? Governance, Governance Everywhere. In E. Ferlie, L. Lynn, \& C. Pollitt (Eds.) The Oxford Handbook of Public Management (pp. 282-304). Oxford: University of Oxford Press.

Freeman, J. (1997). Collaborative governance in the administrative state. UCLA Law Review, 45(1), p. 1-96.

Fung, A., \& Wright, E. (2001). Deepening democracy: Innovations in empowered participatory governance. Politics and Society, 29(1), 5-41.

Gold, M., Mittler, J., Aizer, A., \& Lyons B. (2001). Health insurance expansion through states in a pluralistic system. Journal of Health Politics, Policy and Law, 26(3), $581-615$.

Goldberger, S. (1990). The politics of universal access: The Massachusetts Health Security Act of 1988. Journal of Health Politics, Policy and Law, 15(4), 857-859.

Goldsmith, S., \& Eggers, W. (2004). Governing by network: The new shape of the public sector. Brooking Institution.

Goldsmith, J. (2003). The road to meaningful reform: A conversation with Oregon's John Kitzhaber. Health Affairs, 22(1), 114-124.

Gray, B. (1989). Collaborating: Finding common ground for multiparty problem. San Francisco: Jossey-Bass.

Gunton, T., \& Day, J.C. (2003). The theory and practice of collaborative planning in resource and environmental management. Environments, 31(2), 5-19. 
OREGON HEALTH REFORM AND COORDINATED CARE ORGANIZATIONS 240

Guo, C., \& Acar, M. (2005). Understanding collaboration among nonprofit organizations:

Combining resource dependency, institutional, and network perspectives. Nonprofit and Voluntary Sector Quarterly, 34(3), 340-361.

Hadley, J. (2003). Sicker and poor - the consequences of being uninsured: A review of the research on the relationship between health insurance, medical care use, health, work, and income. Medical Care Research and Review, 60(2), s3-s75.

Hargraves, J., \& Hadley, J. (2003). The contribution of insurance coverage and community resources in reducing racial/ethnic disparities in access to care. Health Services Research, 38(3), 809-829.

Health Affairs (2010, July 27). Health policy brief: Accountable Care Organizations. Retrieved from http://www.healthaffairs.org/healthpolicybriefs/brief.php?brief_id=23

Health Share (2013, March 8). Health Share of Oregon Transformation Plan. Retrieved from: http://www.oregon.gov/oha/OHPB/CCOTransformationPlans/Health\%20Share\% 20Narrative.pdf

Hill, C., \& Lynn. L (2001). What do we Know About Governance? An Analysis of Empirical Research. Prepared for the $6^{\text {th }}$ National Public Management Research Conference, Bloomington, Indiana, October 18-20, 2001. Retrieved from www.spea.indiana.edu/npmrc6/Hill-Lynn.doc. 
OREGON HEALTH REFORM AND COORDINATED CARE ORGANIZATIONS 241

Holahan, J., Weil, A., \& Wiener, J. (2003). Federalism and health policy: An overview. In Holahan, J., Weil, A., \& J. Wiener (Eds.), Federalism and health policy (pp. 123). Washington DC: The Urban Institute Press.

Imperial, M. (2005). Using collaboration as a governance strategy: Lessons from six watershed management programs. Administration and Society, 37 (3), 281-320.

Institute of Medicine (2001). Crossing the quality chasm: A new health system for the $21^{\text {st }}$ century. Washington, DC: National Academy Press.

Jacobs, L., Marmor, T., \& Oberlander, J. (1999). The Oregon Health Plan and the political paradox of rationing: What advocates and critics have claimed and what Oregon did. Journal of Health Politics, Policy and Law, 24(1), 161-180.

Justice, D., Hess, C., \& Weil, A. (2009, November). State policymakers' priorities for improving the health system. National Academy for State Health Policy. Retrieved from http://www.nashp.org/sites/default/files/Policymakers Priorities[1]\%20final.pdf. Kaiser Commission on Medicaid and the Uninsured (2011, October). Affect of the Medicaid fiscal relief provisions in the American Recovery and Reinvestment Act (ARRA): Policy brief (Pub. No. 8252). Retrieved from Kaiser Family Foundation: www.kff.org/medicaid/upload/8252.pdf

Kaiser Family Foundation (2009, March 18). National Health Insurance - A brief health of reform efforts in the U.S. (Pub. No. 7871). Retrieved from http://www.kff.org/healthreform/7871.cfm 
OREGON HEALTH REFORM AND COORDINATED CARE ORGANIZATIONS 242

Kettl, D. (1993). Sharing power: Public Governance and private markets. Washington DC: Brookings Institution.

Kingdon, J. W. (1995). Agendas, alternatives, and public policies (2nd ed.). New York: Harper Collins.

Kitzhaber, J. (1993). The Oregon Health Plan: A process for reform. The Journal of Bone and Joint Surgery, 75-A(7), 1074-1079.

Kumar, K. \& van Dissel, H. (1996). Sustainable collaboration: Managing conflict and cooperation in interorganizational systems. MIS Quarterly, 20(3), 279-300.

Kvale, S., \& Brinkman, S. (2009). Interviews: Learning the Care of Qualitative Research Interviewing. Thousand Oaks, CA: Sage.

Lang, G., \& Heiss, G. (1990). A practice guide to research methods. Lanham, Md.: University Press of America.

Lawrence, T., Phillips, N., \& Hardy, C. (1999). Watching whale-watching: Exploring the discursive foundation of collaboration relationships. The Journal of Applied Behavioral Science, 35(4), 479-502.

Lasker, R., \& Weiss, E. (2003). Broadening participation in community problem-solving: A multidisciplinary model to support collaborative practice and research. Journal of Urban Health, 80(1), 14-60.

Leedy, P. D., \& Ormrod, J. E. (2005). Practical research: Planning and design ( $8^{\text {th }}$ ed.). Upper Saddle River, NJ: Prentice Hall.

Leichter, H. (1999). Oregon's bold experiment: Whatever happened to rationing. Journal of Health Politics, Policy and Law, 24(1), 147-160. 
OREGON HEALTH REFORM AND COORDINATED CARE ORGANIZATIONS 243

Lillie-Blanton, M., \& Hoffman, C. (2005). The role of health insurance coverage in reducing racial/ethnic disparities in health care. Health Affairs, 24(2), 398-408.

Lincoln, Y., \& Guba, E. (1985). Naturalistic Inquiry. Thousand Oaks, CA: Sage.

Liu, K., Wiener, J., \& Niefeld, M. (2006). End of life Medicare and Medicaid expenditures for dually eligible beneficiaries. Health Care Financing, 27(2), 95110.

Lowndes, V., \& Skelcher, C. (1998). The dynamics of multi-organizational partnerships: An analysis of changing models of governance. Public Administration, 76, 313333.

Lynn, L., Heinrich, C., \& Hill, C. (2002). Improving governance, a new logic for empirical research. Washington DC: Georgetown University Press.

Machiavelli, N. (1950). The prince and the discourses. Translated by Ricci, L. New York: Modern College Library College Edition, McGraw-Hill?.

Margerum, R. (2002). Collaborative planning: Building consensus and building a distinct model for practice. Journal of Planning Education and Research, 21(3) 237-53.

Marmot, M., Wilkinson, R. (2006). Social determinants of health ( $2^{\text {nd }}$ ed.). Oxford: University of Oxford Press.

Marshall, C., \& Rossman, G. (2006). Designing Qualitative Research. Thousand Oaks, CA: Sage.

Merriam, Sharan B. (1998) Qualitative Research and Case Study Applications in Education. San Francisco: Jossey-Bass. 
OREGON HEALTH REFORM AND COORDINATED CARE ORGANIZATIONS 244

Meyer, J., \& Rowan, B. (1977). Institutional organizations: Formal structure as myth and ceremony. American Journal of Sociology, 83(2), 340-363.

Meyer, J., \& Scott, R. (1992). Organizational environments, ritual and rationality. Newbury Park, CA: Sage.

McNabb, D. (2002). Research methods in public administration and nonprofit management ( $2^{\text {nd }}$ ed.). Armonk, NY: M.E. Sharpe.

Mead, L. (1977). The need for governance. Annals of the American Academy of Political and Social Science, 434, 39-57.

Mick, S., \& Wyttenbach, M. (2003). Themes, discovery, and rediscovery. In S. Mick \& M. Wyttenbach. (Eds.) Advances in health care theory (1 ${ }^{\text {st }}$ ed.) (pp. 1-22). San Francisco, CA: Wiley \& Sons.

Miller-Millesen, J. (2003). Understanding the behaviors of nonprofit boards of directors: A theory based approach. Nonprofit and Voluntary Sector Quarterly, 32(4), 521547.

Mitchell, S., \& Shortell, S. (2000). The governance and management of effective community health partnerships: A typology for research, policy and practice. The Milbank Quarterly, 78(2), 241-289.

Morone, J. (2001). Introduction. In R. Hackey \& D. Rochefort (Eds.), The new politics of state health policy (pp. 1-7). Kansas City, KA: University Press of Kansas.

National Governors Association (2011). Rx for health reform: Affordable, Accessible, Accountable. Retrieved from 
OREGON HEALTH REFORM AND COORDINATED CARE ORGANIZATIONS 245

http://www.nga.org/files/live/sites/NGA/files/pdf/1007DELIVERYSYSTEMREF

ORM.PDF

Nolte, E., \& McKee, M. (2008). Measuring the health of nations: Updating an earlier analysis. Health Affairs, 27(1), 58-71.

Oberlander, J. (2007). Health reform interrupted: The unraveling of the Oregon Health Plan. Health Affairs, 26(1), w96-w105.

Oregon Department of Consumer and Business Services (2012, January). Health insurance in Oregon. Retrieved from http://www.nsurance.oregon.gov/health_report/3458-health_report-2012.pdf

Office for Oregon Health Policy and Research (2003). The Oregon Health Plan and its components: Report to the $72^{\text {nd }}$ Legislature of the State of Oregon. Retrieved from: http://www.oregon.gov/OHA/OHPR/docs/72legreport.pdf?ga=t

Office for Oregon Health Policy and Research (2000, August). Health care delivery systems in Oregon: A report to the Oregon Health Council. Retrieved from http://www.oregon.gov/OHA/OHPR/RSCH/docs/OHPDeliverySystem.pdf?ga=t

Oregon Health Authority (2012). Coordinated Care Organization implementation proposal: fact sheet. Retrieved February 29, 2012 from: http://www.oregon.gov/OHA/OHPB/health-reform/docs/cco-factsheet.pdf?ga=t Oregon Health Authority (2012, March 19) Oregon's Request for Applications (RFA) for Coordinated Care Organizations, RFA 3042. Retrieved from http://cco.health.oregon.gov 
OREGON HEALTH REFORM AND COORDINATED CARE ORGANIZATIONS 246

Oregon Health Authority (2012, March 1). Oregon's 1115 waiver request. Retrieved from https://cco.health.oregon.gov/DraftDocuments/Pages/CMS-Waiver.aspx

Oregon Health Fund Board (2008, November). Aim High: Building A Healthy Oregon. Retrieved from http://www.oregon.gov/OHA/OHPR/HFB/docs/Final_Report_12_2008.pdf?ga=t

Oregon Health Policy Board (2010, December). Oregon's Action Plan for Health, December 2010. Retrieved from: http://www.oregon.gov/OHA/action-plan/rpt2010.pdf

Oregon Health Policy Board (2012). Coordinated Care Organizations: Implementation proposal. Retrieved from: http://www.health.oregon.gov/OHA/OHPB/healthreform/docs/cco-implementation-proposal.pdf

Paul-Shaheen, P. (1998). The states and health care reform: The road traveled and lessons learned from seven that took the lead. Journal of Health Politics, Policy and Law, 23, (2), 319-363.

Pfeffer, J. \& Salancik, G. (1978). External control of organizations: A resource dependence perspective. Shafritz, J., Ott, J., Jang, S., (Eds.) Classics of Organizational Theory (pp. 521-531). Belmont, CA: Thomson Wadsworth.

Pointer, D., Alexander, J., \& Zuckerman, H. (1995). Loosening the Gordon knot of governance in integrated health care systems. Frontiers of Health Services Management, 11(3), 3-37.

Prybil, L., Levey, S., Peterson, R., Heinrich, D., Brezinski, P., Price, J., et al. 
OREGON HEALTH REFORM AND COORDINATED CARE ORGANIZATIONS 247

(Feb. 2008). Governance in nonprofit community health systems: An initial report on CEO perspectives. Retrieved online from: http://www.americangovernance.com/resources/reports/governance-reports/2008/ Rand (2006). The health insurance experiment: A class Rand study speaks to the current health care reform debate. Rand Corporation. Retrieved from: www.rand.org/pubs/research_briefs/2006/RAND_RB9174.pdf

Rhodes, R. (1997). Understanding governance: Policy networks, governance, reflexivity and accountability. Buckingham: Open University Press

Rhodes, R. (2000). Governance and public administration. In J. Pierre (Ed.), Debating governance (pp. 54-90). Oxford: Oxford University Press.

Rittenhouse, D., Shortell, S., \& Fisher, E. (2009). Primary and accountable care - two essential elements of delivery-system reform. The New England Journal of Medicine, 361(24), 2301-2303.

Ryan, C. (2001). Leadership in collaborative policy-making: An analysis of agency roles in regulatory negotiations. Policy Science, 34 (3-4), 221-45.

Salamon, L. (2002). The tools of government: A guide to the new governance. Oxford: University of Oxford Press.

Salamon, L. (2003). The resilient sector: The state of nonprofit America. Washington DC: Brookings Institution Press.

Saldana, J. (2012). The coding manual qualitative researcher ( $2^{\text {nd }}$ ed.). Thousand Oaks, CA: Sage. 
OREGON HEALTH REFORM AND COORDINATED CARE ORGANIZATIONS 248

Savage, G.,Taylor, R., Rotarius, T., \& Buesseler, J. (1997). Governance of integrated delivery systems/networks: A stakeholder approach. Health Care Management Review, 22(1), 7-20.

Schroeder, S. (2007). We can do better - improving the health of American People. The New England Journal of Medicine, 357, 1221-1228.

Schuster, M., Elizabeth A., McGlynn, \& R. Brook (1999). Taking the pulse of health care in America. Retrieved from Rand Corporation: http://www.rand.org/pubs/research_briefs/RB4524/index1.html

Schwartz, K., \& Damico, A. (2010). Expanding Medicaid under health reform: A look at adults at or below 133 percent of poverty. Kaiser Family Foundation. Retrieved March 20, 2012 from: http://www.kff.org/healthreform/upload/8052-02.pdf

Scott, R. (2003). Organizations: Rational, natural and open systems. Princeton, NJ: Prentice Hall.

Shafritz, J., Ott, S., \& Jang, Y. (2005). Classics of organizational theory $\left(6^{\text {th }}\right.$ Ed.). Belmont, CA: Thompson Wadsworth.

Shi, L., \& Stevens, G. (2005). Vulnerable populations in the United States. San Francisco, CA: Jossey-Bass.

Shi, L., \& Singh, D. (2008). Delivering health care in America: A systems approach $\left(4^{\text {th }}\right.$ ed.). Sudbury, MA: Jones and Bartlett Publishers, Inc.

Shortell, S., Gillies, R., Anderson, A., Mitchell, J., \& Morgan, K. (1993). Creating organized delivery systems: The barriers and facilitators. Hospital and Health Services Administration, 38(4), 447-66. 
OREGON HEALTH REFORM AND COORDINATED CARE ORGANIZATIONS 249

Shortell, S., Casalino, L., \& Fisher, E. (2010). How the Center for Medicare and Medicaid Innovation should test accountable care organizations. Health Affairs, 29(7), 1293-1298.

Singleton, R., \& Straits, B (2005). Approaches to Social Research. New York, NY: Oxford University Press.

Sipes-Metzler, P. (1994). Oregon Health Plan: Ration or reason. Journal of Medicine and Philosophy, 19(4), 305-314.

Skelcher, C. (2007). Public-private partnerships and hybridity. In Ferlie, E., Lynn, L., \& Pollitt, C. (Eds.). The Oxford handbook of public management. New York, NY: Oxford University Press.

Smedley, N. (2008). Moving beyond access: Achieving equity in state health care reform. Health Affairs, 27(2), 447-455.

Smedley, B., Stith, A., \& Nelson, A. (Eds.). (2002). Unequal treatment: Confronting racial and ethnic disparities in health care. Washington DC: Institution of Medicine, National Academy Press.

Smith, B., Graham, Y., \& Guttmacher, S. (2005). Community-based health organizations: Advocating for improvement health. San Francisco, CA: JosseyBass.

Smith, V., Gifford, K., Ellis, E., Rudowitz, R., \& Snyder, L. (2011, October). Moving ahead amid fiscal challenges: A look at Medicaid spending, coverage and policy trends (Pub. No. 8248_ES). Retrieved from Kaiser Family Foundation: http://www.kff.org/medicaid/upload/8248-ES.pdf 
OREGON HEALTH REFORM AND COORDINATED CARE ORGANIZATIONS 250

Sommers, B., Long, S., \& Baicker, K. (2014). Health care reform: A quasi-experimental study changes in mortality after Massachusetts health care reform. Annals of Internal Medicine, 160(9), 585-593.

Sommers, B., Swartz, K., Epstein, A. (2011). Policy makers should prepare for major uncertainties in Medicaid enrollment, costs, and needs for physicians under health reform. Health Affairs, 30(11), 2186-2193.

Stanek, M., Dierker, L., Henderson, M., \& Tollen, L. (2012). Fostering state level policy to support integration delivery systems: Summary of a discussion among state policymakers and delivery system leaders. Retrieved from National Academy for State Health Policy: http://www.nashp.org/publication/fostering-state-policysupport-integrated-delivery-systems-summary-discussion-among

Stake, R. (1994). Case Studies. In N. Denzin \& Y. Lincoln (Eds.) Handbook of Qualitative Research (pp. 236-247). Thousand Oaks, CA: Sage Publications.

Starfield, B., Shi, L., \& Macinko, J. (2005). Contribution of primary care to health systems and health. The Millbank Quarterly, 83(3), 457-502.

Starr, P. (1984). The social transformation of American medicine: The rise of a sovereign profession and the making of a vast industry. New York: Basic Books.

Starr, P. (2011). Remedy and reaction: The peculiar American struggle over health care reform. New Haven, CT: Yale University Press.

Stoker, G. (1998). Governance as theory: Five propositions. International Social Science Journal, 50(155), 17-28. 
OREGON HEALTH REFORM AND COORDINATED CARE ORGANIZATIONS 251

Squires, D. (2012, May). Explaining high health care spending in the United States: An international comparison of supply, utilization, prices and quality. Retrieved from The Commonwealth Fund:

http://www.commonwealthfund.org/Publications/Issue-

Briefs/2012/May/High-Health-Care-Spending.aspx.

Thomas, J., Ketchen, D., Trevino, L., \& McDaniel, R. (1992). Developing

interorganizational relationships in the health care sector: A multicase study. Health Care Management Review, 17(2), 7-19.

Thompson, F., \& Burke, C. (2007). Executive federalism and Medicaid Demonstration Waivers: Implications for policy and democratic process. Journal of Health Politics, Policy and Law, 32(6), 971-1004.

Thompson, J. (2003). Organizations in action. Piscataway, NJ: Transaction Publishers.

Thompson, A., Perry, J., \& Miller, T. (2007). Conceptualizing and measuring collaboration. Journal of Public Administration Research and Theory, 19, 23-56.

Toomey, R., \& Toomey, R. (1993). The role of governing boards in multihospital systems. Health Care Management Review, 18(1), 21-30.

Truffer, C., Klemm, J., Wolfe, C., \& Rennie, K. (2010). 2010 actuarial report on the final outlook for Medicaid. Centers for Medicare and Medicaid Services. Retrieved April 12 from: https://www.cms.gov/Research-Statistics-Data-andSystems/Research/ActuarialStudies/downloads//MedicaidReport2010.pdf 
OREGON HEALTH REFORM AND COORDINATED CARE ORGANIZATIONS 252

Vangen, S., \& Huxham, C. (2003). Nurturing collaborative relationships: Building trust in interorganizational collaboration. Journal of Applied Behavioral Science, 39(1), 5-31.

Wallace, N., McConnell, J., Gallia, C., \& Edlund, T. (2010). Benefit policy and disenrollment of adult Medicaid beneficiaries from the Oregon Health Plan. Journal of Health Care for the Poor and Underserved, 21, 1382-1394.

Weech-Maldonado, R., \& Merril, S. (2000). Building partnerships with the community: Lessons from the Camden Health Improvement Learning Collaborative. Journal of Healthcare Management, 45(3), 189-205.

Weil, A. (2003). There's something about Medicaid. Health Affairs, 22(1), 13-30.

Weil, A., Witgert, K., Scott, J., Gauthier, A., Justice, D., Schwartz, S., Cantrell, C., \& Zemel, S. (2009, November). A state policymakers guide to federal health reform. Retrieved from National Academy for State Health Policy: http://www.nashp.org/sites/default/files/Policymakers\%20Guide\%20Part1.pdf

Weinick, R., Zuvekas, S., \& Cohen, J. (2000). Racial and ethnic differences in access to and use of health care services, 1977-1996. Medical Care Research and Review, 57(1), 36-54.

Weitzman, E. A. 2000. Software and qualitative research. In Handbook of qualitative research, $2^{\text {nd }}$ ed., ed. N. K. Denzin and Y. S. Lincoln, 803-20. Thousand Oaks, CA: Sage. 
OREGON HEALTH REFORM AND COORDINATED CARE ORGANIZATIONS 253

Wholey, D., \& Burns, L. (2003). Understanding health care markets: Actors, products and relations. In S. Mick, \& M. Wyttenbach (Eds.), Advances in Health Care Theory ( $1^{\text {st }}$ ed.) (pp. 99-140). San Francisco: Wiley \& Sons.

Wiener, J. (1992). Oregon's plan for health care rationing: Bold initiative of terrible mistake. The Brookings Review, 10(1), 26-31.

Wolman, D., \& Miller, W. (2004). The consequences of uninsurance on individuals, families, communities, and the nation. The Journal of Law, Medicine, and Ethics, 32(3), 397-403.

World Health Organization (2000). The World Health Report 2000 - health systems; improving performance. Retrieved from http://www.who.int/whr/2000/en/

Wright, B., Carlson, M., Allen, H., Holmgren, A., \& Rustvold, D. (2010). Raising premiums and other costs for Oregon Health Plan enrollees drove many to drop out. Health Affairs, 29(12), 2311-2316.

Yamhill County Care Organizations (2013, February 15). Transformation Plan Yamhill County Care Organization. Retrieved from:

http://www.oregon.gov/oha/OHPB/CCOTransformationPlans/YCCO\%20Narrativ e.pdf

Yin, R. K. (2003). Case study research: Design and methods ( $3^{\text {rd }}$ ed.). Thousand Oaks, CA: Sage.

Zuvekas, S., \& Taliaferro, G. (2003). Pathways to access: Health insurance, the health care delivery system, and racial/ethnic disparities, 1996-1999. Health Affairs, 22(2), 139-153. 


\section{Appendix A: IRB Application}

\section{Project Title \& Prospectus}

Title: “Oregon's Health System Transformation and Coordinated Care Organizations: A Case Study of Collaborative Governance"

Principal Investigator: Oliver J. Droppers, MS, MPH, Portland State University

Dissertation Chair: Sherril B. Gelmon, DrPH, Division of Public Administration

In 2011, the Oregon Legislature and Governor John Kitzhaber through passage of House Bill 3650 laid the foundation for the creation of coordinated care organizations (CCOs). This legislation was the embodiment for transformation of Oregon's health care delivery system around the Triple Aim of improving health, health care, and lowering costs. Oregon's CCOs are intended to create "community-base organizations" governed by health care providers, community members, and organizations responsible for financial risk to create a "more coordinated and affordable, patient-centered health care delivery system" (Oregon Health Authority, 2012, p. 1). ${ }^{32}$ These entities will be responsible for the integration and coordination of physical, mental, behavioral, and dental care services for individuals eligible for Oregon's Medicaid program: the Oregon Health Plan (OHP). Starting September 1, 2012, there are 13 certified CCOs operating in 33 counties covering nearly 500,000 adults and children in OHP.

The proposed multi-case research study will explore CCOs in an effort to understand the process and conditions under which participation and decision-making among stakeholders are facilitated or impeded through a collaborative governance model. This study will observe the governance process in order to be able to assess and evaluate future policy decisions about CCOs, and more broadly, inform state-level health care reform. The theory of collaborative governance offers a promising analytic framework for investigating CCOs. It is unknown whether a preferred model of governance may emerge in terms of facilitating effective CCOs that generate benefits for providers, consumers, local, state and federal agencies, and other stakeholders involved with health care reform efforts. The importance of researching the collaborative governance infrastructure and process is that the presence of a combination of key factors, or their absence, will affect the ability of CCOs to be effective and successful.

32 Oregon Health Authority (2012, May). Coordinated Care Organization implementation proposal: Fact sheet. Retrieved from http://www.oregon.gov/OHA/OHPB/healthreform/docs/cco-factsheet.pdf?ga $=\mathrm{t}$ 


\section{Exemption Claim for Waiver of Review}

This study is part of a doctoral dissertation within the Hatfield School of Government. The application requests an expedited review since the study will examine a public service program, Oregon's CCOs, which are responsible for delivering services for 500,000 individuals enrolled in the Medicaid: the Oregon Health Plan. I anticipate sharing aggregated and de-identified findings through written reports with agency leadership within the Oregon Health Authority to inform early CCO governance arrangements. Research supported through the study includes the collection of existing data, documents, and records that are publicly available except information collected through key informant interviews.

\section{Subject Recruitment}

This purpose of the study is to investigate the collaborative governance model of CCOs by utilizing a mixed-methodology for collecting primary and secondary data among a purposeful sample of Oregon's 13 certified CCOs. Primary data will be collected by conducting two sets of semi-structured interviews. Recruitment of subjects is described below.

Oregon Health Authority and the Office of the Governor

The first set of key interviews will be with 4-6 key informants with the Oregon Health Authority (OHA) and the Governor's Office. Potential participants for the initial interviews include senior leadership and policy advisors within the Oregon Health Authority and the Governor's Office. The purpose of this initial set of interviews is to gather insight and background information from key public officials that led Oregon's effort to establish CCOs through passage of legislation in 2011 and 2012. This initial set of interviews will help guide and inform the CCO selection process, given the in-depth knowledge of these individuals who have been closely involved in the CCO formation and approval process through the OHA and Governor's Office. Specific areas of interest that state officials will be asked to reflect upon include historical and environmental factors unique to the individual CCOs and verification of the presence of facilitative leadership among the study's potential participants.

Officials with the OHA or Governor's Office will not be selecting the CCOs. Rather, these individuals are in a unique position to offer historical local context and information about key environmental factors that might have affected early $\mathrm{CCO}$ formation and implementation efforts across the 13 CCOs in Oregon, particularly initial starting conditions and prior organizational history. The interviewees will also be asked about whether alternative CCOs should be considered in lieu of the four CCOs previously identified as potential participants (see next two sections for selection criteria). If one or more alternatives are suggested, interviewees will be asked to provide their rationale as to why an alternative $\mathrm{CCO}$ ought to be considered. Interviews with key leaders will also offer an opportunity to enhance this applied research study by working to ensure that findings might inform ongoing implementation efforts led by CCOs and overseen by the Oregon Health Authority. The goal of an applied research study, including this study, is 
to construct the study in such a way that findings are relevant and applicable to policymakers and public agencies.

\section{Coordinated Care Organizations (CCOs)}

The second wave of in-depth interviews will be executive staff and board members of CCOs. These interviewees will include Chief Executive Officers/Executive Directors, Chief Financial Officers, and Chairs and Co-chairs of CCOs. Upon selection of the four CCOs to study, 3-4 executive officers and board members will be identified from each $\mathrm{CCO}$ as potential interviewees for the study. The total number of potential CCO interviewees will range from 12-16 participants.

\section{Selection Criteria}

Using pre-constructed selection criteria, and based upon information shared by the initial set of interview participants, four CCOs will be selected for study. Key selection criteria, developed from a review of the theoretical literature related to organizational theory and contemporary governance, include the following: organizational service coverage area (i.e. geography), prior history as a health care organization, history of collaboration, and size and complexity (i.e. geographic coverage area, number of enrolled clients, and number of participating organizations within a $\mathrm{CCO}) .{ }^{33}$ The inclusion criteria consist of CCOs certified by the Oregon Health Authority. The exclusion criterion is any existing Medicaid managed care organization (MCO), certified as a $\mathrm{CCO}$, that has either simply changed the legal status of the existing MCO to a new limited liability company (LLC), or serves as a wholly-owned subsidiary of exiting MCO. Three of the 13 certified CCOs meet the exclusion criteria. From the remaining $10 \mathrm{CCOs,} \mathrm{I} \mathrm{propose} \mathrm{to} \mathrm{study} \mathrm{four} \mathrm{CCOs.}$ This number is because of limitations in resources necessary to support a study of this size and scope. The four organizations selected for inclusion were screened using selection criteria carefully developed, informed and reviewed by my Dissertation Committee. In consultation with my Dissertation Chair, the selected CCOs provide diversity that includes organizational size and structure, geographic coverage area, prior organizational history and starting conditions, and number of participating organizations within a CCO. The four selected CCOs are Health Share of Oregon, PacificSource Community Solutions, Umpqua Health Alliance, and Willamette Valley Community Health. The CEO of each of these CCOs will receive the invitation for the organization to participate; if they decline, another CCO will be contacted.

All interviews will last approximately 45-60 minutes; I will conduct each interview. An email invitation will be sent to each individual potential participant (see Appendices A \& B). Key informants who verbally consent to participate in the interview will be contacted by me to set up a mutually convenient time to conduct the interview. The date, time, and

33 See: Ansell, C., \& Gash, A. (2007). Collaborative governance in theory and practice. Journal of Public Administration Research and Theory, 18(4), 543-571. (or) Pointer, D., Alexander, J., \& Zuckerman, H. (1995). Loosening the Gordon knot of governance in integrated health care systems. Frontiers of Health Services Management, 11(3), 3-37. 
location of the interview will depend on the participant's availability and preferred interview location, such as their place of employment or at an alternate location such as Portland State University. The in-depth interviews will be digitally recorded, and notes will be taken to enable the investigator to capture all the information provided and to accurately represent discussion from the interviews.

Secondary Data Collection

Document analysis is the second form of data collection. Secondary data will be collected through existing published materials including newly enacted policies, statutes, and regulatory frameworks, white papers, documentation from public committees and hearings, and internal CCO application documents; all which are available to the public. There is no implication for the use of publicly available information in terms of this HSRRC application. A structured framework will be developed and used to code collected data into themes with comparisons being explored among potential relations between one of more themes. Legislative reports, internal planning documents (as available), proposed legislative concepts and supporting policy analyses, drafts of CCO legislation, meeting materials including relevant documentation from the Health System Transformation workgroups and corresponding meetings and materials from CCOs, as well as internal analyses and reports prepared to support the CCO legislation will be collected and analyzed. Technical and financial applications submitted to the OHA as part of the $\mathrm{CCO}$ certification process including all planning documents from CCOs will be collected and assessed (as available). Additional pertinent sources of information could include official government records including but not limited to Oregon Administrative Rules, Oregon Revised Statutes, any meeting minutes and related materials generated by entities in the initial stages of becoming and implementing a CCO.

\section{Informed Consent}

Informed Consent

Individuals will consent to participate when they agree to the interview. Participants may refuse to answer any question presented to them, or to exit the study at any time.

Participants will be informed that they may withdraw their consent at any time without penalty. Verbal permission to take notes and digitally record interview sessions will be obtained from the participants prior to commencing the interview, which will be held in a private setting to prevent others (not involved in the conversation) from hearing what is said during the interview. Participants will be encouraged to contact the principal investigator or my dissertation chair to answer questions about any issues discussed both prior and subsequent to their participation.

Key Informant Interviews

All potential participants will be invited to participate in the study via an introductory email (see Appendices A.1 \& A.2). The introductory email will provide a brief introduction describing the purpose and goal of the study and contact information will be provided for the principal investigator. Upon written or verbal acknowledgement and agreement to participate, the principal investigator will schedule the interview(s). 
Prior to starting the interview(s), the principal investigator will provide a brief verbal introduction of the purpose of the study. The interviewer will request a verbal acknowledgment assuring the participant's willingness to participate. Potential participants will be told that they are under no obligation to take part in the study. Refusal to participate is acceptable at any time. All potential participants in this research study will be provided either with a written statement and/or will be read a verbal statement stating, "that you have the right to say 'yes' or 'no' to participating in this study project and that declining to participate in the study, or abstaining from answering certain questions, will not result in any loss of service or result in any other negative consequences." (See Appendices A.3 \& A.4)

\section{First-Person Scenario}

Interview: Executive Staff in OHA \& Governor's Office

"As a member of the Oregon Health Authority's Health System Transformation (HST) leadership team, a partnership between OHA and the Governor's Office, I was invited to participate in an interview that would take approximately 30 minutes by Mr. Droppers as part of his dissertation research at Portland State University. He wanted to ask me questions that arose from my experience in supporting OHA's effort to development and implement coordinated care organizations (CCOs). As part of the OHA HST leadership team, I was interested in participating but had concerns about being interviewed. At first, I was a bit hesitant to grant permission for this request because of the time commitment and I had a couple of questions that I wanted answered. I called Mr. Droppers and found out what type of information he may need to use that could potentially identify me. After speaking with Mr. Droppers, I was assured that he would not use any potentially sensitive information about me and that any information I provided would be kept confidential. I was also informed that any information shared in the interview would be anonymous in any reports, so that I could not be personally linked to any findings. He was willing to listen to my concerns and made me feel safe about participating in the interview. Therefore, we scheduled a time most convenient according to my work schedule. On that date and time, Mr. Droppers arrived at the agreed upon location of my choosing. We met in a secure, private room in my building. Prior to beginning the interview, I was informed of my rights as a study participant and that I could quit at any time. I was also asked for permission for Mr. Droppers to take notes and record our conversation. Mr. Droppers then verbally asked whether I still was willing to participate. I did not foresee any problems from being interviewed, and therefore I proceeded to answer the interview questions."

Interview: CCO Staff and Board Members

“As a board member of one of Oregon's newly formed coordinated care organizations (CCOs), I was invited to participate in an interview that would take approximately 60 minutes. The researcher notified me that they would like to ask questions based upon my experience in helping form my CCO. The research study sounded interesting, but I had concerns about being interviewed because of the internal politics currently at hand within 
my CCO. Initially, I was reluctant to grant permission for this request because of the time commitment and concerns about anonymity and unknown audience for any findings the study resulted in. I had a couple of questions that I needed answered. So I contacted Mr. Droppers and found out what type of information he may need to use that could potentially identify me. After speaking with Mr. Droppers, I was assured he would not use any potentially sensitive information about me and that any information provided during the interview reported in would remain anonymous and not be attributed to the $\mathrm{CCO}$ or myself. After some consideration and speaking with a follow board member about the interview request, I decided to participate. We scheduled a time convenient to my work schedule. On that date and time, Mr. Droppers arrived early. We met in a secure, private room at my organization. Prior to beginning the interview, I was informed of my rights as a study participant and that I could quite at any time. I was also asked for permission for Mr. Droppers to take notes and digitally record my conversation. Mr. Droppers then verbally asked whether I still was willing to participate. I did not foresee any problems from being interviewed but did ask that the interview not be recorded. Mr. Droppers at that point put away the digital recorder and agreed that he would only jot down a few notes during the interview. We agreed, and I proceeded to answer the interview questions."

\section{Potential Risks and Safeguards}

There are no anticipated risks since no identifying information will be made available in any reports generated from the study. Minimal risk to participants includes violation of participant confidentiality through inadvertent divulgence of information to other participants in casual conversation, printed reports or manuscripts, or public presentations. There is no reason to expect any concerns about the interview questions or actual interview process. To manage any potential risks, several precautions will be taken. The interview invitation will include contact information for the HSRRC if interviewees have any questions or concerns about the research study, the interview or their confidentiality. There is a slight possibility that an interviewer's confidentiality could be breached. All electronic and procedural safeguards possible have been established for this research project, so this risk is minimal (see section IX for additional information).

\section{Potential Benefits}

The benefit of the study will be to improve our understanding of a model of community governance intended to improve the health status of individuals and communities by involving local agencies and individuals in an effort to create a new health system that is responsive to, and accountable for, communities across Oregon. Specific benefits include: (1) identifying conditions that facilitate or impede the ability of CCOs to effectively solve problems through governance mechanisms; (2) developing insights into similarities and differences among CCO governance structures; and (3) advancing understanding of the potential for and limitations of a collaborative governance model in supporting health care reform. By learning about conditions that facilitate or impede the ability of CCOs to effectively solve problems through governance mechanisms and 
developing insight into similarities and differences among $\mathrm{CCO}$ governance structures, it may be possible for State officials, governing boards of CCOs, as well as legislative and elected officials to consider meaningful changes related to existing federal and state requirements for CCOs and potentially amend existing contracts between $\mathrm{OHA}$ and CCOs in an effort to further support statewide health care reform. I intend to share my findings with OHA after approval and completion of my dissertation.

Oregon is viewed as a pioneer and leader in state health care reform efforts and is quickly implementing key elements of the federal Affordable Care Act (ACA). Oregon's CCO model serves as a potential model that may inform other states as well as the federal reform efforts aimed to transform the financing and delivery of physical, mental, behavioral, and dental services to Medicaid clients. Findings from this early study have the potential to inform alternative models of health care reform across the country such as Accountable Care Organizations (ACOs). Finally, the study has the potential to advance my professional career as an aspiring health services researcher by examining Oregon's cutting edge and innovative approach to health care reform.

\section{Confidentiality, Records \& Distribution}

Confidentiality

Prior to taking part in the study, all participants will have either read and/or been verbally told about the purpose of the study and that participation is completely voluntary.

Participants will be notified that any information obtained in connection with this study that could be linked to them will be de-identified and remain anonymous. Data will not be used to identify any individual study participant or their organization. All potentially sensitive information will be de-identified and reported in such a way as to protect the identity of relevant individuals and agencies/organizations. No individuals affiliated with the Oregon Health Authority, Governor's Office, or CCOs will have access to the raw data. All data will be reported in the aggregate, and it will not be possible to identify any individual respondent in any reported results. All attempts will be made to completely blind study participants. All written reports or presentations will offer information that is discrete and presented in a manner that protects all study participants and their organization(s) from being identified.

$\underline{\text { Records }}$

All completed interviews and all related data (notes, digital recordings, transcriptions) will be kept in locked cabinets at PSU when not in use. Data entered and stored on the computer will be saved on a computer at PSU in the Hatfield School of Government, only accessible to the principal investigator. All data (interview notes, digital recording files, transcripts etc.) will remain in locked file cabinets for at least three years after the study ends. The principal investigator will control access to the locked files, and electronic data will be solely in the possession of the principal investigator. Only the principal investigator will have access to the data and any identifiable information in digital recordings and transcripts. 
Public Release of Data

No personally identifiable information on study participants will be used in reports, manuscripts, or presentations. All potentially sensitive organizational and personnel information (e.g., official title, proprietary information, etc.) will be de-identified and aggregated to protect the identity of relevant individuals and the agency/organization. If findings from the research study are submitted for publication or dissemination in other arenas, all peer-reviewed presentations and potential manuscripts will be in the aggregate only and will not include the release of raw data. At this time, no plans exist to release data from this study to other researchers.

\section{Training and Experience}

Professional Training and Experience

The research is part of a doctoral program in the Hatfield School of Government. As the principal investigator, I am actively supervised by my Dissertation Committee, with direct supervision by the Committee Chair, Dr. Sherril Gelmon, former Chair, PSU Human Subjects Research Review Committee (HSRRC). Dr. Neal Wallace, another dissertation committee member, currently serves as a member of the PSU HSRRC. From 2005-2011, I worked as a graduate research assistant and research associate at PSU with Dr. Gelmon. This afforded me an opportunity to assist in the preparation of multiple HSRRC applications, develop consent forms and interview protocols, conduct key informant interviews and surveys, analyze findings, and prepare written reports based upon findings from surveys, interviews, and focus groups.

\section{Clarification of Roles and Responsibilities}

It is important to clarify my role as a PSU PhD student by acknowledging my professional responsibilities outside PSU. Currently, I am employed by the Oregon Health Authority and serve in two different positions: (1) Project Director, Children's Health Insurance Program Reauthorization Act (CHIPRA) Quality Demonstration Grant, and (2) Director, Oregon Medicaid Advisory Committee. While my position does not have any direct responsibility or connection to OHA's CCOs, employment by OHA does provide me with access to information that could potentially be perceived as creating a conflict. The purpose of this study is exclusively academic in nature as part of my dissertation and completely separate and independent from my professional responsibilities with the OHA. I will conduct all of my communications from my PSU email account, use my personal cell phone for calls, and not hold any research-related meetings at my office to maintain clear separation between my $\mathrm{PhD}$ studies and my employment.

Nonetheless, if at any time I perceive any potential conflict in my role as a PSU PhD student and my professional role within OHA, I will immediately notify my Dissertation Chair (Dr. Gelmon) and my OHA supervisor, Dr. Jeanene Smith, a PSU MPH:HMP alumna and Administrator of the Office for Oregon Health Policy and Research (OHPR) in OHA. Dr. Gelmon and Dr. Smith are aware of the potential for perception of conflict of interest, and plan to communicate regularly. 


\section{IRB Appendices}

A.1 Oregon Health Authority and Oregon Governor's Office Interview Invitation

A.2 Coordinated Care Organization (CCO) Interview Invitation

A.3 Interview Questionnaire for OHA and Governor's Office Staff

A.4 Interview Questionnaire for Coordinated Care Organizations (CCOs) Staff and/or Board Members 


\title{
Appendix A.1 \\ Oregon Health Authority \& Oregon Governor's Office Interview Invitation
}

\author{
NOTE: The email invitation will be sent by Oliver Droppers from his Portland State \\ University email address.
}

Dear OHA/Governor's Office Official [insert recipient name here]:

You are invited to participate in an interview as part of a research study I am conducting as a PhD candidate in the Public Affairs and Policy Program in the Mark O. Hatfield School of Government at Portland State University (PSU) under the supervision of Dr. Sherril Gelmon, Professor of Public Health and Chair, Division of Public Administration. The purpose of the study is to explore Oregon's coordinated care organizations (CCOs) in an effort to understand the process and conditions under which participation and decision-making among stakeholders within a CCO are facilitated or impeded through different community-based approaches to governance.

During this early CCO implementation phase, there is a unique opportunity to learn about initial starting conditions and contextual factors that might influence the CCO governance process. As a key public official that helped to lead statewide efforts to form CCOs, you can offer valuable historical information about environmental factors that might have affected early $\mathrm{CCO}$ formation and evolving implementation efforts across the 13 certified CCOs. You also have important insights about existing leadership among CCOs and can provide a unique perspective on key factors such as the history of conflict or cooperation within a CCO.

The interview will take approximately 45 minutes, and will be scheduled at your convenience in a location of your choice. With your permission, I will be taking notes and recording the discussion. All individual responses will be kept anonymous in my reporting, and complete confidentiality of your actual responses is assured. The notes and recordings will help me to accurately represent our discussion, but no one except me will ever hear the recordings or see the written transcripts. If there are things that you tell me that you do not wish repeated, please indicate that so that I do not include those comments in any summaries developed from this conversation.

Your willingness to participate in the interview will be viewed as agreement to participate in this phase of the evaluation; no written consent form is requested to minimize the burden of responding with you. I do not intend to link comments back to interviewees. While participating in this study, it is unlikely that you will encounter any risks, as all information provided will be volunteered by you. You may not experience any direct benefits from the study, but it is anticipated that the results will help to inform the Oregon Health Authority in its effort to improve the state's health system transformation efforts, and to assist in future changes that may enhance $\mathrm{CCO}$ governance models in Oregon and elsewhere. 
Your participation in this interview is voluntary. You do not have to answer any question that you do not want to answer, and you may stop the interview at any time without affecting your relationships with the Oregon Health Authority, any other state agencies or CCOs, or Portland State University.

If you have any concerns about your participation in this study or your rights as a research subject, you may contact the Human Subjects Research Review Committee, Office of Research and Strategic Partnerships, Portland State University, 620 Market Center Building, $1600 \mathrm{SW} 4^{\text {th }}$ Avenue, Portland, OR, USA 97201 or by telephone at 503725-4288 or 1-877-480-4400. You may also email the office at hsrrc@lists.pdx.edu. If you have any concerns about the research study, you may contact Dr. Gelmon at 503725-3044 or gelmons@pdx.edu, or me directly at 503-803-1481 or ODropper@pdx.edu.

Your input is very important and will help me to gather important insights about the Oregon's early CCO efforts. If you agree to participate, please send an email to ODropper@pdx.edu indicating your willingness to participate, and I will be in touch with you or your assistant to schedule the interview. Thank you in advance for your input.

Signed: Oliver Droppers, PhD Candidate, Portland State University, Principal Investigator 


\section{Appendix A.2 \\ Coordinated Care Organization Executive Staff/Board Member Interview Invitation}

NOTE: The email invitation will be sent by Oliver Droppers from his Portland State University email address.

Dear [insert recipient name here]:

You are invited to participate in an interview as part of a research study I am conducting as a PhD candidate in the Public Affairs and Policy Program in the Mark O. Hatfield School of Government at Portland State University (PSU) under the supervision of Dr. Sherril Gelmon, Professor of Public Health and Chair, Division of Public Administration. The purpose of the study is to explore Oregon's coordinated care organizations (CCOs) in an effort to understand the process and conditions under which participation and decision-making among stakeholders within a CCO are facilitated or impeded through different community-based approaches to governance.

COOs are leading the effort to transform Oregon's health care delivery system around the Triple Aim of improving health, health care, and lowering costs. As one of the first certified CCOs in Oregon, there is a unique opportunity to learn from [insert name of $\mathrm{CCO}$ ] about the initial set of challenges, opportunities, and lessons learned to date that can help inform future CCOs and guide the development of best practices overtime related to approaches to effective collaborative governance. I will be conducting interviews with 3-4 board members and executive leaders of four of the Oregon approved CCOs in the next few months. I hope you will make the time to share your valuable perspectives.

I will be conducting all of the individual interviews, which will take approximately an hour each. With your permission, I will be taking notes and digitally recording the discussion. All individual responses will be kept anonymous in my reporting, and complete confidentiality of your actual responses is assured. The notes and recordings will help me to accurately represent our discussion, but no one except me will ever hear the recordings or see the written transcripts. If there are things that you tell me that you do not wish repeated, please indicate that so that I do not include those comments in any summaries developed from this conversation. I am confident that I can blind all responses in reports and findings presented from this study due to the participant selection method.

Your willingness to participate in the interview will be viewed as agreement to participate in this phase of the evaluation; no written consent form is requested to minimize the burden of responding on you. I do not intend to link comments back to interviewees. While participating in this study, it is unlikely that you will encounter any risks, as all information provided will be volunteered by you. You may not experience any direct benefits from the study, but it is anticipated that the results will help to inform 
the Oregon Health Authority in its effort to improve the state's health system transformation efforts, and assist in future changes that are may enhance CCO governance models in Oregon. Upon completion of the study, I will gladly share aggregate findings in a written report upon request.

Your participation in this interview is voluntary, and will not affect your relationship with the Oregon Health Authority, affiliated members of your CCO, or any other relationships with the study investigator. You do not have to answer any question that you do not want to answer, and you may stop the interview at any time without affecting your relationships with any state agencies, as this research study is conducted through Portland State University by a PhD candidate and is not funded or affiliated with any other federal, state, or local agency.

If you have any concerns about your participation in this study or your rights as a research subject, you may contact the Human Subjects Research Review Committee, Office of Research and Strategic Partnerships, Portland State University, 620 Market Center Building, $1600 \mathrm{SW} 4^{\text {th }}$ Avenue, Portland, OR, USA 97201 or by telephone at 503725-4288 or 1-877-480-4400. You may also email the office at hsrrc@lists.pdx.edu. If you have any concerns about the research study, you may contact Dr. Gelmon at 503725-3044 or gelmons@pdx.edu, or me directly at 503-803-1481 or ODropper@pdx.edu.

Your input is very important and will help me to gather important insights about the Oregon's early CCO efforts. If you agree to participate, please send an email to ODropper@pdx.edu indicating your willingness to participate, and I will be in touch with you to schedule the interview. Thank you in advance for your input.

Signed: Oliver Droppers, PhD Candidate, Portland State University, Principal Investigator 


\section{Appendix A.3 \\ OHA \& Governor's Office Staff Interview Protocol and Consent Narrative}

I will read the following paragraphs before beginning the interview:

Thank you for making the time to talk with me today for this interview about your experiences in leading Oregon's health care reform efforts, specifically the creation of coordinated care organizations (CCOs). As a key public official that has helped lead statewide efforts to form CCOs across Oregon by working closely with certified CCOs and affiliated organizations, you can provide information about important planning processes, and local political, institutional, and historical factors that might have affected early CCO formation and implementation efforts across CCOs in Oregon.

As CCOs develop, a fundamental challenge will be establishing and maintaining an effective governance model -- one that is able to both meet the criteria proposed by the Oregon Health Authority (OHA) and still be responsive to the needs of its community. The purpose of this study is to learn about conditions that facilitate or impede the ability of CCOs to effectively solve problems through governance mechanisms and identify key factors of collaborative governance. The benefit of this study is it can inform future policy decisions about CCOs, and more broadly inform state-level health care reform.

I have scheduled 45 minutes for this interview. With your permission, I will be taking notes and digitally recording the discussion. Your participation in this interview is voluntary and you may stop the interview at any time. You do not have to answer any question that you do not want to answer. All individual responses will be kept anonymous in any reporting, and complete anonymity of your actual responses is assured.

The intent of these conversations is to help identify key insights related to early development and implementation efforts among Oregon's CCOs from the perspective of state leaders and public officials, so I hope you will be candid. The notes and recordings will help me to accurately represent our discussion, but no one other than me will ever hear the recordings or see the written transcripts. If there are things that you tell me that you do not wish repeated, please indicate this so that I do not include those comments in any summaries I develop from this conversation. Similarly, if at any time you would like me to stop recording, please indicate this and I will turn off the recording device. All comments will be presented without attribution to any individual. The results of these conversations will be synthesized into written summaries that will be analyzed as part of my dissertation study.

At this time, do you have any questions or concerns? [After addressing any questions and/or concerns state...] Then let us begin. 


\section{I have a number of questions to ask you, so please offer brief answers - we can always go back if time permits to expand on any of your answers. First, I would like to ask you some questions that focus on your experience in helping support Oregon's health care reform efforts.}

\section{Questions:}

1. In consultation with my Dissertation Chair, I selected four CCOs that demonstrate variation among important factors such as organizational size and structure, geographic coverage area, prior organizational history and starting conditions, and number of participating organizations within a $\mathrm{CCO}$. The selection criteria were developed from, and informed by, a careful review of theoretical literature. The four preliminary selected CCOs are Health Share of Oregon, PacificSource Community Solutions, Umpqua Health Alliance, and Willamette Valley Community Health. Are there are other CCOs that you would suggest for inclusion or as an alternative based upon this preliminary list of CCOs? If so, please explain your suggestions. (10 minutes)

2. From your perspective, what factors are most important in terms of collaborative governance within a CCO? Examples include composition and structure, prehistory of conflict or cooperation, incentives for, or constraints on participation within a $\mathrm{CCO}$, etc. (10 minutes)

3. Do you have any insights to share about important historical and environmental factors unique to any of the CCOs selected that might affect the study? (10 minutes)

4. Do you have any insights to offer about the importance and role of leadership among the selected CCOs? (5 minutes)

5. Is there anything else you would like to add I have not covered, including any other concerns or thoughts about any of these CCOs? (5 minutes)

Closing: "Thank you for participating in this interview, and for your thoughtful comments, insights, and candor. I am meeting with 4-5 other officials from OHA and the Governor's Office. I will be analyzing and synthesizing the combined responses in order to finalize the $\mathrm{CCO}$ selection process. Findings from the interviews will be included in my dissertation and read by the PSU faculty serving on my dissertation committee. At the conclusion of the study, I would be happy to share any aggregated written findings with the OHA. Again, I appreciate your time and contributions to this dissertation study." 


\section{Appendix A.4 \\ CCO Interview Protocol and Consent Narrative}

Please read the following paragraphs to individuals before beginning with questions:

"My name is Oliver Droppers, and I am a doctoral student in Public Affairs and Policy at Portland State University. As part of my doctoral studies, I am conducting a research project studying Oregon's coordinated care organizations (CCOs). As the [insert position] for the [insert CCO name], you and your newly established $\mathrm{CCO}$ are viewed as key stakeholders in supporting the success of Oregon's health system transformation initiative.

CCOs are at an early phase in their development, and there is a window of opportunity to learn about conditions that facilitate or impede the ability of [insert CCO name] to effectively solve problems through its adopted governance mechanism and develop insights into similarities and differences across CCO governance structures. The purpose of this interview is to capture your perspectives about the early development and implementation of your $\mathrm{CCO}$ and its governance structure, and to identify factors that facilitate or impede achievement of the organization's goals from your professional perspective.

The interview will last approximately one hour. With your permission, I will be taking notes and recording the discussion. Your participation in this interview is voluntary and you may stop it at any time. You do not have to answer any question that you do not want to answer. All individual responses will be kept anonymous and complete confidentiality is assured outside this interview. Since there are only four CCOs that are part of this project, and the intent of these interviews is to help identify opportunities for improvement in this project, it may be some what difficult to completely blind the organization that is the source of the comments, but I will de-identify individual respondents.

The notes and recordings will help me to accurately represent our discussion, but no one other than me will ever hear the recordings or see the written transcripts. If there are things that you tell me that you do not wish repeated, please indicate this so that I do not include those comments in any summaries I develop from this conversation. Similarly, if at any time you would like me to stop the recorder, please indicate this and I will turn off the recording device. All comments will be presented without attribution to any individual. The results of these conversations will be synthesized into written summaries that will be analyzed as part of my dissertation study.

At this time, do you have any questions or concerns? [After addressing and questions and/or concerns state...] Then let us begin. 


\section{I have a number of questions to ask you, so please offer brief answers - we can always go back if time permits to expand on any of your answers. Also, please respond knowing that I have already read your organization's application to $\mathrm{OHA}$ to be recognized as a $\mathrm{CCO}$ as well as pertinent background information.}

Questions:

6. I would like you to think back to the events that lead up to the creation of the [insert CCO name]. Please describe the key events that occurred, identifying what occurred, who were the key players, and when these events occurred. Also, were there any organizations excluded from participating or any that or opted out? If so, why? (5 minutes). Please try to do this in chronological order, but we can skip around if necessary. (10 minutes)

7. Please describe the existing partnership, organizational structure, and prior relationship among the key players within [insert CCO name]. For example, does your CCO have a formal agreement between partner organizations or any guidelines or rules that govern activities including how decisions are made by the CCO board? (10 minutes)

8. How does your organization set priorities and problem-solve through its existing governance structure? For example, does your CCO use standard operational procedures such as formal rules, policies, and committees, or do you have an open, transparent, and inclusive process? (10 minutes)

9. What arrangements do you think work well in your CCO's decision-making process? For example, is there mutual recognition of interdependence within your community, a shared purpose, common problem definition, or shared mission and set of values? Alternatively, what arrangements do you think are not helpful for your organization to date? (10 minutes)

10. Have there been any events or incidents that have created barriers or challenges to establishing an effective governance structure or decision-making? What arrangements would you suggest as helpful to improve the governance structure or decision-making processes of your CCO? (10 minutes)

11. Is there anything else you would like to add that I have not covered? (5 minutes)

Closing: "Thank you for participating in this interview, and for your thoughtful comments, insights and candor. I am meeting with 2-3 other board members from your $\mathrm{CCO}$ as well as from three other CCOs. I will be analyzing and synthesizing the key themes and issues that emerge over the course of the study. If you think of anything else, please contact me. Findings from the interviews will be included in my dissertation and read by PSU faculty serving on my dissertation committee. At the conclusion of the 
study, I would be happy to share any aggregated written findings with your organization. Again, I appreciate your time and contributions to this dissertation study." 


\section{Appendix B: Coordinated Care Organization (CCO): Selection Criteria Matrix (*as of Sept. 2012)}

\begin{tabular}{|c|c|c|c|c|c|c|}
\hline \multirow[b]{2}{*}{$\begin{array}{l}\text { Coordinated } \\
\text { Care } \\
\text { Organization }\end{array}$} & \multicolumn{2}{|c|}{ Organizational Size } & \multirow{2}{*}{$\begin{array}{c}\text { Starting } \\
\text { Conditions } \\
\text { Prior Org. } \\
\text { History: } \\
\text { Yes, Some, } \\
\text { No }\end{array}$} & \multicolumn{2}{|c|}{$\begin{array}{c}\text { Organizational } \\
\text { Structure/Composition }\end{array}$} & \multirow{2}{*}{$\begin{array}{c}\text { Facilitative } \\
\text { Leadership } \\
\\
\text { (High, } \\
\text { Medium, } \\
\text { or Low) }\end{array}$} \\
\hline & $\begin{array}{c}\text { Geographic } \\
\text { Service } \\
\text { Area }(b y \\
\text { County) } \\
1-2,3-4, \geq 5\end{array}$ & $\begin{array}{c}\text { Number } \\
\text { of } \\
\text { Enrollees }\end{array}$ & & $\begin{array}{c}\text { New/ } \\
\text { Existing } \\
\text { Org. }\end{array}$ & $\begin{array}{l}\text { Number of } \\
\text { Partnering } \\
\text { Orgs. } \\
1-2,3-9, \geq 10\end{array}$ & \\
\hline $\begin{array}{l}\text { AllCare Health } \\
\text { Plan }\end{array}$ & $\begin{array}{c}\text { All of } \\
\text { Curry, } \\
\text { Josephine, } \\
\text { Jackson and } \\
\text { part of } \\
\text { Douglas } \\
\text { counties (4) }\end{array}$ & 23,000 & $\begin{array}{c}\text { Yes: } \\
\text { IPA/MCO, } \\
\text { Mid Rogue } \\
\text { Independent } \\
\text { Physicians } \\
\text { Associations, } \\
\text { Inc. }\end{array}$ & $\begin{array}{c}\text { Existing } \\
\text { Org. } \\
\text { [No change] }\end{array}$ & $\begin{array}{c}\text { One } \\
\text { organization }\end{array}$ & $T B D$ \\
\hline $\begin{array}{l}\text { Columbia } \\
\text { Pacific } \\
\text { Coordinated } \\
\text { Care } \\
\text { Organization, } \\
\text { LLC }\end{array}$ & $\begin{array}{c}\text { All of } \\
\text { Clatsop, } \\
\text { Columbia \& } \\
\text { Tillamook. } \\
\text { Parts of } \\
\text { Coos \& } \\
\text { Douglas } \\
\text { counties (5) }\end{array}$ & 9,000 & $\begin{array}{l}\text { Some } \\
\text { history: } \\
\text { MCO } \\
\text { and } \\
\text { MHO }\end{array}$ & $\begin{array}{c}\text { New: } \\
\text { Wholly- } \\
\text { owned } \\
\text { subsidiary } \\
\text { of } \\
\text { CareOregon, } \\
\text { new as a } \\
\text { 501@ (3) }\end{array}$ & $\begin{array}{l}\text { Two } \\
\text { organizati } \\
\text { ons }\end{array}$ & $T B D$ \\
\hline $\begin{array}{l}\text { Eastern Oregon } \\
\text { Coordinated } \\
\text { Care } \\
\text { Organization } \\
\text { (EOCCO) }\end{array}$ & $\begin{array}{l}\text { Baker, } \\
\text { Malheur, } \\
\text { Sherman, } \\
\text { Union, } \\
\text { Wallowa (5) }\end{array}$ & 9,500 & $\begin{array}{l}\text { Some } \\
\text { history: } \\
\text { MCO \& } \\
\text { MHO }\end{array}$ & New: LLC & $\begin{array}{c}\text { Two } \\
\text { organizations } \\
\text { ODS and } \\
\text { Greater } \\
\text { Oregon } \\
\text { Behavioral } \\
\text { Health } \\
\text { (GOBHI) }\end{array}$ & $T B D$ \\
\hline $\begin{array}{l}\text { FamilyCare, } \\
\text { Inc. }\end{array}$ & $\begin{array}{l}\text { Clackamas, } \\
\text { Multnomah, } \\
\text { Washington, } \\
\text { \& part of } \\
\text { Marion } \\
\text { County (4) }\end{array}$ & 54,294 & Yes: MCO & $\begin{array}{c}\text { Existing } \\
\text { MCO } \\
\text { 20+ years as } \\
\text { a MCO [No } \\
\text { change] }\end{array}$ & $\begin{array}{c}\text { One } \\
\text { organization }\end{array}$ & $T B D$ \\
\hline $\begin{array}{l}\text { Health Share of } \\
\text { Oregon }\end{array}$ & $\begin{array}{l}\text { Clackamas, } \\
\text { Multnomah } \\
\& \& \\
\text { Washington } \\
\text { counties (3) }\end{array}$ & 158,000 & No & $\begin{array}{l}\text { New: } \\
\text { Public } \\
\text { benefit } \\
\text { corporation }\end{array}$ & $\begin{array}{l}11 \text { private } \\
\text { and public } \\
\text { affiliates } \\
\text { form Health } \\
\text { Share }\end{array}$ & $T B D$ \\
\hline $\begin{array}{l}\text { Intercommunity } \\
\text { Health Network } \\
\text { Coordinated } \\
\text { Care } \\
\text { Organization }\end{array}$ & $\begin{array}{c}\text { All of } \\
\text { Benton, } \\
\text { Lincoln \& } \\
\text { Linn } \\
\text { counties (3) }\end{array}$ & 32,100 & $\begin{array}{l}\text { Some } \\
\text { history: } \\
3 \text { existing } \\
\text { MCOs }\end{array}$ & $\begin{array}{l}\text { New: } \\
\text { Public } \\
\text { benefit } \\
\text { corporation }\end{array}$ & $\begin{array}{l}13 \text { private } \\
\text { and public } \\
\text { affiliates } \\
\text { form IHN- } \\
\text { CCO }\end{array}$ & $T B D$ \\
\hline
\end{tabular}




\begin{tabular}{|c|c|c|c|c|c|c|}
\hline \multirow[b]{2}{*}{$\begin{array}{l}\text { Coordinated } \\
\text { Care } \\
\text { Organization }\end{array}$} & \multicolumn{2}{|c|}{ Organizational Size } & \multirow{2}{*}{$\begin{array}{c}\text { Starting } \\
\text { Conditions } \\
\text { Prior Org. } \\
\text { History: } \\
\text { Yes, Some, } \\
\text { No }\end{array}$} & \multicolumn{2}{|c|}{$\begin{array}{c}\text { Organizational } \\
\text { Structure/Composition }\end{array}$} & \multirow{2}{*}{$\begin{array}{c}\text { Facilitative } \\
\text { Leadership } \\
\begin{array}{c}\text { (High, } \\
\text { Medium, } \\
\text { or Low) }\end{array}\end{array}$} \\
\hline & $\begin{array}{c}\text { Geographic } \\
\text { Service } \\
\text { Area (by } \\
\text { County) } \\
1-2,3-4, \geq 5\end{array}$ & $\begin{array}{c}\text { Number } \\
\text { of } \\
\text { Enrollees }\end{array}$ & & $\begin{array}{l}\text { New/ } \\
\text { Existing } \\
\text { Org. }\end{array}$ & $\begin{array}{c}\text { Number of } \\
\text { Partnering } \\
\text { Orgs. } \\
1-2,3-9, \geq 10\end{array}$ & \\
\hline \multicolumn{7}{|l|}{ (IHN-CCO) } \\
\hline $\begin{array}{l}\text { Jackson Care } \\
\text { Connect (JCC) }\end{array}$ & $\begin{array}{c}\text { Jackson } \\
\text { County (1) }\end{array}$ & 18,000 & $\begin{array}{c}\text { Yes: existing } \\
\text { MCO, } \\
\text { wholly- } \\
\text { owned } \\
\text { subsidiary of } \\
\text { CareOregon }\end{array}$ & $\begin{array}{l}\text { Existing } \\
\text { MCO }\end{array}$ & $\begin{array}{l}10 \text { private } \\
\text { and public } \\
\text { affiliates } \\
\text { form JCC }\end{array}$ & $T B D$ \\
\hline $\begin{array}{l}\text { PacificSource } \\
\text { Community } \\
\text { Solutions } \\
\text { (PSCS) [Central } \\
\text { Oregon Region] }\end{array}$ & $\begin{array}{c}\text { All of } \\
\text { Deschutes, } \\
\text { Crook \& } \\
\text { Jefferson \& } \\
\text { part of } \\
\text { Klamath } \\
\text { County (4) }\end{array}$ & 38,900 & $\begin{array}{c}\text { Some } \\
\text { history: } \\
\text { Existing } \\
\text { MCO/MHO }\end{array}$ & New: LLC & $\begin{array}{c}9 \text { private and } \\
\text { public } \\
\text { affiliates } \\
\text { form PSCS }\end{array}$ & $T B D$ \\
\hline $\begin{array}{l}\text { Primary Health } \\
\text { of Josephine } \\
\text { County, LLC }\end{array}$ & $\begin{array}{c}\text { Josephine } \\
\text { County \& } \\
\text { parts } \\
\text { Douglas \& } \\
\text { Jackson } \\
\text { counties (3) }\end{array}$ & 5,500 & $\begin{array}{c}\text { Yes: existing } \\
\text { MCO \& } \\
\text { MHO, } \\
\text { wholly- } \\
\text { owned } \\
\text { subsidiary of } \\
\text { CareOregon }\end{array}$ & New: LLC & $\begin{array}{c}\text { Two } \\
\text { organizations }\end{array}$ & $T B D$ \\
\hline $\begin{array}{l}\text { Trillium } \\
\text { Community } \\
\text { Health Plan }\end{array}$ & $\begin{array}{l}\text { All of Lane } \\
\text { County (1) }\end{array}$ & 47,700 & $\begin{array}{c}\text { Yes: } \\
\text { IPA/MCO } \\
\text { Lane } \\
\text { Individual } \\
\text { Practice } \\
\text { Association }\end{array}$ & $\begin{array}{c}\text { New: for- } \\
\text { profit LLC } \\
(96 \% \\
\text { control by } \\
\text { physicians) }\end{array}$ & $\begin{array}{c}\text { Three } \\
\text { organizations } \\
\text { (MCO, } \\
\text { MHO and } \\
\text { County } \\
\text { partnership) }\end{array}$ & $T B D$ \\
\hline $\begin{array}{l}\text { Umpqua Health } \\
\text { Alliance }\end{array}$ & $\begin{array}{c}\text { Most of } \\
\text { Douglas } \\
\text { County (1) }\end{array}$ & 16,300 & $\begin{array}{l}\text { Yes: IPA } \\
\text { Douglas } \\
\text { Country } \\
\text { Independent } \\
\text { Practice } \\
\text { Association } \\
\text { (20+ years) }\end{array}$ & New: LLC & $\begin{array}{c}\text { Four } \\
\text { organizations } \\
\text { (MHO, } \\
\text { DCO, } \\
\text { FQHC, } \\
\text { hospital) }\end{array}$ & $T B D$ \\
\hline $\begin{array}{l}\text { Western } \\
\text { Oregon } \\
\text { Advanced } \\
\text { Health, LLC } \\
\text { (WOAH) }\end{array}$ & $\begin{array}{l}\text { All of Coos } \\
\text { and Curry } \\
\text { counties (2) }\end{array}$ & 11,500 & $\begin{array}{c}\text { Some } \\
\text { history: IPA, } \\
\text { Southwest } \\
\text { Oregon } \\
\text { Independent } \\
\text { Practice } \\
\text { Organization } \\
\text { (18 years, } \\
\text { prior history } \\
\text { as single } \\
\text { MCO) } \\
\end{array}$ & New: LLC & $\begin{array}{c}18+\text { affiliates } \\
\text { including } \\
\text { MCO, MHO, } \\
\& \text { DCO from } \\
\text { WOAH }\end{array}$ & $T B D$ \\
\hline
\end{tabular}


OREGON HEALTH REFORM AND COORDINATED CARE ORGANIZATIONS 274

\begin{tabular}{|c|c|c|c|c|c|c|}
\hline \multirow[b]{2}{*}{$\begin{array}{c}\text { Coordinated } \\
\text { Care } \\
\text { Organization }\end{array}$} & \multicolumn{2}{|c|}{ Organizational Size } & \multirow{2}{*}{$\begin{array}{c}\text { Starting } \\
\text { Conditions } \\
\text { Prior Org. } \\
\text { History: } \\
\text { Yes, Some, } \\
\text { No }\end{array}$} & \multicolumn{2}{|c|}{$\begin{array}{l}\text { Organizational } \\
\text { Structure/Composition }\end{array}$} & \multirow{2}{*}{$\begin{array}{c}\text { Facilitative } \\
\text { Leadership } \\
\begin{array}{c}\text { (High, } \\
\text { Medium, } \\
\text { or Low) }\end{array}\end{array}$} \\
\hline & $\begin{array}{c}\text { Geographic } \\
\text { Service } \\
\text { Area (by } \\
\text { County) } \\
1-2,3-4, \geq 5\end{array}$ & $\begin{array}{c}\text { Number } \\
\text { of } \\
\text { Enrollees }\end{array}$ & & $\begin{array}{l}\text { New/ } \\
\text { Existing } \\
\text { Org. }\end{array}$ & $\begin{array}{c}\text { Number of } \\
\text { Partnering } \\
\text { Orgs. } \\
1-2,3-9, \geq 10\end{array}$ & \\
\hline $\begin{array}{l}\text { Willamette } \\
\text { Valley } \\
\text { Community } \\
\text { Health } \\
\text { (WVCH) LLC }\end{array}$ & $\begin{array}{c}\text { All of } \\
\text { Marion } \\
\text { County and } \\
\text { most of } \\
\text { Polk County } \\
\text { (2) }\end{array}$ & 58,300 & $\begin{array}{c}\text { Some } \\
\text { history: } \\
1 \mathrm{MCO}, \\
\text { MHO, and } \\
\text { DCO }\end{array}$ & New: LLC & $\begin{array}{l}13 \text { private } \\
\text { and public } \\
\text { affiliates } \\
\text { form } \mathrm{WVCH}\end{array}$ & $T B D$ \\
\hline
\end{tabular}

